\title{
WestVirginiaUniversity
}

THE RESEARCH REPOSITORY @ WVU

Graduate Theses, Dissertations, and Problem Reports

2001

\section{Spatial and temporal analysis of radial growth in an Appalachian watershed}

Desta Beyene Fekedulegn

West Virginia University

Follow this and additional works at: https://researchrepository.wvu.edu/etd

\section{Recommended Citation}

Fekedulegn, Desta Beyene, "Spatial and temporal analysis of radial growth in an Appalachian watershed" (2001). Graduate Theses, Dissertations, and Problem Reports. 1427.

https://researchrepository.wvu.edu/etd/1427

This Dissertation is protected by copyright and/or related rights. It has been brought to you by the The Research Repository @ WVU with permission from the rights-holder(s). You are free to use this Dissertation in any way that is permitted by the copyright and related rights legislation that applies to your use. For other uses you must obtain permission from the rights-holder(s) directly, unless additional rights are indicated by a Creative Commons license in the record and/ or on the work itself. This Dissertation has been accepted for inclusion in WVU Graduate Theses, Dissertations, and Problem Reports collection by an authorized administrator of The Research Repository @ WVU.

For more information, please contact researchrepository@mail.wvu.edu. 
Spatial and Temporal Analysis of Radial Growth in an Appalachian Watershed

\author{
Fekedulegn Desta
}

Dissertation submitted to the

College of Agriculture, Forestry and Consumer Sciences

at West Virginia University

in partial fulfillment of the requirements

for the degree of

Doctor of Philosophy

in

Forest Resource Science

Ray R. Hicks, Jr., Ph.D., Chair

Jimmie J. Colbert, Ph.D.

James N. Kochenderfer, M.S.

John C. Sencindiver, Ph.D.

James P. Armstrong, Ph.D.

Division of Forestry

Morgantown, West Virginia

2001

Keywords: Radial Growth, Topographic Aspect, Microclimate, Dendrochronology, Detrending, Response Function

Copyright 2001 Fekedulegn Desta 


\section{ABSTRACT \\ Spatial and Temporal Analysis of Radial Growth in an Appalachian Watershed}

\section{Fekedulegn Desta}

This dendrochronological study used dated and measured tree-ring data to examine relationships between radial growth and climate for four hard wood species, yellow-poplar, northern red oak, chestnut oak and red maple, growing on contrasting topographic aspects of a watershed in north-central West Virginia. The main objectives of the study were to determine variation in growth between mesic and xeric aspects, examine changes in annual growth related to changes in climate, and test for the existence of an interaction between response to climate and topographic aspect.

The study showed that all species except northern red oak showed significant differences in growth between the mesic and xeric aspects. Where significant differences were found all except chestnut oak exhibited higher growth rates at the mesic aspect. The largest and least difference in growth between the mesic and xeric aspects were found for yellow-poplar and northern red oak, respectively.

Among the four species studied, yellow-poplar showed a sharp decline in growth from late 1950's to late 1960's, which was evidently caused by several years of below average precipitation. The more conservative species, red oak, chestnut oak and red maple, showed a mild response to the drought compared to yellow-poplar which experienced 30-40\% less growth relative to its peak growth in the late 1950's. The fast growth recovery, in the early 1970's, following the decline in the late 1960's was associated with wetter than average condition of the early 1970's. Analysis of drought effects in 1953, 1966, 1988 and 1991 indicated that most species experienced belowaverage growth although drought-related growth declines lasted only for a few years and recovery following drought was rapid.

The dendroclimatic analysis revealed that all four species exhibited sensitivity to climate, especially to growing season precipitation. Radial growth of most species was also correlated to precipitation in the fall season, which suggested that moisture stress in autumn was an important factor affecting growth of the species. For all species, regardless of aspect, precipitation was the dominant climatic factor affecting their growth. Sensitivity to climate followed the sequence yellow-poplar > northern red oak > chestnut oak > red maple.

Regarding the interaction of aspect and climatic sensitivity, yellow-poplar displayed greater sensitivity to climate at the xeric site while the oaks showed little evidence of an aspect-related interaction with climate. For red maple, aspect did interact with climatic sensitivity, although this species showed an overall insensitivity to climate. In cases where site interactions were found, the xeric site proved more sensitive to climate than the mesic site. The results of this study are logical in terms of the ecological strategies of the species; yellow-poplar is widely known to be site specific and exploitive, whereas oaks and maples are more conservative. 


\section{ACKNOWLEDGMENT}

I would like to acknowledge several people who have provided help and insight into the development of this dissertation. I thank Dr. Hicks, Jr. for serving as my major professor and especially for his invaluable assistance in biological interpretation of the results of the study. He provided critical reviews and suggestions on most chapters and has spent considerable time editing my dissertation to make it readable. I thank Dr. Colbert for serving on my graduate committee, suggesting the last two chapters of this dissertation, and funding my study during three summer sessions. His involvement and criticism on the mathematical and statistical aspects this study was helpful.

I also thank Mr. Kochenderfer for serving on my graduate committee, providing reviews and reference materials. I thank Dr. Sencindiver for serving on my graduate committee and providing me a special topic course on soils and topography. I thank Dr. Armstrong for serving on my graduate committee and his encouragement.

I especially thank the USDA Forest Service in Morgantown for providing me office space, computers and dendro lab. I also like to thank Dr. Harner and the department of statistics at WVU for financial support while I was working on my dissertation. I want to thank Dr. Tajchman for giving me the opportunity to study at WVU. I would like to thank Mr. Rentch and Mr. Luzador for their assistance in all aspects of my study. Finally I would like to thank all my family in Ethiopia whom I have not seen in five years, and my son, Ezra, for their appreciation, patience and encouragement. 


\section{TABLE OF CONTENTS}

ABSTRACT
ACKNOWLEGMENT
TABLE OF CONTENTS
LIST OF TABLES
LIST OF FIGURES

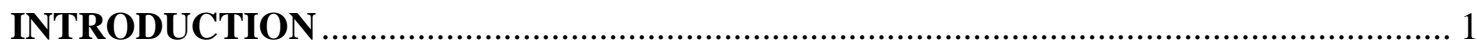

Role of Climate and Topographic Aspect …………………………………………….... 1

Methodological Considerations.................................................................................. 5

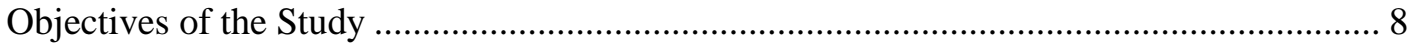

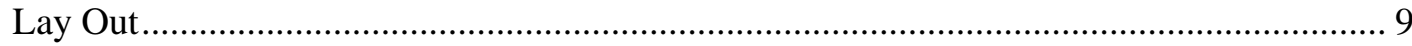

CHAPTER ONE: REVIEW OF LITERATURE ……………………………………..... 11

Spatial Variability in Site Productivity and Forest Growth............................................. 11

Tree-ring Studies on Temporal and Spatial Variability in Radial Growth ........................ 18

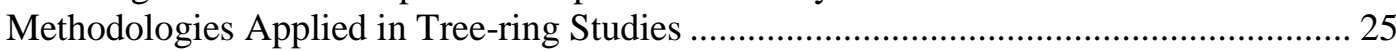

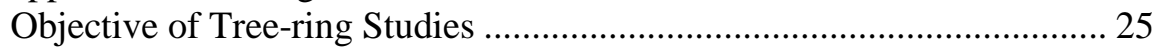

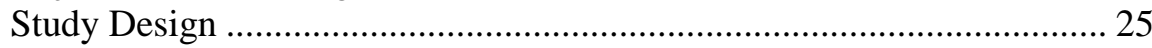

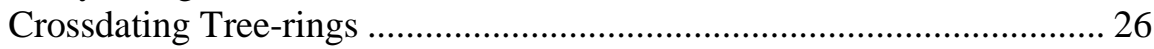

Indexing Tree Growth (Standardization)............................................. 27

Quantification of Climatic Variables...................................................... 29

Statistical Analyses......................................................................... 30

Ecological and Dendroclimatic Characteristics of Four Hardwood Species ..................... 31

Yellow-poplar......................................................................... 32

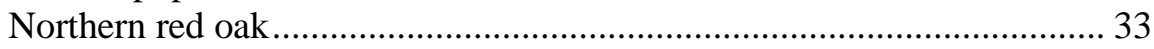

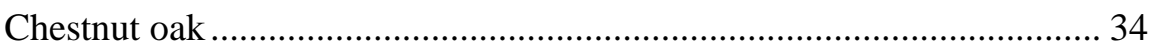

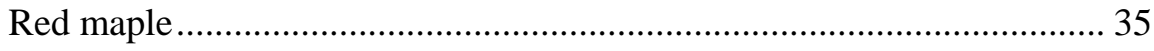

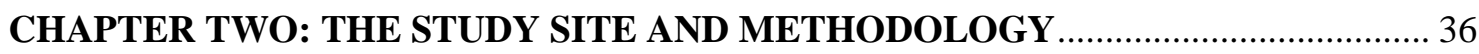

The Study Area

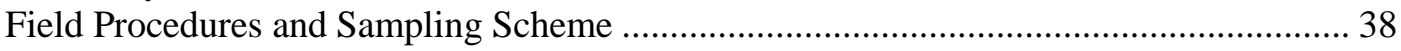

Supplemental Sampling Design ........................................................................... 40

Tree-ring Specimen Collection, Preparation and Measurement........................................... 41

Disc and Core Preparation..................................................................... 41

Crossdating ....................................................................................... 42

Ring-width Measurement ........................................................................ 43

Verification of Crossdating ………………………………………........ 43

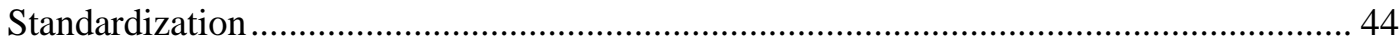

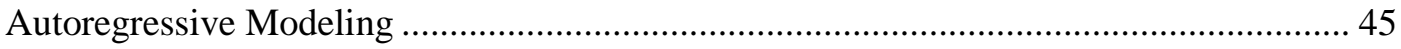

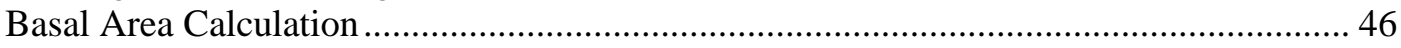

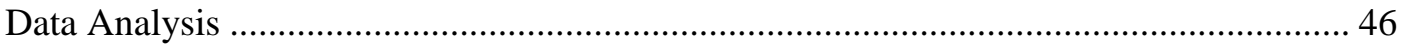

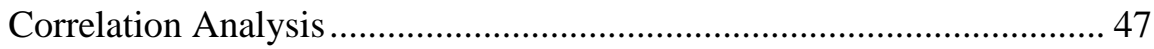

Response Function Analysis.................................................................... 48 
Aspect Related Differences in Vegetation, Soil, and Microclimatic Characteristics at the Study Site

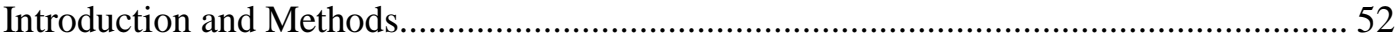

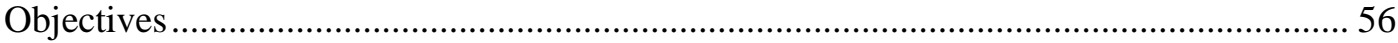

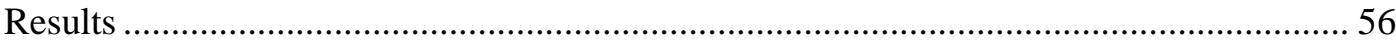

Relationships of Vegetation with Aspect ………............................................ 56

Species, Size, and Frequency Distribution ............................................ 56

Basal Area and Dry Biomass................................................................. 58

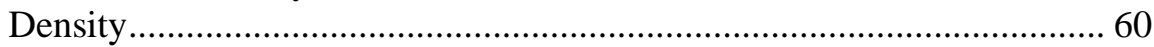

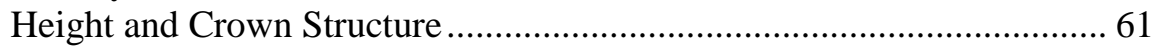

Species Importance Values............................................................. 62

Correlation with Transformed Aspect .................................................... 62

Relationship of Soil Characteristics with Aspect .................................................... 63

Relationship of Air Temperature and Vapor Pressure Deficit with

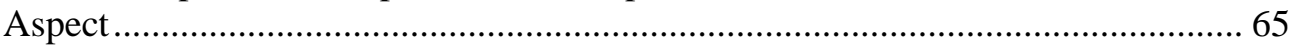

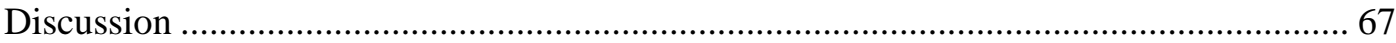

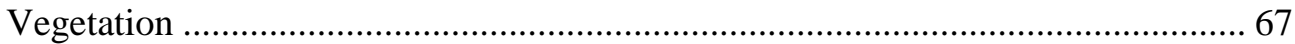

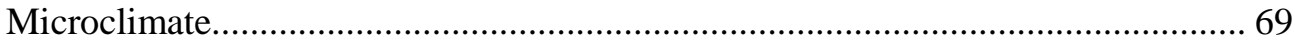

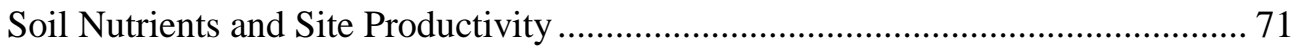

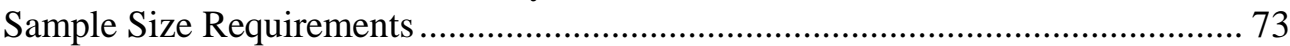

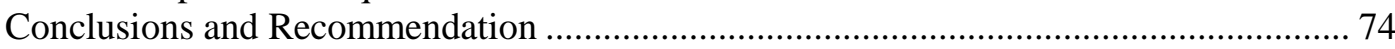

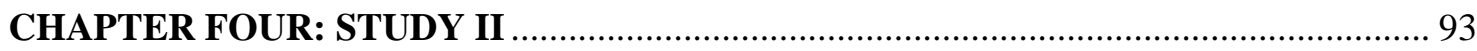

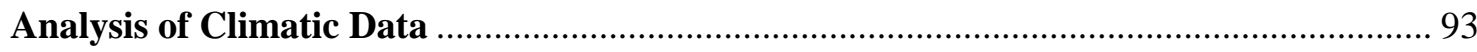

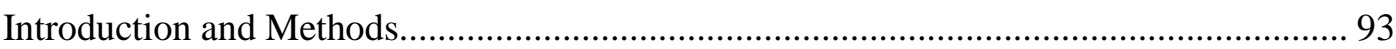

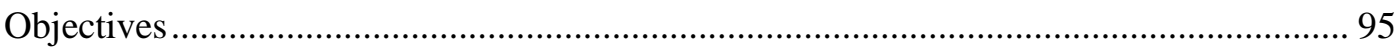

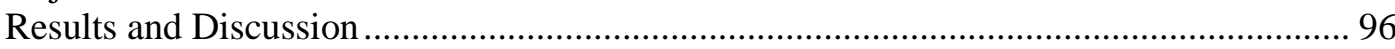

The Relationships Among Stations .................................................................. 96

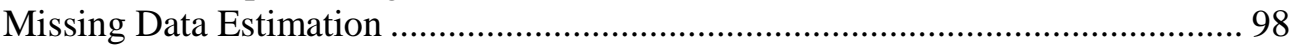

Patterns of Climatic Variation at the Study Site .................................................... 98

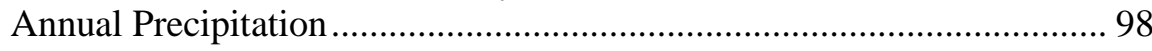

Monthly Precipitation ......................................................................... 100

Annual Air Temperature................................................................... 100

Monthly Air Temperature.................................................................. 102

Interrelationships Among the Three Climatic Factors........................... 102

Tree Growth Period and Multicollinearity .......................................................... 103

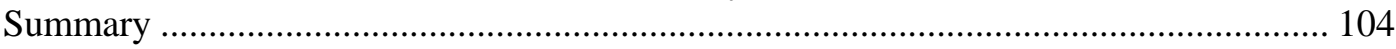

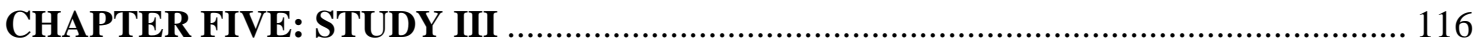

Impact of Climate on Radial Growth of Trees Growing on

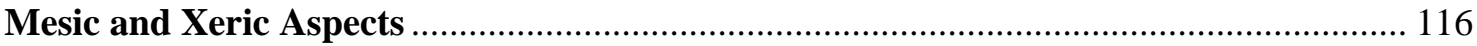

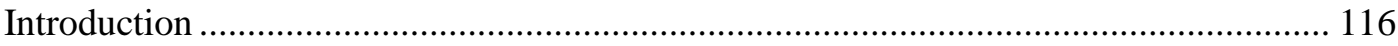

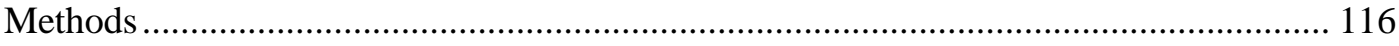

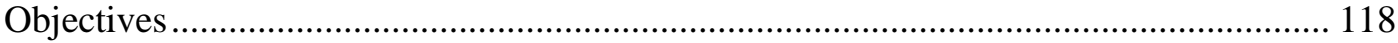




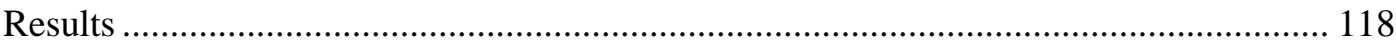

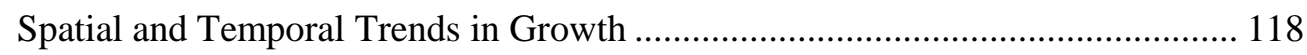

Age distribution of Sampled Trees .................................................... 118

Spatial Variability in Radial and Basal Area Growth............................ 120

Temporal Patterns of Growth .................................................................. 121

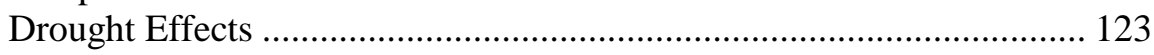

Summary of Results ............................................................................. 125

Radial Growth Response To Climate .............................................................. 139

Response Function Analysis................................................................. 139

Hypothesis Tested ….................................................................... 144

Response Function of Yellow-poplar ................................................. 145

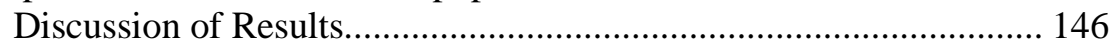

Effect of Aspect on Climate Response of Yellow-poplar.................. 149

Summary of Response Function of Yellow-poplar ........................... 151

Response Function of Red Oak and Chestnut Oak................................. 152

Discussion of Results.................................................................... 153

Effect of Aspect on Climate Response of the Oaks.......................... 157

Summary of Response Function of the Oaks .................................. 159

Response Function of Red Maple............................................................ 159

Discussion of Results..................................................................... 160

Effect of Aspect on Climate Response of Red Maple ....................... 162

Discussion

Summary of Response Function of Red Maple ................................. 163

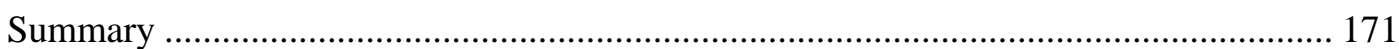

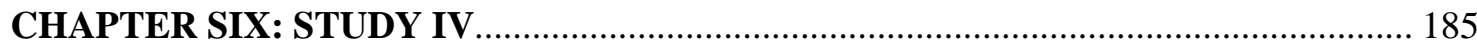

Effect of Detrending Models on Growth-climate Relationships.................................... 185

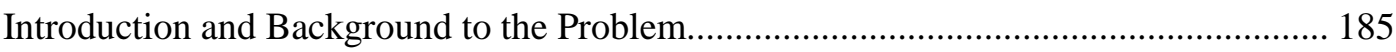

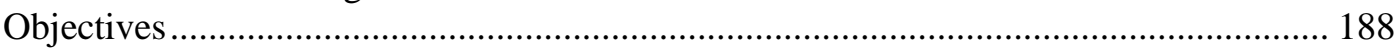

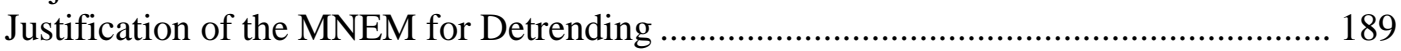

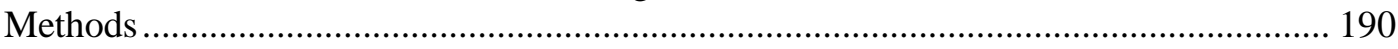

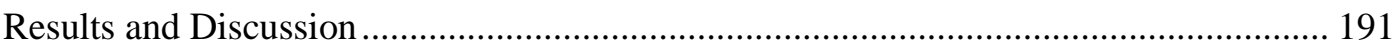

Fitted Detrending Models ...................................................................... 191

Effect of Detrending Models on Ring-width Index (RWI)................... 192

Effect of Detrending Models on Autocorrelation .................................... 193

Effect of Detrending Models on Growth-climate Relationships ............. 194

Program ARSTAN ................................................................................ 195

Suggested Modification of the Convergence Criterion .......................... 196

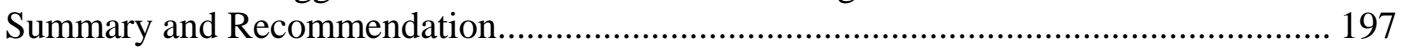

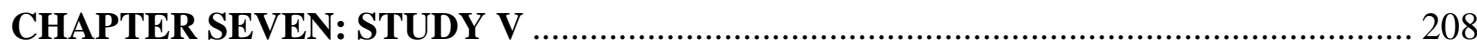

\section{Development of Multivariate Response Function for Analyzing Radial Increment

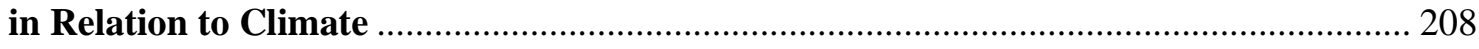

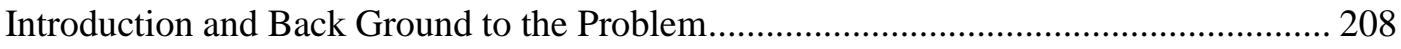

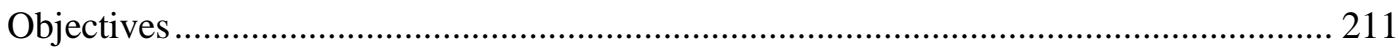

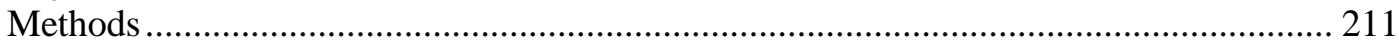

The Multiple Regression Model .......................................................................... 211 


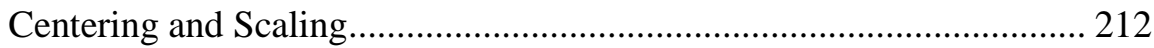

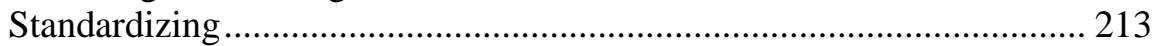

Principal Components Regression (PCR) ....................................................... 215

The Underlying Concept ….......................................................... 215

Computational Technique.................................................................. 215

Elimination of Principal Components .................................................. 217

Transformation Back to the Original Climatic Variables....................... 219

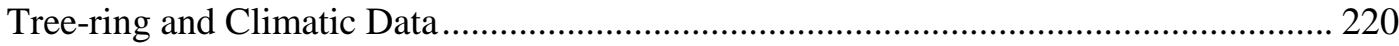

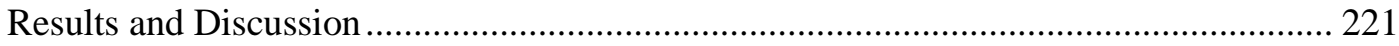

Development of an Appropriate Response Variable .......................................... 221

Violation of the Two Assumptions on the Response Model .................. 221

Transformations Applied to the Raw-ring Width Measurements........... 222

Removing the Long Term Trend (Detrending)......................... 222

Autoregressive Modeling ........................................................ 223

Recalibrated Method of Estimating Response Function ..................................... 226

Response Function Based on Centered and Scaled Variables................ 226

Response Function Based on Standardized Climatic Variables ............. 230

Standard Errors of the Principal Component Estimators....................................... 231

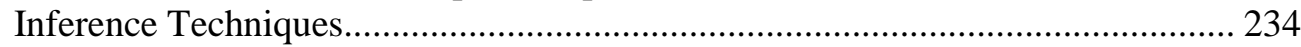

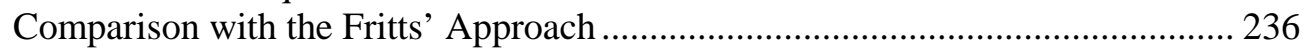

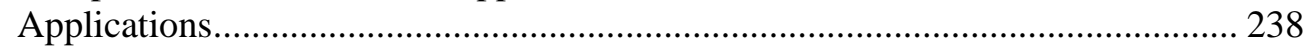

The Response Function and the Inferential Procedures ........................ 241

Comparison of PCR and OLS ............................................................. 242

Sensitivity of the Response Function to PC Selection Rules.................. 242

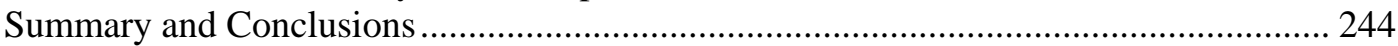

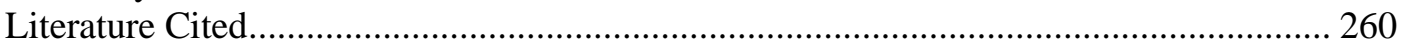




\section{LIST OF TABLES ${ }^{1}$}

Table 2.1. Database: the number of trees sampled for tree-ring specimen.................................51

Table 3.1. Mean diameter at breast height $( \pm \mathrm{SE})$ by species and aspect .................................76

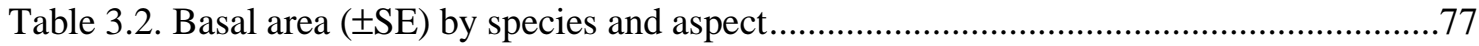

Table 3.3. Above ground dry biomass $( \pm \mathrm{SE})$ by species and aspect .........................................78

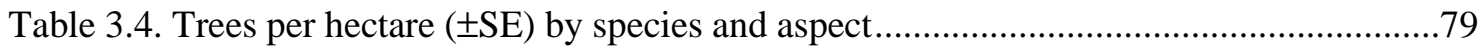

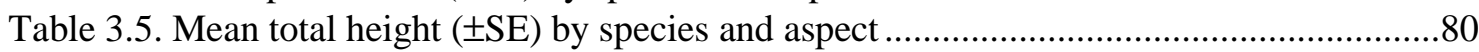

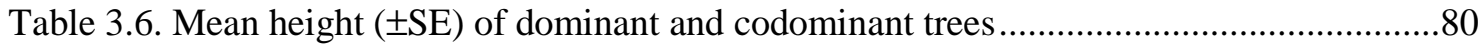

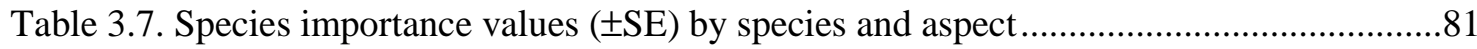

Table 3.8. Correlations between transformed aspect and species variables ................................ 81

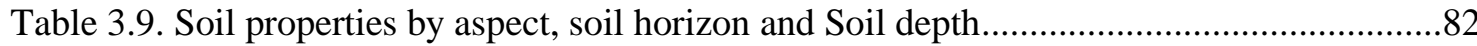

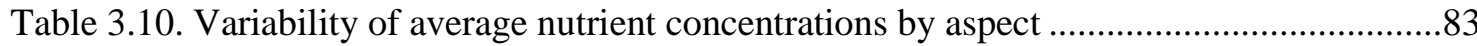

Table 4.1. Summary of climatic information for five weather stations ..................................107

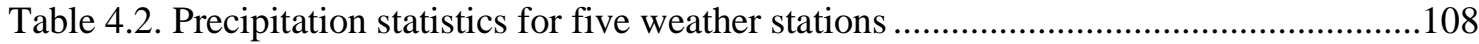

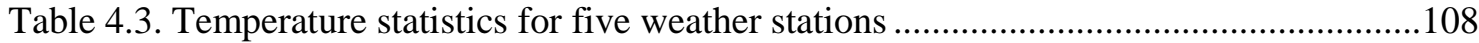

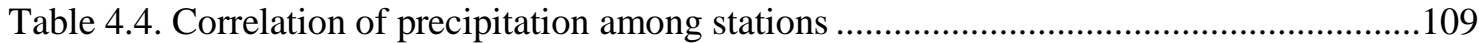

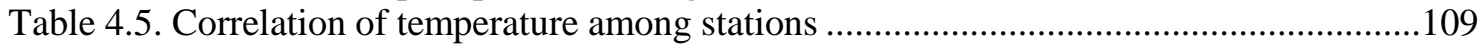

Table 4.6. Models developed to estimate missing climate data .............................................110

Table 4.7. Precipitation and temperature statistics Coopers Rock Weather Station...................110

Table 4.8. Correlations among PDSI, temperature, and precipitation .....................................111

Table 4.9. Drought and wet years based on growing season mean PDSI ..............................111

Table 5.1. Summary statistics of trees sampled for tree-ring analysis ...................................129

Table 5.2. Mean radial and basal area increment by species and aspect ..................................130

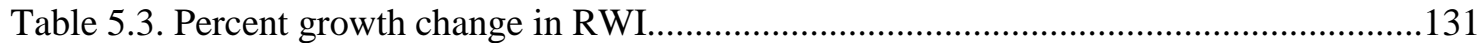

Table 5.4. Correlation between species RWI and precipitation and PDSI ...............................132

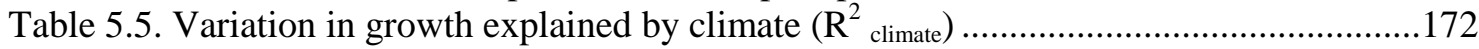

Table 5.6. Frequency of significant climatic variables by aspect and species .........................173

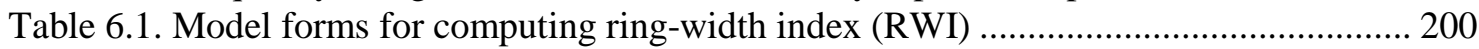

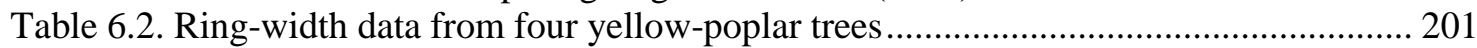

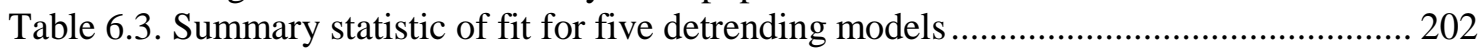

Table 6.4. Properties of ring-width index as function of the detrending model ....................... 202

Table 6.5. Parameter estimates of AR models fitted to RWI ................................................. 202

Table 6.6. Significant response function elements for five detrending models....................... 203

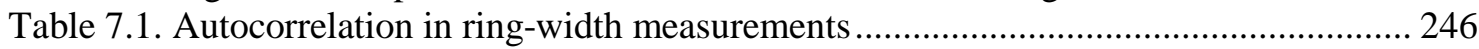

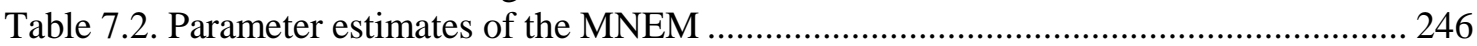

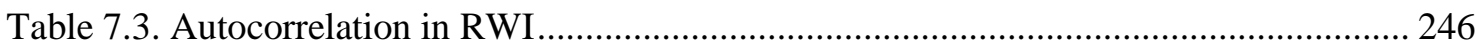

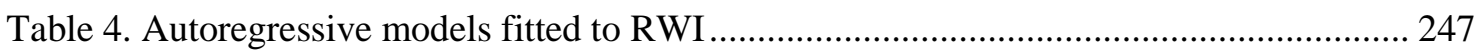

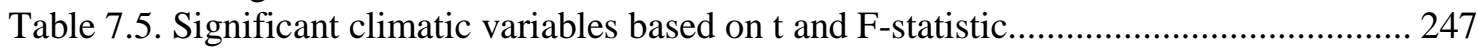

Table 7.6. Comparison of principal components selection rules........................................... 248

${ }^{1}$ The lists of tables are abbreviated versions of the titles within the text. 


\section{LIST OF FIGURES ${ }^{1}$}

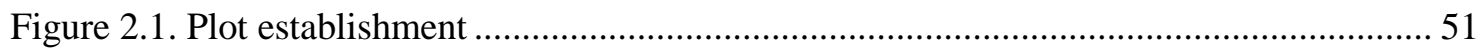

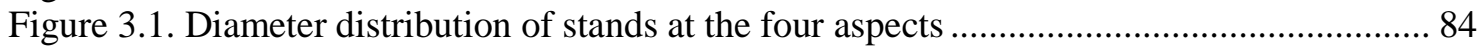

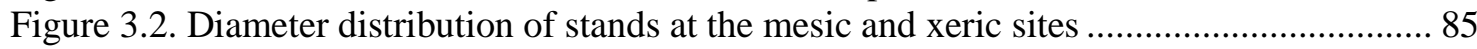

Figure 3.3. Trees per hectare for the mesic and xeric sites............................................... 86

Figure 3.4. Basal area and above ground dry biomass by aspect .......................................... 87

Figure 3.5. Density (stems/ha, $>7 \mathrm{~cm} \mathrm{dbh)} \mathrm{for} \mathrm{each} \mathrm{aspect} \mathrm{by} \mathrm{species} \mathrm{group} \mathrm{...........................} 88$

Figure 3.6. Trees per hectare by height class and species groups ............................................ 89

Figure 3.7. Species importance values by aspect for five species ......................................... 90

Figure 3.8. The diurnal pattern of air temperature and relative humidity ............................... 91

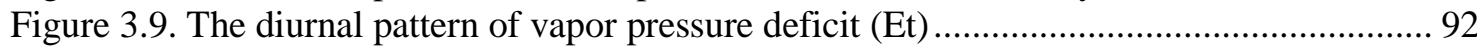

Figure 4.1. Annual precipitation and temperature at five weather stations ............................. 112

Figure 4.2. Estimated and actual precipitation at Coopers Rock Weather Station................... 113

Figure 4.3. Monthly precipitation and temperature at Coopers Rock weather station ............. 113

Figure 4.4. Estimated and actual air temperature at Coopers Rock weather station ................ 114

Figure 4.5. Trend in estimated annual temperature at Coopers Rock ................................... 114

Figure 4.6. The Pattern of PDSI, precipitation and temperature ........................................ 115

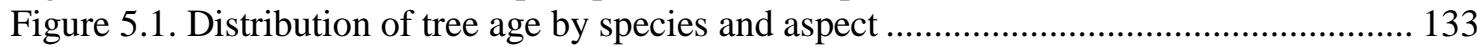

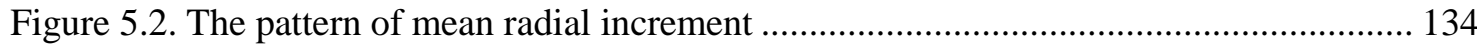

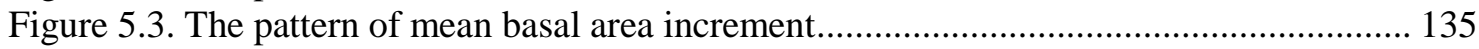

Figure 5.4. Mean basal area increment at intervals of five-years ......................................... 136

Figure 5.5. Precipitation and PDSI at intervals of five-years .............................................. 137

Figure 5.6. Radial growth in wet years expressed as a percent growth of drought years......... 138

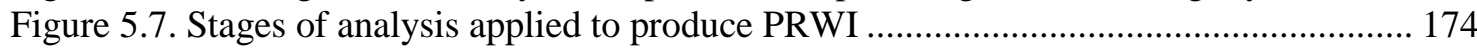

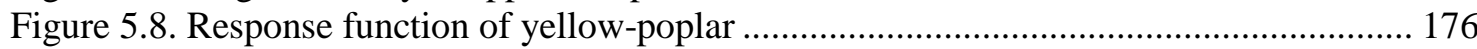

Figure 5.9. Measure of relative importance of climatic variables for yellow-poplar ............... 177

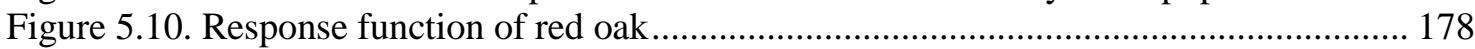

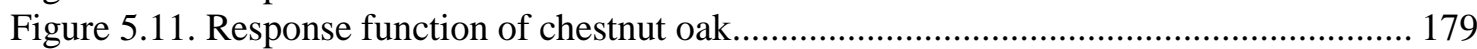

Figure 5.12. Measure of relative importance of climatic variables for red oak...................... 180

Figure 5.13. Measure of relative importance of climatic variables for chestnut oak .............. 181

Figure 5.14. Response function of red maple ................................................................... 182

Figure 5.15. Measure of relative importance of climatic variables for red maple................... 183

Figure 5.15. Coefficient of variation of precipitation and temperature .................................. 184

Figure 6.1. Forms of the MNEM....................................................................................... 204

Figure 6.2. Commonly used detrending models fitted to ring-width data............................ 205

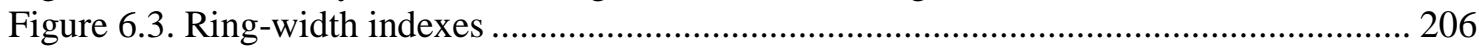

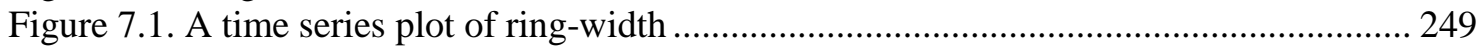

Figure 7.2. A scatter plot of current year ring-width against prior year ring-width ................ 250

Figure 7.3. Standard deviation of five-year segments of the ring-width .............................. 251

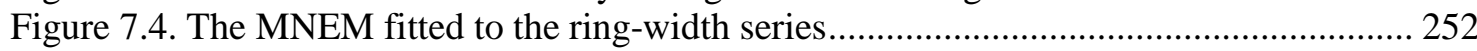

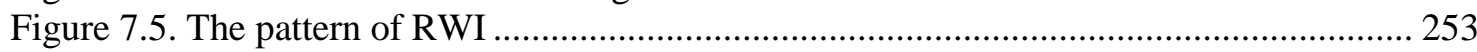

Figure 7.6. Standard deviation of the five-year segments of RWI ...................................... 254

Figure 7.7. Autocorrelation (AC) and partial autocorrelation (PAC) functions....................... 255

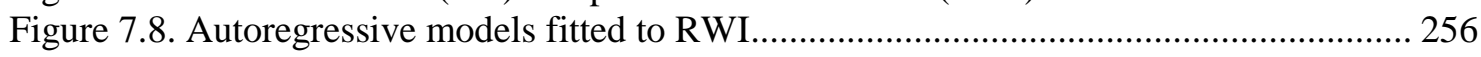

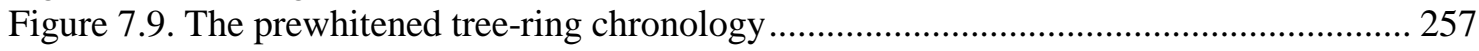

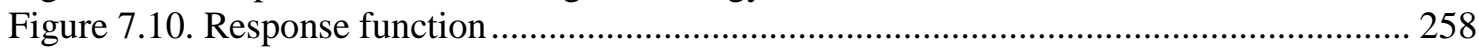

Figure 7.11. Comparison of OLS and principal component estimators ................................ 259

${ }^{1}$ The lists of figures are abbreviated versions of the titles within the text. 


\section{INTRODUCTION}

\section{A. Role of Climate and Topographic Aspect}

Growth rates of forest species are governed by numerous site factors such as soil moisture, air temperature, light, nutrients, response to competition and predation, and disturbance regime (Fritts 1976, Kramer and Kozlowski 1979, Oliver and Larson 1996, Hicks 1998). Variations in these environmental parameters across a landscape are associated with variations in site productivity, forest growth and species composition. Among the climatic factors, precipitation and temperature largely determine the composition and growth rate of forests on a regional basis (Barrett 1995). It has been long understood that the spatial variability in these growth-influencing factors is closely tied to attributes of local topography such as aspect, elevation, and slope position and inclination.

As topography varies, the site factors associated with topographic location vary as well. Among attributes of topography, aspect affects the amount and daily cycle of solar radiation received at different times of the year and has a strong influence on the microclimate, especially on air temperature, humidity, and soil moisture (Lee and Sypolt 1974). For example, a southwestern slope is sunnier and drier than a northeastern slope because the southwest aspect receives more intense solar radiation, which alters the microclimatic conditions of the site. Since aspect, through its control on solar intensity, affects microclimate, a change in aspect across a landscape has been known to result in changes in growth rate, species composition, and site quality. Although it is generally believed that south-facing slopes are drier and soil moisture deficits limit tree growth on 
these sites, a study by Lee and Sypolt (1974) has shown that in West Virginia (where precipitation and soil moisture levels are relatively high during the growing season) differential growth rates between forests on north and south-facing slopes occur primarily due to differences in energy exchange and thermal regimes rather than differences in soil moisture.

Similarly, variation in annual growth associated with annual changes in climate is likely to vary across a range of aspects or topographic positions. Using conventional logic, a tree situated on a southwest aspect or on a ridge should be more sensitive to variations in rainfall than a tree situated on a northeast aspect or on the valley floor. A tree on northeast aspect or on valley floor would be expected to have a higher and steadier supply of water due to the tree's location on more generally moist soils with lower evaporation, and its proximity to the water table and streamflow (in case of a tree on a valley floor); therefore, its growth rate should vary less from year to year than a tree situated on southwest aspect or on a ridge. A tree on southwest aspect or on a ridge would be expected to have more moisture available for growth during a wet season than it would during a dry season; therefore, its rate of growth should be more variable as rainfall fluctuates (increases or decreases) across subsequent growing seasons.

The annual ring-width of forest trees provide a measure of the effects of climatic variation as well as other factors such as the age structure, status of competition, and history of disturbance in the forest. Therefore, based on data from tree-rings, the relationship between climate and radial growth rates in trees has long been investigated by dendrochronologists (Douglass 1920). 
Much is understood about variation in radial growth of tree species distributed across moisture gradients in semi-arid regions. Dendrochronologists in the western states have known for nearly a century that trees that are located on dry sites are more sensitive to climatic variation (Fritts 1976). Scientists interested in maximizing the variance in radial growth due to climate select trees that are growing in resource limited environments. As a result, many of the early climate and tree-ring studies were restricted to drier climates such as the American Southwest. In these moisture-limited environments, climatic "signatures" such as drought years or years of heavy precipitation are readily observable on tree-rings and serve as marker years for cross-dating (Stokes and Smiley 1968). Thus, dry to xeric sites are most often chosen for dendrochronological studies to facilitate cross-dating or pattern matching among trees and study sites (Stokes and Smiley 1968, Fritts 1976).

Though much is known about climate related variation in radial growth of trees in the semi-arid regions of the southwestern United States, not nearly as much is known about climate related variation in growth of trees in the mixed mesophytic hardwood forests of the eastern United States. In fact, recent studies (Orwig and Abrams 1997, Abrams et al. 1998) strongly emphasized that our understanding of the impact of climate and drought on radial growth rates of species across contrasting site conditions is very limited, especially for the eastern United States. They indicated that tree-ring data (dendroclimatic studies) provide an important approach to understanding the long-term impacts and dynamics of climatic variations across species and sites with contrasting topography. Therefore, the challenge of this study is determining how annual growth varies from one topographic aspect to another in four tree species, yellow-poplar 
(Liriodendron tulipifera L.), northern red oak (Quercus rubra L.), chestnut oak (Quercus prinus L.), and red maple (Acer rubum L.), growing in a humid, second-growth, mixedmesophytic hardwood forest in the central Appalachian region. In this region, rainfall is plentiful and even the most xeric sites would be characterized as moist by southwestern United States standards. However, it is hypothesized that the species should respond to the fine scale differences in microclimate due to changing topographic aspect.

This study was designed, based on tree-ring and climatic data (monthly temperature, precipitation, and Palmer Drought Severity Index), to assess the influence of climate and drought events on radial growth rates of these four species growing at different topographic aspects. Tree-ring data were collected from dominant and codominant trees of each species at north, east, west and southwest aspects of a 65-yearold second-growth forest at Little Laurel Run Watershed in north-central West Virginia. The north and east aspects are considered moist (mesic) sites while the west and southwest aspects are considered dry (xeric) sites. Two of the species, yellow-poplar and chestnut oak have a distinct preference for aspect in that the former is a characteristic species of north and east aspects while chestnut oak occurs predominantly on west and southwest aspects. On the other hand, northern red oak and red maple express mild aspect preference but are generally found at all aspects.

The study evaluated the effects of spatial and temporal variation in climate on both the spatial and temporal variation in annual growth of the species. There were two main objectives. The first objective was to determine how temporal and spatial variation in growth was affected by temporal and spatial variation in climate. There are two questions pertaining to this objective. How did topographic aspect affect mean annual 
growth as well as variation in annual growth across a long history of climatic conditions? How did topographic aspect affect the degree of decline in growth during specific climatic conditions such as drought?

There are two hypothesis associated with the first objective. First, mean annual growth for the species is higher on mesic locations than on xeric locations. Second, variation in annual growth of the species associated with variation in climate is lower on mesic locations than on xeric locations. The latter presumes that annual growth would become more variable as topographic aspect limited the moisture available at a site, therefore increasing the influence of year-to-year variation on growth (Fritts 1976, Fritts and Swetnam 1989).

The second objective of this study deals with methodological improvements for studying tree radial growth with a set of intercorrelated (multicollinear) climatic variables. This issue is presented below.

\section{B. Methodological Considerations}

There is a growing interest in the northeastern U.S. to partition the role of climate and disturbance in radial growth. The basic question is to determine the percentage of variance in radial growth attributable to climate $\left(\mathrm{R}_{\text {climate }}^{2}\right.$. Due to multicollinearity (high level of correlation among the climatic variables), the answer to this question strongly depends on the statistical methodology employed to address the problem (Fekedulegn et al. (in preparation)).

It is important to understand that multicollinearity is generally a problem during both types of studies in dendroclimatology; construction of climate (precipitation, temperature, and Palmer Drought Severity Index) backward in time using tree-ring data 
as predictors, and development of radial growth response functions using monthly climatic data as predictors. The focus in this study is with the latter situation. The use of ordinary multiple regressions to relate radial growth with intercorrelated climatic variables results in unstable coefficients (Cook and Jacoby 1977) that are difficult to interpret and also inflates the variation in growth explained by climate $\left(\mathrm{R}^{2}\right.$ climate).

In the closed-canopy forests of eastern North America, detection of climatic signals is often difficult due to competition among trees for limiting factors such as light (Cook and Peters 1981). Furthermore, Phipps (1982) states that growth trends in this region may be more highly influenced by competition than by climate. For example, the episodic occurrences of releases and suppressions caused by opening and closing of canopy gaps may greatly hamper detection of climatic signals (Cook and Peters 1981). As a result, in mesic, closed-crown forests climatic factors are not often significant in relation to radial increment of trees.

However, over the past several decades, numerous dendroclimatological studies in eastern North America (e.g., Bonkovngou et al. 1983, McClenahen and Dochinger 1985, Jacobi and Tainter 1988, Graumlich 1992, Luken et al. 1994, Pan et al. 1997, Abrams et al. 1998, and Rubino and McCarthy 2000) have shown the existence of sufficient year-to-year variation to enable crossdating and permit accurate assignment of calendar years to individual growth rings. Although these studies indicate the presence of strong climatic signals in trees growing under complacent conditions typical of mesophytic forests in eastern U.S., few have reported the overall effect of climate on radial growth $\left(\mathrm{R}_{\text {climate }}^{2}\right)$. This may be because the inherent natures of the climatic 
variables (multicollinearity), as well as ring-width series (trend and autocorrelation) do not lend themselves to ordinary statistical estimation techniques.

According to Heiner and Heiner (1995) statistical modeling is the key to studying environmental history and making environmental forecasts based on tree-rings. Due to their simplicity, simple correlation and linear multiple regression analysis are widely used in dendroclimatic studies. However, since climatic variables are highly intercorrelated (Guiot et al. 1982) these conventional dendroclimatological methods are theoretically inadequate for estimating the overall effect of climate on ring-width, and to rank the climatic variables based on their relative effect on radial growth. Some studies suggest that a climatic relationship to tree radial growth in the northeastern hardwood forests may be more readily obtained with new technical and statistical methods (Cook and Jacoby 1977).

Although it is not frequently used due to its complexity, the statistical methodology most recommended for dendroclimatic studies is the method of principal components regression, which was first introduced into dendroclimatic studies by Fritts et. al. (1971) and Fritts (1976). However, the procedure as described in dendroclimatic literature (Fritts et al. 1971, Fritts 1976, and Guiot et al. 1982) has serious drawbacks that could lead to incorrect inferences. In addition, a step-by-step procedure and demonstration of this multivariate procedure using dendoclimatic data has not been given in the literature and this may be partly the reason for its infrequent application.

Therefore, the second objective of this study is to elucidate the method of principal component regression and provide a user-friendly step-by-step procedure of this 
multivariate technique that effectively estimates the overall role of climate and the relative influence of the climatic variables on radial growth.

Furthermore, most dendroclimatic studies require chronologies or tree-ring series of sufficient length to perform statistical analysis (Fritts 1976, Nowacki and Abrams 1994). Therefore, old-growth forests are of particular interest for performing dendrochronological studies. Since this study is based on tree-ring data from a relatively young, second-growth stand $(\approx 60-65$ years $)$, detrending methodologies that were developed for long chronologies are not entirely appropriate (Colbert, 2000 personal communication). Therefore, this study also provides some modifications on methods of detrending ring-width series for trees that span a relatively short period of time $(<100$ years).

\section{Objectives of the Study}

The specific tasks of the study were:

- To obtain tree-ring data for selected Appalachian hardwood species from sites with varying topographic aspect.

- To determine changes in vegetation, soil nutrients and microclimate associated with differences in aspect at the study site.

- To describe the patterns of variation in precipitation and air temperature at the study site.

- To determine the influence of climatic factors such as precipitation, temperature, and drought severity on radial growth rates of four species growing in different topographic aspects. 
- To evaluate the effects of detrending models on characteristics of ring-width index and the relationship between radial growth and climate.

- To provide a step-by-step procedure for developing a diagnostic model that relates ring-width to climatic variables using the method of principal components regression.

After developing an appropriate methodology for studying radial growth in relation to climate, additional questions of interest include:

1. What is the nature of the relationship (direct or indirect, degree of influence, and significance) between radial growth of each species and the climatic variables?

2. How does the nature of the relationship change with aspect?

3. How do the species respond to abnormal climatic conditions (drought) and is the species response to drought affected by aspect?

4. An estimate of the variation in annual growth attributable to climatic effects, and a comparison of the species within and across aspect based on this criterion are presented.

\section{Lay Out}

This dissertation consists of five studies. The dissertation is partitioned into seven chapters. Chapter one presents a review of literature on (a) variability in forest growth, species composition, and site productivity as a result of variations in topography (especially aspect), (b) tree-ring studies that deal with the relationship between radial growth and climate including reviews on radial growth response of tree species to drought across contrasting sites, (c) methodologies applied in tree-ring or dendroclimatic studies, and (d) ecological and dendroclmatic characteristics of the four species being 
studied. Chapter two presents a description of the study site, study design (field sampling procedures, laboratory work, and amendments to the initial sampling strategy), and the general statistical and mathematical procedures used in the study.

Chapter three (STUDY I) presents analysis of changes in vegetation, soil, and microclimatic characteristics across the four aspects at the study site.

Chapter four (STUDY II) presents analysis of climatic data. Reconstruction of missing temperature and precipitation data for Coopers Rock weather station based on information from neighboring stations, and the analysis of the pattern of annual, seasonal, and monthly temperature, precipitation and Palmer Drought Severity Index are presented.

Chapter five (STUDY III) presents analysis of tree-ring data in relation to climate. The relationship between radial growth and climate and the influence of aspect on growth-climate relationship are presented.

Chapter six (STUDY IV) presents detrending models used for removing tree-size related trends from ring-width series and modifications on the sign of the asymptotic parameter and on the convergence criterion of the modified negative exponential model for young trees $(<100$ years-old). This chapter also presents results on how detrending models affect interpretation of autocorrelation as well as growth-climate relationships.

Chapter seven (STUDY V) presents the statistical methodology used for combating multicollinearity among climatic variables when studying radial growth in relation to several set of climatic variables. A user-friendly step-by-step procedure of principal components regression, a tool for developing response function in dendroclimatic studies, is presented. Criticism of the procedure as given in current literature and suggested improvements are presented. 


\section{CHAPTER 1}

\section{REVIEW OF LITERATURE}

\subsection{Spatial Variability in Site Productivity and Forest Growth (Role of Topography)}

This section provides a review of studies that deal with spatial variability in forest growth and productivity as a result of variations in topographic and soil factors. Emphasis is given to those studies in eastern United States, especially in the Central Appalachian Region. Most of the studies used site index as a measure of site quality and biomass production as measure of productivity. Several topographic and soil attributes were used as as influential or predictor variables.

Topographic position of a site is closely related to the microclimate and to the physical and chemical properties of the soil. Attributes of topography, such as aspect, elevation, slope inclination, and slope position, influence soil depth, and structure of the surface and subsoil, soil and air temperature, runoff, evaporation and transpiration. Through its effect on these parameters, topography influences the composition, development and productivity of forests (Lee and Sypolt 1974, Spurr and Barnes 1980, Hicks 1998). The spatial variability in site quality, species composition, and forest growth, due to differences in topographic characteristics, has long been recognized by foresters in the eastern United States (Auten 1945, Trimble and Weitzman 1956, Doolittle 1957, 1958, Olson and Della-Bianca 1959, Trimble 1964, Phillips 1966, Carmean 1967, 1975, Olson 1969, Lioyd and Lemmon 1970, Lee and Sypolt 1974, Luxmoore et al. 1978, Auchmody and Smith 1979, Spurr and Barnes 1980, Tajchman and Wiant 1983, 
Carmean and Kahn 1983, Frank et al. 1984, Hicks and Frank 1984, Boyles and Tajchman 1984, Tajchman and Lacey 1985, McNab 1989, 1993).

Among the topographic attributes, aspect (slope exposure or slope-facing direction) governs the amount of solar radiation received by a site. Slopes that face the sun capture more radiant energy than those that face away from it (Rosenberg 1983). In the Northern Hemisphere, the sun is to the south during the warmth of the day and south and west facing slopes receive more intense radiation than any other aspect. As a result these two aspects are the warmest and driest sites. On the other hand, north and east facing slopes receive less direct solar radiation and are cooler and moister. Due to its influence on the heat flux, aspect affects forest sites chiefly by modifying the energy dynamics of the system. For example, south and west-facing slopes receive the greatest energy input during the hottest and driest portion of the day, whereas north and eastfacing slopes receive maximum radiation during the morning when growing conditions are most favorable. Several studies in the northeastern U.S. especially in the Appalachian mountains have found that aspect is strongly correlated with species distribution, growth rate and site quality (Trimble and Weitzman 1956, Doolittle 1957, Carmean 1967, 1975, Lee and Sypolt 1974, Boyles and Tajchman 1984, Hicks and Frank 1984, Tajchman and Lacey 1985). Generally speaking, northeast aspects have cool and moist microclimates and are the better sites, while southwest aspects have dry and warm microclimates and hence are usually the poorer sites.

Auten (1945) related site quality for yellow-poplar with several soil and topographic factors. He emphasized that site quality for yellow-poplar was strongly altered by topographic factors that affect available moisture (aspect and slope position). 
He found that on the cool sites (north, northwest, northeast and east aspects) yellowpoplar had an average site index of 89 whereas on the hot sites (south, southwest, southeast and west aspects) the site index reduced to 72. Doolittle (1958) and Olson and Della-Bianca (1959) reported results of studies that showed that yellow-poplar is much more sensitive than red oak to differences in site quality. On very good sites, yellowpoplar site index was much higher than red oak site index, while on poor sites, yellowpoplar site index was considerably below red oak site index. A study in the Central States related yellow-poplar and oak growth, and found that yellow-poplar outcompetes oaks on good and moderate sites, but would not compete as well on poor sites (Carmean and Kahn 1983). Oaks can outcompete yellow-poplar on poor sites such as ridge tops. Another study on soil-plant water relations on the Oak Ridge Reservation, TN modeled yellow-poplar evapotranspiration rates as related to soil depth, root depth, and precipitation inputs (Luxmoore et al. 1978). This study suggested that soil-plant water relations may have a large effect on growth of these trees and even in moist sites growth may be periodically limited by water supply.

A similar study by Trimble and Weitzman (1956) related site index of upland oaks in the northern Appalachians to eleven soil and topographic factors. They found that aspect, slope position, slope inclination and soil depth were the significant variables that accounted for most of the variation in site index. In the southern Appalachian region Doolittle (1957) related site index of scarlet oak and black oak with nearly twenty soil and topographic variables. Three significant variables (thickness of the A horizon, percent sand in A horizon, and slope position) explained the majority of the variation in site index. His final regression equation did not contain aspect and this was probably due 
to strong correlation between aspect and soil physical characteristics, and the method in which the variables were entered into the regression model. McNab (1989) related terrain shape index (curvature of land surface) to yellow-poplar site index in the Southern Appalachians, and found that terrain shape index explained 51\% of the variation in site index. In another study McNab (1993) studied the effects of landform on yellow-poplar site index in the Blue Ridge Physiographic Province. Three variables (landform index, terrain shape index, and cosine of aspect) accounted for $31 \%$ of the variation in site index.

Trimble (1964) found similar results to those of Trimble and Weitzman (1956). He expressed site index of upland oaks in the northern Appalachians as a function of aspect, slope position, slope inclination, and soil depth. These topographic and soil factors explained $76 \%$ of the variation in site index. Similar results were reported by Phillips (1966) in New Jersey where he found that topographic position, depth of soil, and soil drainage were highly correlated with site index. A similar study on the Allegheny Plateau in north central West Virginia (Frank et al. 1984) used a stepwise multiple regression technique to relate biomass with topographic and soil attributes. They found that aspect, iron and copper in the B horizon, lime requirement and calcium in the A horizon, calcium in the B horizon, surface stoniness, A horizon manganese, potassium, and iron explained 65\% of the variation in biomass. In southern Ohio, Carmean (1967) found that empirical equations based solely on topographic features explained more than $75 \%$ of the variation in total height of black oak. Carmean (1975) emphasized that site index curves and height growth patterns vary not only in different parts of the range of the species, but also in local areas of contrasting soil and topography. He found that 
height growth pattern of oak varied not only among different soil texture classes but also with aspect and slope within soil groups. Lioyd and Lemmon (1970) generalized that the relationship of forest growth potential to aspect for mixed upland oak forests in the Appalachian Mountains resembles a cosine curve.

In their study of oak soil-site relationships in northern West Virginia, Auchmody and Smith (1979) indicated that the best sites are found on lower slopes, and north and east aspects; poorer sites are found on ridges, and south and west aspects. In the mixed upland oak forests of the Appalachian Mountains, northeast aspects are 15\% more productive than the south and west aspects, which are the least productive (Spurr and Barnes 1980). At the present study area, studies that described spatial variability in growth, productivity and species composition due to differences in soil and topographic factors include Tajchman and Wiant (1983), Hicks and Frank (1984), Boyles and Tajchman (1984), Tajchman and Lacey (1985), and Tajchman and Minton (1986).

Tajchman and Wiant (1983), in their study at the Little Laurel Run Watershed, mathematically expressed both site index and biomass production as a function of aspect and slope inclination. They found similar results as the earlier studies; north-facing sites had the highest site index and biomass values while the west facing sites had the least of both parameters. At this same study site, Hicks and Frank (1984) studied variation in soil physical and chemical properties, species composition, and biomass across a range of aspects. They observed larger quantities of certain plant nutrients (manganese and potassium) in the topsoil on north and east aspects compared to south and west aspects. They explained that the higher nutrient concentrations on the north and east aspects was due to more complete decomposition and more rapid nutrient cycling on these moist sites. 
In regard to spatial variation in species composition Hicks and Frank (1984) noted that yellow-poplar occurs more frequently than oak on mesic north facing slopes, where soil moisture conditions are more favorable. In contrast, red maple has no distinct preference for aspect.

At the current study site, a study of thickness and rockiness of soil horizons (Boyles and Tajchman 1984) showed that thickness of soil horizons at northeast aspects were slightly greater than southwest aspects. However they argued that thickness of A and B-horizons were characterized by large spatial variability and making predictions about their relationships to topography is difficult and requires more information. With regard to rockiness, their study indicated that northern aspects have less surface stone and rock cover than southern aspects.

A study of measures of bioclimatic factors for assessing forest site potential (Tajchman and Lacey 1985) emphasized that variation of forest growth with topography is due to the effect of aspect-related fluctuations of microclimate. They indicated that depression of forest growth in the Northern Hemisphere increases with aspect (counted clock-wise from the north) and reaches its maximum on west facing slopes. As the daytime progresses, they explained that there is a continuous increase in air temperature, leaf temperature, and water vapor deficit in the crown space due to increase in the flux density of solar radiation. The maxima of these parameters (air temperature, leaf temperature, water vapor deficit in the crown, and flux density) coincide on the west facing slopes causing plant water stress and the depression of net assimilation.

An interesting and comprehensive study in evaluating the difference in forest growth due to differences in aspect was that by Lee and Sypolt (1974). Unlike the earlier 
studies, Lee and Sypolt (1974) indicated that simple soil-site descriptions are inadequate to explain the observed difference in growth due to variation in aspect. Hence, they tested a hypothesis that soil moisture differences among aspects may be less important than differences in radiant energy and thermal regimes. They measured several soil characteristics as well as solar radiation data on north and south facing slopes at the WVU forest. Although they found significant differences in soil moisture content between the two aspects their study concluded that differential growth rates between forests on north and south facing slopes occur primarily due to differences in the microclimate (i.e., energy exchange and thermal regimes).

The studies reviewed above involved measuring many soil and topographic variables and relating them through multiple regression analysis to site index, height growth and biomass production. The studies conclude that local topography undoubtedly exerts a strong influence on the distribution and growth of plants by controlling variations in microclimate. In addition, the studies indicate that topography does not affect site index or growth potential directly; it affects them indirectly by modifying the microclimate and soil conditions. Nearly all the studies found aspect as the most influential factor for explaining spatial variability in growth. Additional information on the effect of topographic attributes on soil physical and chemical properties and crop production can be found in Malo et al. (1974), Hanna et al. (1982), Ciha (1984), Jones et al. (1989), Pierson and Mulla (1990), Brubaker et al. (1993 and 1994).

Although these studies provide abundant information on spatial variability in growth, they do not address the influence of climate and drought on growth rates of forest species across sites with different topographic characteristics. In regard to this issue 
recent studies by Orwig and Abrams (1997) and Abrams et al. (1998) indicate that our understanding of the impact of climate and drought on radial growth of species across contrasting site conditions is very limited, especially for the eastern United States. They point out that tree-ring data (dendroclimatic studies) provide an important approach to understanding the long-term impacts and dynamics of climatic variations across species and sites with contrasting topography. The next section, therefore, presents a review of tree-ring studies that dealt with long-and short-term changes in radial growth of species in relation to climatic and site factors.

\subsection{Tree-ring Studies on Temporal and Spatial Variability in Radial Growth}

Abrams et al. (1998) studied the effects of drought on radial growth of ten hardwood species across a range of sites in the Ridge and Valley Province of central Pennsylvania. They looked at the effects of drought on trees that were growing in wetmesic, mesic, dry-mesic, and xeric sites. They noted that different species responded with varying amounts of growth reduction across the range of sites. They found that trees in general suffered the greatest declines in growth on wet-mesic and xeric sites and the trees that suffered the smallest declines were found in the intermediate mesic areas (mesic and dry-mesic sites). They found that the species showing the greatest decline during drought varied among sites and were red maple in the mesic site (valleys), black cherry in the drymesic (barrens) and wet-mesic (riparian) sites, and red oak and red maple on the xeric site (ridges). They also looked at the relationship between radial growth and summer climatic variables and indicated that annual variation in growth was negatively correlated with summer temperature, particularly on the wet-mesic site where most species showed higher correlations that were often significant. 
In a similar study Orwig and Abrams (1997) examined radial growth responses to drought for six species at two contrasting locations (mesic and dry) in northern Virginia. They also noted that the species showed differential growth reductions during or immediately after four severe drought periods. They found that yellow-poplar growing on mesic sites experienced greater ring-width reductions associated with drought than cooccurring, more drought tolerant white oak and black oak. On the dry sites yellow-poplar also experienced greatly reduced growth as a result of drought, but exhibited significant growth increases following individual drought events. White oak was the only species that exhibited a consistent, significant ring-width decrease associated with all droughts on dry sites. In their study they found that white oak and pignut hickory experienced greatest decline during drought on the dry site, while Virginia pine was least impacted by drought on the dry sites but was much more impacted by drought on mesic sites. Regarding the longevity of drought effects they indicated that most trees showed reductions lasting 2-3 years and drought effects in general are short lived.

The above two studies also briefly presented conflicting views, based on two approaches (tree-ring level and leaf physiology level), on species drought tolerance across contrasting sites. At the tree-ring level or based on tree-ring studies, particularly on arid-site conifers in the western United States, scientists have long been aware that complacent trees growing on more favorable sites may exhibit little tree-ring response to climatic variation, whereas sensitive trees growing on severely limiting sites often have significant growth response associated with climate (Fritts 1976). For eastern North America, Phipps (1982) has indicated that trees on dry sites have greater sensitivity to climate than do trees on mesic sites. On the other hand, at the leaf physiology level or 
based on studies of leaf gas exchange, some studies have reported that tree species on wet-mesic or mesic sites may exhibit greater decreases in gas exchange (or net photosynthesis) during drought than those on xeric sites (Zobel 1974, Kubiske and Abrams 1994). In other words, according to these few studies on leaf gas exchange, trees on moist sites experience a greater reduction in growth during drought than those on dry sites or as Orwig and Abrams (1997) put it "species on xeric sites are better able to tolerate drought despite having lower soil moisture compared to mesic sites".

Comparison of results from the above two tree-ring based studies with the view expressed at the leaf physiology level shows some inconsistencies. For example, based on the study by Abrams et al. (1998) red maple had its greatest decline at the mesic site supporting the view from the leaf physiology level while red oak showed its greatest decline at the dry site supporting the view at the tree-ring level. Similarly the study by Orwig and Abrams (1997) supports the view at the tree-ring level since white oak and pignut hickory showed their greatest reduction at the dry site while the result for Virginia pine, which showed its highest growth reduction at the mesic site, supports the view at the leaf physiology level. The authors emphasized scarcity of information (studies) and lack of agreement concerning drought responses of plants in differing environmental or site conditions, and suggested that more studies from both approaches (tree-ring based or leaf physiology based) are required for a better understanding and assessment of species drought tolerance across contrasting sites.

Although it is not based on tree-ring data, a study (Kolb et al. 1990) under controlled environmental conditions is worth reviewing. The authors compared the growth rates (in weight, height, etc.) of two species at optimal and limiting levels of 
environmental factors. They conducted a nursery experiment in Pennsylvania that compared growth of red oak and yellow-poplar seedlings under three levels of edaphic richness (high moisture/high fertility, low moisture/high fertility, high moisture/low fertility) and two levels of light intensity (full exposure, and $20 \%$ sun light). They hypothesized that growth characteristics of red oak such as large seeds, low shoot : root ratio, and slow relative growth enables the species to have greater tolerance to low resource levels. They found that, compared to the best environment, weight of yellowpoplar was always reduced significantly more than that of red oak in response to low levels of a single resource: moisture, $-65 \%$ (yellow-poplar) versus $-43 \%$ (red oak); fertility, $-64 \%$ (yellow-poplar) versus $-37 \%$ (red oak); light, -67\% (yellow-poplar) versus $-57 \%$ (red oak). Generally their results indicate that yellow-poplar is more sensitive to low levels of all resources compared to red oak, indicating greater stress tolerance for red oak. Yellow-poplar had significantly greater shoot : root ratio and greater absorbing surfaces (leaves) compared to red oak. They pointed out that tolerance of red oak to low resource levels suggests adaptation to moderately unproductive environments (stresstolerant strategy) while the characteristics of yellow-poplar (opportunistic capture of plentiful resources, maintenance of large absorbing surfaces) suggests adaptation to more productive environments (competitive strategy).

Although they did not involve comparison of variations in radial growth due to climate and drought at contrasting sites, tree-ring studies in the eastern U.S. that established a relationship between ring-width and climatic variables at a given site and are relevant to this study include Tryon et al. (1952, 1957, 1958), Fritts (1962), Tryon and True (1962), Fritts et al. (1971), Fritts 1976, Shugart et al. (1979), Kim (1988), 
Tainter et al. (1990), Liu and Muller (1993), Kolb and McCormick (1993), Yin and Arp (1994), Pan et al. (1997), and Rubino and McCarthy (2000).

Rubino and McCarthy (2000) analyzed radial and basal area increment of white oak from an old-growth forest in southeastern Ohio. They found that both ring-width and basal area increments were significantly correlated with growing season precipitation and drought severity. Climatic variables that were significantly correlated with radial growth included several current year as well as previous year values for monthly precipitation, temperature, and drought severity index. They also indicated that extreme climatic events such as droughts resulted in significant declines in radial growth. Out of 10 drought years, they found significant reductions in radial growth during drought for five periods, and a significant extended decrease (5 years after drought) was observed for only one of the 10 years analyzed. They concluded that climatic signals are sufficiently strong to be detected even in old-growth white oak trees growing under the complacent conditions typical of upland, mesophytic forests.

Pan et al. (1997) studied the radial and basal area growth responses of red oak, black cherry, white ash and yellow-poplar at the Fernow Experimental Forest to monthly climatic variables. They found that the species showed positive responses to precipitation during the previous summer, autumn, and current summer while inverse correlation was found for air temperature of the current growing season.

Yin and Arp (1994) studied sugar maple to determine the influence of climate and soil factors. When only climatic data were considered, $63 \%$ of the variation in radial growth was explained. When soil data were added, the variation in radial growth accounted by climate and soil combined increased to $83 \%$. 
Tainter et al. (1990) used basal area increment (BAI) to determine an association between short-term changes in climate and radial growth of red oak species. Short-term droughts caused a decline in radial growth, but did not cause any long-term effects on radial growth. A series of successive short-term droughts caused a marked decline in radial growth and tree health. Short-term droughts had a greater effect on radial growth following the series of accumulating droughts than did droughts before the long series occurred. In a related study Kolb and McCormick (1993) investigated the decline of sugar maple in Pennsylvania using patterns of BAI. They discovered that defoliations and drought during the 1960's and 1970's caused a decline in BAI in sugar maple.

A simulation model was developed for a beech-yellow-poplar stand on the Oak Ridge Reservation to explain the effect of environmental gradients on the stand (Shugart et al. 1979). In this study, increasing mean annual temperature was correlated with decrease in yellow-poplar biomass. The decrease in biomass was probably due to an increase in drought stress associated with higher temperatures.

Liu and Muller (1993) studied the effect of drought and frost on radial growth of hardwood trees in Kentucky. Trees in the dominant and codominant crown classes showed a greater reduction in radial growth due to drought and frost than did trees in the understory.

At the Hubbard Brook Experimental Forest, Kim (1988) studied radial growth responses of four hardwood species to climate and suggested that for better understanding of tree growth in relation to climate, consideration of stress related variables are necessary. In his study he considered soil moisture, growing degree-days, the maximum 
and minimum daily mean temperature and the maximum and minimum daily soil moisture content.

Among the tree-ring studies made in the 1960's and 1970's in northeastern United States, the work of Fritts $(1962,1976)$, and Fritts et al. (1971) have received considerable attention. Fritts (1962) introduced the statistical techniques developed primarily in western North America to the study of eastern hardwood forests. In early 1970's Fritts showed the inadequacy of simple correlation and multiple regression analysis for dendroclimatic studies, and proposed a multivariate regression technique for developing diagnostic models relating ring-width with monthly climatic variables. He analyzed the radial increment of beech from Ohio and white oak from Illinois, and found that tree ring variation was highly correlated to width of the preceding ring as well as to climatic variation. Ring width for beech was directly correlated to the moisture supply during August and to temperature for May-July of the preceding year. For white oak he found that climate alone explained $59 \%$ of the ring-width variance.

In West Virginia, studies on tree ring growth in relation to climate began in the early 1950's. Tryon et al. $(1952,1957,1958)$ conducted dendroclimatological studies that covered a wide range of tree species of the mixed hardwood forest, such as yellowpoplar, red oak, scarlet oak, red maple and beech. For yellow-poplar in West Virginia, they found that periodic precipitation during the summer months was the only factor that was significantly related with radial growth. The growth rings of red oak, chestnut oak, black oak and red maple did not show any apparent correlation with precipitation. Tryon et al. (1957) also investigated the effect of temperature on radial and height increment of yellow-poplar. They stated that the temperature of the present and past seasons had no 
relationship to either radial or height increment of yellow-poplar. In another study Tryon and True (1962) reported that spring frost was probably an important factor influencing tree-ring increment. They found that at the elevation where frost damage occurred, ring width of American beech was less than one-fourth of normal size.

Additional dendroclimatological studies in West Virginia include Dean (1968), Lanasa (1971), Schwegler (1983), Brown (1988) and Pan (1995). These studies used treering data to study the effect of silvicultural treatments and climate (precipitation and temperature) on radial growth of various hardwood species.

\subsection{Methodologies Applied in Tree-ring Studies}

In this section a review of objectives of dendroclimatic studies and the use of treering analysis to measure the relationships between radial growth of trees, climate and site data is presented. The general principles of tree-ring analysis are reviewed.

\section{A. Objectives of Tree-ring Studies}

The ultimate goal of most tree growth studies in dendroecology and dendroecology is to know exactly how trees grow under the influences of environmental changes. This may be a difficult task because of differences in growth response of tree species to the changes of environmental factors by region and time. Tree growth studies using tree-rings have been carried out to address questions with varied objectives: to prove the possibility of crossdating among trees, to describe tree growth fluctuation more objectively by applying various indexing methods, to test the effects of certain environmental factors on tree growth, to identify important environmental variable(s) governing tree growth fluctuation, and to develop more advanced analysis technology (Fritts 1976). The present study focuses on identifying the nature of the relationship (i.e., 
direction, magnitude, and significance of the relationship) between climate and radial growth of four hardwood species. The study also deals with temporal (time) and spatial (topography) changes in growth of the species. To attain these goals the present study has made modifications on two of the statistical methodologies currently being used in dendroclimatology. These results are discussed in chapters 6 (STUDY IV) and chapter 7 (STUDY V).

\section{B. Study Design}

Study design in tree-ring studies includes sampling strategy (site and species selection, sample size determination), sample collection, and laboratory work (crossdating and measurement). The design ultimately determines the reliability of the tree-ring data and hence is the most crucial step. For tree-ring studies dedicated to understanding the effect of climate on tree growth, a study site with a minimum of exogenous and endogenous disturbances, and composed mostly of codominant and dominant trees of older age is desired. In general, to determine the influence of climatic parameters on radial-growth rates, trees that have not been impacted by anthropogenic disturbances, such as silvicultural treatments, are preferred. Additionally, most dendroclimatic studies require chronologies or tree-ring series of sufficient length to perform statistical analysis (Fritts 1976, Nowacki and Abrams 1994, McCarthy and Bailey 1996). Therefore, old-growth forests are of particular interest for performing dendrochronological studies.

Once the species of interest and the appropriate study site are identified, at least two cores from 25 to 30 trees of the same species and general age class are sampled. Several sources explain the principles in tree-ring analysis. Details can be found in Fritts 
(1976) and the step-by-step procedures for collecting increment cores, preparing them for crossdating and measurement are given by Stokes and Smiley (1968).

\section{Crossdating Tree-rings}

After collecting the tree-ring specimens (cores or discs) the next step involves crossdating and measurement. Crossdating of tree-rings, which allows the identification of the exact year in which each ring was formed (Fritts 1976), is one of the most important premises for tree-ring related studies. It compares ring-width patterns in different trees. For each increment core there is a sequence of ring widths that can be identified (i.e., wide ring, wide ring, narrow ring, medium ring, narrow ring, wide ring, etc.). The sequence in the above example would correspond to: wet year, wet year, dry year, normal year, dry year, wet year, etc. The sequencing and widths of rings will generally be similar for all increment cores taken from dominant and codominant individuals of a particular species at a study site. The presence of the ring sequences allows the year assigned to a specific annual ring to be accurately identified in all of the increment cores. The dating of the cores can be verified with climate records for the region of the study site to assure that the ring sequences correspond to climatic events. Crossdating also helps identify missing rings and false rings.

After the tree-ring cores are dated, the widths can be measured. The tree-ring measurements can then be analyzed with a tree-ring dating quality control program to verify that the dating is accurate. Crossdated tree-ring series within a tree, species, site or region show high cross-correlations among themselves. The computer program COFECHA, a tree-ring quality control utility, can be used to statistically analyze crossdated tree-ring measurements and determine if there are any measurement or 
crossdating errors that need to be corrected (Holmes 1983). Once crossdated measurements have been obtained and checked for errors, those measurements are then ready for standardization.

\section{Indexing Tree Growth (Standardization)}

The main purpose of indexing (standardizing) ring-width is to remove the effects of increasing tree size (age), competition, and any other disturbances from the ring-width series in order to evaluate the growth of the tree each year more objectively and to provide a basis to compare the growth of one year to that of the other years (Fritts 1976, Cook and Peters 1981, 1997). Raw ring-width series are not comparable, and the absolute (raw) ring-width should not be used as a measure of tree growth especially when interest centers on studying the effect of climatic variables on tree growth (Cook 1987). There are many ways of indexing ring-width series to remove those undesirable sources of variation. These include standardization by linear or nonlinear models, moving averages, polynomial and exponential functions, and smoothing splines (Fritts 1976, Cook 1985, 1987, Visser and Molenaar 1990). Standardization involves fitting an appropriate model to the ring-width series of each tree and calculating an index as a ratio of measured to predicted ring-with.

Standardizing raw ring-width series yields, for each year, a unitless measure of tree growth called ring-width index (RWI). These indices are used as dependent (response) variables for studying the effect of environmental factors on tree growth and they provide biologically significant information on tree growth. Most of these dendrochronologichal techniques for indexing tree growth were developed and adapted in southwestern United States for studying growth-climate relationships and for climate 
reconstruction using tree-ring data from very old trees. Hence, the techniques are not entirely appropriate for indexing tree-ring series especially from young stands. Use of some of the aforementioned indexing techniques for growth-climate studies especially when the ring-width series span a relatively short period of time ( $<100$ years), yield results of questionable reliability (Fekedulegn et. al. (in preparation)). An appropriate modification of the indexing techniques for short tree-ring series (such as those used in this study) is given in chapter 6 . In addition, this study also points out the drawbacks of the software (program ARSTAN) commonly used by dendrochronologists for indexing ring-width series.

In some studies, basal area increments rather than ring-width indexes are used (e.g., Kolb and McCormick 1993,Tainter et al. 1990, Pan et al. 1997, Rubino and McCarthy 2000) for studying tree growth in relation to climate. Converting ring-width measurements to basal area increments (BAI) is a standardization technique for removing long-term trends due to increasing stem circumference as a tree ages. Basal area increments are an alternative to the use of ring-width indexes. Since ring-widths tend to decrease in older and larger trees, basal area increment is a better indication of growth rates of trees (Phipps 1983). Visser (1995) describes various procedures for calculating basal area increments from tree-ring widths. BAI data can be used for building chronologies and in statistical analysis, using the same methods based on ring-width index.

\section{E. Quantification of Climatic Variables}

When the effect of a certain environmental factor (e.g., climate) is being determined in relation to certain biological phenomena (e.g., tree growth or forest 
productivity), the validity of such determinations depend on identifying a biologically meaningful set of environmental variables for the statistical analysis. Fritts (1976) pointed out that there are various ways of defining the independent climatic variables in dendroclimatology. Among the many possible combinations of data sets, mean monthly temperature and total monthly precipitation were mainly used as independent variables. In southwestern United States, standard dendroclimatic studies relate tree growth in a particular year with a set of 28 monthly climatic variables: total monthly precipitation and monthly mean temperature for the 14-month period extending from June of the prior year to July of the current year. However, in the northeastern U.S. the growing season is somewhat longer and thus most studies (Rubino and Mcarthy 2000, Pan et al. 1997, Rentch et al. 2001) employ about 30 to 32 monthly climatic variables. In the present study, the growing season approximately spans from May to September, thus monthly mean temperature and total monthly precipitation from May of the preceding year to September of the current year were considered.

\section{F. Statistical Analyses}

After the two sets of variables (i.e., the indexed ring-width series and the climatic variables) are established, a statistical analysis is applied to determine the relationships between tree growth and climate. A broad spectrum of statistical methods are available for developing models of tree growth in relation to climate (Fritts 1976, Peters et al. 1981, Cook 1985, 1987, Van Deusen 1989, Cook and Peters 1997). Fritts (1976) presents an excellent review of most of the statistical methods used in dendroclimatic research and is a frequently referenced source on this subject. Van Deusen (1989) explains a step-by- 
step approach to tree-ring analysis and Peters et al. (1981) discuss the use of principal components analysis (PCA) to relate tree-ring mean time series to climate data.

Adoption of relevant statistical methods depends mainly on the nature and hypothesis of the study. The methods range from the simplest correlation and multiple regression analysis to the more complicated multivariate statistical methods of principal component and factor analysis. Due to their simplicity the former two methods have been widely used. But it has been long recognized that the inherent problems of autocorrelation and multicollinearity in dendroclimatic data means that simple correlation and multiple regression analyses are theoretically inadequate, and their use may yield biased results under certain circumstances. Fritts et al. (1971) was the first to suggest the multivariate technique of regression on principal components as an alternative to leastsquares for handling multicollinearity among the climatic variables.

The method as described by Fritts et al. (1971) and Fritts (1976), however, employs an incorrect test-statistic for assessing significance of the climatic variables, includes discrepancies on the definition of the elements of the response function and the associated standard errors, and uses non-standard matrix notation that may lead to confusion. In addition, a demonstration of this multivariate procedure using a dendoclimatic dataset has not been given in the literature and this may partly account for its infrequent usage. In light of these issues, this study provides a re-calibration of the entire procedure by introducing the appropriate distribution of the statistic used for testing significance of the climatic variables. The results are discussed in chapter 7 (STUDY V). 


\subsection{Ecological and Dendroclimatic Characteristics of Four Hardwood Species}

The central Appalachian region because of its mild climate, abundant rainfall and its unique geographical position, has spacious forest cover and a wide variety of species. On a broad scale, the major plant associations of the central Appalachian region are oak forests and northern hardwoods. According to Rumney (1968) there is a wide variety of vegetation types in the region, which is a natural consequence of the variations in topography, weather patterns and underlying bedrock.

In this study the role of aspect on radial growth response of four hardwood species to general climate and drought were investigated. The species studied were yellow-poplar (Liriodendron tulipifera L.), northern red oak (Quercus rubra L.), chestnut oak (Quercus prinus L.), and red maple (Acer rubrum L.). Some ecological and growth characteristics as well as dendrochronological potentials of these species are briefly described.

\section{A. Yellow-poplar}

Yellow-poplar is one of the most important Appalachian hardwood species because of its excellent form, rapid growth rate and the fine working qualities of the wood. It is a fast growing and site demanding species generally found on best sites. In north central West Virginia aspect is the key site factor controlling the importance of yellow-poplar (Hicks and Frank 1984), with yellow-poplar predominating on northeastfacing slopes. It is most abundant and reaches its largest size on the slopes of the Appalachian Mountains. On good sites yellow-poplar can sustain a height growth of 1.5 $\mathrm{ft} /$ year $(0.46 \mathrm{~m} / \mathrm{year})$ and a diameter growth of $0.25 \mathrm{in} /$ year $(0.64 \mathrm{~cm} / \mathrm{year})$. Due to its fast growth yellow-poplar is capable of maintaining dominance in the canopy of mixed stands 
for at least 100 years (Hicks 1998). On poor sites it is usually outgrown by red oak. Unlike red oak, yellow-poplar has smaller seeds, higher shoot: root ratio, and greater relative growth rate, characteristics of competitive plants adapted to fertile, relatively undisturbed environments (Loach 1970, Kolb et al. 1990). Yellow-poplar is shade intolerant and requires full sunlight to grow well. Its optimum development occurs where rainfall is well distributed over a long growing season (Renshaw and Doolittle 1958). The age of natural senescence for yellow-poplar is 200-250 years (Hicks 1998) but for maximum wood production it should not be managed beyond 100-120 years.

The growth rings of yellow-poplar are diffuse-porous. Its pores are small and uniformly distributed through the ring (Panshin and de Zeeuw 1980). The species has been considered in several dendroclimatic studies (e.g., Tryon et al. 1952, 1957, Orwig and Abrams 1997, Pan et al. 1997). Tryon et al. (1957) noted that yellow-poplar was more sensitive to environmental variations than some other species in West Virginia. They compared the ring width of yellow-poplar with precipitation data and found that adequate rainfall early in the growing season had more effect on diameter growth than rainfall during the entire season. Orwing and Abrams (1997) showed that on moist sites, yellow-poplar showed higher ring-width reduction during drought than white oak and black oak. At the Fernow Experimental Forest Pan et al. (1997) showed that abundant precipitation in the previous October and current July is the most important factor to the growth of yellow-poplar.

\section{B. Northern red oak}

Northern red oak is the most valuable species of the red oak group (black, scarlet, and northern red) for lumber. Red oak is capable of growing on a wide variety of sites but 
it grows best on deep, well-drained soils and on north or northeastern aspects (Sander 1957, Hicks 1998). It is a species that tends to exhibit its highest overstory dominance at both mesic and dry sites (Abrams et al. 1998).

Northern red oak is moderate in its shade tolerance, but less tolerant than maples and more tolerant than yellow-poplar. Red oak is thought to be a drought tolerant species (Kolb et al. 1990, Abrams et al. 1998) and is an important constituent of both mesic and xeric sites in the mid-Atlantic region. Weitzman and Trimble (1957) reported that on good sites (site index 70) in West Virginia, the average 10-year diameter growth of the species was $4 \mathrm{~cm}$. Dominant and codominant red oak are capable of diameter growth rates up to $0.4 \mathrm{in} /$ year $(1.02 \mathrm{~cm} /$ year) (Trimble 1969). It sustains a good rate of growth up to 100 years of age and is capable of living longer than 200 years. Red oak possesses characteristics of stress-tolerant plants adapted to resource-poor environments, such as large seeds, a long life-span, and low shoot : root ratio compared to yellow-poplar (Fowells 1965, Kolb et al. 1990).

The growth rings of northern red oak are very distinct (ring-porous). Early wood pores are very large, visible to the naked eye, and they form a conspicuous band (Panshin and de Zeeuw, 1980). Because of its clear annual ring character, wide geographical spectrum and long life spans, red oak is a good species for dendrochronological studies (Hornbeck 1987; Tainter et al. 1990, Graumlich 1992, Abrams et al. 1998, Pan et al. 1997).

\section{Chestnut oak}

Compared to northern red oak, chestnut oak has a limited distribution since it usually occurs at the dry west and southwest aspects and is very infrequent on north and 
east aspects. Chestnut oak is intermediate in its shade tolerance and tends to show its highest overstory dominance at the dry or xeric sites often competing with hickories, white oak and black oak. On these poor sites scarlet oak and red oak can overtop chestnut oak. On good sites, chestnut oak will quickly be overtopped by yellow-poplar, northern red oak, red maple and black cherry, which leads to suppression and death of chestnut oak on such sites (Hicks 1998). It is considered to be the most drought-tolerant species in the mid-Atlantic region (Abrams et al. 1998). Its physiological maturity is reached at relatively late age, and it grows slower than many other oaks, probably because it tends to grow on poorer sites (Campbell, 1961). It employs a conservative growth strategy with heavy seed and slow growth rate. Chestnut oak is capable of living to about 200 years of age, but its growth rate peaks at an age of less than 200 years (Hicks 1998).

Chestnut oak is a ring-porous species. It has distinct growth rings, except in extremely slow-grown stock. Chestnut oak has been widely used in dendrochronological studies (Phipps 1967, Cook and Jacoby 1977, Abrams et al. 1998, Pan et al. 1997). Phipps (1967) studied the ring width of suppressed chestnut oak trees in the southern Ohio valley. He concluded that water was generally not a limiting factor to chestnut oak growth in the early part of the growing season. Cook and Jacoby (1977) utilized the ring chronology of chestnut oak to reconstruct the past climatic change in eastern North America.

\section{Red maple}

Red maple is a species that can tolerate a wider range of soil and climatic conditions than any other forest species in North America (Walters and Yawney 1990) and is becoming a prominent component of many stands in the central hardwood region 
(Abrams 1998). When growing in mixed stands, red maple is most abundant in the understory but also can occupy upper canopy strata. Red maple occurs at both mesic and dry aspects and has no distinct aspect preference (Hicks and Frank 1984). Red maple is classified as a shade tolerant species with a moderate growth rate (Trimble 1975) but is not as shade tolerant as sugar maple and generally more tolerant than oaks. Red maple matures in 70-80 years with a maximum longevity of about 150 years (Hicks 1998). Red maple is considered to be highly drought tolerant (Abrams et al. 1998).

The growth rings of red maple are diffuse-porous. Its pores are small, uniform in size and evenly distributed through the growth ring (Panshin and de Zeeuw, 1980). However, under shaded conditions, its ring widths are very narrow, and measurement of its annual growth becomes difficult. Red maple is often considered in stand dynamics studies (e.g., Abrams 1998, Tift and Fajvan 1999) and in a few dendroclimatic studies (Hornbeck 1987, Abrams et al. 1998). 


\section{CHAPTER 2}

\section{THE STUDY SITE AND METHODOLOGY}

\subsection{The Study Area}

The study area, Little Laurel Run watershed, is located within the West Virginia University Forest, part of Coopers Rock State Forest approximately $16 \mathrm{~km}$ northeast of Morgantown. The watershed encompasses approximately 271 ha and is typical of many Appalachian V-shaped valleys with long, steep and rocky slopes. The watershed orientation is from northwest to southeast. The average relief of the watershed is roughly $224 \mathrm{~m}$, with the highest point of elevation being $796 \mathrm{~m}$ (in the northern part of the watershed) and the lowest being $567 \mathrm{~m}$ (at the southeastern boundary) above the sea level (Tajchman and Wiant 1983). The topography of the area is fairly rugged and the average slope inclination is $14^{\circ}(25 \%)$. The average oak site index is $22.6 \mathrm{~m}(73.9 \mathrm{ft})$ and the average biomass (Knight 1980) is $64.5 \mathrm{t} / \mathrm{acre}(159.4 \mathrm{t} / \mathrm{ha})$. The watershed is covered with an even-aged 60-70 year-old mixed hardwoods forest of mostly sprout origin. Roughly $62 \%$ of the forest is composed of mixed oaks. The predominant species in these stands are white oak, black oak, northern red oak, scarlet oak, and chestnut oak. Scarlet oak and chestnut oak dominate the ridge tops with the other oaks sharing dominance over the more moist intermediate and upper slopes. The remainder, $38 \%$ of the forest, is occupied by mesophytic-hardwood stands. These stands occur on the mesic sites and consist

primarily of yellow-poplar, red maple, black cherry, and northern red oak (Knight 1980).

Soils are predominantly Gray-Brown and Red-Yellow Podozolic (Boyles and Tajchman 
1984); they are mainly derived from acid sandstone and shales. Depth of soil ranges from $0.61 \mathrm{~m}$ to $1.52 \mathrm{~m}$.

The study site has been the center of several soil-site and tree growth related investigations (e.g., Tajchman and Wiant 1983, Boyles and Tajchman 1984, Frank et al. 1984, Hicks and Frank 1984). The average annual precipitation at the climate station in the vicinity of the watershed is $142 \mathrm{~cm}$, and is fairly evenly distributed throughout the year. The average annual air temperature is $8.9^{\circ} \mathrm{C}$, although temperatures as low as -33.9 ${ }^{\circ} \mathrm{C}$ have been recorded in January (Carvell 1983). The maximum temperature rarely exceeds $29.4{ }^{\circ} \mathrm{C}$. The growing season in the study area is approximately May through September and the average length of the growing season is 149 days with shorter periods at the higher elevations (Carvell 1983). The average frost-free season is 167 days (Patton et al., 1959). Annual snowfall is about $229.6 \mathrm{~cm}$ with snow covering the ground throughout the winter months; January $(81.2 \mathrm{~cm})$ followed by February $(53.5 \mathrm{~cm})$ and December $(42 \mathrm{~cm})$ being the months with the greatest snowfall. Generally, the climate of the region can be classified as humid temperate, with hot summers and cold winters, where precipitation and soil moisture are relatively high during the growing season (Lee and Sypolt 1974). Since the trees at the study area were commercially logged during the 1930 's, no major disturbances by logging, silvicultural treatments, and fire were reported till the present time.

For the present study four super plots, each with an area of one hectare, were established at the north $\left(5^{\circ}\right)$, east $\left(80^{\circ}\right)$, west $\left(285^{\circ}\right)$, and southwest $\left(240^{\circ}\right)$ facing slopes of the watershed. Since $77 \%$ of the watershed consists of slopes having inclination from 
$5^{\circ}$ to $20^{\circ}$ an effort was made to choose study plots with similar steepness and comparable to the average for the site. Plots close to a ridge or drainage line were avoided.

\subsection{Field Procedures and Sampling Scheme}

During the fall of 1996, a systematic preliminary survey of the research site was conducted to select the four super plots. At each super plot, a center plot with an area of $400 \mathrm{~m}^{2}$ was identified and corners of these center plots were marked with long wooden stakes. The center plots were intended for felling trees to collect tree-ring samples. Maintaining the center plots as a central point, the one-hectare forest at each aspect was partitioned into twenty-five $400 \mathrm{~m}^{2}$ square sub-plots (Figure 2.1) with the help of compass points. The corners of these plots were marked with wire flags. Before felling was begun (at the center plots) the representativness of the center plots to the site was determined by comparing the above ground biomass per hectare calculated from each center plot with the average for the site. For this, trees larger than $7 \mathrm{~cm}$ diameter at breast height (d.b.h.) within all the 100 plots were tallied by species, diameter at breast height, crown class, and total height. The analysis of these data is given in Chapter 3 (STUDY I).

The aboveground tree biomass in each plot was calculated according to Brenneman et al. (1978). If the deviation of the center plot biomass was considerable (> $|10 \%|$ ) the plot was adjusted in orientation, depending on the knowledge of biomass production of the neighboring plots, until the deviation from the mean was $<|10 \%|$. All trees in these representative adjusted $400 \mathrm{~m}^{2}$ center plots, at each aspect, were felled to take tree ring samples. At the north and west facing sites the dry biomass for the center plots were $5.8 \%$ above and $1 \%$ below the average respectively. At the east and southwest aspects the center plot biomass was $31 \%$ and $11 \%$ above the average and hence the latter 
two center plots were adjusted before felling began. The variation of plot biomass with aspect has practical significance as it relates to the sample size required for such studies and thus this issue is briefly addressed in Chapter 3 (STUDY I).

In the adjusted center plots each tree was numbered and several measurements before and after felling were taken from every individual tree. These included diameter at ground level, stump height, diameter at breast height, vertical height (standing tree), horizontal height (fallen tree), crown height, crown length, diameter at crown base, middiameter at half tree and stem height. After felling, a disc was cut from the stump to determine the age of the trees, and another disc was cut at breast height $(1.4 \mathrm{~m}$ above ground) for radial growth analysis. The discs taken at the stump and d.b.h. were also labeled by plot aspect, tree number, species, and the letter "S" (for discs taken from the stump), and "d.b.h." for discs taken at breast height.

For each tree felled and sampled at the four aspects various site and specimen data were noted. These included: the slope (steepness expressed in percent), relative position on the slope (mid, upper and lower), exposure (aspect) according to azimuth degrees from north, stoniness, associated plant growth (species and neighborhood basal area), any natural or man-made disturbance (e.g., fire or silvicultural cuttings), relative position from the ridge line or drainage line, presence of American chestnut stumps, and any other topographic or vegetation characteristics that were believed to have affected growth of the felled tree was recorded. This information is very important in that it might help to explain anomalies (if any) in tree-rings. As each tree was felled the tree number was written on the corresponding stump using a log marker. As felling progressed a sketch of each plot was made and the relative positions of the trees were plotted. In other words, on 
the sketch of the center plot, each tree was defined in an $\mathrm{x}, \mathrm{y}$-coordinate system. This was done by measuring the distance and bearing of each tree from the center of the plot.

Soil pits were dug at five representative points within the center plot. Thickness of the A-horizon was measured. Soil samples were obtained from three depths, 0-10 cm, 10$20 \mathrm{~cm}$, and $20-30 \mathrm{~cm}$. The soil samples were analyzed to determine soil $\mathrm{pH}$, lime requirement, and major plant nutrients. Diurnal air temperature was monitored using a thermohygrograph on two cloudless days during the 1997 growing season. The analysis of vegetation, soil and microclimatic data collected at each aspect is discussed in Chapter

\section{3 (STUDY I).}

\subsection{Supplemental Sampling Design}

The species and the number of trees felled at the center plots in October of 1996 are given in Table 2.1. The data clearly show that the systematic sampling scheme described above, i.e., felling all trees in a representative center plot(s), resulted in an unbalanced design in terms of the sample size. The number of trees per species was not comparable across aspects. For example, there were 9 yellow-poplar trees at the north aspect and none at the west and southwest aspects; one chestnut oak tree at the mesic north and east aspects while there were 8 at the drier west and southwest aspects. This relates to the previously discussed association between aspect and the distribution and occurrence of certain species groups, where some species are adapted to the west and southwest aspects and others dominate the north and east aspects. This phenomenon was underestimated during the initial sampling and hence additional fieldwork was conducted during the summer of 1999 and 2000 to supplement the data, balance the design and increase the depth of the tree-ring chronology. 
During the $2^{\text {nd }}$ field collection in 1999 and 2000 all cored trees were from within the super plots except for chestnut oak. Chestnut oak was extremely infrequent at the north and east aspects so that we were able to find only one tree at the east-facing super plot and none at the north facing super plot. A more elaborate discussion on changes in species composition and dominance due to differences in aspect is given in Chapter 3 (STUDY I). In tree-ring research, trees to be cored generally are chosen randomly but have to satisfy certain predefined desirable chacterstics, which again depends on the objective of the study. For dendroclimatic studies preferred sample trees are relatively mature, with healthy crowns, free of disease, should be from an area with minimal natural or man-made disturbances, and two cores from at least 25-30 trees of a given species should be sampled (Fritts 1976).

\subsection{Tree-ring Specimen Collection, Preparation and Measurement}

The tree-ring specimens (discs and increment cores) were processed using the methods described by Stokes and Smiley (1968). The discs from the felled trees in 1996 were wrapped with burlap and were placed in plastic bags for transportation to the WVU forest hydrology laboratory where they were air dried before further work. The increment cores collected in 1999 and 2000 were placed in plastic straws, with the ends tapped shut, and were transported to the USDA Forest Service dendrochronology laboratory in Morgantown where they were removed from the straws and air dried.

\section{A. Disc and Core Preparation}

Discs and increment cores were first cleaned and air-dried in the laboratory and one surface of the discs and increment cores was sanded. To facilitate handling and storage, the increment cores were glued into grooved wooden mounts. Air-drying the 
cores prior to mounting ensures that they will not shrink and crack after they are glued in place. For cores broken in the field sequential numbering of the fragments aided in reconstructing the core for mounting. The specimen number and such notes as the species, aspect, and collection date are written on the mount in pencil. For discs the above species and site information was recorded on the side that was not chosen for sanding. A

finely sanded surface is crucial to the crossdating and measurement of ring-width series. Ring boundaries, microrings, and diagnostic characteristics (such as false-rings, and injuries) are often discernible only when the surface of the discs and increment cores is smooth. Hence, visibility of annual rings was enhanced by mechanically sanding a radial surface of the increment cores and the whole cross-section of the discs. To remove any saw marks and to minimize the amount of sanding, the discs were initially surfaced with a belt sander. Sanding with a rotary sander equipped with $80,100,150,220,320$, and 440 grit papers followed the belt sander. The samples were then sanded by hand with finer particle sanding films. Hand sanding was done till tree-rings appeared to be prominent. Finally, the examination of the specimens was made easier by removing dirt and dust particles with a jet of compressed air. At this stage the discs and increment cores were ready for the first stage of cross-dating.

\section{B. Crossdating}

After the tree-ring specimens were sanded, the rings were crossdated according to standard dendrochronological techniques described by Stokes and Smiley (1968). Crossdating of the tree-ring specimens involved the development of skeleton plots on a small number of discs mostly from yellow-poplar. After the skeleton plots were made, they were compiled into a master chronology through a method of averaging the 
individual plots into one master plot. The specific years associated with each tree-ring in a specimen were identified by examining each core or disc under a microscope and making comparisons between the specimen and the master chronology. The crossdating procedure identified where missing rings and false rings were located as well as determining the exact year for each tree-ring specimen. In addition to the skeleton plot crossdating was also performed using the list method of Yamaguchi (1991). Narrow rings were observed in 1953, 1966, 1988, and 1991. Rings from these years were used as markers for crossdating using the list method.

\section{Ring-width Measurement}

The ring-widths of the crossdated specimens from all species were then precisely measured at the USDA Forest Service dendrochronology lab using a Velmex measuring table with a microscope and a fiber optic light source. During measurement of ring-width the attached microscope magnified the specimen image so that annual rings could be discernible and reflected light was used to enhance the view of the rings. Each specimen was measured from bark to pith, and ring-width was read to the closest $0.01 \mathrm{~mm}$. A treering data management computer program was used to record and store the tree-ring width data from the measuring table. The data for each specimen were stored in time series format according to the identification number of the specimen.

\section{Verification of Crossdating}

After all the tree-ring specimens were measured, the computer program COFECHA, was used to identify any possible measurement and crossdating errors (Holmes 1983). COFECHA employs a correlation procedure, which enhances time-series characteristics (i.e., the large and small ring patterns) to ensure accurate calendar year 
assignment to individual tree-rings. The program was executed at three-stages using crossdated measurements of each species per aspect, all species in an aspect, and all species for the site. If potential errors flagged by COFECHA could be verified by reexamination of flagged cores, the appropriate measurement or crossdating correction was made. Any potential errors flagged by COFECHA that could not be verified as true errors were ignored (see Table 2.1). The end result of the crossdating, measuring, and COFECHA quality control was a dated and measured set of tree-ring data that should be error free. The data consisted of dated ring-width measurements in time series format for each individual specimen and were ready for standardization and data analysis.

\subsection{Standardization}

Standardization, using program ARSTAN, is usually performed by fitting linear or negative exponential regressions to each times series to remove the variance associated with age. Most of the dendrochronologichal techniques for indexing tree growth were developed and adapted in southwestern United States for studying growth-climate relationship and for climate reconstruction using tree-ring data from very old trees. The techniques are not entirely appropriate for indexing tree-ring series when the forest stand being studied is not old-growth. Use of some of the current indexing techniques for growth-climate studies, especially when the ring-width series span a relatively short period of time ( $<100$ years), yield results of questionable reliability (Fekedulegn et. al. (in preparation)). In addition, program ARSTAN also fits biologically unrealistic models to some series (see STUDY IV for details). An appropriate modification of the indexing techniques for short tree-ring series (such as those used in this study) is given in chapter 6 (STUDY IV). For this study standardization was accomplished by fitting a modified 
negative exponential model in SAS using a modified convergence criterion and when this model failed, a smoothing spline of segment length 32 was employed. The standardized tree-ring index at time $t, I_{t}$, was calculated as

$$
I_{t}=\frac{R_{t}}{G_{t}}
$$

where $R_{t}$ is the ring width at time $t$, and $G_{t}$ is the expected value of $R_{t}$ from the fitted model. $I_{t}$ is a dimensionless ring-width index where an index of one represents average growth, while values greater or less than one indicate above- and below-average growth respectively.

\subsection{Autoregressive Modeling}

Standardized ring-width (also called ring-width index) is the most commonly used growth index for modeling tree growth-climate relationships (Fritts 1976, Cook et al. 1987). However, the standardized ring-width index usually exhibits a high positive autocorrelation and in this study the variance due to autocorrelation was removed form each tree by fitting a first or second order autoregressive model of the form

$$
I_{t}=\phi+\phi_{1} I_{t-1}+\phi_{2} I_{t-2}+a_{t}
$$

where $I_{t}, I_{t-1}$ and $I_{t-2}$ are ring-width index at time $t, t-1$ and $t-2, \phi$ 's are the autoregressive parameters, and the residual $a_{t}$ (also called the prewhitened ring-width index) is assumed to reflect the year-to-year variation in radial growth of the tree associated with climate and was used as the response variable for growth-climate analysis. 


\subsection{Basal Area Calculation}

For comparing growth rates across the four aspects, ring-widths were converted to annual basal-area increment using the procedure described by Visser (1995) and by Kolb and McCormick (1993):

$$
B A I=\pi\left(R_{n}^{2}-R_{n-1}^{2}\right)
$$

where $R$ is the tree radius obtained by summing ring-widths, and $n$ is year. This conversion was suggested by Phipps (1983) as a means of showing whether narrowing ring-widths in maturing trees represent a true growth decline. The use of BAI removes the variation in radial growth caused by increasing stem circumference as trees age (Kolb and McCormick 1993). To compare growth rates across aspect, for each year average basal area increment $\left(\mathrm{cm}^{2} \mathrm{yr}^{-1}\right)$ was obtained by averaging over all trees for a species.

\subsection{Data Analysis}

Data analysis used both graphical representations and statistical testing of the data to determine temporal and spatial patterns in ring-width and BAI of the species. There are two methods by which the ring-width and BAI data from each tree were organized for statistical analysis.

In the first data organization method, temporally distributed data were used for analysis of temporal variation in ring-width and BAI. Individual tree-level ring-width and BAI time series were averaged into a mean ring-width and BAI time series by species and aspect. The temporal analysis began by making a time series plot of the mean ringwidth and mean BAI for all sampled trees of each species by aspect. These time series plots were examined to identify peaks (increases or decreases) in growth. 
In the second data organization method, spatially distributed BAI data were used to compare growth rates and variability in growth across aspects. For this analysis, mean BAI and coefficient of variation $(\mathrm{CV})$ of BAI for the whole range of measured growth were calculated for each tree. Using ANOVA, growth rates and the degree of year-toyear growth variation were compared across the four aspects for each species. Mean BAI was used as a measure of growth rate and $\mathrm{CV}$ of $\mathrm{BAI}$ was used as a measure of variability.

In addition, the analysis consisted of categorizing the individual tree data into two topographic aspects; mesic site (north and east aspects) and dry site (west and southwest aspects). BAI and $\mathrm{CV}$ data were calculated for trees of each species at the two topographic classes (mesic and dry sites). Independent t-tests were then performed to compare growth rates and variability, for each species, between the mesic and dry sites.

\section{A. Correlation Analysis}

Relationships between species ring-width index (RWI) values and growing season data on the three climatic factors (precipitation, temperature, and PDSI) between 1935 to 1996 were examined using Spearman rank correlation and Pearson's product-moment correlation. The Pearson test was used when the two variables are normally distributed while the Spearman rank test was applied when the assumption of normality was not satisfied.

In addition, paired t-tests were used to determine if climatic anomalies such as droughts influence the growth rate of the four species. To determine if radial growth rate was suppressed beyond the year of drought, paired t-tests were performed comparing the 
mean prewhitened index value for the five-year previous to and the five years following each drought. Additional details are given in Chapter 5 (STUDY III).

\section{B. Response Function Analysis}

To study the growth response of the species to monthly climatic variables and to determine the overall effect of climate on radial growth, the method of principal components regression was employed. This method is developed in chapter 7 (STUDY V). In the response function, the predictor climatic variables were total monthly precipitation and mean monthly temperature for 17-month period extending from May of the preceding year to September of the current year and the response variable was averaged prewhitened ring-width index.

In the response function analysis, models were estimated for trees grouped into two categories determined by the spatial distribution of moisture availability, i.e., for mesic (north and east aspects) and dry (west and southwest aspects) topographic locations. This grouping was done to increase the depth and reliability of the chronology to ensure appropriate interpretation of the growth responses of the species to climate. After the regression models were selected, model $\mathrm{R}^{2}$ for each topographic category was compared and climatic predictor variables selected for each group were examined to determine how climate affects the temporal variation of radial growth of each species. To

compare the percentage of growth variance accounted by climate across aspect, $\mathrm{R}^{2}$ values were calculated for each aspect.

For all statistical tests, the level of significance was held at $95 \%$ level or $\alpha=0.05$.

Using ANOVA, groups were significantly different if the null hypothesis was rejected at $\alpha=0.05$ level. All statistical analyses including ANOVA, regression, correlation, and t- 
tests were performed with SAS (1989). For every statistical test, underlying assumptions that validate the use of that test had to be met. Parametric procedures require independence within and between groups, normal distributions, and homogeneity of variance among groups. There were instances where a $\log (10)$ transform of the BAI data was required to produce distributions that were approximately Gaussian in shape with homogeneous variance. In some analyses, nonparametric procedures based on rank transform of the BAI data (Conover and Iman 1981, and Conover 1999) were used. For any test where the underlying assumptions were violated, remedial measures were used. 
Table 2.1. Database: the number of trees sampled for tree-ring specimen (discs or cores). Values in bracket are the number of trees felled at the center plots of each aspect in 1996.

\begin{tabular}{|c|c|c|c|c|c|c|c|c|c|}
\hline \multirow{7}{*}{$\begin{array}{l}\text { Main } \\
\text { Species }\end{array}$} & \multirow{3}{*}{$\begin{array}{l}\text { Species } \\
\text { Yellow-poplar }\end{array}$} & \multicolumn{8}{|c|}{ Aspect } \\
\hline & & \multicolumn{2}{|c|}{ North } & \multicolumn{2}{|r|}{ East } & \multicolumn{2}{|c|}{ West } & \multicolumn{2}{|c|}{ Southwest } \\
\hline & & $23^{*}$ & (9) & $20^{*}$ & (2) & $17^{*}$ & $(0)$ & $15^{*}$ & $(0)$ \\
\hline & Northern red oak & 20 & (1) & 18 & (1) & 20 & (3) & 19 & $(0)$ \\
\hline & Chestnut oak & 6 & (0) & 6 & (1) & 22 & (7) & 20 & (1) \\
\hline & Red maple & 26 & (10) & 25 & (7) & 18 & (10) & 16 & $(5)$ \\
\hline & Sub total & 75 & (20) & 69 & (11) & 77 & $(20)$ & 70 & $(6)$ \\
\hline & Black cherry & & (1) & & (3) & & $(0)$ & & $(0)$ \\
\hline & Scarlet oak & & $(0)$ & & (2) & & (1) & & $(4)$ \\
\hline Secondary & White oak & & (0) & & (0) & & $(0)$ & & $(2)$ \\
\hline Species & Black gum & & (0) & & (1) & & (10) & & $(6)$ \\
\hline & Birch & & (3) & & $(0)$ & & (1) & & $(0)$ \\
\hline & Cucumber tree & & (4) & & (0) & & (0) & & $(2)$ \\
\hline & Hickory & & (0) & & (1) & & (0) & & $(0)$ \\
\hline & Sasfrass & & $(0)$ & & (0) & & (1) & & $(0)$ \\
\hline & Sub total & & (8) & & (7) & & (13) & & (14) \\
\hline Total & & 83 & (28) & 76 & (18) & 90 & (33) & 84 & (20) \\
\hline
\end{tabular}

"The total number of trees sampled including the cores collected in 1999 and 2000. For example, at the north aspect 9 yellow-poplar trees were felled in 1996 and $(23-9=14)$ trees were cored in 1999 and 2000. In total 23 trees were sampled for tree-ring analysis.

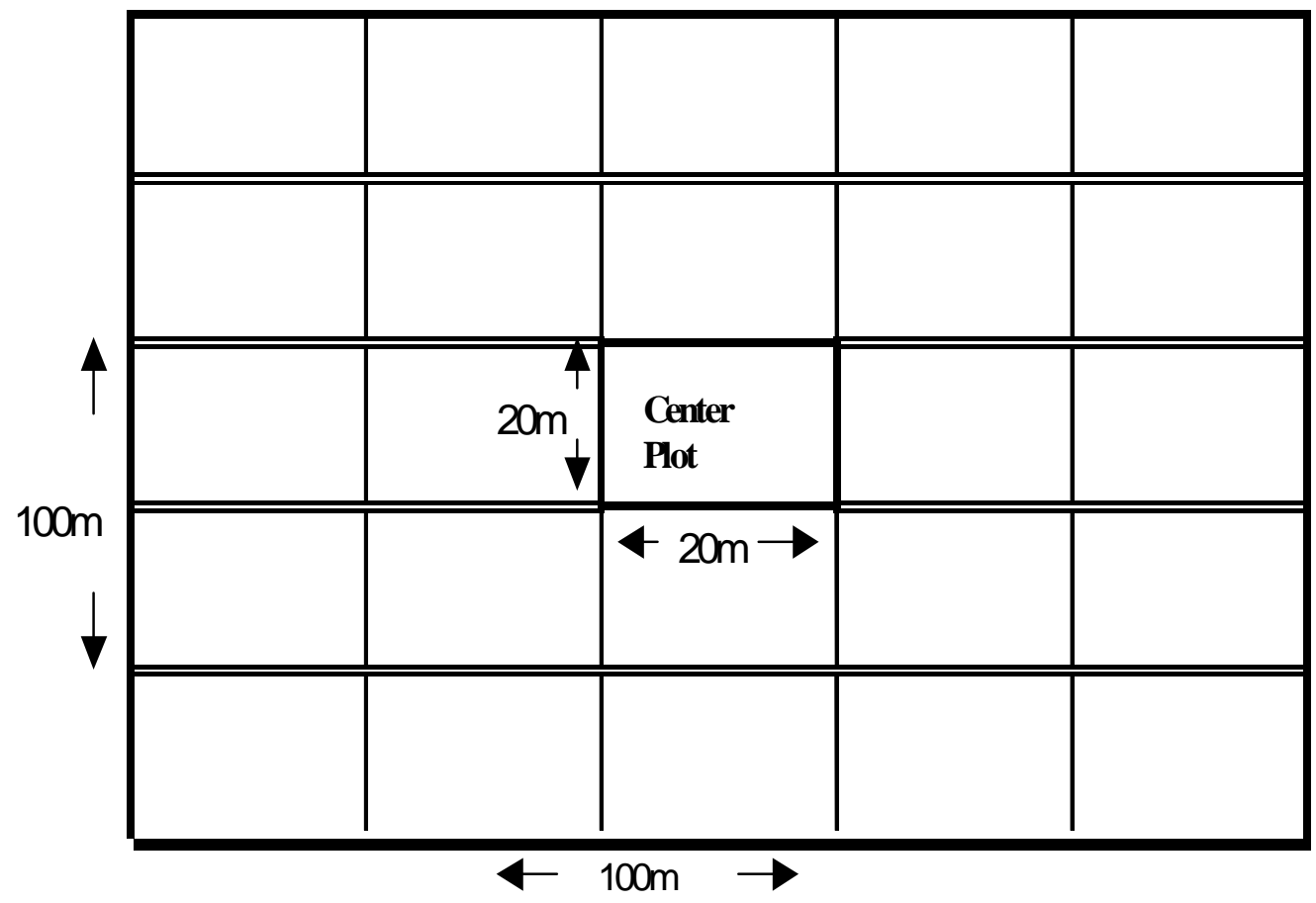

Figure 2.1. Plot establishment. The super-plot partitioned into $25400 \mathrm{~m}^{2}$ sub-plots. 


\section{CHAPTER 3: STUDY I}

\section{ASPECT RELATED DIFFERENCES IN VEGETATION, SOIL, AND MICROCLIMATIC CHARCTERSTICS AT THE STUDY SITE}

\subsection{Introduction and Methods}

The objective of this chapter was to examine changes in vegetation characteristics, soil-plant nutrients, and microclimatic variables related to aspect differences at the study site. Measures used to characterize aspect-induced changes in vegetation include species composition, basal area, dry biomass, vegetation density, tree diameter at breast height, total height, and species importance values. Measures of microclimate parameters included air temperature, relative humidity, and vapor pressure deficit. Tree data were collected on 100 0.04-ha plots. Twenty-five plots each were established on north, east, west and southwest facing aspects. All trees with diameters $>7$ $\mathrm{cm}$ dbh were measured. The above ground dry biomass for each tree was then computed according to Brenneman et al. (1978):

$$
Y=a(X)^{b}
$$

where $\mathrm{Y}$ is the above ground dry biomass $(\mathrm{lbm}), \mathrm{X}$ is the diameter at breast height of the tree (in), and $\mathrm{a}$ and $\mathrm{b}$ are scaling coefficients. The coefficients ( $\mathrm{a}$ and $\mathrm{b}$ ) had been estimated by Brenneman et al. (1978) for major Appalachian tree species. These coefficients were used to estimate tree dry biomass at each plot. Tree species importance values (Phillips 1959) were computed for each plot and species by summing the relative density, relative dominance (basal area), and relative frequency, where 
Relative density $=\frac{\text { number of individuals of the species }}{\text { total individuals of all species }} \times 100$,

Relative basal area $=\frac{\text { total basal area of the species }}{\text { total basal area of all species }} \times 100$,

and Relative frequency $=\frac{\text { number of points of occurrence of the species }}{\text { number of points of occurrence of all species }} \times 100$.

For each aspect the dominant species was assumed to have the highest importance value which provides a means for comparing species dominance across the four aspects.

Soil samples were collected from five locations within the center plot $^{1}$ at each aspect. The samples at each pit were taken from three depths: 0-10 cm, 10-20 cm, and 20$30 \mathrm{~cm}$. The soil samples were chemically analyzed at the West Virginia soil-testing laboratory to provide estimates of $\mathrm{pH}$, lime requirement, phosphorus, potassium, calcium, and magnesium.

Air temperature readings were taken at two hour intervals from 6 am to $8 \mathrm{pm}$ using a psychrometer at each aspect during two cloudless (sunny) days: July $14^{\text {th }}$ and $16^{\text {th }}$ of 1997. Temperature readings taken at breast height were made at four observation points, each $15 \mathrm{~m}$ apart, across the center plot where trees were felled. During measurement the instrument was not exposed to direct solar radiation. The psychrometer consists of two ventilated thermometers, the dry bulb thermometer measured the air temperature directly, while the wet bulb thermometer measured a temperature lowered by an amount determined by the evaporative cooling caused by the ambient air. The temperature data were then used to provide estimates of actual and saturated vapor pressure, relative humidity, and vapor pressure deficit.

\footnotetext{
${ }^{1}$ There were 25 plots/aspect. In all the 25 plots, the species, dbh, and crown class of all trees with $\mathrm{dbh}>7$ $\mathrm{cm}$ were recorded. Only trees in the center (middle) plot were felled to obtain tree-ring data.
} 
The actual vapor pressure was computed based on the relationship (Rosenberg et al. 1983):

$$
e_{a}=e_{s}^{\prime}-A P_{z}\left(T_{d}-T_{w}\right)
$$

where $T_{d}$ is the dry bulb temperature $\left({ }^{\circ} \mathrm{C}\right), T_{w}$ is the wet bulb temperature $\left({ }^{\circ} \mathrm{C}\right), P_{z}$ is the atmospheric pressure at average height of the watershed $(z \approx 224 m), e_{a}$ is the actual vapor pressure in millibar (mb), $e_{s}^{\prime}$ is the saturation vapor pressure (mb) at $T_{w}$, and $A$ is a constant of proportionality $\left(A \approx 7.99 * 10^{-4}\right)$. The atmospheric pressure $\left(P_{z}\right)$ at the average height of the watershed in equation [3.2] was calculated from the following relationship (Rosenberg et al. 1983, Burman and Pochop, 1994):

$$
\frac{P_{z}}{P_{o}}=\left(\frac{288-0.0065}{288}\right)^{5.256}
$$

where $P_{o}$ is the air pressure at sea level $\left(P_{o} \approx 1000 \mathrm{mb}\right)$. For the study site $P_{z}$ was calculated to be $973.7 \mathrm{mb}$ and hence equation [3.1] reduces to

$$
e_{a}=e_{s}^{\prime}-0.777996\left(T_{d}-T_{w}\right)
$$

The saturation vapor pressure at $T_{w}, e_{s}^{\prime}$, in equation [3.2] was computed using the relationship by (Goff-Grach 1986):

$$
\begin{aligned}
& \log _{10} e_{s}^{\prime}=-7.90298\left(\frac{T_{s}}{T_{w}}-1\right)+5.02808 \log _{10}\left(\frac{T_{s}}{T_{w}}\right)-1.3816^{*} * 10^{-7}\left(10^{11.344\left(1-\frac{T_{w}}{T_{s}}\right)}\right) \\
& +8.1328 * 10^{-3}\left(10^{-3.19149\left(\frac{T_{s}}{T_{w}}-1\right)}\right)+\log _{10} e_{s s}
\end{aligned}
$$

where $e_{s}^{\prime}(\mathrm{mb})$ and $T_{w}\left({ }^{\circ} \mathrm{K}\right)$ are defined as above, $T_{s}$ is steam-point temperature (373.16 ${ }^{\circ} \mathrm{K}$ ), and $e_{s s}$ is saturation pressure of pure ordinary liquid water at steam-point 
temperature $\left(e_{s s}=\right.$ one standard atmosphere $=1013.146 \mathrm{mb}$ ). Relative humidity, which is defined as the ratio of actual to saturation vapor pressure at the same temperature was computed as

$$
R H(\%)=\frac{e_{a}}{e_{s}} * 100
$$

where $e_{s}$ is the saturation vapor pressure of the air and was computed using equation [3.5] but by replacing $T_{w}$ by dry bulb temperature, $T_{d}$. The vapor pressure deficit, $E t$,

$$
E t=e_{s}-e_{a}
$$

was calculated as the difference between the saturation vapor pressure and the actual vapor pressure $e_{a}$. Burman and Pochop (1994) and Rosenberg et al. (1983) comment that $E t$ is a rough measure of the drying power of the air, in that rates of evaporation and transpiration are indicated by the magnitude of the vapor pressure deficit. A SAS program was written to compute the estimates of the above parameters (actual and saturated vapor pressure, relative humidity, and vapor pressure deficit).

The relationship between vegetation data and aspect was analyzed using analysis of variance (ANOVA), t-test, and nonparametric statistical method (Wilcoxon's test) depending on the distribution of the measures of vegetation. Pearson's correlation coefficients were calculated correlating transforming aspect with the vegetation variables. For the purpose of this analysis, azimuth from north was transformed as the sine of azimuth taken clockwise from southeast and adding 1 (Trimble 1964). Starting at the southeast puts the southwest aspect, which has the lowest site index, and the northeast aspect, which has the highest site index, into their proper positions. Adding the sine plus 
1 eliminated negative numbers. This transformation is consistent with biological relationship of aspect with site quality.

\subsection{Objectives}

The specific objectives of this chapter were (a) to examine the spatial variability in vegetation (species importance values, biomass, density, etc.), (b) to examine the spatial variability in soil-plant nutrients, and (c) to examine the spatial variability in microclimate (air temperature, relative humidity, and vapor pressure deficit). Generally, this chapter is dedicated to quantifying how aspect influences site characteristics.

\subsection{RESULTS}

\subsubsection{Relationships of Vegetation with Aspect}

\section{A. Species, Size, and Frequency ${ }^{2}$ Distribution}

Yellow-poplar (Liriodendron tulipifera), black cherry (Prunus serotina), sugar maple (Acer saccharum), cucumber tree (Magnolia acuminata), and sweet birch (Betula lenta) occurred most frequently on north-facing slopes. Shagbark hickory (Carya ovata) obtained maximum frequency on east aspects. Red maple (Acer rubrum), northern red oak (Quercus rubra), and chestnut oak (Quercus prinus) occured most frequently on the west-facing slopes whereas scarlet oak (Quercus coccinea), white oak (Quercus alba), black oak (Quercus velutina), sassafras (Sassafras albidum), and black gum (Nyssa sylvatica.) were more frequent on southwest aspects. Among the species recorded in the watershed, the most prevalent species in terms of stem count at the north-facing site were red maple, yellow-poplar, and northern red oak accounting 61 percent of the trees

\footnotetext{
${ }^{2}$ Frequency is the percentage of plots within a stand in which individuals of a species are found.
} 
whereas at the east-facing site these same species made up 73 percent of the trees. At the southwest aspect 80 percent of the trees constituted of scarlet oak, red maple, black gum and northern red oak, and 69 percent of the trees at the west-facing site were made up of red maple, northern red oak and chestnut oak. The data clearly show that oak types are most frequently found on west and southwest aspects. On mesic exposures (north and east aspects) oak types are generally less common. At these exposures they are replaced by cove hardwood species like yellow-poplar and cucumber tree. Major tree species that exhibited the greatest variation $(>100 \%)$ in occurrence between the dry and moist exposures were yellow-poplar, black cherry, sugar maple, white oak, chestnut oak, black oak, and scarlet oak. The data suggest that these species tend to show aspect preference and this is discussed in detail in a later section.

The diameter distributions of the stands at each aspect show a polymorphic structure typical of most even-aged stratified, mixed species stands (Figures 3.1 and 3.2). The diameter distributions at the dry site, west and southwest aspects, follow the reverse $\mathrm{j}$-shaped structure more closely than that at the mesic site, north and east aspects (Figure 3.2). Yellow-polar, northern red oak, and black cherry combined account for 75 and 83 percent of trees larger than $31 \mathrm{~cm}$ dbh on the north and east-facing sites respectively. Red maple accounted for 70 percent of trees less than $19 \mathrm{~cm}$ dbh on both the north and eastfacing sites. On the dry site oaks (Quercus spp.) tend to dominant the higher dbh classes (Figure 3.2). The red oak group (northern red oak, scarlet oak, and black oak) and the white oak group (white oak and chestnut oak) combined accounted for 79 and 85 percent of trees larger than $31 \mathrm{~cm}$ dbh on the southwest and west facing slopes respectively. Red maple and other species (sweet birch, shagbark hickory, sugar maple, cucumber tree, 
black gum, sassafras) accounted for 63 (southwest) and 74 (west) percent of trees less than $19 \mathrm{~cm}$ dbh. Yellow-poplar and the red oak group had the largest mean dbh at all aspects (Table 3.1). Red maple and the other species group had the smallest mean dbh at the mesic and dry site respectively. Generally, there were more small trees on the dry site and more large trees on the mesic site (Figure 3.3). The red oak group growing on the northeast aspect was composed of 95 percent northern red oak while the red oak group on the southwest aspect was composed of 44 percent northern red oak and 52 percent scarlet oak.

\section{B. Basal Area and Dry Biomass}

The total basal area per hectare at the north $\left(37.9 \mathrm{~m}^{2} \mathrm{ha}^{-1}\right)$ and east $\left(34.1 \mathrm{~m}^{2} \mathrm{ha}^{-1}\right)$ aspects is higher than that at the west $\left(31 \mathrm{~m}^{2} \mathrm{ha}^{-1}\right)$ and southwest $\left(25 \mathrm{~m}^{2} \mathrm{ha}^{-1}\right)$ aspects (Table 3.2). The basal area per hectare on the mesic site $\left(36 \mathrm{~m}^{2} \mathrm{ha}^{-1}\right)$ was 28 percent higher than that obtained on the dry site $\left(28 \mathrm{~m}^{2} \mathrm{ha}^{-1}\right)$. Yellow-poplar and northern red oak accounted for over half of the total basal area on the mesic site (Figure 3.4). On the dry sites the red oak group and the white oak group accounted for 78 percent of the total basal area. Red maple basal area was similar across all four aspects (Figure 3.4), ranging from $2.2 \mathrm{~m}^{2} \mathrm{ha}^{-1}$ on the southwest aspect to $4.7 \mathrm{~m}^{2} \mathrm{ha}^{-1}$ on the east-facing site. Red maple made up a smaller percentage of total basal area on mesic sites but represented a larger percentage of basal area than either yellow-poplar or the other species group on the dry site. In general, yellow-poplar is the dominant species in terms of basal area on north and east-facing aspects, and the red oak group dominate the west and southwest aspects. The greater basal area on the mesic site can be attributed to the presence of more trees in the larger $(>31 \mathrm{~cm})$ diameter classes (Figure 3.3). 
The total above ground dry biomass at the north $\left(331 \mathrm{t} \mathrm{ha}^{-1}\right)$ and east $\left(276 \mathrm{tha}^{-1}\right)$ facing sites were significantly higher $(\mathrm{p}<0.05)$ than those at the west $\left(240 \mathrm{t} \mathrm{ha}^{-1}\right)$ and southwest (160 tha ${ }^{-1}$ ) facing slopes (Table 3.3). The above ground biomass at the mesic site $\left(303 \mathrm{t} \mathrm{ha}^{-1}\right)$ is 51 percent higher than that at the dry site $\left(200 \mathrm{t} \mathrm{ha}^{-1}\right)$. Yellow-poplar (126 t ha ${ }^{-1}$ on north, $86 \mathrm{t} \mathrm{ha}^{-1}$ on east) and northern red oak (49 $\mathrm{t} \mathrm{ha}^{-1}$ on north, $65 \mathrm{t} \mathrm{ha}^{-1}$ on east) combined account for about 54 percent of the total above ground dry biomass at the mesic site. The red oak group (109 $\mathrm{t} \mathrm{ha}^{-1}$ on west, $107 \mathrm{t} \mathrm{ha}^{-1}$ on southwest) and white oak group (93 $\mathrm{t} \mathrm{ha}^{-1}$ on west, $26 \mathrm{t} \mathrm{ha}^{-1}$ on southwest) together account for 83 percent of the dry biomass at the dry site (Figure 3.4). Scarlet oak alone accounts for over 40 percent of the dry biomass on the southwest facing site but on the north and east aspects its contribution is less than one percent. The percent contribution of red maple to the total above ground dry biomass is similar on all four aspects. However, red maple dry biomass at the mesic site, $28 \mathrm{t} \mathrm{ha}^{-1}$, is about 86 percent higher than the $15 \mathrm{t} /$ ha measured on the dry site. This difference was attributed to the larger trees on the mesic sites. On the mesic site 23 percent of the red maple trees had diameters greater than $19 \mathrm{~cm}$ as opposed to the dry site where only 12 percent of the red maple trees had diameters larger than $19 \mathrm{~cm}$.

The result in Tables 3.2 and 3.3 clearly show how aspect affects specific species groups. The white oak group (white oak and chestnut oak) contributes less than 2 percent to the total above ground biomass and basal area at the north and east aspects. However, on the dry site the white oak group contributes over 30 (west) and 13 (southwest) percent to both basal area and above ground biomass. On the other hand, black cherry accounts for 14 percent of the total biomass on the mesic site but on the west and southwest-facing sites it accounts for less than one percent in both basal area and above ground biomass. 
Other species (sweet birch, shagbark hickory, sugar maple, cucumber tree, black gum, and sassafras) all have greater basal areas and biomass on mesic sites (Tables 3.2 and 3.3, Figure 3.4).

\section{Density}

The density (stems per hectare) on the north (443 trees/ha) and east (430 trees/ha) aspects was significantly lower than that observed on the west (671 trees/ha) and southwest (682 trees/ha) aspects (Table 3.4). Red maple accounted for the largest percentage of stems on all but the southwest aspect where the red oak group dominated (Figure 3.5). Red maple stems per hectare on the west (230 trees/ha) and southwest (150 trees/ha) aspects was larger than that on the north (117 trees/ha) aspect. The east (169 trees/ha) facing site had a higher red maple density than the southwest and north facing aspects. Although there were generally more red maple stems present on most aspects, red maple accounted only for a small percentage of the total basal area and above ground biomass (Figure 3.4). This can be attributed to the presence of more red maple trees in the smaller diameter classes (Figure 3.3); 88 and 77 percent of the red maple trees had diameters less than $19 \mathrm{~cm}$ on the dry and mesic sites respectively. Yellow-poplar and northern red oak together accounted for about 40 percent of the trees per hectare on the mesic site (Figure 3.5). On the dry site, the red oak group and white oak group account for over 50 percent of the trees per hectare. Although the mesic site (north and east aspects) had greater basal area and above ground biomass, the dry site (west and southwest aspects) had about 54 percent more trees per hectare. 


\section{Height and Crown Structure}

The trees on the north and east-facing sites were taller than trees on the west and southwest aspects (Table 3.5) indicating a higher site index for the former. All dominant and codominant trees on the mesic site, north and east aspects, were significantly taller $(\mathrm{p}<0.05)$ than those on the west and southwest aspects (Table 3.6). Most dominant and codominant species on the north and east-facing sites had similar mean heights except yellow-poplar which was significantly taller (Table 3.6). On the west and southwest aspects, however, mean height of dominant and codominant yellow-poplar trees was not significantly taller than the trees in the red oak group. The stands on the mesic (north and east aspects) and dry (west and southwest aspects) sites had two distinct strata, an overstory stratum (>24 m tall) dominated by shade-intolerant species and an understory stratum (<14 m tall) dominated by shade-tolerant species (Figure 3.6). The understory stratum (trees $<12$ to $14 \mathrm{~m}$ tall) on the north and east aspects is mostly composed of red maple (63 percent). On the west and southwest aspects red maple (46 percent) and other species (42 percent) make up 88 percent of the understory vegetation. On the north and east-facing sites, most of the dominant and codominant trees in the overstory stratum were greater than $25 \mathrm{~m}$ tall. However, there were considerably few trees taller than $25 \mathrm{~m}$ on the west and southwest aspects and most of the codominant trees were between 17 and $25 \mathrm{~m}$ tall. Yellow-poplar (40 percent) and the red oak group (20 percent) make up 60 percent of the dominant and codominant trees in the north and east aspects whereas on the west and southwest aspects the red oak group (64 percent) and the white oak group (22 percent) together account for 86 percent of the trees in the overstory stratum $(>25 \mathrm{~m}$ tall). 


\section{E. Species Importance Values}

Species importance values (summation of relative density, relative dominance, and relative frequency) was highest for yellow-poplar, red maple, and northern red oak in that order on the north-facing site (Table 3.7). On the east facing aspect red maple followed by northern red oak and yellow-poplar had the highest species importance values. On the west and southest aspects northern red oak, red maple and chestnut oak were most prevalent in terms of dominance, density, and frequency combined. The graph showing species importance values by aspect (Figure 3.7) clearly shows species that are specialists and generalists with respect to aspect. Northern red oak and red maple yield above average species importance values at all four aspects, and this reflects the rather broad ecological amplitudes of these species. On the other hand, yellow-poplar, chestnut oak, and black cherry seem to be specialists with respect to aspect in that yellow-poplar and black cherry occur primarily on the mesic slope (north and east aspects), and chestnut oak dominate the west and southwest aspects. Still, Hicks and Frank (1984) indicate that relative to other variables measured, aspect was more highly correlated with biomass than anything else.

\section{F. Correlation with Transformed Aspect}

Biomass at the study site was reported to be associated with aspect (Tajchman and Wiant 1983, Hicks and Frank 1984). In the present study, transformed aspect was highly correlated with biomass $(r=0.66)$ and basal area $(r=0.68)$ (Table 3.8). These correlation coefficients were twice in magnitude than that reported by Hicks and Frank (1984). This is attributed to the difference in study design. In the present study only four aspects rather than a range of azimuth were considered and hence the amount of noise in the 
relationship between tree variables and transformed aspect was minimal yielding higher correlation coefficients.

The importance values of most species or species groups were correlated with aspect (Table 3.8). Most species groups expressed some site specificity relative to aspect, i.e., chestnut oak, the red oak and white oak groups, and other species were negatively correlated, whereas red maple, yellow-poplar, northern red oak, and black cherry were positively correlated. The negative correlations imply that these species are associated with the drier west and southwest aspects while positive correlations indicate one of the following: (a) an association with the north-and east-facing sites, or (b) the species is generalist with respect to aspect but its importance value increases from the dry to moist site. For chestnut oak, red oak group and the white oak group, tree variables (basal area, biomass, density, and importance value) were all negatively correlated with aspect (Table 3.8) indicating the dominance of these species at the west and southwest aspects (Figures 3.4 and 3.5). Other species, even though they had larger basal area and biomass at the mesic aspects, displayed negative correlations of transformed aspect with importance value and density indicates their association (mainly in terms of frequency of occurrence) with the west and southwest aspects (see Figure 3.5). However, their basal area and biomass is positively correlated with aspect and this was because on the mesic site 60 percent of other species had diameters $>20 \mathrm{~cm}$ but the corresponding value for west and southwest aspects was 11 percent.

\subsubsection{Relationship of Soil Characteristics with Aspect}

In Table 3.9, the averages for soil chemical properties indicate that soils in the study area were acidic with $\mathrm{pH}<4.5$ at all aspects. The soils at the study area contain 
substantial quantities of potassium but major plant nutrient elements (calcium, phosphorus, and magnesium) were generally quite low relative to potassium. In the shallower surface layer, the lowest $\mathrm{pH}$ (3.9) and hence, the highest lime requirement was observed at the southwest facing site (Table 3.9). Phosphorus and magnesium had the least variation with aspect; phosphorus concentration in the surface layer ranged from $10.8 \mathrm{ppm}$ at the southwest aspect to $11.5 \mathrm{ppm}$ at the east facing site while magnesium varied from $18.8 \mathrm{ppm}$ at the west to $23.4 \mathrm{ppm}$ at the north aspect. Calcium concentration was highest at the northeast aspect $(10.35 \mathrm{ppm})$ and lowest on the drier west and southwest aspects $(6.95 \mathrm{ppm})$. Generally, potassium $(\mathrm{SD}=4.34)$ followed by calcium $(\mathrm{SD}=2.25)$ showed relatively higher aspect related variation than did phosphorus $(\mathrm{SD}=0.3)$ and magnesium (1.89). Although differences were not large in magnitude, the plant nutrients exhibited consistently higher concentrations on the northeast aspects than on the west and southwest aspects (Table 3.10).

Aspect related variation in phosphorus concentration in the subsoil layers $(\mathrm{SD}=2.2)$, although minimal, was higher than that in the surface layers but unlike the surface layer the relationship is reversed; the west and southwest aspects had 3-4 ppm more phosphorus than the north and east aspects (Table 3.10). Calcium $(\mathrm{SD}=1.73)$, magnesium $(\mathrm{SD}=2.1)$, and phosphorus showed the least aspect related variation in the subsoil; magnesium ranged from $18.8 \mathrm{ppm}$ at the northeast aspect to $15.5 \mathrm{ppm}$ at the southwest aspect while calcium varied from 10.4 to 6.9 ppm between the northeast and southwest aspects. Potassium concentration, however, showed considerable variation with aspect. 
The subsoil had a 3-5 ppm higher phosphorus concentration than surface layer on the west and southwest aspects, but differences are negligible on the north and east facing sites (Table 3.10). Generally, nutrient concentrations, except phosphorus, are higher in the surface layer than the subsoil at all aspects with the north and southwest aspects showing the largest differences. The $\mathrm{pH}$ in the surface layer is generally lower than the subsoil and relative differences are larger on the west and southwest aspects. Estimates of $\mathrm{pH}$ for the two layers on the north and east aspects were identical. Conversely, the lime requirement for the surface layers is higher than those recommended for the subsoil, and the difference in lime requirements between the two layers is highest on the west and southwest aspects.

\subsubsection{Relationships of Air Temperature and Vapor Pressure Deficit with Aspect}

Figures 3.8 and 3.9 show the diurnal variation of air temperature, vapor pressure deficit, and relative humidity at breast height $(1.4 \mathrm{~m}$ above ground) during two observation periods (July $14^{\text {th }}$ and $16^{\text {th }}$ of 1997 ). Each plotted point represents an average for two days. At breast height, air temperature on the west and southwest aspects were lower early in the morning and much higher during midday and in the afternoon than the corresponding temperature on the north and east facing slopes. During early morning, from 7 to $11 \mathrm{am}$, air temperature at the north and east aspects were about $2.74{ }^{\circ} \mathrm{C}$ higher than those of the west and southwest facing sites. However, during midday period, from 12 to $4 \mathrm{pm}$, west and southwest aspects had air temperature about $4.86{ }^{\circ} \mathrm{C}$ higher than those at the north and east aspects. This is because, the sun is to the south during the warmth of the day, and south-facing slopes receive more intense radiation than any other aspect (Kondratev 1977, Rosenberg et al. 1983) and at any latitude, the hottest and driest 
sites are those that nearly face the sun during the middle of the summer day (Spurr and Barnes 1980). Lower midday breast height temperature at the north and east facingslopes could also be due to higher canopy density (shading) at these aspects (Hicks, Division of Forestry, WVU, personal communication) The maximum temperature difference between the dry and mesic site was $5.55^{\circ} \mathrm{C}$ and was observed at noon (Figure 3.8). During the two observation periods air temperature ranged from 15 to $25.6^{\circ} \mathrm{C}$ on the north and east aspects, and from 13 to $30.8^{\circ} \mathrm{C}$ on the west and southwest aspects.

The amount of water vapor present in the air is one of the most important environmental factors affecting tree growth (Kramer and Kozlowski 1960) as it directly influences the rate of evapotranspiration. In the present study it was represented in terms of relative humidity. The relative humidity at the west and southwest aspects was about 25 percent lower than that at the north and east aspects during midday periods (Figure 3.8). This was due to the higher midday temperatures at the drier aspects. The maximum difference in relative humidity between the two sites was observed during noon to $3 \mathrm{pm}$. The pattern of vapor pressure deficit (Et) follows that of air temperature (Figure 3.9). Vapor pressure deficit (Et) is an approximate measure of potential evapotranspiration in that large values of Et indicate higher rates of evapotranspiration and plant water stress and lower values indicate lower rates of evapotranspiration. The data in Figure 3.9 shows that evapotranspiration rates on the west and southwest aspects begin slower in the morning, reaching maximum rates at noon and remain higher throughout the afternoon than those on the north and east aspects. Plant water stress as measured by vapor pressure difference (Et) is about 37 percent higher on west and southwest aspects during midday periods than on north and east aspects. Both relative humidity and vapor pressure deficit 
depend on the air temperature; as temperatures increase vapor pressure differences between the surrounding air and leaves increases, and the relative humidity decreases. For example, at $50 \%$ relative humidity, the vapor pressure difference (Et) doubles when the canopy temperature increases from $25^{\circ} \mathrm{C}$ to $32{ }^{\circ} \mathrm{C}$ and this effect is less at lower relative humidity and greater at higher relative humidity (Lee and Sypolt, 1974).

\subsection{DISCUSSION}

\section{A. Vegetation}

Forest types on the west and southwest aspects (Figures 3.4 and 3.5) closely are upland oak types, primarily white oak (Quercus alba), chestnut oak (Q. prinus), northern red oak (Q.rubra), and black oak (Q.velutina). The north and east aspects were dominated primarily by yellow-poplar (Liriodendron tulipifera), and northern red oak. Red maple (Acer rubrum) was a substantial component across all aspects, especially in terms of density (stems/ha). Species groups that exhibited the greatest variation in occurrence between the two exposures were chestnut oak, black cherry, yellow-poplar, and the red oak and white oak groups. The data show that chestnut oak and white oak were uncommon on north and east exposures, and black cherry occurred infrequently on west and southwest exposures. Yellow-poplar was about six-times more frequent on mesic aspects whereas the density of the red oak group was over $100 \%$ higher on the west and southwest aspects.

The mean DBH $(29.69 \mathrm{~cm})$, total height $(20.82 \mathrm{~m})$, and basal area $\left(35.97 \mathrm{~m}^{2} \mathrm{ha}^{-1}\right)$ were all higher for the stands on mesic aspects. The diameter, height, and basal area

averaged $8.3 \mathrm{~cm}, 3.3 \mathrm{~m}$, and $7.84 \mathrm{~m}^{2}$ higher respectively on the mesic aspects. A study at 
the WVU forest by Lee and Sypolt (1974) showed that at age 40 the stands on the north facing sites had $5.1 \mathrm{~cm}, 5.4 \mathrm{~m}$, and $3 \mathrm{~m}^{2} \mathrm{ha}^{-1}$ larger diameter, total height, and basal area respectively than stands growing on south facing slopes, thus the magnitude of the difference appears to be increasing over time. Basal area and dry biomass data collected on 100 plots from trees $>7 \mathrm{~cm}$ dbh, averaged approximately $32 \mathrm{~m}^{2} \mathrm{ha}^{-1}$ and $252 \mathrm{t} \mathrm{ha}^{-1}$ respectively. The southwest aspect was 21 percent (in basal area) and 36 percent (in dry biomass) below the overall average for the site. The north and east facing aspects were 50 (in dry biomass) and 27 (in basal area) percent more productive than the west and southwest aspects. Spurr and Barnes (1980) cite a much smaller difference between the northeast and the southwest aspects. They indicated that in the mixed upland oak forests of the Appalachian Mountains, northeast aspects were 15 percent more productive than the south and west aspects. In the present study yellow-poplar (Liriodendron tulipifera), northern red oak (Quercus rubra), sugar maple (Acer saccharum), black cherry (Prunus serotina), and red maple (Acer rubrum) account for 85 percent of the dry biomass on both the north and east facing slopes. On the west and southwest aspects, white oak (Quercus alba), scarlet oak (Quercus coccinea), chestnut oak (Quercus prinus) and northern red oak constitute 81 percent of the dry biomass. The examination of importance values of species groups reveal that black cherry, yellow-poplar, and chestnut oak are largely confined to specific aspects while red maple and northern red oak occur across all aspects.

Tree density on the dry exposures was 54 percent higher than that observed on the moist exposures; the west and southwest aspects had 240 more stems per hectare than the north and east aspects. This is consistent with findings of Lee and Sypolt (1974) who 
reported that at age 40 the stands at the south facing site at the WVU forest had 24 percent or 140 more trees per hectare than the stands at the north facing site. The higher tree density on the dry exposures could primarily be due to the presence of more shade tolerant species capable of competing on poorer sites (Kochenderfer, USDA Forest Service, Parsons, personal communication). The presence of more stems per hectare on the west and southwest exposures may also be due to the more open conditions of the crown canopy, and the greater amount of light reaching the lower strata favoring the growth of shade tolerant species such as red maple. On moist exposures slow growing species could have been smothered quickly by the dense cover of other fast growing species such as yellow-poplar. Generally, trees on the north and east aspects attain greater diameter and therefore wider crowns (Hicks, Division of Forestry, WVU, personal communication). These crowns fill up the available growing space with fewer trees. Inclusion of small tress with dbh of 7 to $10 \mathrm{~cm}$ may have exaggerated the difference in density between the mesic and dry exposures. When only trees with dbh $\geq 10 \mathrm{~cm}$ were considered, density averaged 425 trees/ha at the mesic site and 522 trees/ha at the dry site, $23 \%$ higher at the dry site.

\section{B. Microclimate}

Higher radiant energy inputs results in higher midday temperatures, lower relative humidity, and higher vapor pressure deficits on west and southwest aspects (Figures 3.8 and 3.9). A study by Lee and Sypolt (1974) at the WVU forest demonstrated that the net radiation on south facing slopes $\left(1.05 \mathrm{cal} \mathrm{cm}^{-2} \mathrm{~min}^{-1}\right)$ exceeded that on north-facing slope (0.85 cal $\left.\mathrm{cm}^{-2} \mathrm{~min}^{-1}\right)$ by 24 percent. Net radiation is the difference between the total upward and downward radiation fluxes and is an exact measure of the total energy 
exchange and is often referred to as " radiation balance" (Federer 1968, Lee 1978, Rosenberg et al. 1983). The importance of net radiation is that it is the fundamental quantity of energy available at the earth's surface to drive the processes of evaporation, air and soil heating, as well as other smaller-energy consuming processes such as photosynthesis. At the study site the large differences in temperature, relative humidity and vapor pressure deficits on the dry and moist exposures can therefore be attributed to differences in the amount of net radiation received at each aspect. The data in Figures 3.8 and 3.9 show that the breast height air temperature during midday period averaged 25.2 ${ }^{\circ} \mathrm{C}, 24.9{ }^{\circ} \mathrm{C}, 30.5{ }^{\circ} \mathrm{C}$, and $29.4{ }^{\circ} \mathrm{C}$ for the north, east, west and southwest aspects respectively. For relative humidities of 30 to 40 percent, vapor pressure differences were $22.1 \mathrm{mb}$ for north and east aspects and $30.2 \mathrm{mb}$ for the west and southwest aspects. Evapotranspiration during midday period was about 36 percent greater on the west and southwest aspects.

Higher midday temperatures and vapor pressure deficits on dry exposures results in a depression of net assimilation rates (Kramer and Kozlowski 1960, Delvin and Baker 1971, Lee and Sypolt 1974) because of an exponential increase in respiration rates with increasing temperatures (Rosenberg et al. 1983). Stomatal closure and increased mesophyll resistance to $\mathrm{CO}_{2}$ diffusion induced by leaf water deficits also contribute to reduced net assimilation (Delvin 1975). Lower dry biomass at the west and southwest exposures could be associated with higher respiration rates and stomatal closure in response to extreme plant water deficits. Simply put, the high vapor pressure gradient between the surrounding air and the plant canopies on the west and southwest aspects induces higher transpiration rates and in response to these higher transpiration demands 
plants tend to close their stomata. This reduces the influx of $\mathrm{CO}_{2}$ into plant leaves which consequently depresses the rate of photosynthesis. Delvin (1975) and Spurr (1964) indicate that the optimum net assimilation temperature for forest species in the middle latitudes is about $25^{\circ} \mathrm{C}$. The air temperature patterns shown in Figure 3.8 suggest a significantly greater reduction of net assimilation on west and southwest facing slopes during midday periods, because during midday periods west and southwest aspects had temperatures well past the optimum level.

\section{Soil Nutrients and Site Productivity}

The $\mathrm{pH}$ of soils (surface layer) on the north and east facing slopes was slightly higher, probably because the northeast aspects had more calcium than the west and southwest aspects. Ward and Bowersox (1970) found that calcium fertilization increased volume growth of two oak species by about 10 percent. On the north-facing slope, potassium and calcium contents were the highest in the surface layer. Nutrient concentrations at the study site (Table 3.10) were higher in the surface layer, except for phosphorus, irrespective of aspect. Also, average nutrient concentration for north and east aspects, except for phosphorus, were higher than average nutrient concentrations for the west and southwest aspects in both horizons. Nutrient concentrations in soil are dependent on inputs from weathering, precipitation, and litter fall. Hicks and Frank (1984) explain that the higher nutrient concentrations in the surface soils compared to sub-soils is likely a function of recycling. The greater concentration of nutrient elements at the moist aspects (north and east facing sites) could be due to greater litter production, more rapid weathering, and the more rapid decomposition rate of litter at these sites. 
In the present study differences in site productivity (soil-plant nutrients and dry biomass) associated with aspect can in part be explained in terms of aspect-induced differences in microclimate (air temperature and soil moisture). The exposure of a site determines the intensity of radiation received, which in turn modifies the microclimate of the soil and air. North and east facing slopes receive much less energy than west and southwest aspects. The large energy input increases evapotranspiration on west and southwest aspects making them much warmer than the cooler north and east facing slopes. Aspect also affects site productivity through its impacts on microclimate. Mesic sheltered sites (north and east aspects, gentle slopes, lower landscape positions) support more luxuriant vegetation than do hot, exposed ridges or west and southwest aspects; therefore moist sites receive more plant debris (Spurr and Barnes 1980). The depth of organic matter accumulation in the mineral soil depends, in part, on soil moisture (Brady 1974, Forth 1978) because the decomposition rate is related to microclimate and the soil flora and fauna. The moist conditions at north and east aspects affords much better living conditions for soil fauna than at the southwest aspect and this facilitates a more rapid incorporation of organic matter in to the mineral soil through decomposition of litter. Humus being highly colloidal, has the ability to adsorb and retain for future plant use many of the ions such as calcium, magnesium, potassium, phosphates and ammonia which might be leached from the soil and lost in drainage (Brady 1974). Therefore, the mesic aspects (north and east facing slopes) have microclimatic advantages that favors more litter fall on the forest floor and its consequent rapid decomposition compared to drier aspects. 
Increased net radiation on southwest aspects is the primary microclimatic difference relative to northeast aspects. The microclimatic data from two summer days (Figure 3.8 and 3.9) show the effects of increased radiation. Temperatures are increased at the soil surface which increases evaporation from the litter layer. The litter layer on west and southwest aspects frequently becomes drier owing to higher evapotranspiration and this results in slower decomposition and deeper accumulation of litter on these aspects. Dry litter decomposes slower and provides a less favorable environment to soil flora and fauna, further slowing decomposition. The lower soil nutrient concentrations and dry biomass on these aspects can in part be attributed to these effects. In the present study the relationships between species composition and aspect in terms of basal area and dry biomass (Figure 3.5) and species importance values (Figure 3.7) indicate that oaks dominate the west and southwest aspects. A study by Lang and Orndorf (1983) attributed deeper litter layers on the south and west facing slopes to the slower decomposition rate characteristics of oak litter, which predominates these sites. This is in agreement with Melillo et al. (1982) who reported that oak leaves have high lignin content and decompose slowly.

\section{Sample Size Requirements}

The coefficient of variation (CV) of dry biomass at the east-facing site $(33.4 \%)$ of the watershed was significantly higher $(\mathrm{p}<0.01)$ than those at the north $(26.7 \%)$, west (31\%), and southwest (29.4\%) aspects. A related study at the Fernow Experimental Forest (Tajchman et al. 1995) attributed a higher coefficient of variation of plot biomass on the east facing slope (29.9\%) and a lower coefficient $(25.3 \%)$ on the west aspects to complexity and uniformity of the topography respectively. The coefficient of variation of 
dry biomass has practical importance since it affects the determination of appropriate sample size required for biomass studies. The magnitude of the coefficient of variation is in direct proportion to the size and number of plots required to determine estimates of above ground biomass within certain error limits. Larger coefficients of variation require larger number and/or size of plots. In the present study, in order to determine how the magnitude of $\mathrm{CV}$ changes with number of plots, the coefficient of variation of dry biomass was computed by varying the number of plots from 1 to 25 . The coefficient of variation decreased with increasing number of plots but did not reach a steady value. This suggests that aspect related biomass studies at the watershed may require more number of plots than currently used $(n=25)$ or that the plot size should be increased for $n=25$.

\subsection{Conclusions and Recommendation}

These data show that aspect has a profound effect in species composition, size class distribution, dry biomass, basal area, air temperature, relative humidity and evapotranspiration. The relationship of these parameters with aspect in the present study were stronger than commonly reported (Hicks and Frank 1984, Tajchman et al. 1995) because the study plots were chosen to represent the two extremes, rather than cover a wide range of aspects. The results can be used for practical applications in aspect-related dendroclimatic studies. Since aspect strongly influences the distribution and occurrence of certain species groups, restricted systematic sampling and felling or coring trees in a few plots might leave out aspect specific species groups. For example, in the present study, the center or felled plots at the west and southwest aspects had no yellow-poplar (Liriodendron tulipifera). On the other hand, there was only one chestnut oak (Quercus prinus) in the center plots for the north and east aspects. This occurred because chestnut 
oak is a characteristic species of west and southwest aspects whereas yellow-poplar favors the moist aspects. Therefore, the sampling procedure in all aspect-related dendrochronological studies should be stratified to reflect the natural distribution of the species with respect to aspect. Given resources and expertise, a more comprehensive study of a wide range of aspect classes (for example 72 aspect classes; $0-5^{\circ}, 5-10^{\circ}$, etc. with sufficient sampling plots within each aspect class) in relation to soil physical and chemical characteristics (depth, profile, moisture, nutrients, heat and temperature), microclimate (components of radiation, air temperature, relative humidity, vapor pressure deficit, wind, and precipitation), and vegetation may yield the necessary data to better define the environmental factors causing aspect related differences in bioproductivity and consequently to develop an appropriate biophysical model of tree growth. 
Table 3.1. Mean diameter at breast height $( \pm \mathrm{SE})$ by species and aspect.

\begin{tabular}{|c|c|c|c|c|c|c|c|c|}
\hline \multirow[b]{3}{*}{$\begin{array}{l}\text { Species } \\
\text { Groups }{ }^{1}\end{array}$} & \multicolumn{4}{|c|}{ Mesic Site } & \multicolumn{4}{|c|}{ Dry Site } \\
\hline & \multicolumn{2}{|c|}{ North Facing } & \multicolumn{2}{|c|}{ East Facing } & \multicolumn{2}{|c|}{ West Facing } & \multicolumn{2}{|c|}{ Southwest Facing } \\
\hline & $\begin{array}{l}\text { Mean DBH } \\
(\mathrm{cm})\end{array}$ & $\mathrm{n}$ & $\begin{array}{c}\text { Mean DBH } \\
(\mathrm{cm})\end{array}$ & $\mathrm{n}$ & $\begin{array}{c}\text { Mean DBH } \\
(\mathrm{cm})\end{array}$ & $\mathrm{n}$ & $\begin{array}{c}\text { Mean DBH } \\
(\mathrm{cm})\end{array}$ & $\bar{n}$ \\
\hline Red maple & $17.63 \quad(0.97)^{\mathrm{a}}$ & 117 & $16.78(0.68)^{\mathrm{a}}$ & 169 & $13.13(0.39)^{b}$ & 230 & $12.70(0.43)^{b}$ & 154 \\
\hline Yellow-poplar & $44.15(1.03)^{\mathrm{a}}$ & 99 & $41.46(1.13)^{\mathrm{b}}$ & 91 & $37.35(3.08)^{c}$ & 8 & $33.42(1.93)^{\mathrm{c}}$ & 25 \\
\hline Red oak & $34.11(1.94)^{\mathrm{a}}$ & 56 & $30.00 \quad(1.63)^{b}$ & 88 & $30.27(0.95)^{b}$ & 126 & $22.92(0.93)^{\mathrm{c}}$ & 68 \\
\hline Chestnut oak $^{3}$ & 47.50 & 1 & $(----)$ & 1 & $25.91(1.07)^{\mathrm{a}}$ & 108 & $19.28(1.38)^{b}$ & 51 \\
\hline Black cherry $^{3}$ & $32.68(1.86)^{\mathrm{a}}$ & 40 & $39.57 \quad(1.89)^{b}$ & 24 & 12.50 (----) & 1 & $(----)$ & 5 \\
\hline Red oak group & $34.11(1.91)^{\mathrm{a}}$ & 57 & $30.21(1.56)^{b}$ & 96 & $30.31(0.76)^{b}$ & 182 & $27.11(0.55)^{\mathrm{c}}$ & 257 \\
\hline White oak group ${ }^{3}$ & 47.15 (-----) & 4 & 38.85 & 2 & $27.01(1.11)^{\mathrm{a}}$ & 135 & $23.06(1.68)^{b}$ & 105 \\
\hline Other & $31.51(2.50)^{\mathrm{a}}$ & 70 & $(1.65)^{b}$ & 49 & $12.96(0.86)^{\mathrm{c}}$ & 115 & $10.63(0.46)^{\mathrm{c}}$ & 136 \\
\hline Total & $31.41 \quad(0.80)$ & 443 & $27.97 \quad(0.66)$ & 430 & $22.75 \quad(0.42)$ & 671 & $20.04 \quad(0.47)$ & 682 \\
\hline
\end{tabular}

Means with the same letter are not significantly different between aspects according to ANOVA (alpha $=0.05)$.

${ }^{1}$ Species Groups: Red oak group (northern red oak, scarlet oak, black oak), White oak group (white oak, chestnut oak), Other (sweet birch, shagbark hickory, sugar maple, cucumber tree, black gum, sassafras).

${ }^{3}$ Since chestnut oak and the white oak group at the north and east aspects, and black cherry at the west and southwest aspects are the most infrequent species groups, mean comparisons for these species groups was carried out only at those aspects where they are abundant. Mean comparison for black cherry was made between the north and east aspects, and mean comparison for chestnut oak and the white oak group was made between the west and southwest aspects. Mean comparisons for the remaining species groups were made among the four aspects. 
Table 3.2. Basal area ( \pm SE) by species and aspect.

\begin{tabular}{|c|c|c|c|c|c|c|c|c|c|}
\hline \multirow[b]{3}{*}{$\begin{array}{l}\text { Species } \\
\text { Groups }{ }^{1}\end{array}$} & \multicolumn{5}{|c|}{ Mesic Site } & \multicolumn{4}{|c|}{ Dry Site } \\
\hline & \multicolumn{2}{|c|}{ North Facing } & \multicolumn{3}{|c|}{ East Facing } & \multicolumn{2}{|c|}{ West Facing } & \multicolumn{2}{|c|}{ Southwest Facing } \\
\hline & $\begin{array}{l}\text { Basal Area } \\
\left(\mathrm{m}^{2} \mathrm{ha}^{-1}\right)\end{array}$ & $\% \mathrm{BA}^{2}$ & $\begin{array}{l}\text { Basal } \\
\left(\mathrm{m}^{2} \mathrm{~h} z\right.\end{array}$ & $\begin{array}{l}\text { Area } \\
\left.a^{-1}\right)\end{array}$ & $\% \mathrm{BA}$ & $\begin{array}{l}\text { Basal Area } \\
\left(\mathrm{m}^{2} \mathrm{ha}^{-1}\right)\end{array}$ & $\% \mathrm{BA}$ & $\begin{array}{l}\text { Basal Area } \\
\left(\mathrm{m}^{2} \mathrm{ha}^{-1}\right)\end{array}$ & $\% \mathrm{BA}$ \\
\hline Red maple & $3.85(0.95)^{\mathrm{a}}$ & 10.15 & 4.74 & $(0.86)^{\mathrm{a}}$ & 13.94 & $3.75(0.38)^{\mathrm{a} b}$ & 12.07 & $2.22(0.32)^{b}$ & 8.80 \\
\hline Yellow-poplar & $16.05(2.64)^{\mathrm{a}}$ & 42.29 & 11.28 & $(2.05)^{\mathrm{a}}$ & 33.19 & $0.92(0.42)^{\mathrm{b}}$ & 2.96 & $1.86(0.76)^{b}$ & 7.36 \\
\hline Red oak & $6.02(1.25)^{\mathrm{a}}$ & 15.87 & 8.13 & $(1.29)^{\mathrm{a}}$ & 23.93 & $10.18(1.27)^{\mathrm{a}}$ & 32.81 & $2.48(0.39)^{\mathrm{b}}$ & 9.83 \\
\hline Chestnut oak $^{3}$ & 0.18 & 0.49 & 0.14 & $(-----)$ & 0.41 & $6.74(0.93)^{\mathrm{a}}$ & 21.70 & $1.86(0.39)^{b}$ & 7.37 \\
\hline Black cherry ${ }^{3}$ & $3.50(0.83)^{\mathrm{a}}$ & 9.23 & 5.50 & $(1.45)^{\mathrm{a}}$ & 16.18 & 0.01 & 0.04 & 0.02 & 0.09 \\
\hline Red oak group & $6.12(1.25)^{\mathrm{a}}$ & 16.12 & 8.74 & $(1.26)^{\mathrm{a}}$ & 25.70 & $14.62(1.51)^{b}$ & 47.10 & $16.37(1.12)^{b}$ & 64.87 \\
\hline White oak group ${ }^{3}$ & 0.73 & 1.92 & 0.24 & (-----) & 0.70 & $9.47(1.31)^{\mathrm{a}}$ & 30.51 & $3.51(0.90)^{\mathrm{b}}$ & 13.89 \\
\hline Other & $7.70(1.59)^{\mathrm{a}}$ & 20.30 & 3.58 & $(0.85)^{b}$ & 10.52 & $2.28(0.63)^{b}$ & 7.33 & $1.26(0.28)^{\mathrm{c}}$ & 4.98 \\
\hline Total & 37.90 (1.69) & 100 & 34.05 & $(3.92)$ & 100 & $31.04(2.64)$ & 100 & $25.23(1.94)$ & 100 \\
\hline
\end{tabular}

Means with the same letter are not significantly different between aspects according to ANOVA (alpha $=0.05)$.

${ }^{1}$ Species Groups: Red oak group (northern red oak, scarlet oak, black oak), White oak group (white oak, chestnut oak), Other (sweet birch, shagbark hickory, sugar maple, cucumber tree, black gum, sassafras).

$2 \%$ BA: Percentage of basal area per hectare accounted by each species groups.

${ }^{3}$ Same as in Table 1. 
Table 3.3. Above ground dry biomass $( \pm \mathrm{SE})$ by species and aspect.

\begin{tabular}{|c|c|c|c|c|c|c|c|c|}
\hline \multirow[b]{3}{*}{$\begin{array}{l}\text { Species } \\
\text { Groups }{ }^{1}\end{array}$} & \multicolumn{4}{|c|}{ Mesic Site } & \multicolumn{4}{|c|}{ Dry Site } \\
\hline & \multicolumn{2}{|c|}{ North Facing } & \multicolumn{2}{|c|}{ East Facing } & \multicolumn{2}{|c|}{ West Facing } & \multicolumn{2}{|c|}{ Southwest Facing } \\
\hline & $\begin{array}{l}\text { Dry Biomass } \\
\left(\mathrm{t} \mathrm{ha}^{-1}\right)\end{array}$ & $\begin{array}{c}\% \\
\mathrm{BIO}^{2}\end{array}$ & $\begin{array}{l}\text { Dry Biomass } \\
\left(\mathrm{t} \mathrm{ha}^{-1}\right)\end{array}$ & $\begin{array}{c}\% \\
\mathrm{BIO}\end{array}$ & $\begin{array}{l}\text { Dry Biomass } \\
\left(\mathrm{t} \mathrm{ha}^{-1}\right)\end{array}$ & $\begin{array}{c}\% \\
\mathrm{BIO}\end{array}$ & $\begin{array}{l}\text { Dry Biomass } \\
\left(\mathrm{t} \mathrm{ha}^{-1}\right)\end{array}$ & $\begin{array}{c}\% \\
\mathrm{BIO}\end{array}$ \\
\hline Red maple & $25.77(9.07)^{\mathrm{a}}$ & 7.79 & $30.02(8.6)^{\mathrm{a}}$ & 10.9 & $19.09(2.32)^{b}$ & 7.94 & $10.23(1.79)^{\mathrm{c}}$ & 6.39 \\
\hline Yellow-poplar & $126.47(20.89)^{\mathrm{a}}$ & 38.22 & $85.76(15.6)^{b}$ & 31.1 & $6.39 \quad(3.06)^{c}$ & 2.66 & $11.79(5.10)^{\mathrm{d}}$ & 7.37 \\
\hline Red oak & $48.99(11.12)^{\mathrm{a}}$ & 14.80 & $65.22(11.05)^{b}$ & 23.7 & $76.11(10.48)^{c}$ & 31.67 & $15.35(2.52)^{\mathrm{d}}$ & 9.60 \\
\hline Chestnut oak ${ }^{3}$ & 2.15 & 0.65 & 1.49 & 0.54 & $63.47(10.69)^{\mathrm{a}}$ & 26.41 & $11.83(2.81)^{b}$ & 7.40 \\
\hline Black cherry $^{3}$ & $30.85(7.66)^{\mathrm{a}}$ & 9.32 & $52.87(14.02)^{b}$ & 19.1 & 0.05 & 0.02 & 0.07 & 0.05 \\
\hline Red oak group & $49.66(11.09)^{\mathrm{a}}$ & 15.00 & $69.99(10.92)^{b}$ & 25.4 & $108.80(12.33)^{\mathrm{c}}$ & 45.28 & $107.07(7.94)^{\mathrm{c}}$ & 66.95 \\
\hline White oak group 3 & 7.90 & 2.39 & 2.35 & 0.85 & $92.69(16.01)^{\mathrm{a}}$ & 38.57 & $25.70(8.98)^{b}$ & 16.07 \\
\hline Other & $90.27 \quad(21.61)^{\mathrm{a}}$ & 27.29 & $34.75(8.74)^{b}$ & 12.6 & $13.27(4.21)^{c}$ & 5.52 & $5.07 \quad(1.38)^{\mathrm{d}}$ & 3.17 \\
\hline Total & $330.92(17.85)$ & 100 & $275.73(33.63)$ & 100 & $240.30(23.77)$ & 100 & $159.92(14.34)$ & 100 \\
\hline
\end{tabular}

Means with the same letter are not significantly different between aspects according to Wilcoxon's test $($ alpha $=0.05)$.

${ }^{1}$ Species Groups: Red oak group (northern red oak, scarlet oak, black oak), White oak group (white oak, chestnut oak), Other (sweet birch, shagbark hickory, sugar maple, cucumber tree, black gum, sassafras).

${ }^{2} \%$ BIO: Percentage of above ground biomass per hectare accounted by each species groups.

${ }^{3}$ Same as in Table 1 . 
Table 3.4. Trees per hectare $( \pm$ SE) by species and aspect.

\begin{tabular}{|c|c|c|c|c|c|c|c|c|c|c|c|}
\hline \multirow[b]{3}{*}{$\begin{array}{l}\text { Species } \\
\text { Groups }{ }^{1}\end{array}$} & \multicolumn{6}{|c|}{ Mesic Site } & \multicolumn{5}{|c|}{ Dry Site } \\
\hline & \multicolumn{3}{|c|}{ North Facing } & \multicolumn{3}{|c|}{ East Facing } & \multicolumn{3}{|c|}{ West Facing } & \multicolumn{2}{|c|}{ Southwest Facing } \\
\hline & $\begin{array}{r}\mathrm{Tr} \\
\text { (No. S } \\
\end{array}$ & $\begin{array}{l}\text { ees/ha } \\
\left.\text { tems }^{-1} a^{-1}\right)\end{array}$ & $\begin{array}{c}\% \\
\mathrm{TPH}^{2} \\
\end{array}$ & $\begin{array}{r}\operatorname{Tr} \\
\text { (No. S } \\
\end{array}$ & $\begin{array}{l}\text { ees/ha } \\
\text { tems ha }{ }^{-1} \text { ) }\end{array}$ & $\begin{array}{c}\% \\
\mathrm{TPH} \\
\end{array}$ & $\begin{array}{r}\mathrm{T}_{1} \\
\text { (No. } s \\
\end{array}$ & $\begin{array}{l}\text { ees/ha } \\
\text { tems ha }\end{array}$ & $\begin{array}{c}\% \\
\mathrm{TPH} \\
\end{array}$ & $\begin{array}{c}\text { Trees/ha } \\
\left(\text { No. Stems ha }{ }^{-1}\right)\end{array}$ & $\begin{array}{c}\% \\
\mathrm{TPH} \\
\end{array}$ \\
\hline Red maple & 116.67 & $(11.33)^{\mathrm{a}}$ & 26.28 & 168.97 & $(10.72)^{b}$ & 39.3 & 230.01 & $(12.99)^{\mathrm{c}}$ & 34.28 & $154.01 \quad(18.86)^{b}$ & 22.58 \\
\hline Yellow-poplar & 98.96 & $(16.31)^{\mathrm{a}}$ & 22.29 & 90.52 & $(14.65)^{\mathrm{a}}$ & 21.1 & 8.12 & $(3.14)^{b}$ & 1.19 & $(8.54)^{c}$ & 3.67 \\
\hline Red oak & 56.25 & $(9.90)^{\mathrm{a}}$ & 12.67 & 87.93 & $(8.83)^{b}$ & 20.4 & 126.00 & $(11.04)^{c}$ & 18.78 & $(12.21)^{\mathrm{a}}$ & 9.97 \\
\hline Chestnut oak $^{3}$ & 1.04 & (------) & 0.23 & 0.86 & $(----)$ & 0.2 & 108.00 & $(13.90)^{\mathrm{a}}$ & 16.10 & $(11.04)^{b}$ & 7.48 \\
\hline Black cherry $^{3}$ & 39.58 & $(8.50)^{\mathrm{a}}$ & 8.92 & 24.14 & $(9.96)^{b}$ & 5.6 & 1.00 & (-------) & 0.15 & (------) & 0.73 \\
\hline Red oak group & 57.29 & $(9.81)^{\mathrm{a}}$ & 12.90 & 95.69 & $(8.42)^{b}$ & 22.3 & 182.12 & $(16.49)^{c}$ & 27.12 & $257.02(23.16)^{d}$ & 37.68 \\
\hline White oak group ${ }^{3}$ & 4.17 & $(----)$ & 0.93 & 1.72 & $(----)$ & 0.4 & 135.03 & $(13.77)^{\mathrm{a}}$ & 20.12 & $105.03(11.81)^{\mathrm{b}}$ & 15.40 \\
\hline Other & 69.79 & $(21.61)^{\mathrm{a}}$ & 15.72 & 49.14 & $(10.27)^{b}$ & 11.4 & 115.12 & $(16.20)^{c}$ & 17.14 & $136.05(17.45)^{\mathrm{c}}$ & 19.94 \\
\hline Total & 443.75 & (18.91) & 100 & 430.17 & $(24.98)$ & 100 & 671.40 & $(23.08)$ & 100 & $682.81 \quad(33.74)$ & 100 \\
\hline
\end{tabular}

Means with the same letter are not significantly different between aspects according to ANOVA (alpha $=0.05)$.

${ }^{1}$ Species Groups: Red oak group (northern red oak, scarlet oak, black oak), White oak group (white oak, chestnut oak), Other (sweet birch, shagbark hickory, sugar maple, cucumber tree, black gum, sassafras).

${ }^{2} \%$ TPH: Percent of trees per hectare.

${ }^{3}$ Same as in Table 1. 
Table 3.5. Mean total height $( \pm S E)$ by species and aspect.

\begin{tabular}{|c|c|c|c|c|c|c|c|c|c|c|c|c|}
\hline \multirow[b]{3}{*}{$\begin{array}{l}\text { Species } \\
\text { Groups }{ }^{1}\end{array}$} & \multicolumn{6}{|c|}{ Mesic Site } & \multicolumn{6}{|c|}{ Dry Site } \\
\hline & \multicolumn{3}{|c|}{ North Facing } & \multicolumn{3}{|c|}{ East Facing } & \multicolumn{3}{|c|}{ West Facing } & \multicolumn{3}{|c|}{ Southwest Facing } \\
\hline & & $\begin{array}{l}\text { an Height } \\
\text { (m) }\end{array}$ & $\mathrm{n}$ & & $\begin{array}{l}\text { an Height } \\
\text { (m) }\end{array}$ & $\mathrm{n}$ & & $\begin{array}{l}\text { an Height } \\
\text { (m) }\end{array}$ & $\mathrm{n}$ & & $\begin{array}{l}\text { an Height } \\
\text { (m) }\end{array}$ & $\mathrm{n}$ \\
\hline Red maple & 14.76 & $(0.56)^{\mathrm{a}}$ & 117 & 13.12 & $(0.41)^{\mathrm{a} b}$ & 169 & 12.16 & $(0.28)^{b}$ & 230 & 14.00 & $(0.41)^{\mathrm{a}}$ & 154 \\
\hline Yellow-poplar & 30.32 & $(0.51)^{\mathrm{a}}$ & 99 & 28.08 & $(0.60)^{\mathrm{a}}$ & 91 & 23.94 & $(1.35)^{b}$ & 8 & 23.32 & $(1.20)^{\mathrm{c}}$ & 25 \\
\hline Red oak & 23.45 & $(0.86)^{\mathrm{a}}$ & 56 & 20.03 & $(0.76)^{b}$ & 88 & 21.03 & $(0.38)^{\mathrm{b}}$ & 126 & 21.08 & $(0.57)^{\mathrm{b}}$ & 68 \\
\hline Chestnut oak & 26.5 & $(----)$ & 1 & 25.60 & $(---)$ & 1 & 19.94 & $(0.41)^{\mathrm{a}}$ & 108 & 19.43 & $(0.87)^{\mathrm{a}}$ & 51 \\
\hline Black cherry & 24.46 & $(1.02)^{\mathrm{a}}$ & 40 & 24.34 & $(0.90)^{\mathrm{a}}$ & 24 & 11.30 & $(----)$ & 1 & 9.81 & $(----)$ & 5 \\
\hline Red oak group & 23.39 & $(0.84)^{\mathrm{a}}$ & 57 & 20.08 & $(0.72)^{b}$ & 96 & 21.14 & $(0.30)^{\mathrm{b}}$ & 182 & 23.29 & $(0.31)^{\mathrm{a}}$ & 257 \\
\hline White oak group & 28.96 & $(----)$ & 4 & 23.16 & $(----)$ & 2 & 20.01 & $(0.39)^{\mathrm{a}}$ & 135 & 18.88 & $(0.63)^{\mathrm{a}}$ & 105 \\
\hline Other & 20.57 & $(0.95)^{\mathrm{a}}$ & 70 & 19.84 & $(1.01)^{\mathrm{a}}$ & 49 & 10.11 & $(0.53)^{b}$ & 115 & 10.18 & $(0.39)^{\mathrm{b}}$ & 136 \\
\hline Average & 22.28 & $(0.41)$ & 443 & 19.36 & $(0.35)$ & 430 & 17.14 & $(0.21)$ & 671 & 17.91 & $(0.29)$ & 682 \\
\hline
\end{tabular}

Means with the same letter are not significantly different between aspects according to ANOVA (alpha $=0.05$ ).

${ }^{1}$ Species Groups: Red oak group (northern red oak, scarlet oak, black oak), White oak group (white oak, chestnut oak), Other (sweet

birch, shagbark hickory, sugar maple, cucumber tree, black gum, sassafras).

Table 3.6. Mean height $( \pm$ SE) of dominant and codominant trees by species and site.

\begin{tabular}{lllllll}
\hline & & \multicolumn{2}{c}{ Species Group } & \\
Site & Red maple & Yellow-poplar & Black cherry & Red oak group & White oak group & Other \\
\hline Mesic site & $26.26(0.50)^{\mathrm{a}}$ & $30.91(0.29)^{\mathrm{b}}$ & $28.49(0.47)^{\mathrm{a}}$ & $27.67(0.39)^{\mathrm{a}}$ & $----^{\mathrm{a}}$ & \\
Dry site & $22.33(0.59)^{\mathrm{a}}$ & $25.8(1.23)^{\mathrm{b}}$ & ------ & $26.63(0.30)^{\mathrm{a}}$ \\
\hline
\end{tabular}

Means with the same letter are not significantly different within each site according to ANOVA (alpha $=0.05)$. 
Table 3.7. Species importance values ${ }^{2}( \pm$ SE) by species and aspect.

\begin{tabular}{llllll}
\hline & \multicolumn{2}{c}{ Mesic Site } & \multicolumn{2}{c}{ Dry Site } \\
$\begin{array}{l}\text { Species } \\
\text { Groups }\end{array}$ & North facing & East Facing & West Facing & Southwest Facing \\
\hline Red maple & $60.2(4.5)^{\mathrm{a}}$ & $85.3(5.5)^{\mathrm{b}}$ & $69.7(4.0)^{\mathrm{a}}$ & $54.1(3.1)^{\mathrm{c}}$ \\
Yellow-poplar & $86.2(10.9)^{\mathrm{a}}$ & $69.2(4.8)^{\mathrm{b}}$ & 7.2 & $(2.1)^{\mathrm{c}}$ & $16.8(5.2)^{\mathrm{d}}$ \\
Red oak & $51.6(7.5)^{\mathrm{a}}$ & $72.0(5.6)^{\mathrm{b}}$ & $77.3(5.5)^{\mathrm{b}}$ & $39.2(1.6)^{\mathrm{c}}$ \\
Chestnut oak $^{3}$ & $1.9(----)$ & $1.2(---)$ & $53.9(2.8)^{\mathrm{a}}$ & $31.9(2.5)^{\mathrm{b}}$ \\
Black cherry $^{3}$ & $32.3(5.5)^{\mathrm{a}}$ & $26.4(4.8)^{\mathrm{a}}$ & $0.9(----)$ & $2.9(---)$ \\
\hline
\end{tabular}

Means with the same letter are not significantly different between aspects according to ANOVA (alpha $=0.05)$.

${ }^{2}$ Species importance value $=$ Relative density + Relative dominance + Relative frequency . Relative density $(\%)=($ Number of individuals of the species/Number of individuals of all species) $* 100$. Relative dominance $(\%)=$ (Total basal area of the species/Total basal area of all species) $* 100$. Relative frequency $(\%)=$ (Number of points of occurrence of the species/Number of points of occurrence of all species) $* 100$.

Table 3.8. Pearson's correlation coefficients of transformed aspect with species variables.

\begin{tabular}{|c|c|c|c|c|}
\hline \multirow[b]{2}{*}{ Species Groups ${ }^{1}$} & \multicolumn{4}{|c|}{ Species Variables } \\
\hline & Basal Area & Dry Biomass & Density & Importance Value \\
\hline Red maple & 0.96 & 0.95 & -0.01 & 0.91 \\
\hline Yellow-poplar & 0.61 & 0.60 & 0.68 & 0.64 \\
\hline Red oak & 0.58 & 0.66 & 0.12 & 0.64 \\
\hline Chestnut oak & -0.38 & -0.29 & -0.53 & -0.61 \\
\hline Black cherry & 0.90 & 0.91 & 0.52 & 0.68 \\
\hline Red oak group & -0.7 & -0.60 & -0.76 & -0.66 \\
\hline White oak group & -0.45 & -0.38 & -0.72 & -0.73 \\
\hline Other & 0.37 & 0.37 & -0.93 & -0.28 \\
\hline
\end{tabular}

${ }^{1}$ Species Groups: Red oak group (northern red oak, scarlet oak, black oak), White oak group (white oak, chestnut oak), Other (sweet birch, shagbark hickory, sugar maple, cucumber tree, black gum, sassafras). 
Table 3.9. Average values for soil properties by aspect, soil horizon and soil depth.

\begin{tabular}{|c|c|c|c|c|c|}
\hline \multirow{3}{*}{ Soil Property } & \multirow{3}{*}{ Depth } & \multicolumn{2}{|c|}{ Mesic Site } & \multicolumn{2}{|c|}{ Dry Site } \\
\hline & & North & East & West & Southwest \\
\hline & & Facing & Facing & Facing & Facing \\
\hline \multirow{4}{*}{$\mathrm{pH}$} & $0-10 \mathrm{~cm}$ & 4.2 & 4.2 & 4.1 & 3.9 \\
\hline & $10-20 \mathrm{~cm}$ & 4.3 & 4.4 & 4.3 & 4.3 \\
\hline & $20-30 \mathrm{~cm}$ & 4.1 & 4.3 & 4.3 & 4.5 \\
\hline & $10-30 \mathrm{~cm}$ & 4.2 & 4.2 & 4.3 & 4.4 \\
\hline \multirow{4}{*}{ Lime Requirement (t/ac) } & $0-10 \mathrm{~cm}$ & 9.8 & 10.5 & 11.4 & 15.2 \\
\hline & $10-20 \mathrm{~cm}$ & 8.7 & 23.4 & 8.8 & 9.3 \\
\hline & $20-30 \mathrm{~cm}$ & 11.9 & 8.5 & 9.8 & 5.0 \\
\hline & $10-30 \mathrm{~cm}$ & 10.4 & 10.4 & 9.3 & 7.15 \\
\hline \multirow{4}{*}{ Phosphorus (ppm) } & $0-10 \mathrm{~cm}$ & 11.1 & 11.5 & 11.4 & 10.8 \\
\hline & $10-20 \mathrm{~cm}$ & 11.6 & 12.6 & 11.8 & 15.6 \\
\hline & $20-30 \mathrm{~cm}$ & 10.6 & 13.0 & 16.6 & 15.6 \\
\hline & $10-30 \mathrm{~cm}$ & 10.4 & 11.3 & 14.2 & 15.6 \\
\hline \multirow{4}{*}{ Potassium (ppm) } & $0-10 \mathrm{~cm}$ & 63.7 & 56.9 & 61.5 & 54.1 \\
\hline & $10-20 \mathrm{~cm}$ & 46.9 & 53.9 & 53.9 & 54.6 \\
\hline & $20-30 \mathrm{~cm}$ & 54.6 & 54.7 & 48.5 & 38.0 \\
\hline & $10-30 \mathrm{~cm}$ & 50.7 & 53.8 & 51.2 & 46.3 \\
\hline \multirow{4}{*}{ Calcium (ppm) } & $0-10 \mathrm{~cm}$ & 11.7 & 9.0 & 7.0 & 6.9 \\
\hline & $10-20 \mathrm{~cm}$ & 7.1 & 5.8 & 6.9 & 3.8 \\
\hline & $20-30 \mathrm{~cm}$ & 7.1 & 5.3 & 5.9 & 4.2 \\
\hline & $10-30 \mathrm{~cm}$ & 7.1 & 8.1 & 6.4 & 4.0 \\
\hline \multirow{4}{*}{ Magnesium (ppm) } & $0-10 \mathrm{~cm}$ & 23.4 & 20.7 & 18.8 & 21.4 \\
\hline & $10-20 \mathrm{~cm}$ & 16.0 & 15.6 & 16.9 & 14.9 \\
\hline & $20-30 \mathrm{~cm}$ & 20.3 & 14.0 & 15.2 & 14.8 \\
\hline & $10-30 \mathrm{~cm}$ & 18.2 & 19.4 & 16.1 & 14.9 \\
\hline
\end{tabular}


Table 3.10. Variability of average nutrient concentrations by aspect and soil horizon.

\begin{tabular}{|c|c|c|c|c|}
\hline Nutrient & $\begin{array}{l}\text { Descending order } \\
\text { of concentration }\end{array}$ & $\begin{array}{l}\text { Range } \\
(\mathrm{ppm})\end{array}$ & $\begin{array}{l}\text { Mesic }^{1}-\text { Dry }^{2} \\
\text { (ppm) }\end{array}$ & $\begin{array}{l}\mathrm{SD}^{3} \\
(\mathrm{ppm})\end{array}$ \\
\hline & \multicolumn{4}{|c|}{ Surface layer } \\
\hline Phosphorus & $\mathrm{E}, \mathrm{W}, \mathrm{N}, \mathrm{SW}$ & 0.7 & 0.2 & 0.30 \\
\hline Potassium & $\mathrm{N}, \mathrm{W}, \mathrm{E}, \mathrm{SW}$ & 9.6 & 2.5 & 4.34 \\
\hline Calcium & $\mathrm{N}, \mathrm{E}, \mathrm{W}, \mathrm{SW}$ & 4.8 & 3.4 & 2.25 \\
\hline Magnesium & $\mathrm{N}, \mathrm{SW}, \mathrm{E}, \mathrm{W}$ & \multicolumn{2}{|l|}{ Subsoil } & 1.89 \\
\hline Phosphorus & $\mathrm{SW}, \mathrm{W}, \mathrm{E}, \mathrm{N}$ & 4.5 & -3.7 & 2.20 \\
\hline Potassium & $\mathrm{E}, \mathrm{W}, \mathrm{N}, \mathrm{SW}$ & 7.5 & 3.5 & 3.12 \\
\hline Calcium & $\mathrm{E}, \mathrm{N}, \mathrm{W}, \mathrm{SW}$ & 4.1 & 2.4 & 1.73 \\
\hline \multirow[t]{2}{*}{ Magnesium } & $\mathrm{E}, \mathrm{N}, \mathrm{W}, \mathrm{SW}$ & 4.6 & 3.3 & 2.1 \\
\hline & \multicolumn{4}{|c|}{ Differences in nutrient concentration between the surface layer and the subsoil in ppm } \\
\hline Aspect & Phosphorus & Potassium & Calcium & Magnesium \\
\hline North & 0.0 & 12.9 & 4.6 & 5.30 \\
\hline East & 0.2 & 3.07 & 0.95 & 1.30 \\
\hline West & -2.8 & 10.3 & 0.6 & 2.75 \\
\hline Southwest & -4.8 & 7.8 & 2.9 & 6.55 \\
\hline $\mathrm{SD}^{4}$ & 2.39 & 4.2 & 1.85 & 2.38 \\
\hline
\end{tabular}

${ }^{\mathrm{T}}$ Mesic: average nutrient concentration for the mesic site (north and east aspects).

${ }^{2}$ Dry: average nutrient concentration for the dry site (west and southwest aspects).

${ }^{3}$ SD: Standard deviation of nutrient concentration across aspect. A value of zero indicates nutrient concentrations are not related to aspect while larger values imply that nutrient concentrations are influenced by aspect.

${ }^{4} \mathrm{SD}$ : Standard deviation of the differences across aspect. A value of zero indicates differences in nutrient concentration between the A- and B-horizons are not related to aspect while larger values imply that the differences are aspect related.

The southwest aspect has the smallest concentration for all nutrients but phosphorus.

The large number of positive differences between the surface- and subsoil layer indicates higher nutrient concentration on the surface layer than the subsoil. 


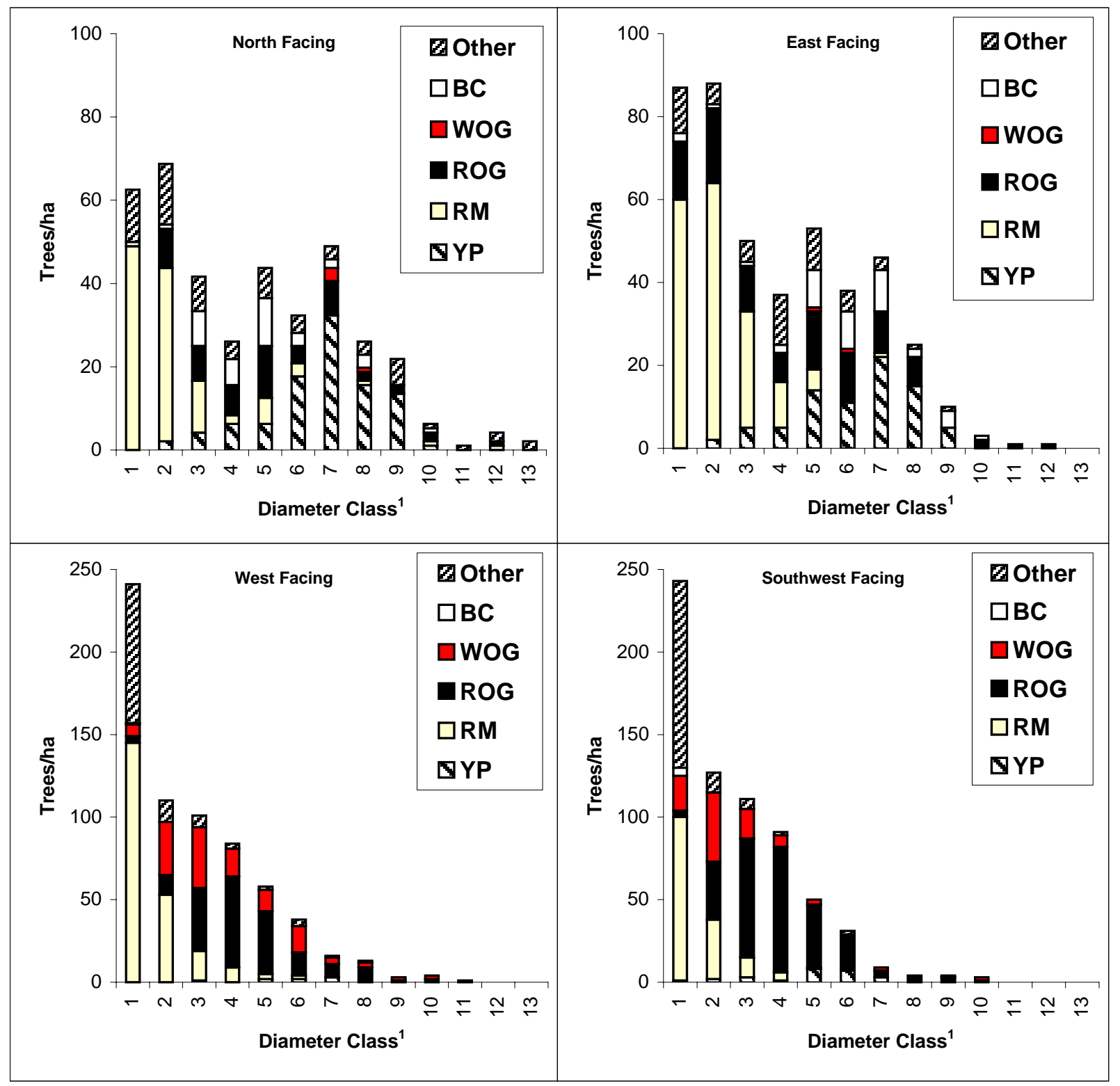

Figure 3.1. Diameter distribution across the four aspects by diameter class and species ${ }^{2}$ groups showing an approximate reverse $\mathrm{J}$-shaped structure.

${ }^{1}$ Diameter Class: $1=7-12.9 \mathrm{~cm}, 2=13-18.9 \mathrm{~cm}, 3=19-24.9 \mathrm{~cm}, \ldots, 13=79 \mathrm{~cm}+$.

${ }^{2}$ Species groups:YP (yellow-poplar), BC (black cherry), RM (red maple),

WOG (white oak, chestnut oak), ROG (northern red oak, scarlet oak, black oak),

Other (sweet birch, shagbark hickory, sugar maple, cucumber tree, black gum, sassafras). 


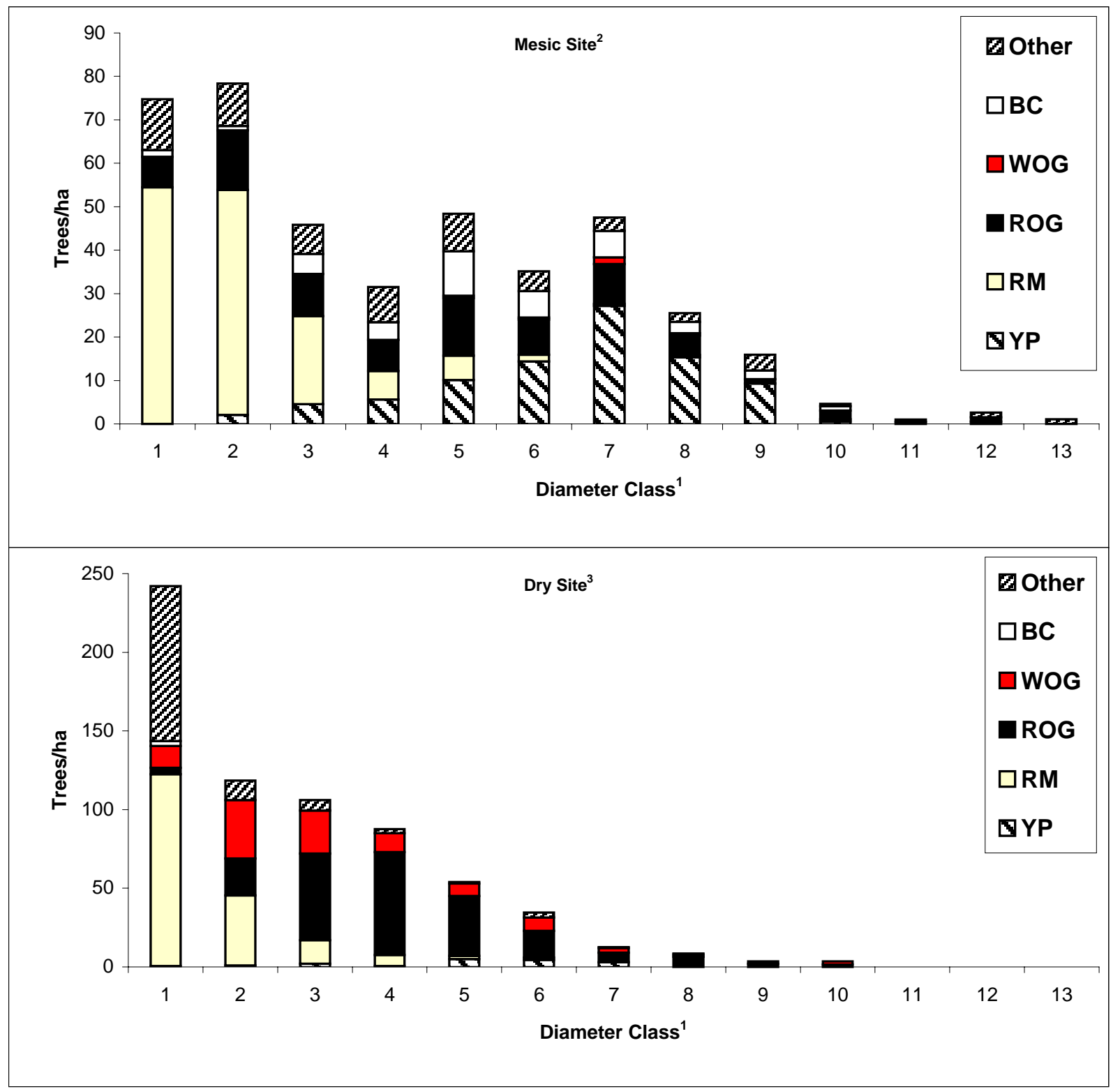

Figure 3.2. Diameter distribution for the mesic and dry sites by diameter class and species groups ${ }^{4}$ showing a polymorphic J-shaped structure.

${ }^{1}$ Diameter Class: $1=7-12.9 \mathrm{~cm}, 2=13-18.9 \mathrm{~cm}, 3=19-24.9 \mathrm{~cm}, \ldots, 13=79 \mathrm{~cm}+$.

${ }^{2}$ Mesic Site: (north and east facing slopes).

${ }^{4}$ Species groups:YP (yellow-poplar), BC (black cherry), RM (red maple), WOG (white oak, chestnut oak), ROG (northern red oak, scarlet oak, black oak), Other (sweet birch, shagbark hickory, sugar maple, cucumber tree, black gum, sassafras). 


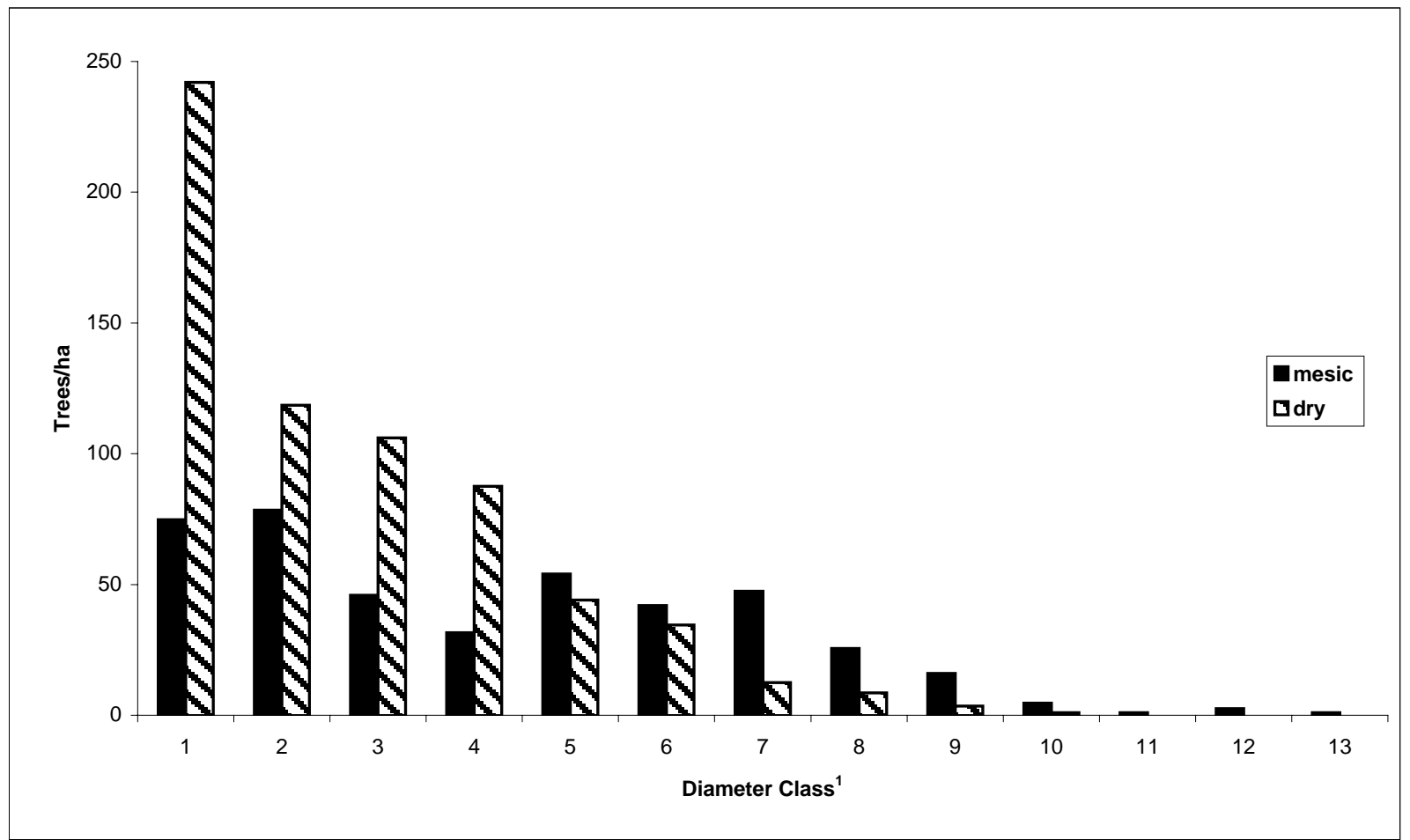

Figure 3.3. Diameter distribution (trees per hectare) for the mesic ${ }^{2}$ and dry ${ }^{3}$ sites. There were twice as many small $(<37 \mathrm{~cm})$ trees on the dry site. The number of large $(>37 \mathrm{~cm})$ trees was much higher on the mesic site.

${ }^{1}$ Diameter Class: $1=7-12.9 \mathrm{~cm}, 2=13-18.9 \mathrm{~cm}, 3=19-24.9 \mathrm{~cm}, \ldots, 13=79 \mathrm{~cm}+$.

${ }^{2}$ Mesic Site: (north and east facing slopes).

${ }^{3}$ Dry Site: (west and southwest facing slopes). 


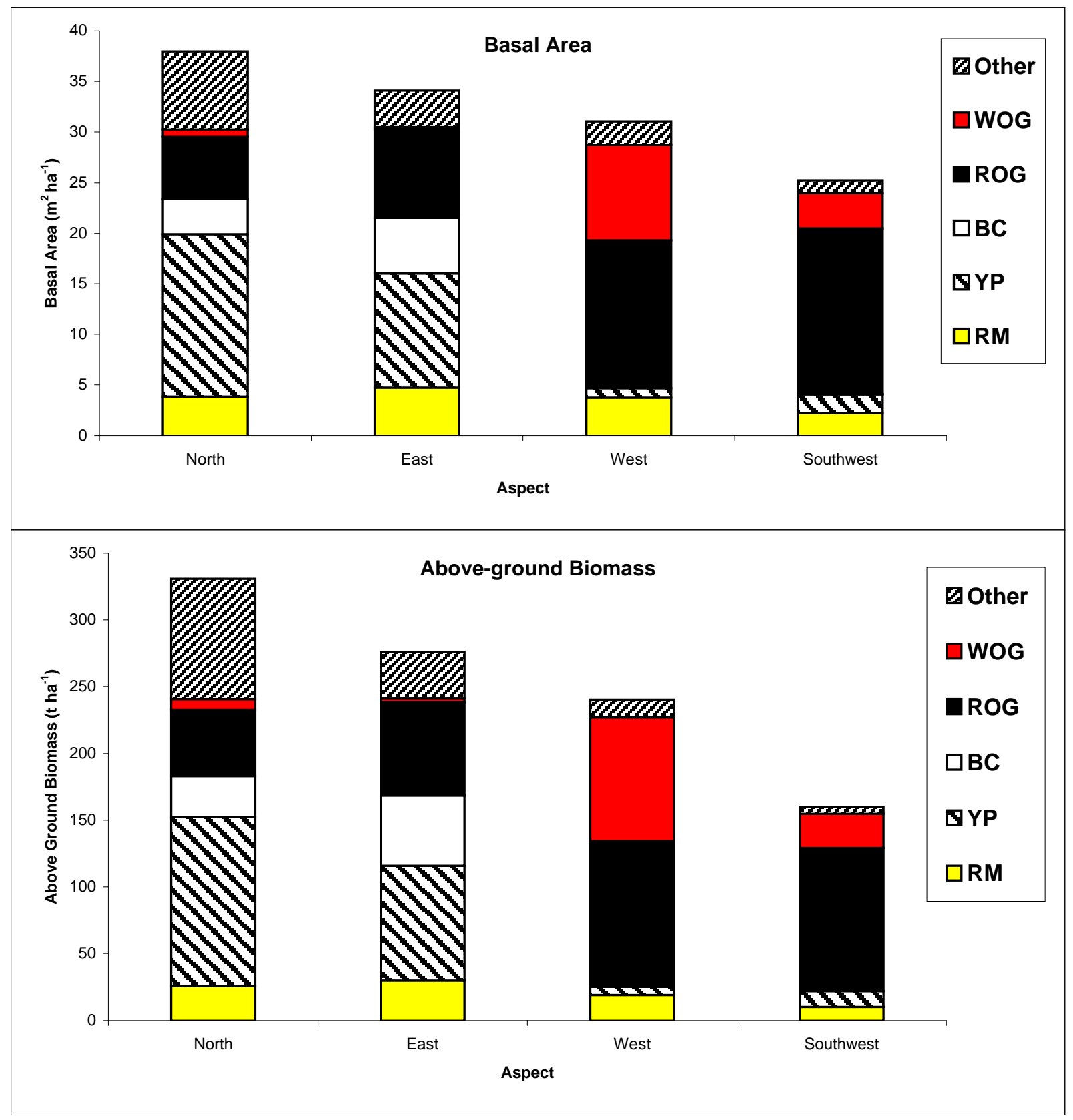

Figure 3.4. Charts showing basal area (a) and above ground dry biomass (b) by aspect and species groups ${ }^{1}$. Yellow-poplar dominates the mesic site (north and east aspects) and the red oak group dominates the dry site (west and southwest aspects). The other species group account for more basal area and biomass on the mesic sites.

${ }^{1}$ Species groups:YP (yellow-poplar), BC (black cherry), RM (red maple), WOG (white oak, chestnut oak), ROG (northern red oak, scarlet oak, black oak), Other (sweet birch, shagbark hickory, sugar maple, cucumber tree, black gum, sassafras). 


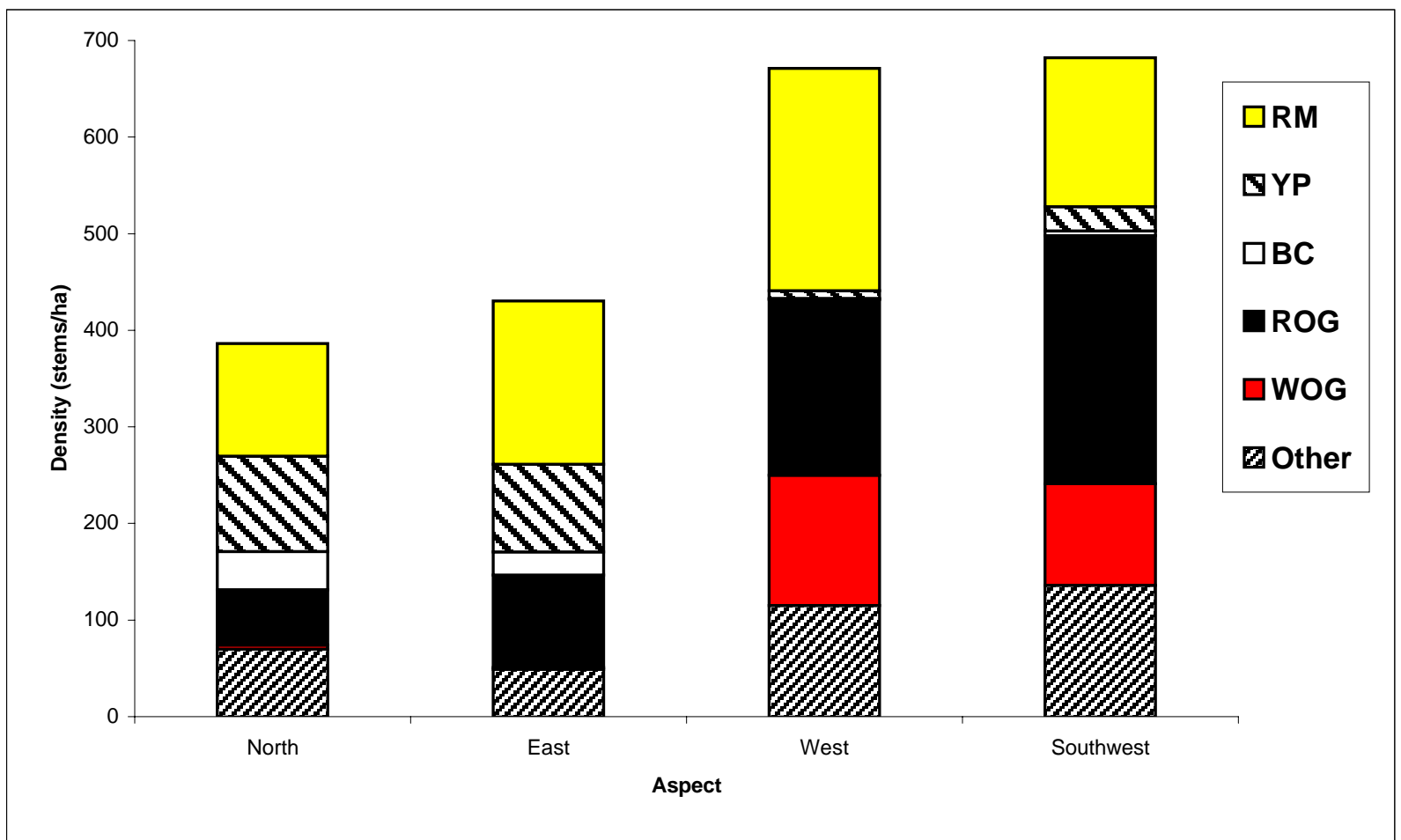

Figure 3.5. Chart of density ( $\left(\mathrm{stems} / \mathrm{ha},>7 \mathrm{~cm} \mathrm{dbh}\right.$ ) for each aspect by species group ${ }^{1}$. The red maple, yellow-poplar, and red oak group accounted for 62 and 82 percent of the trees on north and east aspects respectively. The red oak and white oak group accounted for 81 and 76 percent of the trees on the west and southwest aspects respectively.

${ }^{1}$ Species groups:YP (yellow-poplar), BC (black cherry), RM (red maple), WOG (white oak, chestnut oak), ROG (northern red oak, scarlet oak, black oak), Other (sweet birch, shagbark hickory, sugar maple, cucumber tree, black gum, sassafras). 


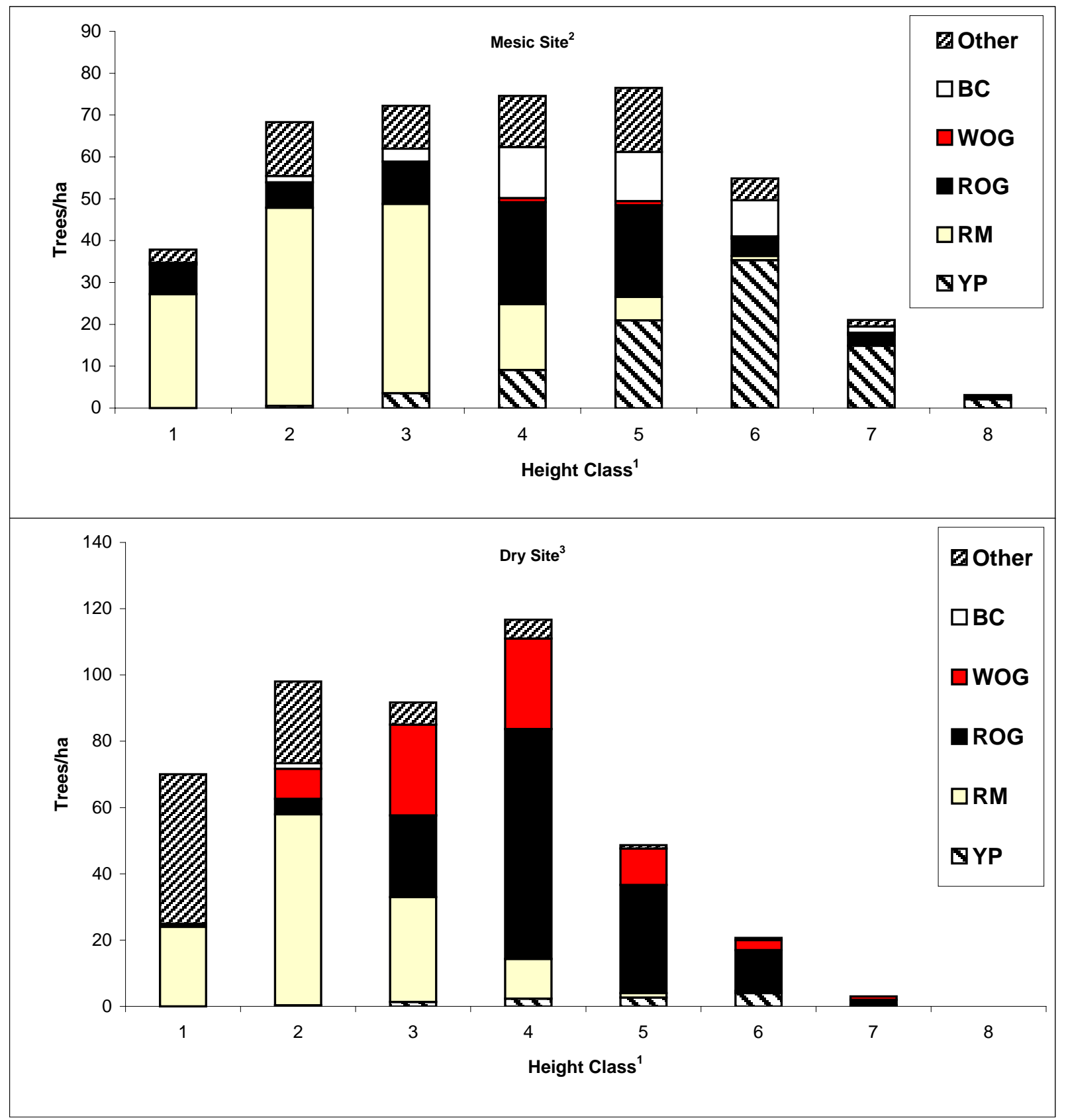

Figure 3.6. Trees per hectare by height class and species groups ${ }^{4}$ for the mesic and dry sites . ${ }^{1}$ Height Class: $1=4-8.9 \mathrm{~m}, 2=9-13.9 \mathrm{~m}, 3=14-18.9 \mathrm{~m}, \ldots, 8=39 \mathrm{~m}+$.

${ }^{2}$ Mesic Site: (north and east facing slopes). ${ }^{3}$ Dry Site: (west and southwest facing slopes). ${ }^{4}$ Species groups:YP (yellow-poplar), BC (black cherry), RM (red maple), WOG (white oak, chestnut oak), ROG (northern red oak, scarlet oak, black oak), Other (sweet birch, shagbark hickory, sugar maple, cucumber tree, black gum, sassafras). 


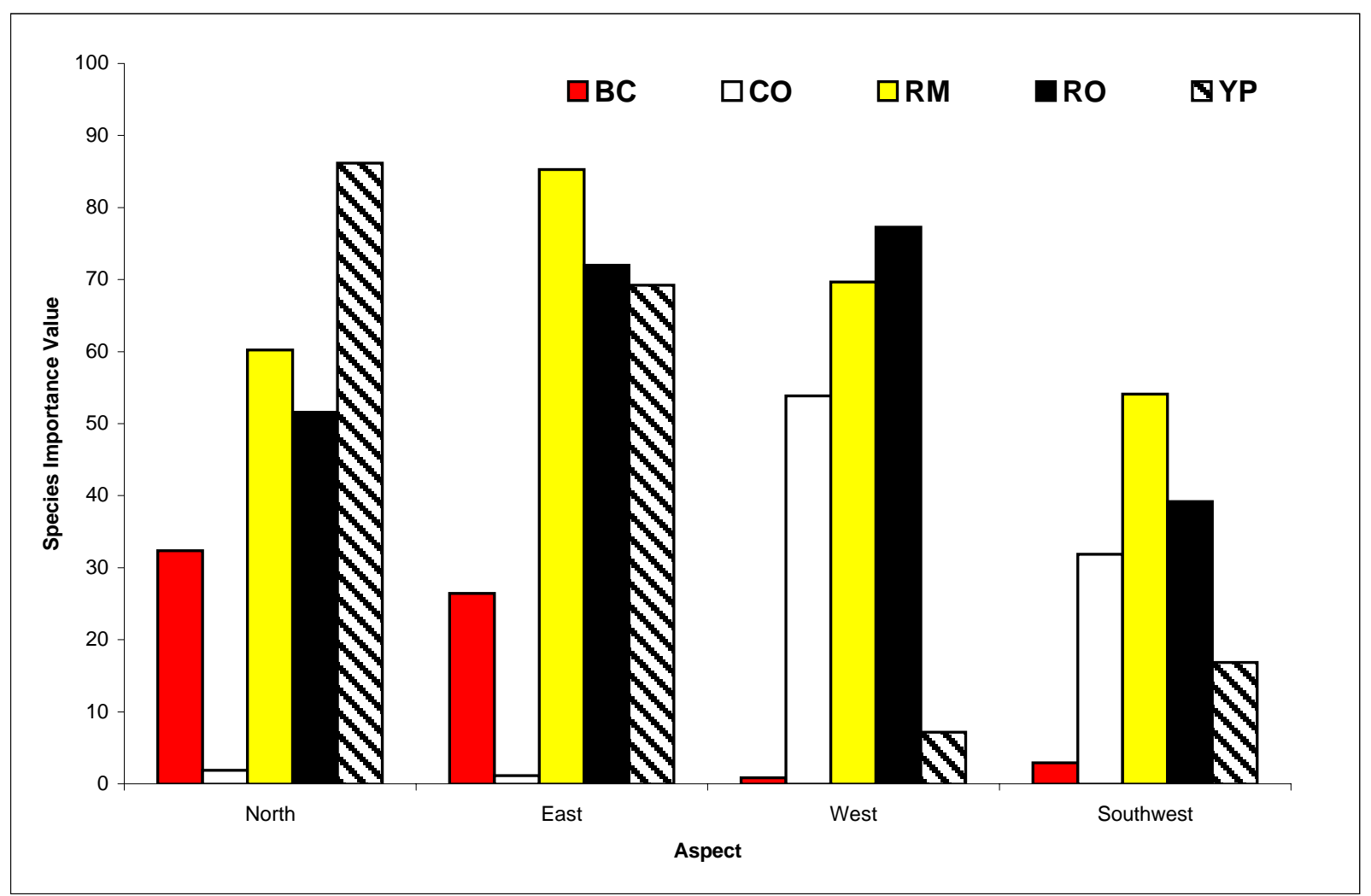

Figure 3.7. Species importance values by aspect for five species ${ }^{1}$. Yellow-poplar and black cherry show highest values at the mesic (north and east aspects) site and chestnut oak tend to dominate the drier sites (west and southwest aspects).

${ }^{1}$ Species groups:YP (yellow-poplar), RO (northern red oak), RM (red maple), CO (chestnut oak), $\mathrm{BC}$ (black cherry). 


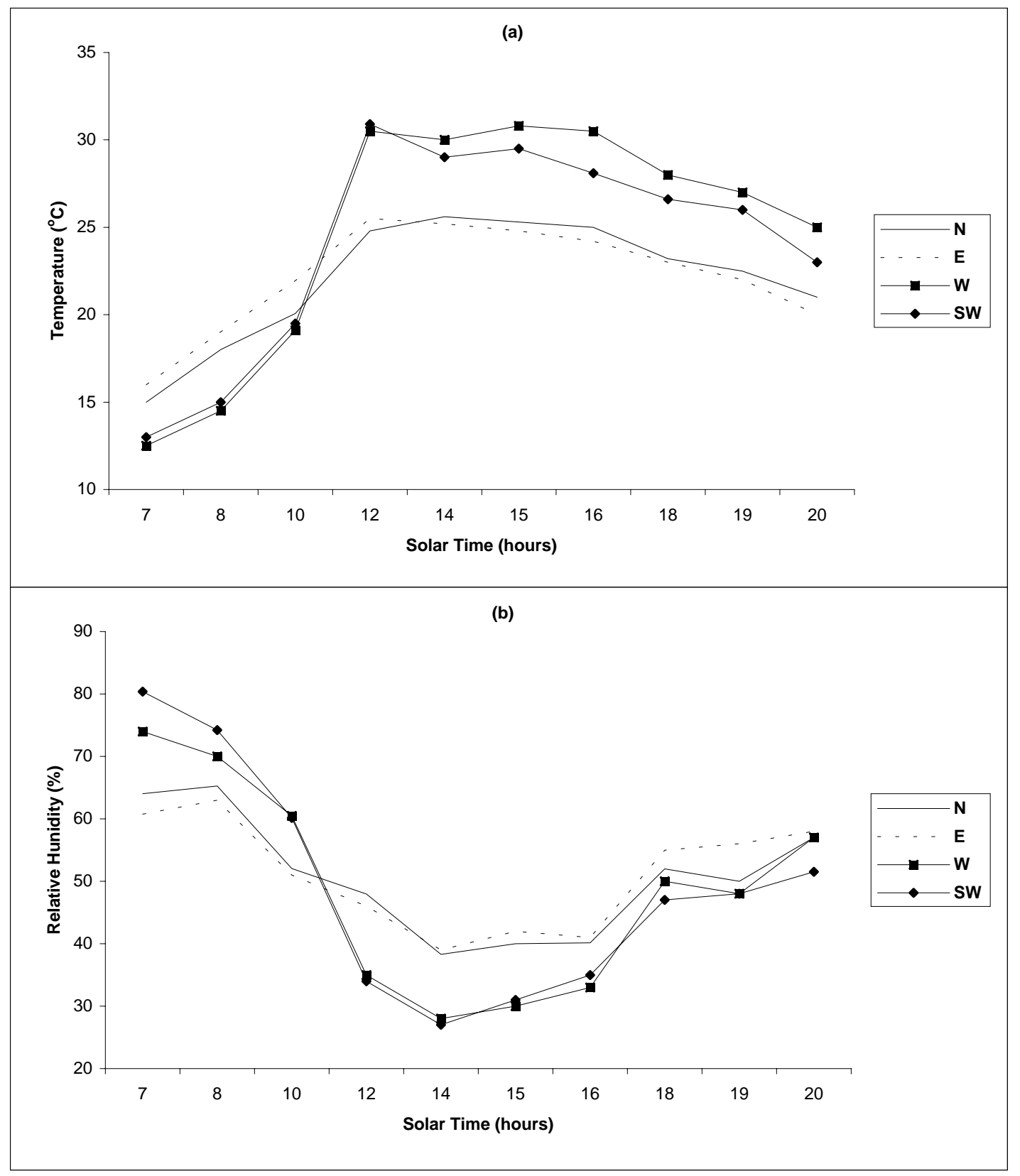

Figure 3.8. The diurnal pattern of air temperature (a) and estimated relative humidity (b) across the four aspects during two growing season days(July 14th and 16th of 1997). 


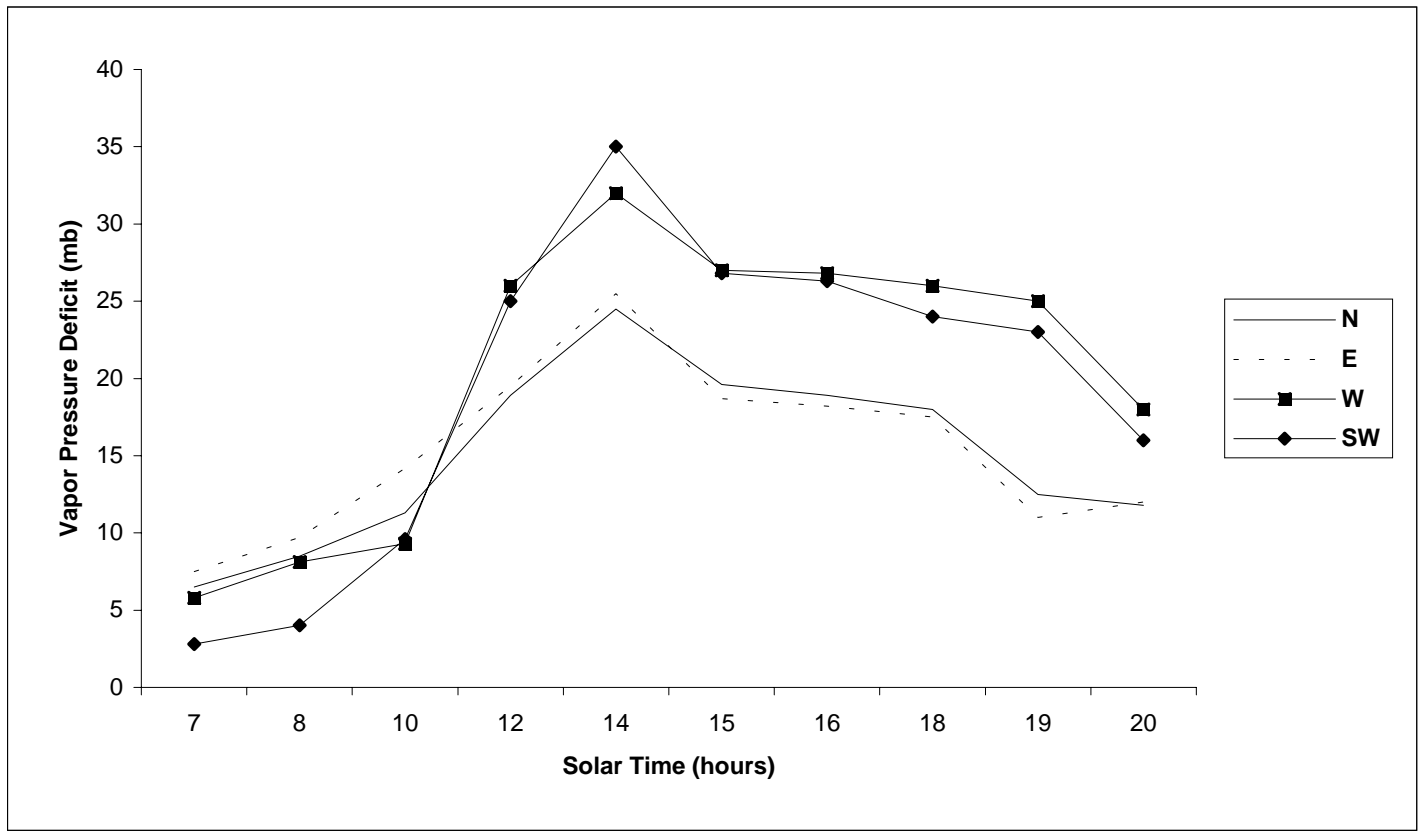

Figure 3.9. The diurnal pattern of estimated vapor pressure defecit (Et) across the four aspects during two growing season days (July 14th and 16th of 1997). Et is a measure of the demand for evapotranspiration. 


\section{CHAPTER 4: STUDY II}

\section{ANALYSIS OF CLIMATIC DATA}

\subsection{Introduction and Methods}

Some of the issues addressed in this dissertation require data on climate. These issues include: How does aspect affect radial growth response to a long history of climate? And how does aspect affect radial growth during specific (extremely dry or wet) climatic conditions? The first question requires climatic data that covers the entire life span of the trees and the second requires identification of drought and wet years. This chapter, therefore, examines the pattern and variability of climatic data at the study site and identifies drought periods using the Palmer Drought Severity Index (PDSI).

Since most sampled (felled and cored) trees were, in average, 60-years old, this study examined climatic data for the period 1930-1996. The climatic data used in the present study were monthly total precipitation $(\mathrm{cm})$, monthly mean temperature $\left({ }^{\circ} \mathrm{c}\right)$, and the Palmer Drought Severity Index (PDSI). The data were obtained from the National Climatic Data Center (NCDC), North Carolina. The NCDC provides temperature (in tenths of degree F.) and precipitation (in hundredths of inches) as an ASCII file. Based on the information from NCDC documentation manual a SAS program was written to read, screen, format, translate the variables to metric units, and compute summary statistics.

Monthly total precipitation and monthly mean temperature for Coopers Rock weather station ranges from 1973 to 1996 , a total of 23 records. Because the study period starts earlier than 1973, additional climatic data were required for the period 1930 to 
1972. Before the Coopers Rock weather station at the University Forest was established in 1972, researchers had to rely on weather records from Brandonville or the Morgantown Airport (Carvell, 1983). The Coopers Rock weather station is located on Chestnut Ridge along the Sand Springs Road, 1.5 miles north of Route 48 (Carvell, 1983) and it is at a walking distance from the present study plots. The Coopers Rock weather station is 11 miles west of the Brandonville weather station and 8 miles east of the Morgantown Airport station.

Climatic data from four closest weather stations: Brandonville, Morgantown Airport, Morgantown Lock \& Dam, and Fairmont were considered to estimate (reconstruct) the missing temperature and precipitation data at Coopers Rock weather station. The climatic information at these weather stations was also obtained from the NCDC. Table 4.1 presents the relevant summary (measurement period, elevation above sea level, longitudinal and latitudinal limits, etc.) of these five weather stations. Missing values were estimated in steps. First, a correlation analysis was employed to measure the strength of the linear relationship in the pattern of temperature and precipitation at Coopers Rock vs. neighboring station. Then linear regression equations were developed relating temperature and precipitation at Coopers Rock with those stations that showed the highest correlation with Coopers Rock and these models were used to estimate missing values of the period 1930-1972.

Since the study site is located in climate district 2, identification of drought years was made using PDSI data for climate district 2. The Palmer Drought Severity Index (PDSI) was developed by Palmer (1965) to represent the severity of dry and wet spells of weather over the U.S. based on monthly temperature and precipitation data as well as the 
soil-water holding capacity at that location. This metrological drought index is used extensively as a measure of drought in several dendroclimatic studies (Cook and Jacoby 1977, Orwig and Abrams 1997, Abrams et al. 1998, Rubino and McCarthy 2000). The index generally ranges from -6 to +6 , with negative values denoting dry spells and positive values indicating wet spells. To help identify which PDSI values corresponded to specific climatic conditions, description of PDSI classifications was obtained from National Drought Mitigation Center (1999). PDSI values were categorized as follows: 0 to -0.49 indicate normal condition, -0.5 to $-0.99=$ incipient drought, -1.0 to $-1.99=$ mild drought, -2.0 to $-2.99=$ moderate drought, -3.0 to $-3.99=$ severe drought, and less than or equal to -4 indicates extreme drought. Similar adjectives are attached to positive values of wet spells. Monthly PDSI data for the period 1935-1996 were obtained for West Virginia Climatic district 2 from CLIMVIS web page of NCDC/NOAA (2001). Using the monthly data, annual and growing season PDSI were computed.

\subsection{Objectives}

The specific objectives of this chapter were (a) to estimate missing climatic data, (b) to describe the patterns of annual, seasonal, and monthly variation in precipitation and temperature, and (c) to examine synchronous patterns between precipitation, temperature and the Palmer Drought Severity Index and identify years of abnormal climatic conditions. 


\subsection{RESULTS AND DISCUSSION}

\subsubsection{The Relationship Among Stations}

To examine whether there was a close relationship between the climatic variables at the five stations, monthly averages of precipitation and air temperature at Coopers Rock weather station were compared with similar data from the stations at Brandonville, Morgantown Airport, Morgantown Lock and Dam, and Fairmont for the period 1973 to 1989 (common interval for the five weather stations, Table 4.1). Tables 4.2 and 4.3 present the long term average and variability of precipitation and air temperature for the five stations based on seventeen-year data. The effects of elevation are evident, with Coopers Rock precipitation being 14.8, 21.4, 28.8, and 24.9 percent higher than that at Brandonville, Fairmont, Morgantown Airport, and Morgantown Lock and Dam respectively. The Precipitation at Brandonville was 5.7, 12.2, and 8.8 percent higher than that at Fairmont, Morgantown Airport, and Morgantown Lock and Dam respectively.

Similarly the average annual temperature (based on seventeen-year data) at Coopers Rock was $4.6 \%\left(0.42{ }^{\circ} \mathrm{C}\right), 20.9 \%\left(2.3{ }^{\circ} \mathrm{C}\right), 23.7 \%\left(2.7^{\circ} \mathrm{C}\right)$, and $21.6 \%(2.4$ ${ }^{\circ} \mathrm{C}$ ) lower than that at the Brandonville, Fairmont, Morgantown Airport, and Morgantown Lock and Dam respectively. Seventeen-year average of annual mean temperature at Brandonville was $17.1 \%\left(1.9{ }^{\circ} \mathrm{C}\right), 20 \%\left(2.3{ }^{\circ} \mathrm{C}\right)$, and $17.8 \%\left(1.98{ }^{\circ} \mathrm{C}\right)$ lower than that Fairmont, Morgantown Airport, and Morgantown Lock and Dam respectively. These data suggest that the climate station at Brandonville provides the closest estimates of precipitation and air temperature as that of the Coopers Rock weather station. Even though the climatic data at Coopers Rock weather station was distinctly different from the other stations, the long-term trends of the climatic variables at the four stations 
exhibit a similar pattern (Figure 4.1), and hence, a simple correlation and regression analysis can be used for estimating the missing data.

A correlation analyses of monthly precipitation and monthly mean temperature at Coopers Rock with those at Brandonville, Morgantown Airport, Morgantown L\&D, and Fairmont were carried out (Tables 4.4 and 4.5). Correlations of monthly precipitation at Coopers Rock with the other four stations are all significant (Table 4.4). However, correlation's were consistently highest with data from Brandonville, followed by Morgantown Airport and Fairmont for most months. Thus, monthly precipitation from Brandonville was used as the independent variable to estimate the missing Coopers Rock precipitation for the period 1957 to 1972 . Since the precipitation data at Brandonville does not start earlier than 1957 (Table 4.1), monthly precipitation from Morgantown Airport was used as the independent variable to estimate the missing Coopers Rock precipitation for the period 1945 to 1956 . As both Brandonville and Morgantown Airport do not have recorded data for the period 1930 to 1944, precipitation data for the period 1931 to 1944 are estimated using data from Fairmont weather station.

Similarly the correlations of monthly mean temperature at Coopers Rock with the other stations are all significant (except September, Table 4.5). Monthly mean temperature at Coopers Rock showed the highest correlations with data from Brandonville, followed by Morgantown Airport and Fairmont weather stations. Hence, monthly mean temperature from Brandonville, Morgantown Airport, and Fairmont were used as the independent variables to estimate the missing Coopers Rock temperature data for the period 1957 to 1972,1945 to 1956 , and 1931 to 1944 respectively. Tables 4.4 and 4.5 show that the correlation coefficients of precipitation and temperature between 
Coopers Rock weather station and Morgantown Lock and Dam, though significant for nearly all months, were the lowest compared to the remaining three stations. This could be attributed to the large elevation difference between the two stations. The data from Morgantown Lock and Dam were not used for estimating missing values at Coopers Rock weather station.

\subsubsection{Missing Data Estimation}

To estimate the missing monthly precipitation and monthly mean temperature at Coopers Rock, a linear regression model of the form $Y_{C R}=\beta_{0}+\beta_{1} X+\varepsilon$ was fitted for each month and for each climatic variable, where $Y_{C R}$ is monthly total precipitation or monthly mean temperature at Coopers Rock, and $X$ is monthly total precipitation or monthly mean temperature at Brandonville, Morgantown Airport, or Fairmont, $\beta_{0}$ and $\beta_{1}$ are parameters to be estimated, and $\varepsilon$ is a random error term assumed to be normally distributed with homogenous variance, $\varepsilon \sim N\left(0, \sigma^{2}\right)$. The estimated parameters are given in Table 4.6. The complete temperature and precipitation data for Coopers Rock (1931 to 1996) as well as the monthly PDSI data are given in the Appendix.

\subsubsection{Patterns of Climatic Variation at the Study Site}

\section{A. Annual Precipitation}

The long-term average of annual precipitation and the standard deviation (SD) for the whole study period (1930-1996) were $129 \mathrm{~cm}$ and $17 \mathrm{~cm}$, respectively. Annual precipitation data was normally distributed (Wilks test, $\mathrm{W}=0.96, \operatorname{Pr}<\mathrm{W}=0.15$ ) and nearly all the observations lie within the mean $\pm 2 \mathrm{SD}$. The time-plot of annual precipitation (Figure 4.2(a)) and the average precipitation for non-overlapping ten-year intervals (Figure 4.2(b)) do not indicate a linear increasing or decreasing trend in precipitation. 
Comparison of the average precipitation for each decade (Figure 4.2(b)) shows that the 1970's were the period with maximum total rainfall.

The highest annual precipitation was $164.5 \mathrm{~cm}$ (1956) and the lowest was $97 \mathrm{~cm}$ (1991). The total annual precipitation in 1991, 1953, 1965 and 1988 (Figure 4.2(a)) were 26 to $32 \mathrm{~cm}$ below average and on the other extreme, $30-36 \mathrm{~cm}$ higher than average annual precipitation occurred in 1956, 1948, 1978, and in 1972. Radial growth during these years will be a topic of further investigation.

To determine whether or not a defined cyclic pattern of "dry" and "wet" years exist, the intervals (length) between years with annual precipitation $15 \%$ above and below normal were examined. Periods with annual precipitation 15 percent below the long-term average include $1934(99.6 \mathrm{~cm}), 1941(109.3 \mathrm{~cm}), 1953(102.6 \mathrm{~cm}), 1965$ $(102.5 \mathrm{~cm}), 1988(102.9 \mathrm{~cm}), 1991(97 \mathrm{~cm})$, and $1993(110.4 \mathrm{~cm})$. The precipitations in 1934, 1953, 1965, 1988, and 1991 were $20 \%$ less than average. On the other hand, $15 \%$ above average annual precipitation occurred in $1948(161.1 \mathrm{~cm}), 1950(156.2 \mathrm{~cm}), 1956$ (164.5 cm), $1961(157.1 \mathrm{~cm}), 1972(158.5 \mathrm{~cm}), 1974(150.9 \mathrm{~cm}), 1978(160.9 \mathrm{~cm}), 1979$ $(157.1 \mathrm{~cm}), 1984(151.9 \mathrm{~cm}), 1985(152.9 \mathrm{~cm})$, and in $1994(152.7 \mathrm{~cm})$. The annual precipitations in $1948,1956,1961,1972,1978$, and 1979 were 20 percent above the long-term average. The interval between two consecutive "dry" years or "wet" years was irregular, implying non-existence of cyclic fluctuation in the precipitation series. Spectral analysis (Fritts 1976, SAS 1989) is a technique used to look for cyclical patterns in a time series data such as annual precipitation or annual mean temperature. The absence of cyclical patterns, frequencies or periodicities in the precipitation data was also confirmed through a formal test using spectral analysis. 


\section{B. Monthly Precipitation}

The distribution of monthly precipitation is shown in Figure 4.3(a). The average monthly mean precipitation over the whole study period was $10.9 \mathrm{~cm}$ with estimated standard deviation of $1.7 \mathrm{~cm}$. The highest values of monthly mean precipitation occurred in the month of June $(13.7 \mathrm{~cm})$ and July $(13.5 \mathrm{~cm})$ and the lowest in October $(8.8 \mathrm{~cm})$ and November $(8.9 \mathrm{~cm})$. On average, summer and spring received the most precipitation $(12.88 \mathrm{~cm}$ and $11.51 \mathrm{~cm}$, respectively), fall received the least $(9.19 \mathrm{~cm})$. Approximately $47 \%(60.8 \mathrm{~cm})$ of the average annual precipitation $(130.8 \mathrm{~cm})$ was received during the growing season (May through September). Months with the highest year-to-year variability in precipitation include four growing season periods (May, Jun, July, and August), November and January (Table 4.7). But the growing season months (except May) exhibit the lowest variability in temperature (Table 4.7). Precipitation in fall was 20 and 30 percent lower than those during spring and summer respectively (Table 4.7). This data suggests that lower than average precipitation during autumn could be an important growth influencing factor at the study site.

\section{Annual Air Temperature}

The long-term average of annual mean temperature for the whole study period (1930-1996) was $8.8{ }^{\circ} \mathrm{C}$ with a standard deviation of $0.74{ }^{\circ} \mathrm{C}$. The corresponding values for the period 1973 to 1996 (recorded data) were $8.6{ }^{\circ} \mathrm{C}$ and $0.69{ }^{\circ} \mathrm{C}$ respectively. The distribution of annual mean temperature during the whole study period (1931 to 1996) was normal (Shapiro-Wilk $\mathrm{W}$ test, $\mathrm{W}=0.98, \operatorname{Pr}<\mathrm{W}=0.87$ ). However, there are two years (1931 and 1992) with annual temperature outside the two standard deviation range, i.e., mean $\pm 2 \mathrm{SD}$. The variability and trend in the annual mean temperature was examined by 
plotting the yearly average temperature (Figure 4.4(a)) and the average for each decade (Figure 4.4(b)). The data in Figure 4.4 (a)) tends to suggest that there was a linear decreasing trend in annual mean temperature from 1931 to mid 1960's. The plot of decadal mean temperature (Figure 4.4(b)) indicates that there was a 15 percent linear decrease in temperature from 1930 's $\left(9.79^{\circ} \mathrm{c}\right)$ to 1960 's $\left(8.29^{\circ} \mathrm{c}\right)$. However, a trend in annual mean temperature was not apparent for the period 1970 to 1996 (Figure 4.1). To assess the significance of the change in annual mean temperature (1930's to 1960's) a trend line was fitted to the annual mean temperature data for the period 1931 to 1970 (Figure 4.5 (a)) and the fitted model reveals that there was a statistically significant $\left(\mathrm{P}<0.0001, \mathrm{R}^{2}=0.54\right)$ decrease in annual mean temperature during the interval. A similar significant trend was observed at Morgantown Lock and Dam (1944 to 1970) and Fairmont (1931 to 1970) weather stations, but the data at the Airport (1945 to 1970) did not exhibit a significant decreasing trend (Figure 4.5 (b)).

The highest annual air temperature was $10.55{ }^{\circ} \mathrm{C}(1931)$ and the lowest was 6.25 ${ }^{\circ} \mathrm{C}$ (1992). The corresponding values for the period 1973 to 1996 were $9.7{ }^{\circ} \mathrm{C}(1987)$ and $6.25{ }^{\circ} \mathrm{C}(1992)$ respectively. A warm period, with annual mean temperature $10.2 \%$ above the long-term average occurred during the 1930's (1931 (10.55 $\left.{ }^{\circ} \mathrm{C}\right), 1932\left(10.09{ }^{\circ} \mathrm{C}\right)$, $\left.1933\left(9.95{ }^{\circ} \mathrm{C}\right), 1934\left(10.03{ }^{\circ} \mathrm{C}\right), 1935\left(9.90{ }^{\circ} \mathrm{C}\right), 1936\left(9.74{ }^{\circ} \mathrm{C}\right), 1938\left(10.11{ }^{\circ} \mathrm{C}\right)\right)$ and in $1987\left(9.69{ }^{\circ} \mathrm{C}\right)$. The temperatures in $1931,1932,1933,1934,1935$, and 1938 were 12.7 $\%$ above the long-term average. The annual mean temperatures in $1941\left(9.57{ }^{\circ} \mathrm{C}\right)$ and $1944\left(9.60{ }^{\circ} \mathrm{C}\right)$ were $9 \%$ above the long-term mean. There was only one year (1931) with annual temperature $17 \%$ above the long-term average. A relatively cold period where the annual mean temperature was about $10.2 \%$ below the long-term average includes 1950 
$\left(7.76{ }^{\circ} \mathrm{C}\right), 1958\left(7.57{ }^{\circ} \mathrm{C}\right), 1963\left(7.41{ }^{\circ} \mathrm{C}\right), 1989\left(7.62{ }^{\circ} \mathrm{C}\right)$ and $1992\left(6.25{ }^{\circ} \mathrm{C}\right)$ with the latter four periods being $12.7 \%$ below the long-term average (Figure 4.4(a)). The temperatures in $1960\left(7.97{ }^{\circ} \mathrm{C}\right), 1966\left(7.89^{\circ} \mathrm{C}\right)$, and $1976\left(7.89^{\circ} \mathrm{C}\right)$ were $9 \%$ below the long-term mean. There was only one year (1992) with annual mean temperature $17 \%$ below the long-term average. The interval between consecutive warm or cold years was irregular and hence, there were no cyclical patterns of cold or warm periods in the annual mean temperature series.

\section{Monthly Air Temperature}

The distribution of the seasonal variation of monthly mean air temperature is depicted in Figure 4.3(b). Based on the long-term average, the highest air temperature $\left(20.16{ }^{\circ} \mathrm{C}\right)$ occurred in the month of July and the lowest $\left(-3.62{ }^{\circ} \mathrm{C}\right)$ in January. The maximum $\left(23.93{ }^{\circ} \mathrm{C}\right)$ and minimum $\left(16.72{ }^{\circ} \mathrm{C}\right)$ mean air temperature for July occurred in 1934 and 1992 respectively (Table 4.7). The corresponding values for January were 0.46 ${ }^{\circ} \mathrm{C}$ (in 1937) and $-9.06{ }^{\circ} \mathrm{C}$ (in 1977). The months of June and July (followed by August and September) showed the least variability in air temperature, with standard deviation of $1.36,1.37,1.46$ and $1.48{ }^{\circ} \mathrm{C}$ respectively. The air temperature in December (followed by February and January) showed the highest variability with standard deviation of 2.38, 2.27, and $2.04{ }^{\circ} \mathrm{C}$ respectively. The average temperature of the growing season (May through September) was about $17.44^{\circ} \mathrm{C}$ with standard deviation of $1.05{ }^{\circ} \mathrm{C}$.

\section{E. Interrelationships Among the Three Climatic Factors}

To study the existence of synchronous patterns (interrelationships) between the three climatic factors, i.e., drought index, precipitation and temperature, correlation analysis was applied to annual and growing season data for the period 1935-1996 (Figure 
4.6). PDSI is positively and significantly correlated with precipitation (Table 4.8). The positive correlation between PDSI and precipitation imply that periods with smaller precipitation are associated with smaller PDSI values (drought years) and years of higher precipitation are associated with larger PDSI values (wet years). The negative correlation between PDSI and temperature (Table 4.8), although not significant, is an indication of a tendency that smaller PDSI values (drought years) are associated with warmer periods. Generally, precipitation showed stronger correlation to PDSI than temperature. Another important point from Table 4.8 is that the general assumption of significant correlation between temperature and precipitation was not validated.

Drought and wet years identified using the growing season PDSI are given in Table 4.9. There are four obvious drought years with smallest annual and growing season PDSI (Figure 4.6). These were 1953, 1966, 1988 and 1991. Figure 4.6 also indicates that the 1960's were drier while the 1970's were wetter than average.

\subsubsection{Tree Growth Period and Multicollinearity Among the Monthly Climate Data}

As tree growth of the current year is affected by weather conditions of the current year as well as the previous year, time period from May of the previous year to August (some times, to September) of the current year (on monthly basis) were used in most treering studies (Fritts 1976). At the study site, the growing season spans from May to September. Therefore, tree growth period from May of the previous year to September of the current year is considered for the present study. Similar growth period was considered by Pan et al. (1998) and Rubino and McCarthy (2000). This constitutes 17 monthly variables for each climatic factor (temperature and precipitation) to be used in response function analysis. 
Response function analysis is a procedure that requires some knowledge of the nature of multicollinearity (redundancy) among the monthly climatic variables. Hence, a correlation analysis was applied on monthly means of temperature and monthly totals of precipitation from May of the prior year to September of the current year. There were a total of 48 significant correlations: 21 of them were positive correlations, which ranged from 0.26 to 0.54 , only among the temperature variables, 4 were between precipitation variables, and 23 were between temperature and precipitation variables. These significant correlations among the predictor monthly variables necessitate the use of more complicated multivariate statistical method for studying radial growth response of trees to climatic variables. Under the presence of such large number of significant relations among the monthly climatic variables, use of multiple regression analysis to study radial growth in relation to climate provides unreliable results.

\subsection{Summary}

The trends of monthly mean temperature and total precipitation and their variation during 1930-1996 indicated that both environmental factors showed a seasonal trend. For temperature, the magnitude of variation in winter was larger than that in summer. For precipitation, the magnitude of variation in summer and spring were larger than fall and winter. Considering the fact that the magnitude and the variability of precipitation were large during summer season, moisture during the period may be very important in affecting tree growth at the site. In addition, precipitation during fall was the lowest. Hence, water stress in autumn could be an important factor affecting radial growth of trees at the study site. Series of droughts in 1960's and higher than average precipitation in 1970's were an important feature at the study site. 
The discussion in general may be summarized as follows: (a) the long-term average of annual precipitation at the study area was $129 \mathrm{~cm}$ with estimated standard deviation of $17 \mathrm{~cm}$. The corresponding values for annual air temperature were $8.8^{\circ} \mathrm{c}$ and $0.74{ }^{\circ} \mathrm{c}$ respectively. The variability in annual precipitation was twice as large as the variation in annual air temperature. Annual precipitation had a range of $68 \mathrm{~cm}$ (Max $=$ $165 \mathrm{~cm}$, Min $=97 \mathrm{~cm})$ and annual air temperature varied from $10.55^{\circ} \mathrm{c}(\mathrm{Max})$ to $6.25^{\circ} \mathrm{C}$ (Min), (b) there was no clear increasing or decreasing trend in annual variation of precipitation during the study period, however, a statistically significant 15 percent linear decrease in air temperature was observed from 1930's to 1960's. There were no cyclical patterns or periodicities in either precipitation or temperature series, (c) long-term data indicates that the least variability in monthly mean temperature and the highest variation in precipitation were both observed during the growing season (May through September). The average air temperature of the growing season was $17.44{ }^{\circ} \mathrm{C}$ and the total rainfall was $61 \mathrm{~cm}$. About $47 \%$ of the average annual precipitation was received during this critical period of tree growth, May through September, (d) the mean Palmer Drought Severity Index for the growing season for West Virginia climate district 2 indicated that consecutive droughts occurred in 1960's. Generally the 1960's can be characterized as a drought period and the 1970's received the highest precipitation.

Infrequent severe droughts are also reported in other areas of the eastern U.S. For example, at the Black Rock Forest in southern New York, precipitation from May through September was an average 22\% below normal from 1962 to 1966. At the Harvard Forest, mean annual precipitation averaged 27\% below normal from 1961 to 1966, with driest year in 1965 (42\% below normal) and the driest summer in $1964(6.8 \mathrm{~cm}$ 
in July and August) (Lorimer 1984). Cook and Jacoby (1977), in their study of climate reconstruction for the Hudson Valley region (NY), reported that severe July droughts (PDSI<-3.0) have occurred 10 times in the last 272 years, but the drought of 1962-1966 was slightly more severe (PDSI<-5.0) than any other droughts since 1700 . The data in the current study is consistent with these reports. 
Table 4.1. Summary of climatic information for five weather stations in north-central West Virginia. The years for data interval were based on the record kept by NCDC.

\begin{tabular}{|c|c|c|c|c|c|c|c|c|}
\hline \multirow{2}{*}{$\begin{array}{l}\text { Station } \\
\text { Code } \\
461900\end{array}$} & \multirow{2}{*}{$\begin{array}{l}\text { Station Name } \\
\text { Coopers Rock }\end{array}$} & \multirow{2}{*}{$\begin{array}{c}\begin{array}{c}\text { Elevation } \\
(\mathrm{m})\end{array} \\
694\end{array}$} & \multirow{2}{*}{$\begin{array}{l}\text { Variable } \\
\text { Type } \\
\text { MNTM }^{1}\end{array}$} & \multicolumn{2}{|c|}{$\begin{array}{l}\text { Data } \\
\text { Interval }\end{array}$} & \multirow{2}{*}{$\begin{array}{c}\begin{array}{c}\text { Total } \\
\text { Years }\end{array} \\
24\end{array}$} & \multirow{3}{*}{$\begin{array}{l}\text { Latitude } \\
39^{\circ} 41^{\prime} \mathrm{N}\end{array}$} & \multirow{2}{*}{$\frac{\text { Longitude }}{79^{\circ} 46^{\prime} \mathrm{W}}$} \\
\hline & & & & 1973 & 1996 & & & \\
\hline & & & $\mathrm{TPCP}^{2}$ & 1973 & 1996 & 24 & & \\
\hline \multirow[t]{2}{*}{461083} & Brandonville & 548 & MNTM & 1957 & 1989 & 33 & $39^{\circ} 40^{\prime} \mathrm{N}$ & $79^{\circ} 37^{\prime} \mathrm{W}$ \\
\hline & & & ТPCP & 1957 & 1989 & 33 & & \\
\hline \multirow[t]{2}{*}{466202} & Airport & 378 & MNTM & 1945 & 1996 & 52 & $39^{\circ} 39^{\prime} \mathrm{N}$ & $79^{\circ} 55^{\prime} \mathrm{W}$ \\
\hline & & & ТPCP & 1945 & 1996 & 52 & & \\
\hline \multirow[t]{2}{*}{466212} & $\begin{array}{l}\text { Lock and } \\
\text { Dam }\end{array}$ & 251 & MNTM & 1944 & 1996 & 53 & $39^{\circ} 37^{\prime} \mathrm{N}$ & $79^{\circ} 58^{\prime} \mathrm{W}$ \\
\hline & & & ТPCP & 1931 & 1996 & 66 & & \\
\hline \multirow[t]{2}{*}{462920} & Fairmont & 395 & MNTM & 1931 & 1996 & 66 & $39^{\circ} 28^{\prime} \mathrm{N}$ & $80^{\circ} 08^{\prime} \mathrm{W}$ \\
\hline & & & TPCP & 1931 & 1996 & 66 & & \\
\hline
\end{tabular}

\footnotetext{
${ }^{1}$ MNTM: Monthly mean temperature.

${ }^{2}$ TPCP: Total monthly precipitation.
} 
Table 4.2. Seventeen-year (1973-1989) average precipitation statistics for the Coopers Rock, Brandonville, Morgantown Airport, Morgantown Lock and Dam, and Fairmont weather stations. Average precipitation was computed as the mean of total monthly precipitation in cm based on 17-year data $(\mathrm{n}=17)$.

\begin{tabular}{|c|c|c|c|c|c|}
\hline Month & $\begin{array}{l}\text { Coopers Rock } \\
(694 \mathrm{~m})^{1}\end{array}$ & $\begin{array}{l}\text { Brandonville } \\
(548 \mathrm{~m})\end{array}$ & $\begin{array}{l}\text { Morgantown } \\
\text { Airport }(378 \mathrm{~m})\end{array}$ & $\begin{array}{l}\text { Morgantown } \\
\text { Lock and Dam } \\
(251 \mathrm{~m})\end{array}$ & $\begin{array}{l}\text { Fairmont } \\
(395 \mathrm{~m})\end{array}$ \\
\hline Jan & $10.63 \pm 1.27^{2}$ & $8.99 \pm 1.07$ & $6.88 \pm 0.87$ & $7.54 \pm 1.01$ & $7.91 \pm 1.09$ \\
\hline Feb & $8.93 \pm 1.02$ & $7.59 \pm 0.92$ & $6.19 \pm 0.91$ & $6.44 \pm 0.91$ & $6.65 \pm 0.89$ \\
\hline Mar & $11.26 \pm 0.82$ & $9.50 \pm 0.81$ & $9.16 \pm 0.85$ & $9.24 \pm 0.77$ & $9.64 \pm 0.90$ \\
\hline Apr & $12.69 \pm 1.12$ & $10.51 \pm 0.89$ & $8.77 \pm 0.81$ & $9.79 \pm 0.78$ & $9.42 \pm 0.89$ \\
\hline May & $13.73 \pm 1.20$ & $12.01 \pm 0.94$ & $11.34 \pm 0.80$ & $11.45 \pm 0.81$ & $12.34 \pm 1.07$ \\
\hline Jun & $13.44 \pm 1.29$ & $11.09 \pm 1.15$ & $10.71 \pm 1.21$ & $10.61 \pm 1.29$ & $11.14 \pm 1.17$ \\
\hline Jul & $14.40 \pm 1.45$ & $13.20 \pm 1.12$ & $10.99 \pm 1.03$ & $11.88 \pm 1.14$ & $12.79 \pm 1.24$ \\
\hline Aug & $11.75 \pm 1.15$ & $12.35 \pm 1.09$ & $11.34 \pm 1.49$ & $10.97 \pm 1.61$ & $11.21 \pm 1.16$ \\
\hline Sep & $10.80 \pm 0.96$ & $8.33 \pm 1.07$ & $8.49 \pm 0.81$ & $8.22 \pm 0.93$ & $7.98 \pm 0.90$ \\
\hline Oct & $10.55 \pm 1.14$ & $8.93 \pm 1.13$ & $8.18 \pm 1.06$ & $8.54 \pm 1.07$ & $8.64 \pm 0.87$ \\
\hline Nov & $10.08 \pm 1.68$ & $9.47 \pm 1.38$ & $8.64 \pm 1.37$ & $9.28 \pm 1.32$ & $9.34 \pm 1.25$ \\
\hline Dec & $10.36 \pm 1.05$ & $9.56 \pm 0.88$ & $7.68 \pm 0.79$ & $7.78 \pm 0.75$ & $7.99 \pm 1.04$ \\
\hline Total & 139.62 & 121.58 & 108.36 & 111.72 & 115.04 \\
\hline
\end{tabular}

${ }^{1}$ Elevation above sea level, ${ }^{2}$ Standard error.

Table 4.3. Seventeen-year (1973-1989) average temperature statistics for the Coopers Rock, Brandonville, Morgantown Airport, Morgantown Lock and Dam, and Fairmont weather stations. Average temperature was computed as the mean of monthly temperature in degree centigrade based on 17-year data $(n=17)$.

\begin{tabular}{|c|c|c|c|c|c|}
\hline Month & $\begin{array}{l}\text { Coopers Rock } \\
(694 \mathrm{~m})^{1}\end{array}$ & $\begin{array}{l}\text { Brandonville } \\
(548 \mathrm{~m})\end{array}$ & $\begin{array}{l}\text { Morgantown } \\
\text { Airport }(378 \mathrm{~m})\end{array}$ & $\begin{array}{l}\text { Morgantown } \\
\text { Lock and Dam } \\
(251 \mathrm{~m})\end{array}$ & $\begin{array}{l}\text { Fairmont } \\
(395 \mathrm{~m})\end{array}$ \\
\hline Jan & $-4.36 \pm 0.55^{2}$ & $-3.96 \pm 0.79$ & $-1.85 \pm 0.7$ & $-1.71 \pm 0.76$ & $-2.17 \pm 0.77$ \\
\hline Feb & $-2.40 \pm 0.64$ & $-2.25 \pm 0.73$ & $0.06 \pm 0.66$ & $-0.003 \pm 0.72$ & $-0.10 \pm 0.68$ \\
\hline Mar & $3.11 \pm 0.46$ & $3.66 \pm 0.54$ & $6.19 \pm 0.53$ & $5.97 \pm 0.57$ & $6.08 \pm 0.55$ \\
\hline Apr & $8.26 \pm 0.49$ & $8.67 \pm 0.35$ & $11.01 \pm 0.37$ & $10.86 \pm 0.39$ & $10.96 \pm 0.35$ \\
\hline May & $14.18 \pm 0.38$ & $14.05 \pm 0.33$ & $16.38 \pm 0.46$ & $16.04 \pm 0.38$ & $16.11 \pm 0.37$ \\
\hline Jun & $17.63 \pm 0.24$ & $18.26 \pm 0.27$ & $20.37 \pm 0.31$ & $20.20 \pm 0.36$ & $20.11 \pm 0.31$ \\
\hline Jul & $19.90 \pm 0.25$ & $20.55 \pm 0.22$ & $22.81 \pm 0.25$ & $22.58 \pm 0.25$ & $22.43 \pm 0.21$ \\
\hline Aug & $19.28 \pm 0.27$ & $20.09 \pm 0.29$ & $22.25 \pm 0.32$ & $21.94 \pm 0.31$ & $21.82 \pm 0.31$ \\
\hline Sep & $15.60 \pm 0.32$ & $16.20 \pm 0.26$ & $18.47 \pm 0.34$ & $18.27 \pm 0.29$ & $18.05 \pm 0.30$ \\
\hline Oct & $9.62 \pm 0.43$ & $9.67 \pm 0.50$ & $11.96 \pm 0.42$ & $11.71 \pm 0.55$ & $11.56 \pm 0.52$ \\
\hline Nov & \pm 0.42 & $5.22 \pm 0.46$ & $7.12 \pm 0.46$ & $6.82 \pm 0.52$ & $6.64 \pm 0.47$ \\
\hline Dec & $-1.01 \pm 0.63$ & $-0.66 \pm 0.57$ & $1.13 \pm 0.73$ & $1.06 \pm 0.69$ & $0.63 \pm 0.71$ \\
\hline Mean $^{3}$ & 8.7 & 9.12 & 11.4 & 11.1 & 11.0 \\
\hline
\end{tabular}

${ }^{1}$ Elevation above sea level, ${ }^{2}$ Standard error, ${ }^{3}$ Average of annual mean air temperature for 17-year period. 
Table 4.4. Pearson's correlation coefficients for precipitation at Coopers Rock, Brandonville, Morgantown Airport, Fairmont, and Morgantown L\&D weather stations.

\begin{tabular}{ccccccccc}
\hline & \multicolumn{7}{c}{ Correlation Coefficients } \\
\cline { 2 - 9 } Month & \multicolumn{2}{c}{$P_{C R}$ vs $P_{B V}{ }^{1}$} & \multicolumn{2}{c}{$P_{C R}$ vs $P_{A P}$} & \multicolumn{2}{c}{$P_{C R}$ vs $P_{F A}$} & \multicolumn{2}{c}{$P_{C R}$ vs $P_{L D}$} \\
\hline Jan & 0.92 & $(0.0001)^{2}$ & 0.91 & $(0.0001)$ & 0.91 & $(0.0001)$ & 0.88 & $(0.0001)$ \\
Feb & 0.90 & $(0.0001)$ & 0.88 & $(0.0001)$ & 0.95 & $(0.0001)$ & 0.86 & $(0.0001)$ \\
Mar & 0.85 & $(0.0004)$ & 0.78 & $(0.0001)$ & 0.86 & $(0.0001)$ & 0.81 & $(0.0001)$ \\
Apr & 0.92 & $(0.0001)$ & 0.75 & $(0.0002)$ & 0.73 & $(0.0004)$ & 0.86 & $(0.0001)$ \\
May & 0.89 & $(0.0001)$ & 0.80 & $(0.0001)$ & 0.91 & $(0.0001)$ & 0.83 & $(0.0001)$ \\
Jun & 0.89 & $(0.001)$ & 0.84 & $(0.0001)$ & 0.92 & $(0.0001)$ & 0.83 & $(0.0001)$ \\
Jul & 0.91 & $(0.0001)$ & 0.86 & $(0.0001)$ & 0.77 & $(0.0001)$ & 0.83 & $(0.0001)$ \\
Aug & 0.80 & $(0.001)$ & 0.85 & $(0.0001)$ & 0.71 & $(0.0006)$ & 0.81 & $(0.0001)$ \\
Sep & 0.87 & $(0.0001)$ & 0.89 & $(0.0001)$ & 0.84 & $(0.0001)$ & 0.87 & $(0.0001)$ \\
Oct & 0.94 & $(0.0001)$ & 0.75 & $(0.0002)$ & 0.82 & $(0.0001)$ & 0.89 & $(0.0001)$ \\
Nov & 0.95 & $(0.0001)$ & 0.91 & $(0.0001)$ & 0.91 & $(0.0001)$ & 0.93 & $(0.0001)$ \\
Dec & 0.88 & $(0.0002)$ & 0.97 & $(0.0001)$ & 0.92 & $(0.0001)$ & 0.94 & $(0.0001)$ \\
\hline
\end{tabular}

${ }^{1} P_{C R}$ : Precipitation at Coopers Rock. $\quad P_{B V}$ : Precipitation at Brandonville.

$P_{A P}$ : Precipitation at Morgantown Airport. $\quad P_{F A}$ : Precipitation at Fairmont.

$P_{L D}$ : Precipitation at Morgantown L\&D.

${ }^{2}$ The value in ( ) is the probability $>|\mathrm{R}|$ under $\mathrm{H}_{0}: \mathrm{Rh}_{0}=0$.

Table 4.5. Pearson's correlation coefficients for temperature at Coopers Rock, Brandonville, Morgantown Airport, Fairmont, and Morgantown L\&D weather stations.

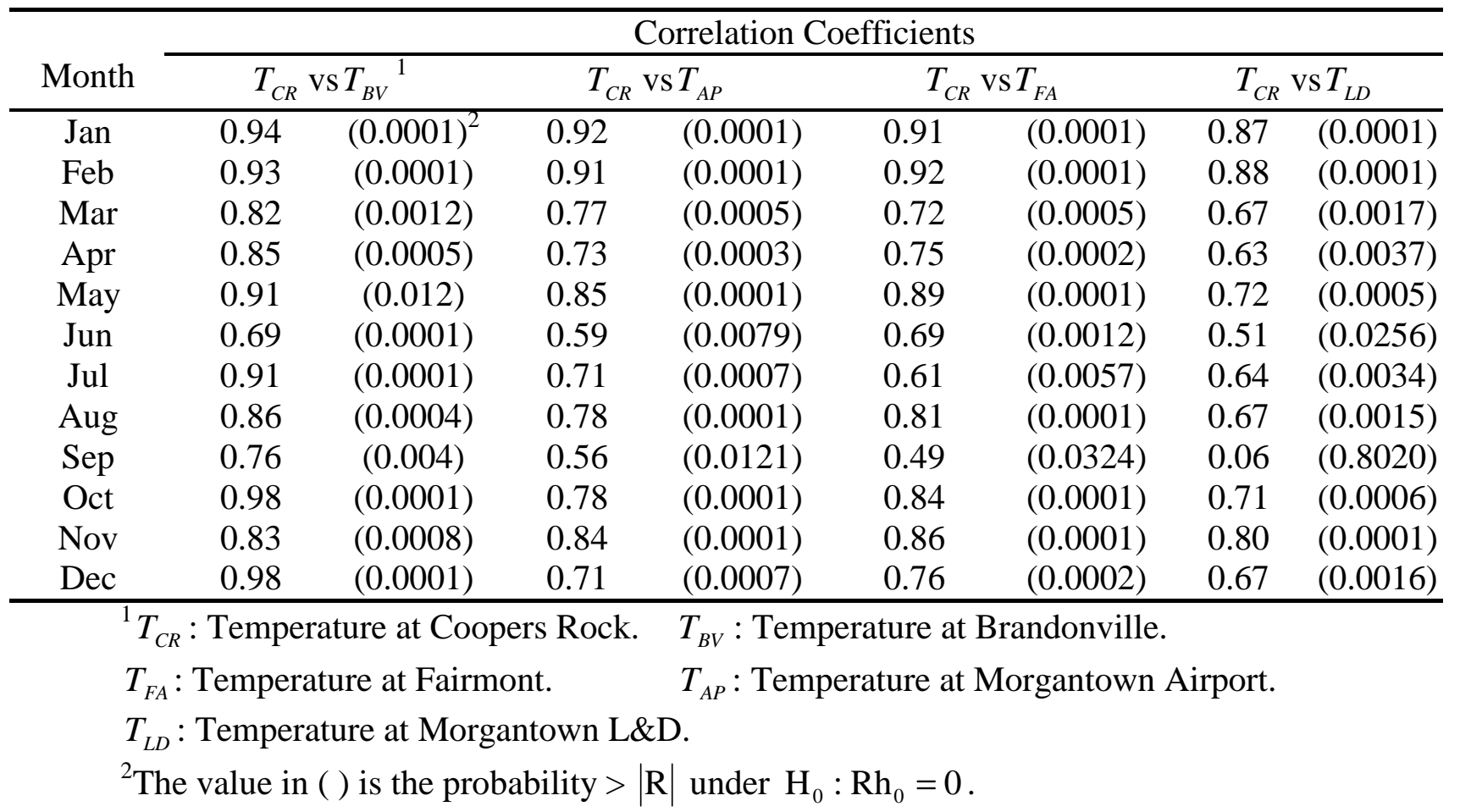


Table 4.6. Models ${ }^{1}$ developed to estimate missing temperature and precipitation at Coopers Rock station. For each month $\hat{\beta}_{1}$ is significant at $\alpha=0.05$ level.

\begin{tabular}{|c|c|c|c|c|c|c|c|c|c|c|c|c|}
\hline \multirow[b]{3}{*}{ Month } & \multicolumn{12}{|c|}{ Parameter estimates } \\
\hline & \multicolumn{2}{|c|}{$\hat{T}_{C R}=\hat{\beta}_{0}+\hat{\beta}_{1} T_{B V}$} & \multicolumn{2}{|c|}{$\hat{T}_{C R}=\hat{\beta}_{0}+\hat{\beta}_{1} T_{A P}$} & \multicolumn{2}{|c|}{$\hat{T}_{C R}=\hat{\beta}_{0}+\hat{\beta}_{1} T_{F A}$} & \multicolumn{2}{|c|}{$\hat{P}_{C R}=\hat{\beta}_{0}+\hat{\beta}_{1} P_{B V}$} & \multicolumn{2}{|c|}{$\hat{P}_{C R}=\hat{\beta}_{0}+\hat{\beta}_{1} P_{A P}$} & \multicolumn{2}{|c|}{$\hat{P}_{C R}=\hat{\beta}_{0}+\hat{\beta}_{1} P_{F A}$} \\
\hline & $\hat{\beta}_{0}$ & $\hat{\beta}_{1}$ & $\hat{\beta}_{0}$ & $\hat{\beta}_{1}$ & $\overline{\hat{\beta}_{0}}$ & $\hat{\beta}_{1}$ & $\hat{\beta}_{0}$ & $\hat{\beta}_{1}$ & $\hat{\beta}_{0}$ & $\hat{\beta}_{1}$ & $\hat{\beta}_{0}$ & $\overline{\hat{\beta}_{1}}$ \\
\hline Jan & -1.65 & 0.68 & -3.7 & 0.59 & -3.17 & 0.60 & 0.84 & 1.13 & 1.21 & 1.30 & 2.19 & 0.93 \\
\hline Feb & -0.52 & 0.84 & -2.94 & 0.88 & -2.22 & 0.87 & 1.33 & 1.01 & 3.16 & 0.91 & 1.18 & 1.06 \\
\hline Mar & 0.29 & 0.77 & -1.81 & 0.72 & -1.03 & 0.65 & 2.44 & 0.88 & 2.71 & 0.78 & 2.09 & 0.79 \\
\hline Apr & -2.68 & 1.26 & -4.12 & 1.09 & -3.61 & 1.10 & -0.15 & 1.18 & 1.59 & 1.09 & 2.01 & 1.03 \\
\hline May & -0.79 & 1.07 & 2.29 & 0.71 & 2.41 & 0.73 & -0.98 & 1.23 & 0.44 & 1.20 & 0.18 & 1.07 \\
\hline Jun & 4.94 & 0.69 & 4.09 & 0.64 & 0.49 & 0.84 & 2.79 & 1.03 & 2.72 & 0.99 & 1.31 & 1.11 \\
\hline Jul & -1.02 & 1.02 & -1.89 & 0.94 & -0.87 & 0.92 & 1.21 & 1.05 & 1.24 & 1.19 & 2.00 & 0.94 \\
\hline Aug & 2.69 & 0.83 & -0.55 & 0.88 & -3.06 & 1.02 & 0.69 & 0.83 & 2.42 & 0.88 & 2.21 & 0.89 \\
\hline Sep & -0.94 & 1.02 & -0.41 & 0.84 & 1.68 & 0.75 & 2.58 & 0.89 & 0.91 & 1.17 & 2.95 & 0.84 \\
\hline Oct & 1.37 & 0.85 & -0.19 & 0.79 & 0.31 & 0.79 & 2.08 & 0.95 & 2.77 & 0.87 & -0.35 & 1.21 \\
\hline Nov & 0.27 & 0.83 & -1.12 & 0.78 & -0.71 & 0.81 & -0.91 & 1.20 & 0.12 & 1.21 & -2.63 & 1.37 \\
\hline Dec & -0.29 & 1.08 & -1.99 & 0.61 & -1.50 & 0.08 & 0.77 & 0.89 & 0.32 & 1.28 & 2.56 & 0.86 \\
\hline
\end{tabular}

Table 4.7. Sixty-six year (1931-1996) average precipitation and temperature statistics for the Coopers Rock Weather Station.

\begin{tabular}{lcccccccc}
\hline & \multicolumn{4}{c}{ Precipitation $(\mathbf{c m})$} & \multicolumn{4}{c}{ Temperature $\left({ }^{\mathbf{0}} \mathbf{C}\right)$} \\
\cline { 2 - 8 } Month & Mean & SD $^{1}$ & Min. $^{2}$ & Max. $^{3}$ & Mean & SD & Min. & Max. \\
\hline Jan & $11.01 \pm 0.62^{4}$ & 5.00 & $3.3(1967)$ & $28.0(1950)$ & $-3.60 \pm 0.25$ & 2.04 & $-9.06(1977)$ & $0.46(1937)$ \\
Feb & $9.04 \pm 0.39$ & 3.19 & $2.9(1987)$ & $16.9(1986)$ & $-2.18 \pm 0.28$ & 2.27 & $-7.83(1978)$ & $2.03(1932)$ \\
Mar & $10.48 \pm 0.44$ & 3.55 & $2.7(1990)$ & $20.0(1967)$ & $2.25 \pm 0.23$ & 1.84 & $-3.57(1960)$ & $6.45(1973)$ \\
Apr & $11.69 \pm 0.50$ & 4.05 & $4.2(1992)$ & $20.9(1973)$ & $8.44 \pm 0.23$ & 1.90 & $4.15(1961)$ & $12.37(1941)$ \\
May & $12.35 \pm 0.68$ & 5.52 & $1.2(1939)$ & $28.2(1968)$ & $14.23 \pm 0.20$ & 1.61 & $11.09(1967)$ & $17.78(1944)$ \\
Jun & $13.68 \pm 0.66$ & 5.33 & $2.9(1992)$ & $27.9(1939)$ & $17.93 \pm 0.17$ & 1.36 & $13.39(1992)$ & $21.85(1934)$ \\
Jul & $13.51 \pm 0.60$ & 4.91 & $4.5(1975)$ & $26.5(1978)$ & $20.16 \pm 0.17$ & 1.37 & $16.72(1992)$ & $23.93(1934)$ \\
Aug & $11.44 \pm 0.62$ & 5.00 & $3.6(1981)$ & $27.6(1994)$ & $19.29 \pm 0.18$ & 1.46 & $14.72(1992)$ & $22.64(1936)$ \\
Sep & $9.90 \pm 0.44$ & 3.54 & $3.3(1995)$ & $17.9(1979)$ & $15.58 \pm 0.18$ & 1.48 & $12.67(1991)$ & $18.49(1931)$ \\
Oct & $8.75 \pm 0.51$ & 4.16 & $1.7(1994)$ & $22.3(1976)$ & $10.04 \pm 0.19$ & 1.54 & $6.06(1992)$ & $13.11(1984)$ \\
Nov & $8.92 \pm 0.64$ & 5.25 & $1.3(1939)$ & $34.8(1985)$ & $4.29 \pm 0.18$ & 1.50 & $0.61(1976)$ & $8.78(1931)$ \\
Dec & $10.01 \pm 0.50$ & 4.03 & $3.3(1965)$ & $24.4(1990)$ & $-1.10 \pm 0.29$ & 2.38 & $-6.84(1963)$ & $4.11(1984)$ \\
\hline Growing & $12.18 \pm 0.27$ & 2.22 & $6.1(1991)$ & $18.4(1956)$ & $17.44 \pm 0.13$ & 1.05 & $14.12(1992)$ & $20.04(1934)$ \\
Season & & & & & & & & \\
Spring & $11.51 \pm 0.33$ & 2.64 & $6.7(1941)$ & $18.9(1967)$ & $8.30 \pm 0.13$ & 1.07 & $5.76(1989)$ & $10.54(1985)$ \\
Summer & $12.88 \pm 0.34$ & 2.75 & $6.2(1991)$ & $18.5(1956)$ & $19.13 \pm 0.14$ & 1.16 & $14.94(1992)$ & $22.09(1934)$ \\
Fall & $9.19 \pm 0.27$ & 2.21 & $4.4(1953)$ & $16.5(1985)$ & $9.97 \pm 0.13$ & 1.04 & $7.32(1976)$ & $13.21(1931)$ \\
Winter & $10.2 \pm 0.31$ & 2.55 & $5.7(1980)$ & $15.7(1950)$ & $-2.30 \pm 0.18$ & 1.46 & $-6.30(1963)$ & $0.85(1932)$ \\
\hline
\end{tabular}

\footnotetext{
${ }^{\mathrm{T}}$ Standard deviation. ${ }^{2}$ Minimum value. ${ }^{3}$ Maximum value.

${ }^{4}$ Standard error (standard deviation of the mean). ${ }^{5}$ Growing season: May through September.

Values in bracket are the years in which the particular event occurred.
}

\footnotetext{
${ }^{1}$ The regression equations in Table 4.6 were used to estimate monthly means for temperature and monthly totals for precipitation for the period 1931 to 1972.
} 
Table 4.8. Correlations between annual (A_) and growing season $\left(\mathrm{G}_{-}\right)$Palmer Drought Severity Index (PDSI), temperature (TEMP) and precipitation (PCP).

\begin{tabular}{llllll}
\hline & A_PDSI & G_PDSI & A_TEMP & G_TEMP & A_PCP \\
\cline { 2 - 6 } G_PDSI & $0.95^{* *}$ & & & & \\
A_TEMP & -0.10 & -0.14 & & & \\
G_TEMP & -0.16 & -0.21 & $0.80^{* *}$ & & \\
A_PCP & $0.67^{* *}$ & $0.71^{* * *}$ & -0.06 & -0.18 & \\
G_PCP & $0.45^{* *}$ & $0.61^{* * *}$ & -0.17 & -0.23 & $0.69^{* *}$ \\
\hline
\end{tabular}

Significant at $\mathrm{p}<0.001$.

Table 4.9. Drought and wet years based on growing season mean PDSI.

\begin{tabular}{cccccc}
\hline & \multicolumn{2}{c}{ Drought years } & \multicolumn{2}{c}{ Wet years } \\
\hline Year & $\begin{array}{l}\text { Growing } \\
\text { season } \\
\text { mean PDSI }\end{array}$ & $\begin{array}{l}\text { Growing season } \\
\text { total precipitation } \\
\text { (\% deviation } \\
\text { from average) }\end{array}$ & Year & $\begin{array}{l}\text { Growing } \\
\text { season } \\
\text { mean PDSI }\end{array}$ & $\begin{array}{l}\text { Growing season } \\
\text { total precipitation } \\
\text { (\% deviation } \\
\text { from average) }\end{array}$ \\
\hline 1966 & -4.00 & $44.55(-27)$ & 1996 & 4.22 & $53.76(-12)$ \\
1988 & -2.65 & $53.34(-13)$ & 1994 & 3.53 & $69.32(13)$ \\
1947 & -2.61 & $70.76(16)$ & 1989 & 3.09 & $72.97(19)$ \\
1959 & -2.51 & $44.08(-28)$ & 1956 & 3.00 & $92.19(51)$ \\
1953 & -2.42 & $41.30(-32)$ & 1980 & 2.67 & $72.64(19)$ \\
1991 & -2.33 & $30.70(-50)$ & 1979 & 2.40 & $72.64(19)$ \\
1969 & -2.27 & $58.71(-4)$ & 1945 & 2.35 & $64.13(5)$ \\
1965 & -2.09 & $41.70(-32)$ & 1950 & 2.34 & $62.90(3)$ \\
& & & 1974 & 2.14 & $73.58(20)$ \\
& & & 1990 & 2.14 & $71.93(18)$ \\
\hline
\end{tabular}

\footnotetext{
${ }^{1}$ Values in bracket are deviations (in percent) of growing season precipitation from the long-term average $(61.12 \mathrm{~cm})$. For example -27 indicates that the growing season total precipitation in 1966 was $27 \%$ below the long-term average.
} 


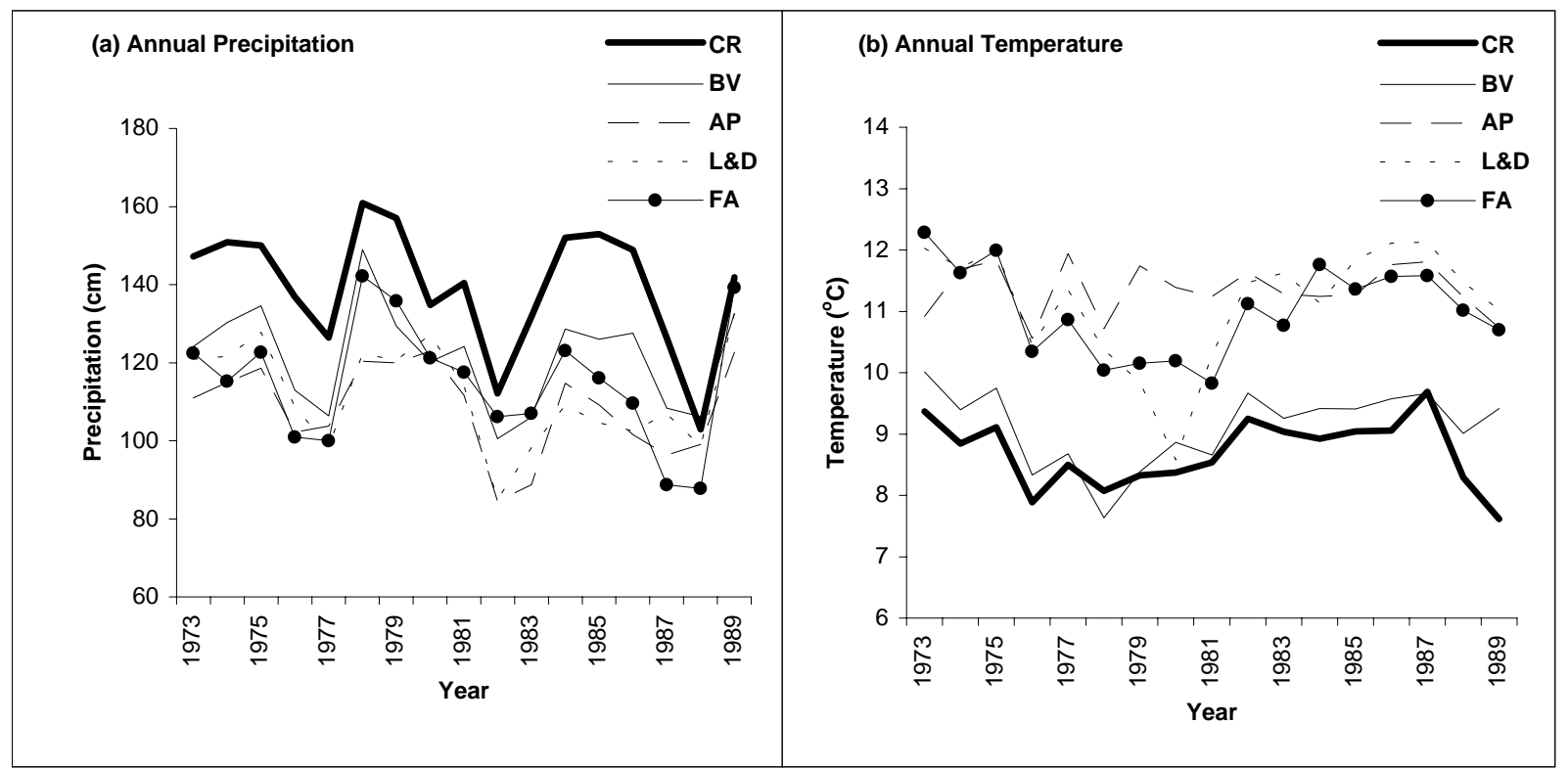

Figure 4.1. The pattern of annual precipitation and temperature at five weather stations ${ }^{1}$ for the common period (1973-1989).

${ }^{1}$ Stations: CR (Coopers Rock), BV (Brandonville), AP (Morgantown Airport), L\&D (Morgantown Lock and Dam), and FA (Fairmont). 


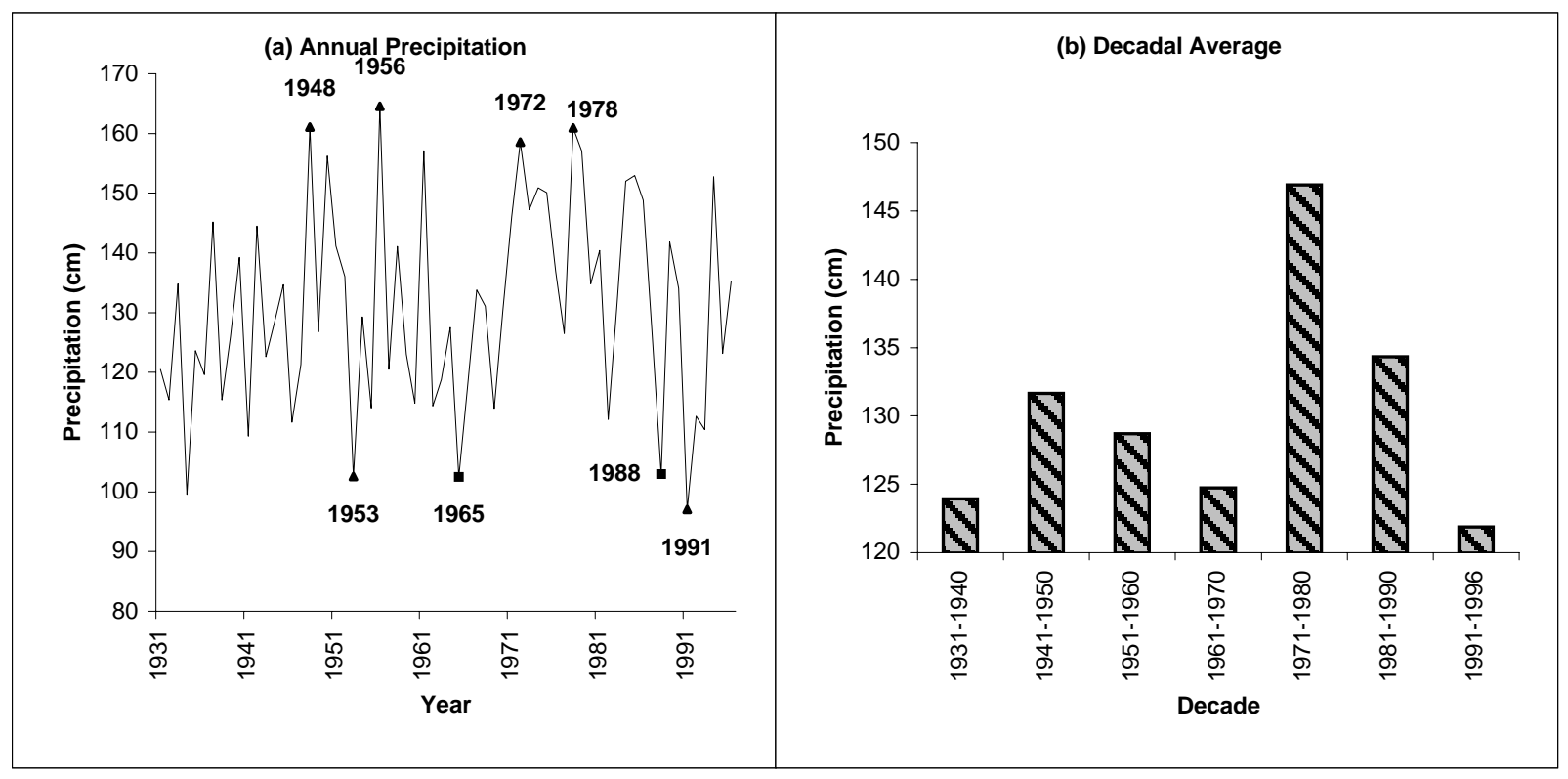

Figure 4.2. The pattern of estimated (1931-1972) and actual (1973-1996) precipitation at Coopers Rock weather station:(a) annual precipitation and (b) average precipitation by decade. Years with abnormally high and low precipitation are indicated.

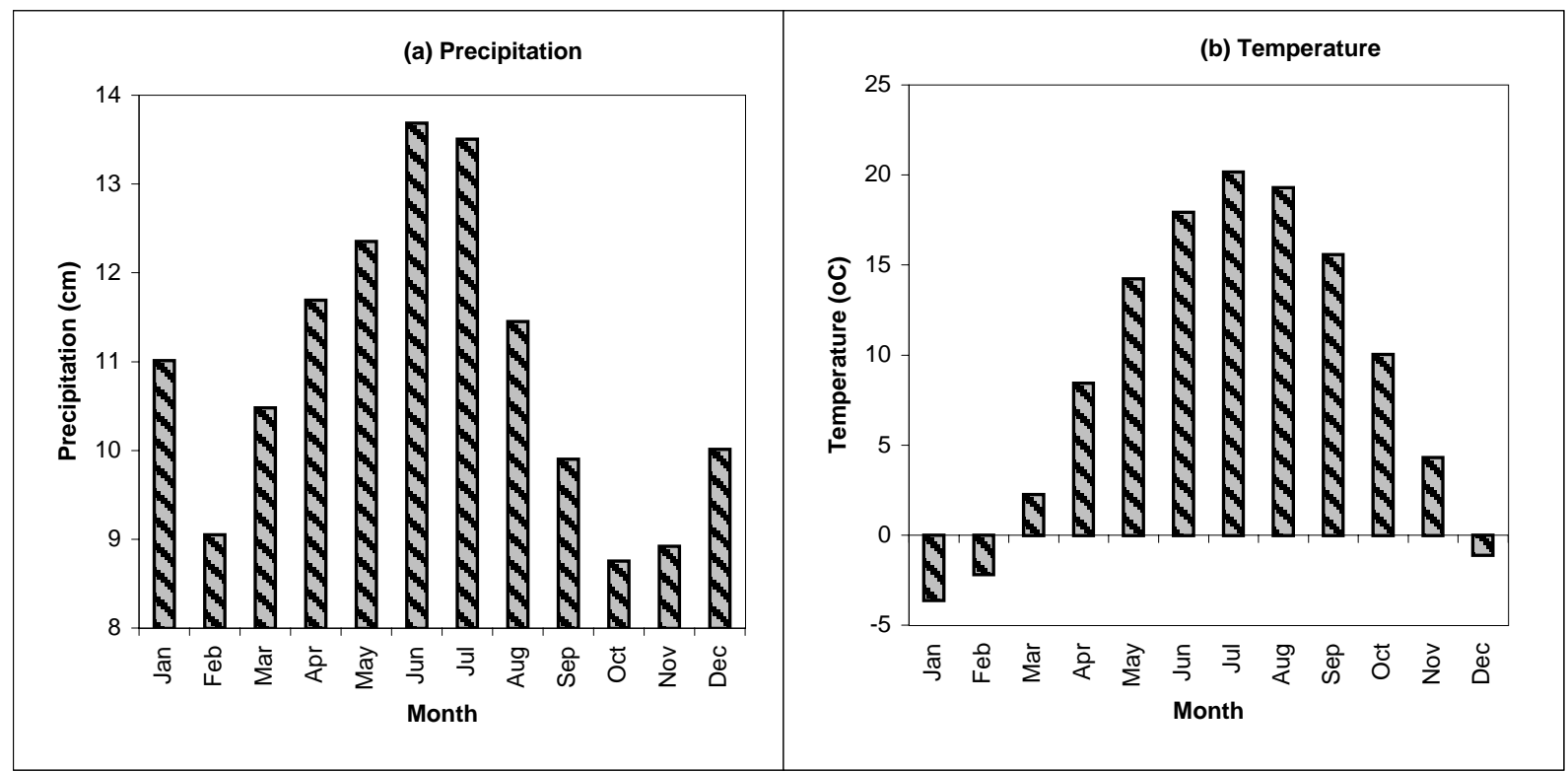

Figure 4.3. The distribution of monthly precipitation and temperature at Coopers Rock weather station for the period 1931 to 1996. 


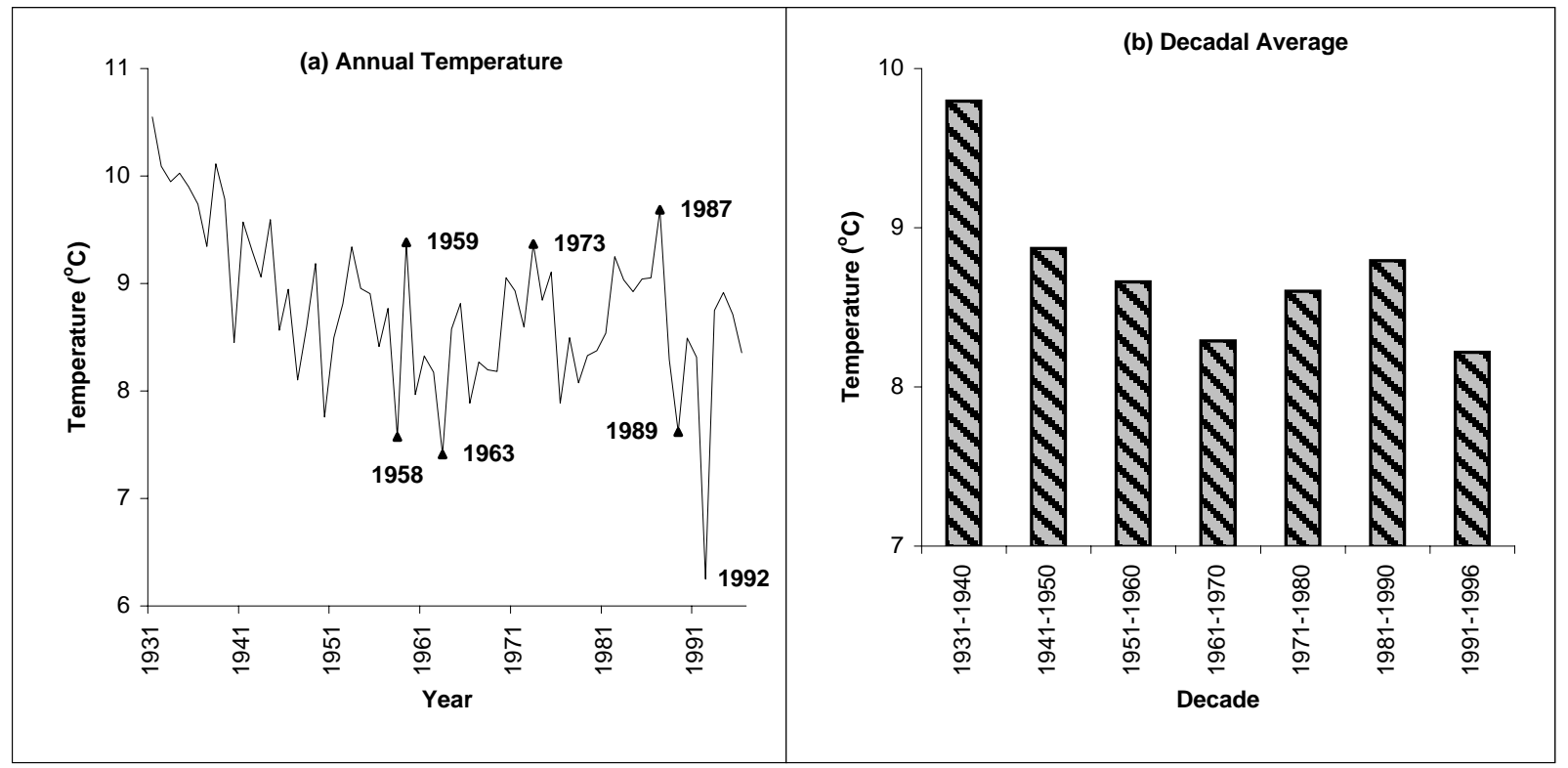

Figure 4.4. Pattern of estimated (1931-1972) and actual (1973-1996) air temperature at Coopers Rock weather station: (a) annual temperature and (b) average temperature by decade. Years with high and low temperatures are indicated.

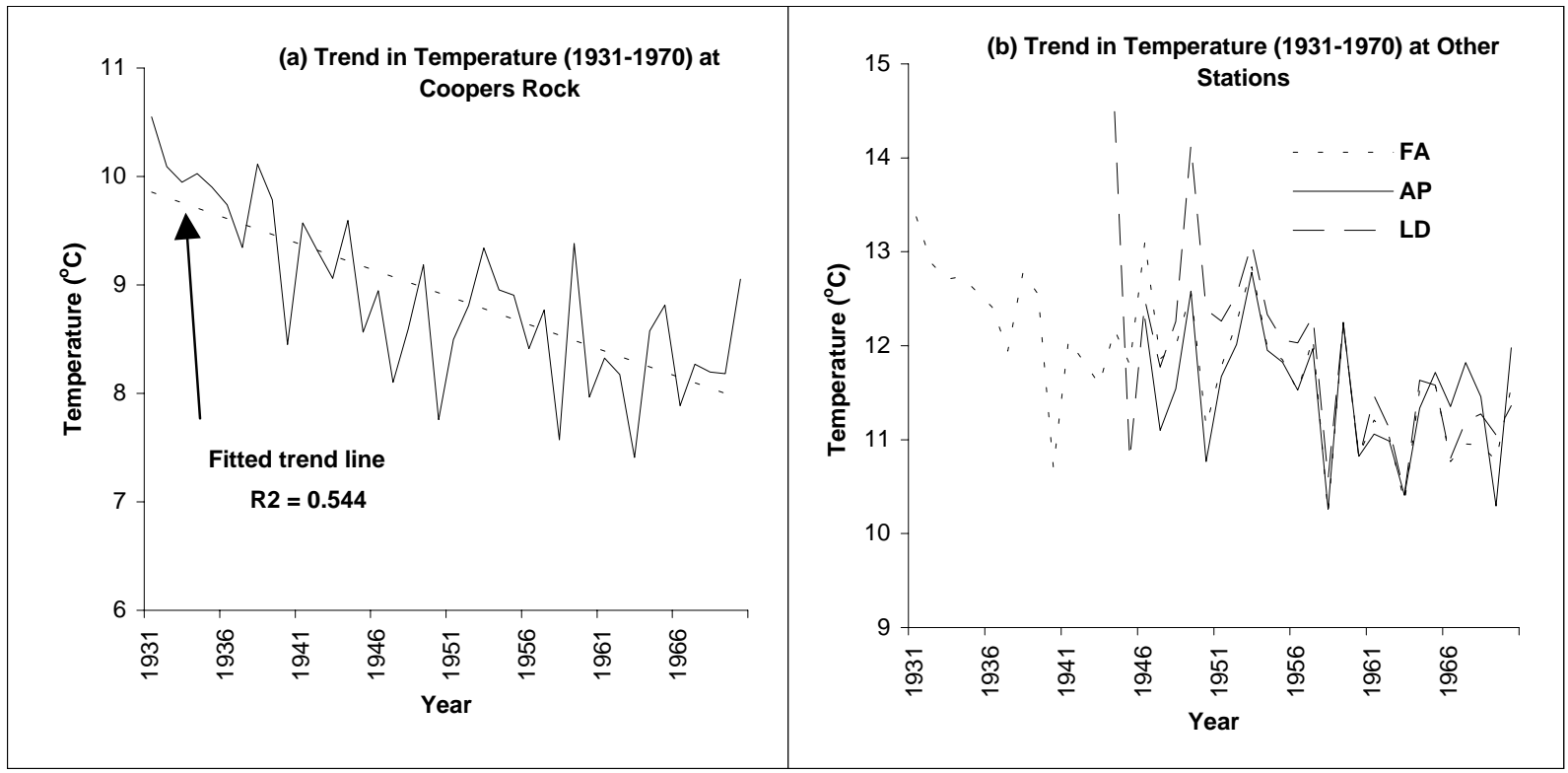

Figure 4.5. Trend in estimated annual temperature at Coopers Rock (1931-1970), the fitted trend line (a), and the pattern of actual air temperature at Morgantown Airport (AP), Morgantown Lock and Dam (LD), and Fairmont (FA) weather stations (1931-1970). 


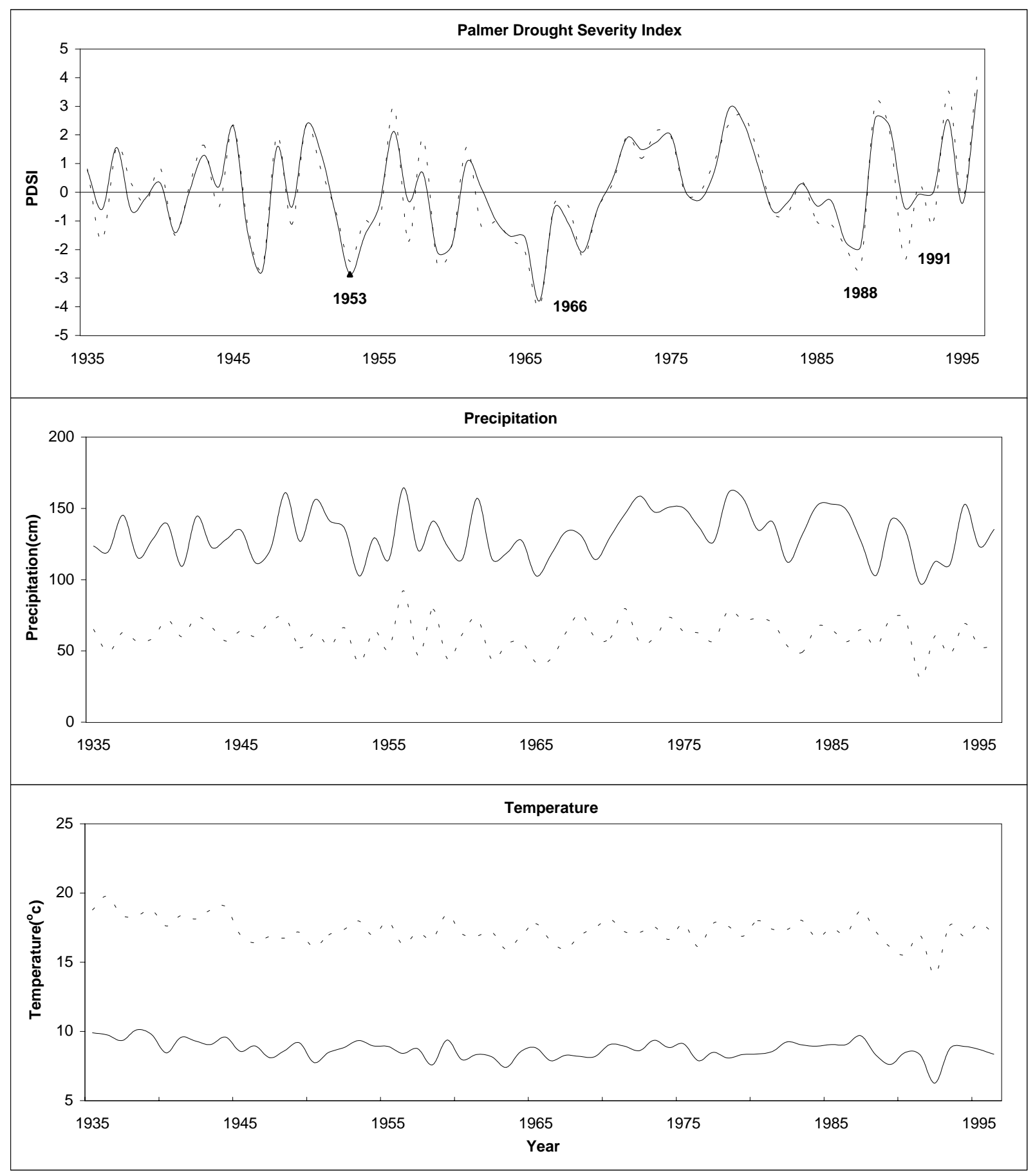

Figure 4.6. The Pattern of annual (solid lines) and growing season (dashed lines) Palmer Drought Severity Index, precipitation $(\mathrm{cm})$ and temperature $\left({ }^{\circ} \mathrm{c}\right)$. Drought years based on growing season PDSI are indicated. 


\section{CHAPTER 5: STUDY V}

\section{IMPACT OF CLIMATE ON RADIAL GROWTH OF TREES GROWING ON MESIC AND XERIC ASPECTS}

\subsection{Introduction}

This chapter uses dated ring-width data to examine spatial and temporal variation in growth, and the relationship between radial growth and climate. The chapter examines two broad issues. First, spatial and temporal trends in growth are evaluated using the variation in radial and basal area growth with topographic aspect over time. Secondly, the radial growth response to climate is assessed by examining the relationship between annual radial increment and monthly climatic variables.

\subsection{Methods}

Trees from four species, yellow-poplar, red oak, chestnut oak, and red maple, were sampled from north, east, west and southwest facing slopes at the study site. Ringwidths measured from discs or cores taken at breast height (1.4 $\mathrm{m}$ above ground) were exclusively used as a source of data in this study. For each tree, ring-widths were measured along two axes. These two sets of measurements were considered as replicates of the same process and hence were averaged. For most analyses, trees sampled at the north and east aspects were combined into one group (mesic site) and those sampled at the west and southwest aspects were combined into another group (xeric site). Such grouping was biologically meaningful due to similarities in microclimatic characteristics 
in each pair of aspects and also increases the sample size to facilitate sound statistical analyses.

Mean ring-width and basal area increment (BAI) for each species were obtained by calculating mean ring-width and BAI for each ring on each tree and then averaging these mean values for all trees of the same species. ANOVA and t-test procedures were used to determine if there were significant differences in mean ring-width and basal area increment between sites and among species. Year-to-year variability in growth of each species between the mesic and xeric sites was compared using the coefficient of variation (CV) of BAI. The temporal patterns of mean ring-width and BAI were examined to determine if years with low and high growth are associated with variations in growing season precipitation.

To evaluate the effect of drought on radial growth of the species, three moderate (1953, 1988 and 1991) and one extreme (1966) drought years were selected. These years have the smallest annual and growing season Palmer Drought Severity Index (PDSI) (see Figure 4.6, Chapter 4). Paired t-tests were then used to compare growth in drought years with average growth and growth in the prior year. To understand rate of recovery, growth in the year following drought (post-drought growth rate) was compared with the growth in the year prior to drought (pre-drought growth rate). Finally, to determine if radial growth rate was suppressed beyond the year of drought, paired t-tests were performed comparing the mean growth for the five years previous to and the five years following each drought (Rubino and McCarthy 2000, Abrams et.al. 1998). Prior to these analyses, the ring-width series of each tree was transformed into ring-width index (RWI) by fitting the modified negative exponential model and calculating RWI as the ratio of actual to 
expected growth. Hence, the measure of growth used to evaluate drought effects is the ring-width index, a standardized measure of growth that is not sensitive to tree-size. This transformation is thoroughly illustrated in Chapters 6 and 7.

Relationships between the species ring-width index values and growing season precipitation and Palmer Drought Severity Index (PDSI) were examined using Pearson's product-moment correlation. To explore the relationship between radial increment and monthly climatic variables, the method of principal components regression was used.

\subsection{Objectives}

The main objectives of this chapter were: (1) to identify if there are extended growth declines associated with adverse climate, (2) to determine how severe droughts affected radial growth rates, (3) to examine the nature and strength of the relationship between radial increment and monthly climatic variables, (4) to test if response to climate interact with topographic aspect, and (5) to estimate the percentage of variation in annual radial growth explained by climate $\left(\mathrm{R}_{\text {climate }}^{2}\right)$.

\subsection{RESULTS}

\subsubsection{SPATIAL AND TEMPORAL TRENDS IN GROWTH}

\section{A. Age Distribution of Sampled Trees}

About 80 percent of the trees sampled at both the mesic and xeric aspects reached their coring height consistently around 1926-1940 (Figure 5.1). The stands at both the mesic and xeric sites were even-aged, originating around the mid 1920's. Stand initiation lasted from 1922 to 1946 and peaked between 1927 and 1931 (Figure 5.1). Examination of the data in Table 5.1 shows that the sampled trees were relatively young, with a mean age of 61-years. The regeneration pattern (Figure 5.1) suggests that there was a major 
stand-replacing disturbance at the study area around the mid 1920's. The extent of the disturbance was inferred from the fact that all species, both shade tolerant and shade intolerant, regenerated simultaneously suggesting that the disturbance was a stand replacing disturbance rather than a minor disturbance (e.g. tree falls) that usually favor the recruitment of shade tolerant species. It seems clear that the site was regenerated around the year of 1925. According to the site history, the area was logged for timber from 1912 to 1930 (Carvell 1973).

The stands at both mesic and xeric aspects had very few trees that were older than 70-years. Red maple entered the stand for over 25 years but yellow-poplar, northern red oak and chestnut oak were only recruited for about 10-15 years (Figure 5.1). Different tree species require different minimal light intensities to carry on photosynthesis and differ in their tolerances to light. Seedlings of species that require high light intensities (e.g., yellow-poplar) can become established in a site only after disturbance and opening of the canopy or in early successional stages when there is sufficient light to carry on photosynthesis. The more shade tolerant species (e.g. red maple) can establish themselves at any time, though they usually become established later in successional sequence (Lorimer 1984, Oliver and Larson 1996). The regeneration pattern in Figure 5.1 does seem to reflect this phenomenon.

For all species, except chestnut oak, trees sampled at the mesic site had higher mean dbh than those at the xeric site (Table 5.1). At the study site, chestnut oak was extremely infrequent at the north and east aspects and chestnut oak trees sampled at the mesic site had small diameters and were all located near a ridge top. 
On all stands red maple was the youngest and smallest compared to other three species (Table 5.1). In even-aged stands that develop after clearcutting, red maple tends to become quickly overtopped by faster growing species such as yellow-poplar, so that in mature stands it is not well represented in the canopy layer (Oliver and Larson 1996). Yellow-poplar was the largest in average diameter at coring height (Table 5.1). For the four main species considered in the study, stem-analyzed trees averaged 3-4 years to reach breast height (Table 5.1). Generally, the number of years elapsed to reach coring height was highest for red maple.

The time interval covered by coring of most tree species was 1935 to 1996 (Figure 5.1). Hence, the period 1935 to 1996 is considered as the study period and ringwidth and climate data during this period constitute the two main sources of data for this study.

\section{B. Spatial Variability in Radial and Basal Area Growth}

Radial and basal area growth patterns of the species, for the whole study period (1935-1996), are illustrated in Figures 5.2 and 5.3. The radial and basal area growth patterns in Figures 5.2 and 5.3 were derived by averaging data from all trees. The statistics of growth are summarized in Table 5.2.

All species, except chestnut oak, showed higher mean ring-width and basal area increment at the mesic site (Table 5.2). Significant differences in growth rates between the mesic and xeric sites were observed for all species except northern red oak (Table 5.2). At the mesic site, radial growth averaged 3.61, 2.41, 1.44, and $1.52 \mathrm{~mm} / \mathrm{yr}$ for yellow-poplar, red oak, chestnut oak, and red maple respectively. Yellow-poplar was the fastest growing species at this site with mean radial increment significantly higher than 
the other three species. At the xeric site, however, mean radial growth of yellow-poplar (2.03 $\mathrm{mm} / \mathrm{yr})$ was not significantly different from that of red oak $(2.33 \mathrm{~mm} / \mathrm{yr})$ and chestnut oak $(2.20 \mathrm{~mm} / \mathrm{yr})$ but was significantly higher than red maple $(1.25 \mathrm{~mm} / \mathrm{yr})$ (Table 5.2). At both sites red maple grew significantly more slowly than yellow-poplar and red oak.

The largest difference in growth rates between the mesic and xeric sites occurred for yellow-poplar, a species which has a defined aspect preference and the smallest occurred for northern red oak, a species that is a generalist with respect to its aspect preference. Unlike the other three species, chestnut oak showed a significantly larger mean ring-width and basal area increment at the xeric site. This is possibly due to a competitive advantage of chestnut oak at the xeric site (Hicks 2001, personal communication). This may have been an artifact of the sample of trees collected but it is quite possibly a real effect of aspect. For example, xeric sites typically carry a lower tree stocking level than mesic sites. Chestnut oak trees which favor xeric sites would have more room for crown expansion, have greater dbh growth on xeric sites. The data indicate that growth rates of yellow-poplar, red maple and chestnut oak showed larger aspect-induced spatial variability compared to northern red oak.

Year-to year variability in growth as measured by $\mathrm{CV}$ of BAI shows that all species exhibited larger variability at the xeric site (Table 5.2). Largest differences in CV of BAI between the mesic and xeric sites were observed for yellow-poplar.

\section{Temporal Patterns of Growth}

Radial growth: Examination of the radial growth patterns of the species (Figure 5.2) shows similarities and differences in annual growth. Sharp declines in radial growth 
of all species were apparent in 1953, 1988 and 1991, which proved to be good years to cross-date tree-ring series. Increased growth rate (peaks) were observed for most species in 1958, 1980, and 1992. The depressions and peaks in radial growth were present for each species at the mesic and xeric sites indicating that regardless of aspect, the trees were responding similarly to common environmental factors.

The marked declines in growth around years 1953, 1966, 1988, and 1991 are related to low precipitation. Examination of climatic data from the vicinity of the study site indicates that the annual precipitation for those years were $25-30 \%$ below the longterm average. Sharp declines in growth in 1988 and in the mid 1960's were also reported in other dendroclimatic studies (Cook and Jacoby 1977, Rubino and MaCarthy 2000). Growth spikes in 1958, 1980 and 1992 are also associated with increased amount of precipitation that occurred in those years. Growing season precipitation in 1958 and 1980 were $20-30 \%$ above the long-term average. In 1992 growing season precipitation was average but the increase in growth from 1991 to 1992 is due to the relative effect of higher precipitation in 1992 compared to the previous year (1991). Growing season precipitation in $1992(61 \mathrm{~cm})$ was twice larger than that in $1991(31 \mathrm{~cm})$.

Basal area growth: Basal area growth of all species showed an increasing pattern from 1935 to late 1950's, with a sharp decline in 1953 and a sharp increase in 1958 (Figure 5.3). From 1960 to the end of the time series, basal area growth of yellow-poplar showed a more fluctuating pattern while the other three species showed a consistent increasing pattern. The most striking feature is that BAI of yellow-poplar declined for a ten-year period, from 1958 to 1968, with a short period of accelerated growth form 19621964. 
To better understand changes in growth trends, basal area growth of each species was analyzed by 5-year intervals (Figures 5.4). The plots in Figure 5.4 indicate that yellow-poplar was the only species that showed a pronounced decline in growth from late 1950's to late 1960's.

In the early 1960's, all species showed 10-15\% smaller growth relative to late 1950's but the highest decline especially for yellow-poplar was observed in the late 1960's. Compared to mean BAI in late 1950's, BAI of yellow-poplar in the late 1960's was 32 and $38 \%$ smaller at the mesic and xeric sites respectively. Red maple showed, on average, a 5-8\% decline in BAI at both sites. Growth declines in the late 1960's was not observed for the two oak species. The decline in growth from late 1950s to late 1960's is evidently associated with declining precipitation during this period (Figure 5.5). Precipitation decreased from late 1950 s to late 1960 s. The recovery following the decline is associated with the increased precipitation in the early 1970's (Figure 5.5).

Three periods characterized with substantial increase in BAI compared to the previous five years include the late 1950's, the early 1970's, and early 1980's. These spikes are more noticeable on yellow-poplar than the other three species.

\section{Drought Effects}

The majority of the species showed below-average growth at both sites in all drought years analyzed (Table 5.3(a)). However, significant below-average growth in all drought years analyzed was observed only for yellow-poplar. Northern red oak exhibited significant declines only in 1988 and 1991 but there were no significant declines for chestnut oak in any of the drought years analyzed. For yellow-poplar, the amount of 
decline was generally higher at the xeric site except in the extreme drought year (1966) in which case the decline at the mesic site was larger (Table 5.3(a)).

How did growth rate in drought years compare to pre-drought levels? In all drought years analyzed, yellow-poplar at both the mesic and xeric sites showed significantly smaller growth compared to its pre-drought growth rate (Table 5.3(b)). The decrease in growth during drought years relative to pre-drought growth rates ranged from 27 to $50 \%$ with those at the xeric site experiencing the highest percent reduction (except in 1996). Red oak and chestnut oak showed significant drought-induced reductions in 1988 (both sites) and 1953 (mesic site) compared to pre-drought levels. Red maple growth in 1953 (both sites) and 1991 (xeric site) were significantly smaller compared to pre-drought levels.

Growth comparisons before and after droughts (Table 5.3(c)) revealed that all species at both aspects grew more slowly following the drought in 1953. Growing season precipitation in $1953(41 \mathrm{~cm})$ was $32 \%$ below normal. Yellow-poplar was the only species that experienced statistically significant growth reductions at both sites following the drought in 1953 and 1988. For the recovery period immediately following the extreme drought in 1966, all species, except yellow-poplar, showed higher growth rates compared to pre-drought levels. That is, for red oak, chestnut oak, and red maple, radial growth in 1967 was larger than that in 1965 which was also another moderate drought year with growing season PDSI of -2.1. All species recovered following the drought in 1991. This was probably because the growing season precipitation in $1992(61 \mathrm{~cm})$ was twice that in $1991(31 \mathrm{~cm})$. 
Average growth in the 5-year period following drought events was not significantly smaller for any species or site combination than the corresponding predrought growth rates (Table 5.3(d)). This indicates that drought effects at the study site were short lived. The only exception is a $20 \%$ smaller growth in the 5-year period following the 1988 drought for yellow-poplar but it was not significant.

\section{E. Summary of Results}

Among the four species, yellow-poplar showed declining basal area growth from 1958 to 1968 (Figure 5.3). The decline of growth during this period is parallel with the pattern of precipitation and PDSI (Figure 5.5). That is, the sharp decline in basal area growth of yellow-poplar from late 1950's through late 1960's (Figure 5.4) corresponds to a sharp decline in precipitation and PDSI during the same time period (Figure 5.5). This suggests that the decline is most likely linked to below average precipitation.

In the late 1960's, basal area growth of yellow-poplar was 30-40\% smaller compared to its peak growth in the late 1950's. Consecutive droughts, a moderate drought in 1965 and an extreme drought in 1966, seem to be the casual factor for the reduced growth rate during this period.

Generally, all species experienced reduced growth rates in the 1960's but the effect on yellow-poplar was the greatest. The apparent one to one correspondence between the growth of yellow-poplar and precipitation indicate that yellow-poplar is more sensitive to moisture than the other three species. This can also be seen from the high correlation between radial growth of yellow-poplar and growing season precipitation (Table 5.4). It was very interesting that in such mesophytic forests, yellow-poplar was the only species substantially affected by periods of lower than average precipitation. 
Growth declines in 1960's, especially from 1961 to 1966, have been reported by other researchers in northeastern United States (e.g., Cook and Jacoby 1977, Lorimer 1984). The subsequent recovery of growth rates in the 1970's (Figure 5.4) suggests that the wetter than average condition of this decade is responsible for this (Figure 5.5). The strong recovery in the early 1970's suggests that the decline in the previous years was temporary. In general, in this study, temporary periods of declining growth coincided with periods of documented below-average precipitation and there were no obvious unexplained growth declines.

This study revealed several trends in the ring-width response to droughts. Yellowpoplar showed larger drought induced growth decreases on xeric sites except during the extreme drought year of 1966 where the opposite was true. Due to the development of larger above-ground biomass of trees growing on north east aspects, these trees may become more stressed when subjected to drought than trees on southwest aspects which have a more balanced root: shoot ratio (Hicks 2001, personal communication). This may explain why yellow-poplar trees experienced larger drought-induced growth decrease at the mesic site during the extreme drought year of 1966.

For red oak, chestnut oak and red maple, there was no clear trend in droughtinduced growth decrease between the mesic and xeric aspects. For example, in 1953 these three species showed higher drought induced growth decrease at the mesic site while in 1988 red oak and red maple showed lager decrease at the xeric site.

The ratio of growth in wet years to dry years (Figure 5.6) also suggest a clear drought response-site interaction for yellow-poplar. The data shows that relative to growth during dry years, growth of yellow-poplar in moist years was 30\% larger at the 
mesic site and $68 \%$ larger at the xeric site. Red oak and chestnut oak showed negligible difference between the mesic and xeric sites.

Comparison of pre and post drought growth rates of the species generally indicate that the more conservative species (red oak, chestnut oak and red maple) tend to recover their growth following drought faster than yellow-poplar but when precipitation in the year following the drought is higher (example 1992) the increase in growth rate of yellow-poplar is much larger than the other three species. Generally, the two oak species were less affected by drought compared to yellow-poplar, and red maple was intermediate in response.

Drought and drought-related growth decline in mesic forests of the eastern US have been shown to last for only a few years (Cook and Jacoby 1977) and growth recovery is relatively rapid (Orwig and Abrams 1997). For example, reviewing a 374year chronology of white oak in Ohio, Rubino and McCarthy (2000) found that only one of the ten severe droughts resulted in an extended (5-years) growth decline. In the current study none of the species showed significant growth declines 5-years following drought events. The longest drought effect observed was for yellow-poplar where mean growth three years following the drought in 1988 was $33 \%$ smaller than the pre-drought threeyear average.

It is interesting to note that although 1988 is classified as a moderate drought year $(\mathrm{PDSI}=-2.65)$ compared to 1966 classified as an extreme drought year $(\mathrm{PDSI}=-4.00)$, the magnitude and frequency of growth declines of the species (especially yellow-poplar) was higher for the drought that occurred in 1988. In addition, growing season precipitation in $1988(53 \mathrm{~cm})$ was higher than in $1966(45 \mathrm{~cm})$. Growth declines in 1988 
have been reported in other dendroclimatic studies (e.g., Abrams et al. 1997, Rubino and McCarthy 2000). The two oak species also showed large declines in 1988 compared to 1987 (Table 5.3) but their growth following the 1988 drought was not reduced as much as that of yellow-polar compared to pre-drought rates. This supports the conclusion that although drought is a major factor controlling radial growth of trees, it is not the sole factor. Other factors such as temperature, species, site interactions and tree age may confound the effects of drought in any given year and may serve to amplify or diminish its impact. 
Table 5.1. Summary statistics (mean values) of trees sampled for tree-ring analyses.

\begin{tabular}{|c|c|c|c|c|}
\hline Species and aspect & $\bar{n}$ & $\begin{array}{l}\text { Diameter } \\
(\mathrm{cm}) \pm \mathrm{SE}\end{array}$ & $\begin{array}{l}\text { Age } \\
(\text { years })^{1}\end{array}$ & $\begin{array}{l}\text { Years to } \\
\text { height }^{2}(\mathrm{r}\end{array}$ \\
\hline \multicolumn{5}{|l|}{ Yellow-poplar } \\
\hline Mesic & 38 & $39.5 \pm 3.0$ & 62.6 & $2.1(2-4)$ \\
\hline Xeric & 27 & $30.3 \pm 2.8$ & 62.0 & $3.2(3-5)$ \\
\hline
\end{tabular}

Red oak

$\begin{array}{lllll}\text { Mesic } & 36 & 28.9 \pm 2.3 & 64.6 & 3.0(3-4) \\ \text { Xeric } & 34 & 26.7 \pm 1.9 & 60.9 & 3.0(3-5)\end{array}$

Chestnut oak

$\begin{array}{lllll}\text { Mesic } & 11 & 17.8 \pm 0.9 & 60.2 & 3.0(3-5) \\ \text { Xeric } & 39 & 23.0 \pm 1.7 & 61.8 & 3.0(3-4)\end{array}$

Red maple

$\begin{array}{lllll}\text { Mesic } & 40 & 18.8 \pm 0.9 & 58.9 & 4.0(3-8) \\ \text { Xeric } & 27 & 15.5 \pm 0.4 & 57.5 & 4.0(4-7)\end{array}$

\footnotetext{
${ }^{1}$ Tree age refers to the number of annual rings at breast height. ${ }^{\times}$

${ }^{2}$ The number of years required for growing to a height of $1.4 \mathrm{~m}$. This is the difference between the number of annual rings at stump height and breast height.
}

${ }^{\times}$On average, the number of annual rings at breast was 61 . Assuming 3 to 4 years to grow to breast height level, the trees at the watershed are about 64 years-old. 
Table 5.2. Mean radial and basal area increment by species and aspect (1935-1996).

\begin{tabular}{|c|l|llll|llllll|}
\hline & & \multicolumn{5}{|c|}{$\begin{array}{c}\text { Radial Increment } \\
(\mathbf{m m} / \mathbf{y r} .)\end{array}$} & \multicolumn{5}{c|}{$\begin{array}{c}\text { Basal Area Increment } \\
\left(\mathbf{c m}^{2} / \mathbf{y r} .\right)\end{array}$} \\
\hline $\begin{array}{c}\text { Species and } \\
\text { aspect }\end{array}$ & $\begin{array}{l}\text { d.b.h. } \\
(\mathrm{cm})\end{array}$ & Mean & $\mathrm{SD}^{2}$ & Min $^{3}$ & $\mathrm{Max}^{4}$ & Mean & SD & Min & Max & $\mathrm{CV}^{5}$ \\
\hline Yellow-poplar & & & & & & & & & & \\
Mesic & 39.5 & $3.61^{\mathrm{a}}$ & 1.32 & 1.67 & 6.82 & $25.3^{\mathrm{a}}$ & 12.0 & 1.38 & 48.0 & 47.3 \\
Xeric & 30.3 & $2.03^{\mathrm{b}}$ & 0.9 & 0.47 & 3.78 & $8.30^{\mathrm{b}}$ & 5.1 & 0.39 & 16.8 & 61.6 \\
Red oak & & & & & & & & & & \\
Mesic & 28.9 & $2.41^{\mathrm{c}}$ & 0.53 & 1.46 & 3.84 & $11.3^{\mathrm{c}}$ & 4.5 & 0.32 & 21.1 & 39.7 \\
Xeric & 26.7 & $2.33^{\mathrm{cb}}$ & 0.40 & 1.42 & 3.19 & $10.6^{\mathrm{cb}}$ & 5.3 & 0.21 & 20.4 & 49.8 \\
Chestnut oak & & & & & & & & & & \\
Mesic & 17.8 & $1.44^{\mathrm{d}}$ & 0.61 & 0.80 & 3.21 & $4.0^{\mathrm{d}}$ & 1.4 & 0.05 & 6.8 & 34.5 \\
Xeric & 23.0 & $2.20^{\mathrm{c}}$ & 0.42 & 1.54 & 3.04 & $9.4^{\mathrm{c}}$ & 4.3 & 0.18 & 17.4 & 46.5 \\
Red maple & & & & & & & & & & \\
Mesic & 18.8 & $1.52^{\mathrm{d}}$ & 0.51 & 0.93 & 2.75 & $4.5^{\mathrm{d}}$ & 1.3 & 0.13 & 9.4 & 30.6 \\
Xeric & 15.5 & $1.25^{\mathrm{e}}$ & 0.39 & 0.76 & 2.21 & $3.1^{\mathrm{e}}$ & 1.4 & 0.12 & 7.1 & 44.3 \\
\hline
\end{tabular}

Means with the same letter are not significantly different (alpha 0.05).

Due to heterogeneous variance in basal area increment between the mesic and xeric aspects, ANOVA was performed on log-transformed values.

${ }^{1}$ Diameter at breast height

${ }^{2}$ Standard deviation

${ }^{3}$ Minimum

${ }^{4}$ Maximum

${ }^{5}$ Coefficient of variation of BAI (\%) 
Table 5.3. Percent growth change ${ }^{1}$ in ring-width index (RWI).

\begin{tabular}{|c|c|c|c|c|c|c|c|c|c|}
\hline Species & Aspect & & a) Dro & $\begin{array}{l}\text { ght yea } \\
\text { age }\end{array}$ & & & Dro & $\begin{array}{l}\text { sht yea } \\
\text { year }\end{array}$ & \\
\hline & & 1953 & 1966 & 1988 & 1991 & 1953 & 1966 & 1988 & 1991 \\
\hline Yellow-poplar & Mesic & -36 & -40 & -32 & -26 & -46 & -33 & -38 & -6 \\
\hline & Xeric & -39 & -31 & -42 & -29 & -50 & -27 & -50 & -30 \\
\hline Red oak & Mesic & -21 & -14 & -33 & -26 & -24 & 12 & -34 & -20 \\
\hline & Xeric & -20 & -10 & -38 & -25 & -17 & 10 & -42 & -19 \\
\hline Chestnut oak & Mesic & -9 & -11 & -14 & 6 & -27 & 14 & -39 & 16 \\
\hline & Xeric & -5 & -3 & -8 & 8 & -21 & 9 & -30 & 4 \\
\hline Red maple & Mesic & -18 & -25 & 1 & -8 & -32 & 13 & -4 & -20 \\
\hline & Xeric & -22 & -23 & -8 & -16 & -25 & 13 & -13 & -33 \\
\hline & & & $\begin{array}{l}\text { (c) Pre } \\
\text { Post- }\end{array}$ & $\begin{array}{l}\text { rough } \\
\text { ought } \\
\end{array}$ & & & $\begin{array}{l}\text {-year } \\
\text { ear p }\end{array}$ & $\begin{array}{l}\text { re-drol } \\
\text { t droug }\end{array}$ & \\
\hline & & 1953 & 1966 & 1988 & 1991 & 1953 & 1966 & 1988 & 1991 \\
\hline Yellow-poplar & Mesic & -28 & -18 & -30 & 37 & 11 & 0 & -21 & 13 \\
\hline & Xeric & -47 & -16 & -39 & 27 & -14 & 21 & -22 & 12 \\
\hline Red oak & Mesic & -10 & 14 & 1 & 6 & 0 & 15 & -8 & 10 \\
\hline & Xeric & -7 & 10 & -5 & 11 & -2 & 10 & -11 & 6 \\
\hline Chestnut oak & Mesic & -32 & 44 & -13 & 30 & -13 & 15 & -9 & -5 \\
\hline & Xeric & -13 & 2 & -10 & 7 & 21 & -5 & 3 & -8 \\
\hline Red maple & Mesic & -27 & 21 & 14 & 30 & -22 & 16 & 19 & 17 \\
\hline & Xeric & -22 & 12 & 25 & 25 & -15 & 17 & 9 & 3 \\
\hline
\end{tabular}

${ }^{1}$ Percent growth changes in RWI are calculated as follows:

Drought year vs. average $(\%)=[(\mathrm{M} 1-\mathrm{M} 2) / \mathrm{M} 2]^{*} 100$

Drought year vs. prior year $(\%)=[(\mathrm{M} 1-\mathrm{M} 3) / \mathrm{M} 3]^{* 100}$

Pre-drought vs. post-drought $(\%)=[(\mathrm{M} 4-\mathrm{M} 3) / \mathrm{M} 3]^{*} 100$

5 -year pre-drought vs. 5-year post-drought $=[(\mathrm{M} 6-\mathrm{M} 5) / \mathrm{M} 5]^{*} 100$

where

M1= RWI in the drought year

M2= Average RWI

M3= RWI one year prior to drought

M4= RWI one year after drought

M5= Average RWI of 5-years prior to drought

M6= Average RWI of 5-years after drought

Percent growth changes $<|24|$ were not significant at 5\% level. 
Table 5.4. Correlation coefficients between species mean ring-width index values and growing season precipitation and Palmer Drought Severity Index.

Species and aspect Growing season Growing season

Precipitation PDSI

Yellow-poplar

$\begin{array}{lll}\text { Mesic } & 0.41^{*} & 0.25^{*} \\ \text { Xeric } & 0.59^{*} & 0.27^{*}\end{array}$

Red oak

$\begin{array}{lll}\text { Mesic } & 0.31^{*} & 0.22 \\ \text { Xeric } & 0.35^{*} & 0.26^{*}\end{array}$

Chestnut oak

$\begin{array}{lll}\text { Mesic } & 0.28^{*} & 0.18 \\ \text { Xeric } & 0.33^{*} & 0.22\end{array}$

Red maple

$\begin{array}{lll}\text { Mesic } & 0.20 & 0.23 \\ \text { Xeric } & 0.31^{*} & 0.34^{*}\end{array}$

${ }^{*}$ Coefficients are significant at alpha $=0.05$ level. 


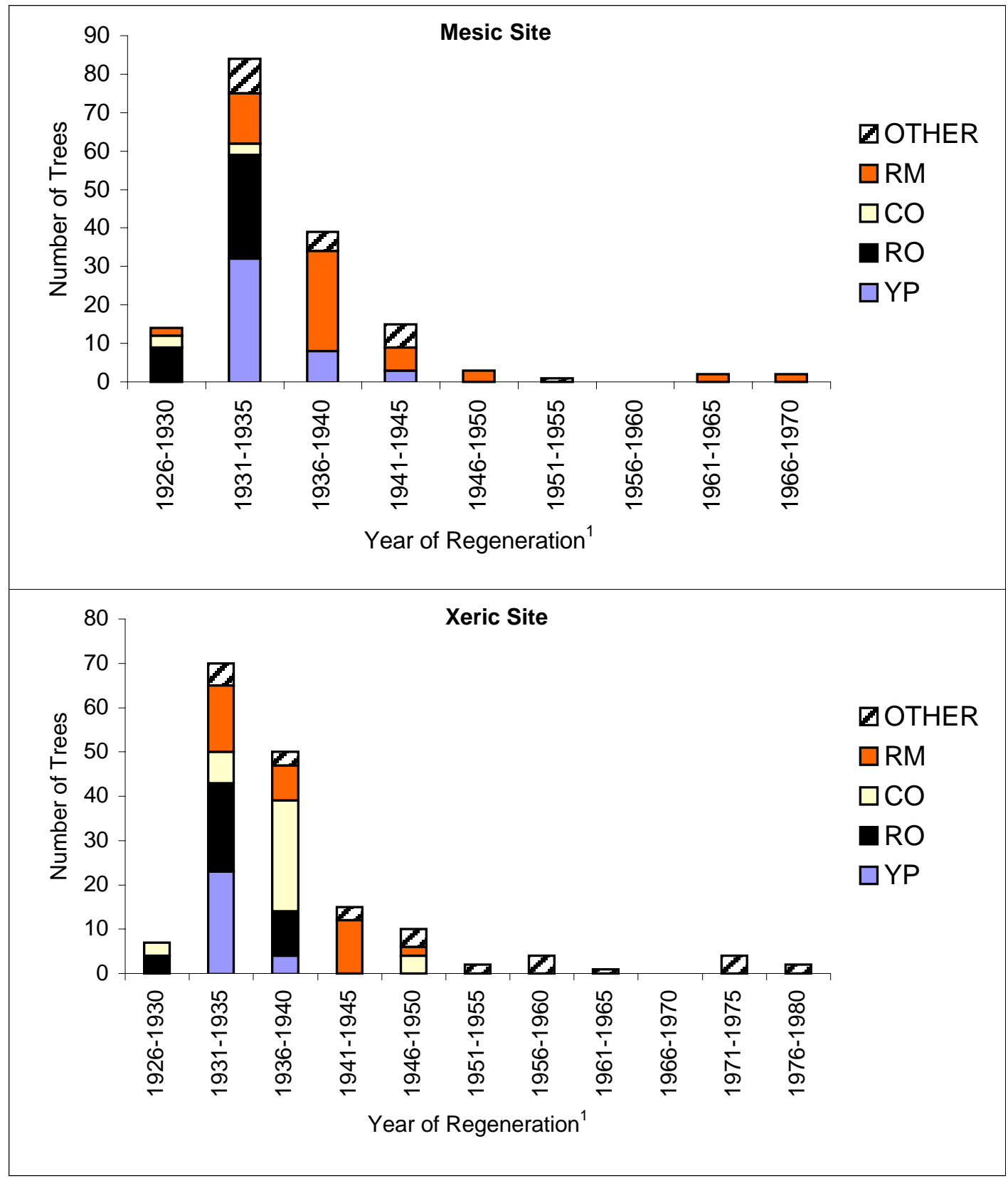

Figure 5.1. Distribution of tree age by species and site.

${ }^{1}$ The calendar year in which the inner most growth-ring at breast height was formed. The actual regeneration year is on average three-four years behind.

OTHER species includes black cherry, black birch, black gum, cucumber tree, scarlet oak, white oak, hickory, and sasafrass. 


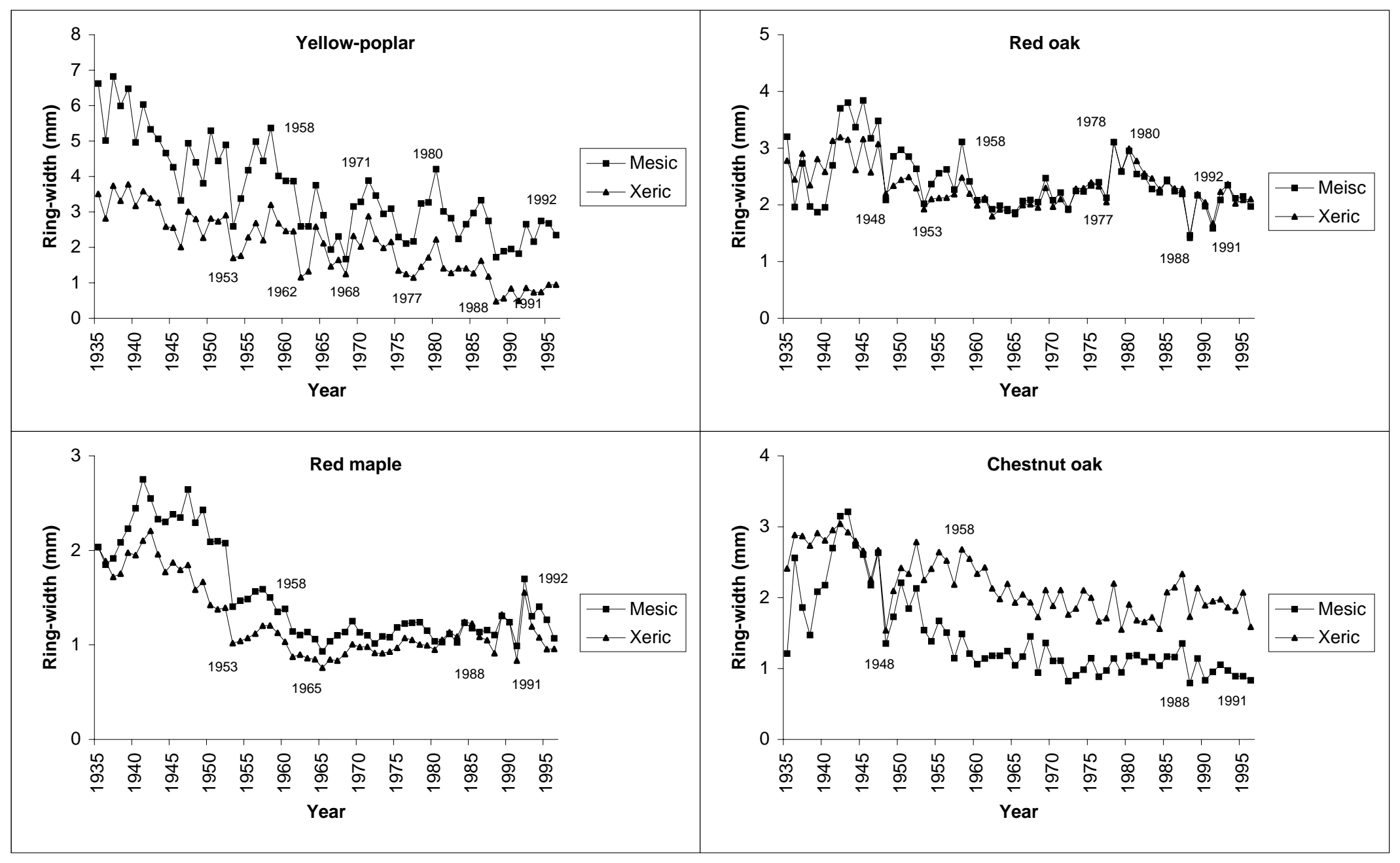

Figure 5.2. The pattern of mean radial increment. 


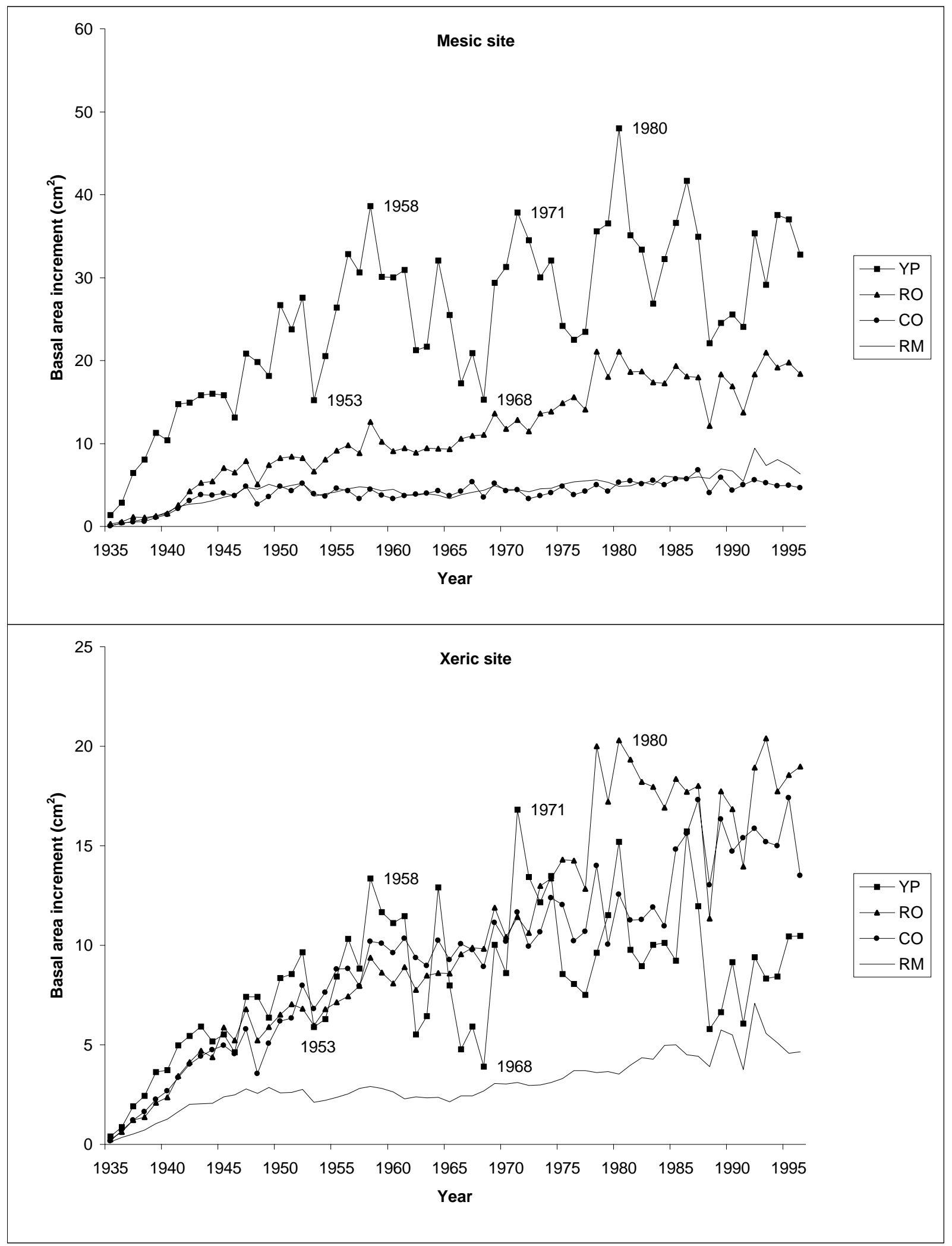

Figure 5.3. The pattern of mean basal area increment. 


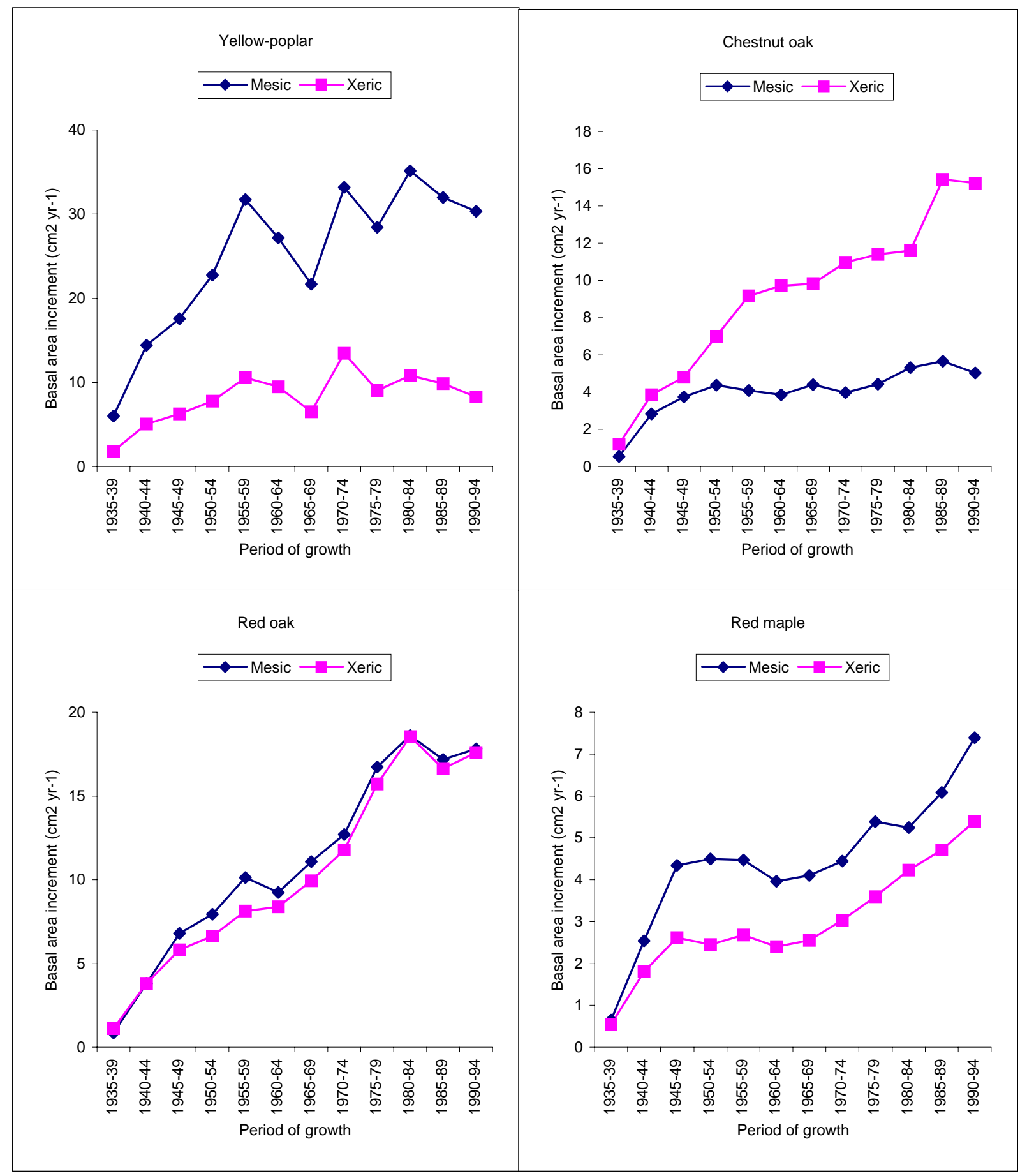

Figure 5.4. Mean basal area increment at intervals of 5-years. 


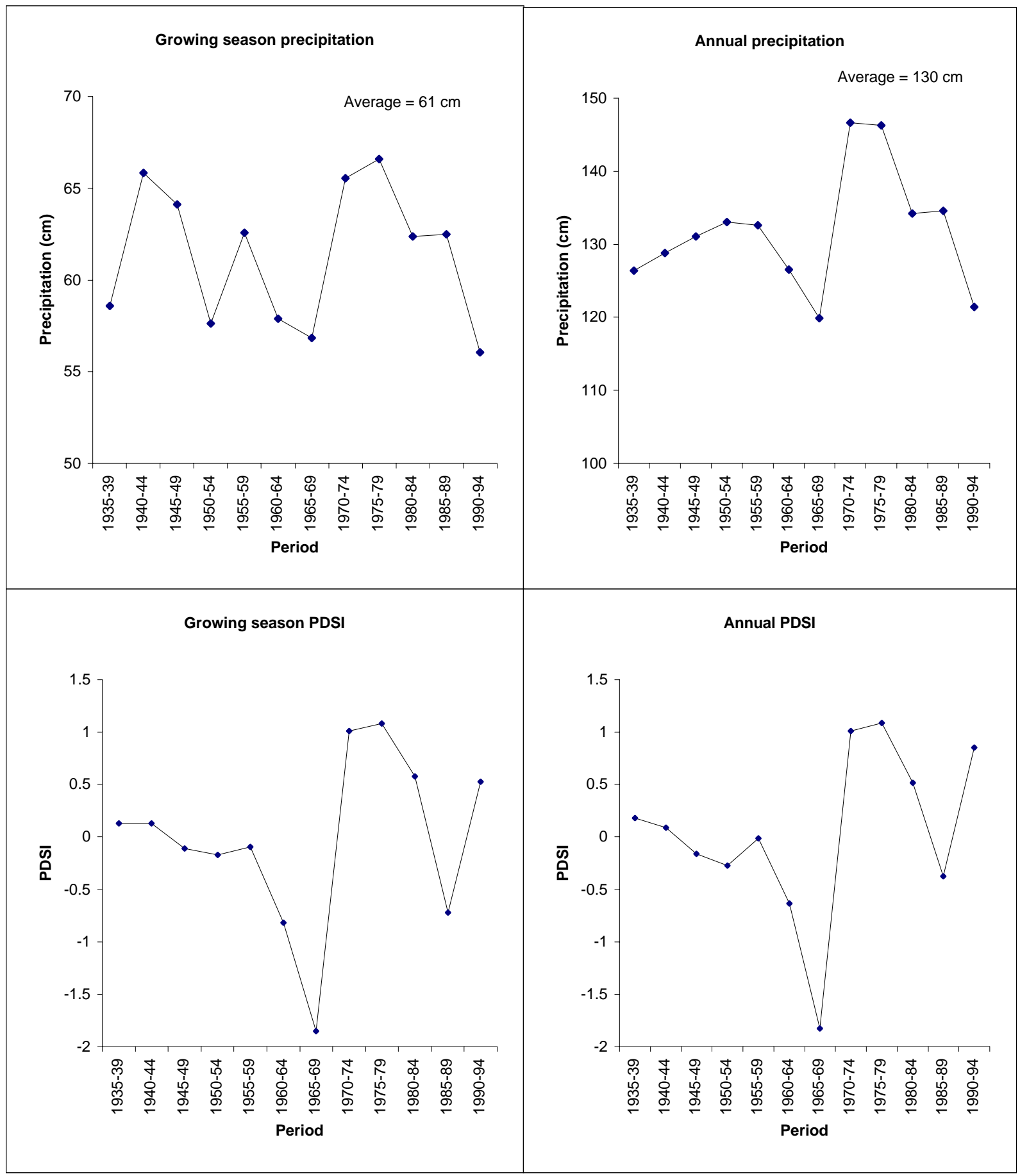

Figure 5.5. Growing season and annual precipitation and PDSI by 5-year intervals. 


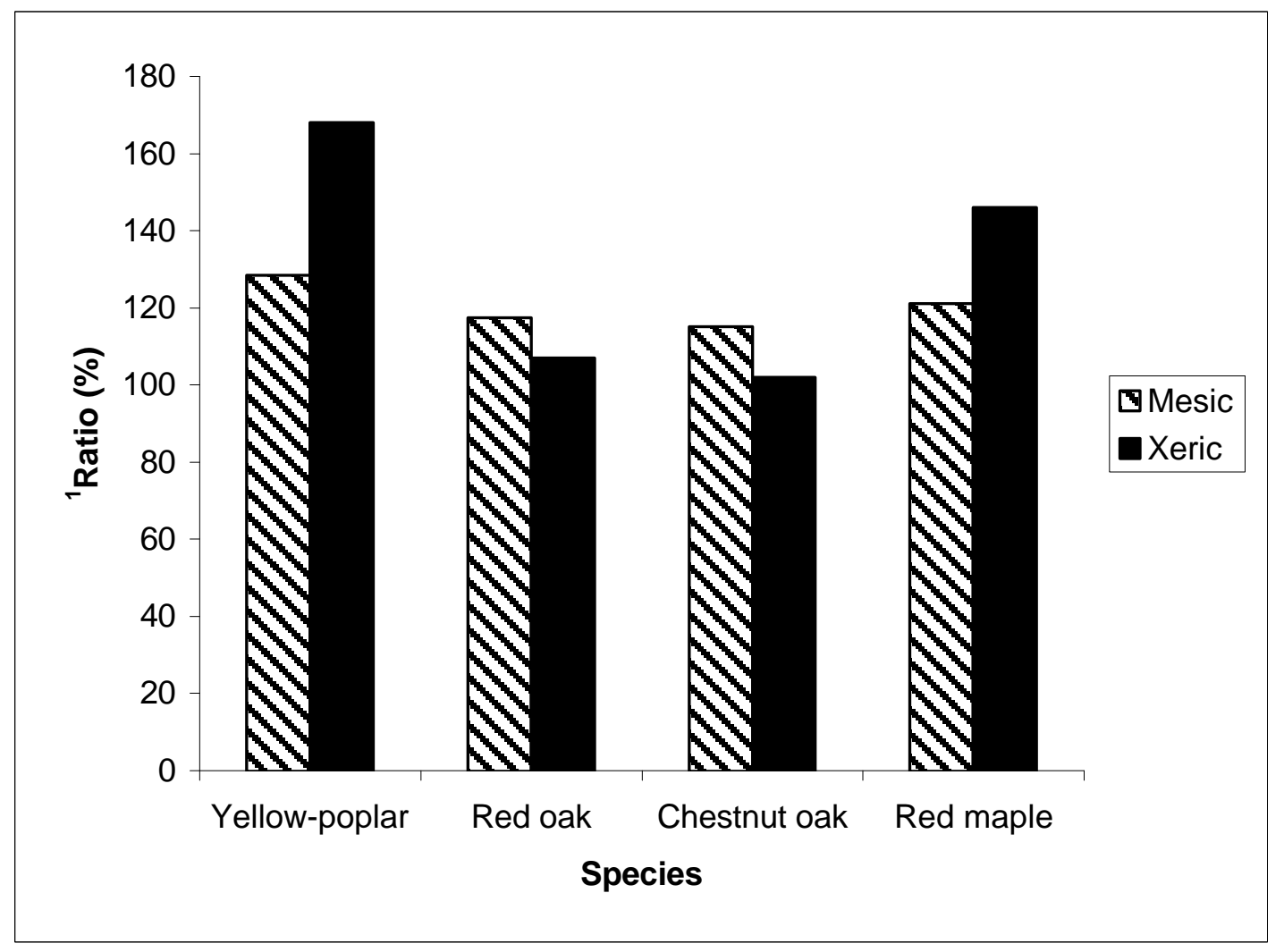

Figure 5.6. Radial growth in wet years expressed as a percent of drought years.

${ }^{1}$ Ratio=(Average RWI in 8 wet years/Average RWI in 8 drought years)*100

The wet and drought years considered to calculate the ratio are given in Table 4.9, Chapter 4. 


\subsubsection{RADIAL GROWTH RESPONSE TO CLIMATE}

\section{A. Response Function Analysis}

Response functions are models used for interpreting the way in which monthly precipitation and temperature during and preceding the current growing season are related to changes (increases or decreases) in radial growth. Therefore, it should be noted that response functions are not used for prediction of radial growth based on monthly climate data. They are primarily employed to provide diagnosis of ring-width response to past variations in climate.

In this study, response functions were derived using principal components regression (PCR) where the response variable was the mean prewhitened ring-width index (PRWI) for each species and the predictors were monthly total precipitation and monthly mean temperature from prior May to current September; a total of 34 monthly climatic variables. Since the monthly climatic variables are highly intercorrelated or multicollinear (see Chapter 4 section 4.3.4), use of ordinary regression analysis to study the relationship between radial growth and the monthly climate data often yields coefficients that are unstable and difficult to interpret (Cook and Jacoby 1977, Myers 1986). Most importantly, due to multicollinearity, the variance in annual growth explained by climate $\left(\mathrm{R}_{\text {climate }}^{2}\right)$ may be inflated. Hence, response functions were derived using a multivariate method designed to account for multicollinearity. The complete stepby-step procedure for derivation of response functions using PCR is described in chapter 7 (STUDY V).

The computation of growth response functions using PCR provides partial regression coefficients for each of the 34 monthly climatic variables. These partial 
regression coefficients, usually called elements or weights of the response function, represent the response of tree growth to variations in precipitation and temperature for the particular month. In this study, the elements of the response function are partial regression coefficients associated with the standardized monthly climatic variables.

There are few points to keep in mind while interpreting response functions. First, monthly precipitation and temperature of prior years are included in the derivation of response function for all species because climatic events during prior season can physiologically precondition a tree's potential for growth the next year (Fritts 1976, Cook and Jacoby 1977). Second, response functions may indicate previously unrecognized relationships between radial growth and climate (Fritts 1976).

Third, the results of response function can be constrained by the year-to-year fluctuations of the monthly climatic variables above and below their mean values. If the mean and the range of variability in the climate are near the optimum for physiological processes, the natural variations in climate may not be sufficient to limit growth processes, and there may likely be no correlation and no significant response function elements. On the other hand, if the mean and the range of variability in climate are near the limits of one or more plant processes, there is likely to be a marked effect on these processes and subsequent correlation between climate and radial growth.

Fourth, since Fritts' suggestion in early 1970's, several dendroclimatic studies have transformed the elements of the response function by dividing each element by the standard deviation of all the elements and then multiplying by an unknown constant (Fritts 1976, p. 373). This transformation of the coefficients is unnecessary. In addition, such transformation provides incorrect inferences if, for example, a need arises to 
interpret the coefficients as rates of change in growth associated with a unit change in monthly climatic variables. Therefore, in the present study, such transformation of the coefficient was not performed and the elements of the response function, as already indicated, are partial regression coefficients associated with the standardized monthly climatic variables. In this study, all response functions were derived using the methodology described in chapter 7 (STUDY V). A recent application of the methodology developed in chapter 7 (STUDY V) can be found in Rentch et al. (2001) where it was used to study the radial growth response of red and chestnut oak at the WVU Forest.

Due to multicollinearity (high level of correlations) among the 34 natural or measured monthly climatic variables, the response functions were derived first by mathematically transforming the original predictor variables into 34 orthogonal (or independent) new variables called principal components. From these orthogonal components, the first twenty explained nearly $90 \%$ of the variation in the original climatic data. From the 34 orthogonal variables only few selected components were used to develop the response function. Selection of principal components was achieved first by applying the cumulative eigenvalue product rule (CIVPR) followed by screening of components, from the reduced set, that were significant at probability level of $15 \%$.

Unlike most dendroclimatic studies (e.g., Fritts 1976, Pan et al. 1997, Lindholm et al. 2000) the response variable in the derivation of the response function for each species was not the mean ring-width index (RWI). For the analyses in the present study, the mean prewhitened ring-width index (PRWI) was used as the response variable of growth. An example of the stages of analysis applied to the raw ring-width data of each tree to 
produce the mean PRWI for a particular species is shown in Figure 5.7. Plot (A) in Figure 5.7 shows the ring-width data from a chestnut oak tree sampled at the west facing site and the model fitted to remove the effect of tree-size from the ring-width series. Plot (B) shows a measure of annual growth, called ring-width index (RWI), which does not contain the long-term decreasing trend caused by increasing tree size. A RWI of one represents average growth, while values greater or less than one indicate above-and below-average growth, respectively. The RWI is the most commonly used measure of growth for studying tree radial growth in relation to climate. However, RWI contains undesirable source of variation, autocorrelation, which should be removed before developing models that relate radial growth to climate.

Plot (C) shows the RWI of this particular tree and the second order autoregressive model fitted to the RWI series to remove autocorrelation. The first order autocorrelation coefficient for this particular RWI series was 0.51 and significant at $5 \%$ level. Serial correlation is undesirable source of variation within the RWI series for studying the relationship between radial growth and climate (see Chapter 7, section 7.5.1 (B.2)) and hence, was filtered out using an autoregressive (AR) model. Plot (D) shows the prewhitened ring-width index (PRWI) for this particular tree. The PRWI is the difference between the values of RWI for each year and the corresponding values of RWI from the fitted autoregressive model in plot (C). A PRWI of zero represents average growth, while values greater or less than zero indicate above-and below-average growth, respectively. The first order autocorrelation coefficient for the PRWI of this particular tree was nearly zero (-0.04) and was not statistically significant. The PRWI, therefore, does not exhibit a 
serial correlation and its annual variation is assumed to reflect the variation in growth associated with changes in climate.

In dendroclimatic studies, the stages of analysis applied to the ring-width data from each tree is commonly terminated at stage (B) of Figure 5.7. Then RWI's from all sampled trees are averaged to produce what is commonly known as the standard chronology (Plot (E)). The standard chronology is most commonly used as the response variable for studying radial growth response to climate. Plot (F) of Figure 5.7 shows the average of PRWI from all sampled trees, referred to as the prewhitened chronology, which is a statistically sound measure of annual growth that was used as a response variable for developing response functions in this study. More details on the methodology of developing this biologically and statistically sound measure of annual growth from ring-width data, and the reason for preference of prewhitened chronology (mean of PRWI from all trees of a species) as opposed to standard chronology (mean of RWI from all trees of a species) as a measure of annul growth is given in chapter 7 (STUDY V).

Response functions for each species at the mesic and xeric sites are depicted in graphical form. The vertical bars in the response functions represent the $95 \%$ confidence intervals for the partial regression coefficients associated with each month. Significant monthly variables are those for which the confidence interval does not cross the zero line. For each month, the magnitude, sign, and statistical significance of the partial regression coefficients were used to interpret the effect of variation in precipitation and temperature on radial growth. The importance of the partial regression coefficients lies both in their magnitude and variance. Hence, in order to compare coefficients with small magnitude and small standard error with those that have larger magnitude but also larger standard 
errors, a measure of relative influence (MRI) was calculated. For each month, measure of relative influence was calculated as

Measure of Relative Influence $(M R I)=\frac{\text { Response coefficient for the particular month }}{\text { Standard error of the coefficient for the month }}$

Generally, values of MRI larger than 2 indicate higher relative importance of a monthly variable.

Based on response functions calculated for each species at the mesic and xeric sites, the percentage of variation in annual growth of each species accounted for by climate $\left(\mathrm{R}_{\text {climate }}^{2}\right)$ was calculated. Growth response to climate within and between aspects is compared based on this criterion. Differences in $\mathrm{R}_{\text {climate }}^{2}$ caused by differences in estimation technique (ordinary vs. principal components regression) are also presented.

Detailed analyses of these response functions were made for each species to examine the influence of monthly climatic variables on tree radial growth. The most important characteristics used to interpret the effect of climate on radial growth were sign and magnitude of the coefficients, magnitude of MRI, frequency of significant growthclimate relationships and $\mathrm{R}_{\text {climate. }}^{2}$

\section{B. Hypothesis Tested}

At the study site, precipitation is higher during the growing season. Soil moisture may be higher in the spring, but due to transpiration is lower in late summer than at other times of the year (Hicks 2001 personal communication). In addition, differences in soil moisture between north and south facing slopes were found to be less important than differences in energy balance for causing differential tree growth rates (Lee and Sypolt 1974). It has been long known that due to the more favorable microclimatic condition, trees at north and east aspects show higher growth rates than those at west and southwest 
aspects. But how is sensitivity of radial growth to climate affected by aspect? The primary question is: Do representative mesophytic hardwood tree species growing on contrasting aspects respond differently to variations in precipitation and temperature? In the western states, it has been long known that trees located at xeric sites are more sensitive to climatic variations than those at mesic sites. However, little is known about differences in growth-climate linkage across contrasting sites for tree species in the mixed mesophytic hardwood forests of the eastern United States (Orwig and Abrams 1998, Abrams et al. 1997). On the basis of studies from the more arid sites the following hypothesis was tested:

The Null Hypothesis: Growth response of the species to variations in climate is not affected by topographic aspect. Trees growing at north and east aspects show a similar response to variations in climate as those growing at west and southwest aspects.

The Alternative Hypothesis: Growth response of the species to variations in climate is affected by topographic aspect.

In the following sections, results of response function analysis, for each species, are presented. First, the significant monthly variables of precipitation and temperature were identified. This was followed by discussion of the most important relationships and finally a brief summary of the response function for each species was given.

\section{Response Function of Yellow-poplar}

Precipitation: The response function of yellow-poplar at the mesic site (Figure 5.8 (a)) shows that radial growth of the species is positively and significantly correlated with precipitation from March through August of the current year and in November and 
December of the prior year. Response of xeric yellow-poplar (Figure 5.8(b)), was roughly the same, except precipitation during the previous growing season was also significant.

Temperature: For both mesic and xeric yellow-polar, the correlations between radial growth and monthly temperature were negative from May through August during the current as well as the previous year (Figurer 5.8 (a) and (b)). For mesic yellow-poplar, significant negative relationships between radial growth and monthly temperature are indicated only for July of the prior year, and March, June and August of the current year while for xeric yellow-poplar, temperature coefficients for May and July of the prior year, and May, June, and July of the current year were negative and significant. At both mesic and xeric sites, the radial growth of yellow-poplar showed significant positive correlations with temperatures in September of the prior and current year and October of the prior year.

$\mathbf{R}_{\text {climate }}^{2}$ For yellow-poplar growing at the north and east aspects, the variation in annual radial growth explained by climate $\left(\mathrm{R}_{\text {climate }}^{2}\right)$ was $47 \%$, while for those growing at the west and southwest aspects, climate explained nearly $60 \%$ of the variation in annual radial growth (Table 5.5). This was the highest $\mathrm{R}_{\text {climate }}^{2}$ obtained from all species and site combinations considered in this study and indicates that yellow-poplar is the most climatically sensitive tree species.

\section{C.1 Discussion of Results}

Precipitation: At both the mesic and xeric sites, the large magnitudes of precipitation coefficients in the response function (Figures 5.8 (a) and (b)) indicate that abundant precipitation during the growing season is important to radial growth of yellowpoplar. What were the most important precipitation variables? Using a measure of 
relative influence (MRI, Figure 5.9 (a)), the growth of yellow-poplar is largely dependent upon the variation of precipitation during the current July. Large magnitudes of MRI for precipitation in July followed by June suggest that above average rainfall during the early to mid-growing season is critical to radial growth of yellow-poplar. Similar results were reported by Pan et al. (1997) and Tryon and Myers (1952). At the Fernow Experimental Forest, Pan et al. (1997) indicated that abundant precipitation in current July and the previous October is the most important factor to radial growth of yellow-poplar. Tryon and Myers (1952) found that adequate rainfall early in the growing season (May to June) had more effect on radial growth of yellow-poplar than rainfall during the entire growing season. In the present study, the fact that MRI for precipitation in July and June were the highest is consistent with the results reported in previous dendroclimatic studies. Generally, the response of yellow-poplar to precipitation indicates that the species responds to abundant moisture during the growing season for the species, approximately May 1 through August 15 (Tryon and Myers 1952) and shows wider annual rings when precipitation during June, and especially July, are higher than average (Figure 5.9 (a)).

Temperature: Yellow-poplar growing at both the mesic and xeric sites showed negative correlations with monthly temperatures during the growing season; a result reported in nearly all dendroclimatic studies. The most important temperature variables (Figure 5.9 (b)) were those in June (for both sites) and July (for the xeric site). In other dendroclimatic studies (Fritts 1976), high summer temperatures have been linked to reduced radial growth due to high rates of leaf transpiration and soil water evaporation, which together produce water stress, and eventually premature stomatal closure. Hence, 
lower than average temperature during the growing season reduces plant water stress and may induce production of wider annual rings.

In addition, in the current study, yellow-poplar growing at both the mesic and xeric sites showed significant positive correlations with monthly temperatures in September and October of the prior and September of the current year which suggest that above average temperature during fall favors the radial growth of the species. Especially, the large value of MRI for temperature in prior September (Figure 5.9(a)) indicates that the species prefers higher than average temperature during early autumn of the preceding year. Pan et al. (1997) have also reported significant positive correlations between radial growth of yellow-poplar and temperature in prior fall (October).

Climate in previous vs. current year: For yellow-poplar how does the influence of climate in the previous year compare to influence of climatic variation in the current year? Examinations of the frequencies of significant variables (Table 5.6) indicate that over $60 \%$ of the significant climatic variables (temperature and precipitation combined) occurred during the current year. Additionally, comparison of MRI for precipitation from May through September of the prior and current year (Figure 5.9 (a)) clearly shows that the variation in precipitation during the current year is more important than variation in precipitation in the prior year. The data show that climate in the current year plays the dominant role compared to climate in the prior year suggesting that the radial growth of yellow-poplar is largely based on current photosynthetic production and is sensitive to environmental conditions, especially moisture during the current year.

My results for yellow-poplar contradict the result obtained by Pan et al. (1997). In their study at the Fernow Experimental Forest, Pan et al. indicated that for growth of 
yellow-poplar, black cherry, red oak and white ash the variation in precipitation during the prior year was more important than the variation in precipitation in the current year. Yellow-poplar, however, is a species with indeterminate growth type. For species with indeterminate growth type, buds formed at the end of a growing season contain only a portion of the potential leaf and stem tissue that will develop the following year. Such species have the capacity to exploit temporary episodes of resource abundance and their growth in the current year is not as dependent on the condition of the prior year (Hicks 1998) as are species with determinate growth type. Therefore, the results obtained in this study are consistent with the aforementioned explanation.

There are also important methodological differences between the current study and that of Pan et al. (1997). In their study, the response variable used in the response function analysis was the mean BAI index while in the current study it was the mean PRWI. In their study, they chose the first 10 principal components to develop the response function while in the current study principal components were selected using the CIVPR followed by screening of components that were significant at $15 \%$ level. The principal component selection rule adopted by Pan et al. (1997) does not guarantee that the selected components have significant effect on the response variable (Fritts 1976, Myers 1986).

\section{C.2 Effect of Aspect on the Growth-Climate Relationship of Yellow-poplar \\ Differences in $\mathbf{R}_{\text {climate, }}$ MRI and frequency of significant variables: Yellow-} poplar trees growing at the west and southwest aspects were more sensitive to variations in climate than those at the north and east aspects. The variation in annual growth of 
yellow-poplar explained by climate $\left(\mathrm{R}_{\text {climate }}^{2}\right)$ was $13 \%$ larger at the xeric site $\left(\mathrm{R}_{\text {climate }}^{2}=\right.$ $60 \%)$ compared to that at the mesic site $\left(\mathrm{R}_{\text {climate }}^{2}=47 \%\right)($ Table 5.5).

The frequencies of significant climatic variables (temperature and precipitation combined) were considerably higher at the xeric site (Table 5.6). From the 34 climatic variables analyzed, 17 at the mesic site and 21 the xeric site were significant. A closer examination of MRI for the significant climatic variables (Figure 5.9) shows that there are higher numbers of variables with large relative influence (|MRI $>4)$ at the xeric site. Precipitation in current July and June have |MRI| greater than eight at the xeric site while there are no variables with $|\mathrm{MRI}|>8$ at the mesic site. The data in Figure 5.9 show that, the relative importance of the most important variables (precipitation and temperature in current July and June) is substantially higher for yellow-poplars growing at the xeric site.

The dominant climatic factor: Comparison of MRI for temperature and precipitation (Figure 5.9), especially during the current growing season and November and December of the prior year, indicate that precipitation plays a dominant role affecting the radial growth of the species at both the mesic and xeric sites. In addition, radial growth of the species was more often correlated with precipitation than with temperature (Table 5.6). Regardless of aspect, precipitation is the most important climatic factor affecting the radial growth of the species. Therefore, moisture is probably the factor most limiting to growth of yellow-poplar.

Precipitation and temperature at the mesic vs. xeric aspects: The relative influence of precipitation is highest for trees growing at the xeric site. For the same input of precipitation, yellow-poplar growing at the west and southwest aspects showed a higher response compared to those growing at the north and east aspects. This is evident 
from the larger magnitude of MRI for June and July precipitation at the xeric compared to the mesic site (Figure 5.9 (a)). Unlike those at the north and east aspects, yellow-poplar growing on the west and southwest aspects showed significant positive correlations with precipitation in the prior summer. This could be due to the ability of yellow-poplar on xeric sites (which generally have lower canopy density) to build crown in wet years, gaining on advantage over competitors. This allows them to have a greater competitive edge the following year (Hicks 2001, personal communication). Similarly, there were higher numbers of significant temperature variables at the xeric than at the mesic aspect (Table 5.6) and on average; the relative influence of temperature was slightly higher at the xeric aspect.

The data clearly indicate that due to differences in topographic aspect, yellowpoplar showed a substantial difference in growth response to the same climatic factor.

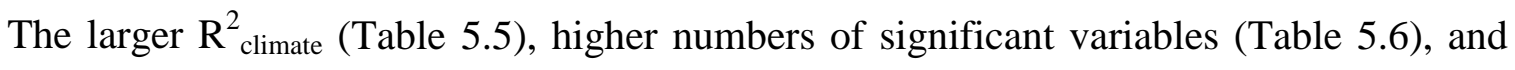
higher numbers of variables with large relative influence (Figure 5.9) at the xeric site provides sufficient evidence to conclude that the variation in radial growth of yellowpoplar between the mesic and xeric sites conforms with the model postulated in the alternative hypothesis. Yellow-poplars growing at xeric sites are more sensitive and show higher response to variations in climate compared to those at the mesic sites.

\section{C.3 Summary of Response Function of Yellow-poplar}

The response of yellow-poplar to climate may be summarized as follows:

- From all variables considered, the variation in radial growth of yellow-poplar is related the most to July precipitation in the current year. 
- A significant positive response to precipitation during the previous fall season may indicate that moisture stress in fall is an important factor affecting storage and allocation of photosynthates in yellow-poplar. A positive response to September precipitation in the current year indicates that, for this indeterminate species, radial growth response may extend into the latter stages of the growing season (Hicks 2001 personal communication).

- Regarding temperature variables, radial growth showed the highest negative correlations with June-July temperature while the correlation with temperature in September was positive and significant.

- Regardless of aspect, precipitation was the most dominant climatic factor affecting the radial growth of yellow-poplar in my study.

- Climatic variation in the current year is more important to radial growth of yellow-poplar than that of the previous year.

\section{Response Function of Northern Red Oak and Chestnut Oak}

Precipitation: At the north and east aspects (Figures 5.10 (a) and 5.11 (a)), radial growth of red oak and chestnut oak was positively and significantly correlated with precipitation in previous June, July, and August and in current May, June, July and September. At the west and southwest aspects (Figures 5.10 (b) and 5.11 (b)), significant positive correlations with precipitation occurred in the early growing season (May and June) of the previous and the current year. The species also showed a common positive response to precipitation for the prior fall at both the mesic and xeric sites.

Temperature: Oaks growing on the mesic site responded significantly and negatively to temperatures in previous June and current July and August while the 
response to temperature in current May was positive for both species but significant only for red oak (Figures 5.10 (a) and 5.11 (a)). The radial growth of oaks at the xeric site (Figures 5.10 (b) and 5.11 (b)) showed significant negative correlations with temperatures for the current March, April, June (for chestnut oak only), July and August. In the previous year, red oak responded negatively to temperatures in June, July, and August while for chestnut oak only August temperature was negative and significant. Regardless of aspect, both species showed positive and significant response to temperature in the prior fall.

$\mathbf{R}^{2}$ climate: At the mesic site, the percentage of variation in annual radial growth explained by climate was $31 \%$ for red oak and $23.8 \%$ for chestnut oak (Table 5.5) while at the xeric site, the estimates of $\mathrm{R}^{2}$ climate were $32.6 \%$ for red oak and $25 \%$ for chestnut oak. The estimates of $\mathrm{R}^{2}$ climate for both species showed negligible variation between the mesic and xeric aspects.

\section{1 Discussion of Results}

Precipitation: Both species of oaks responded similarly to precipitation. However, oaks at the mesic site were affected by the amount of precipitation during the entire growing season while those at the xeric site were affected by precipitation during the early and late portion. In terms of monthly precipitation, current May and June (combined) had the largest effect on radial growth of oaks at both the mesic and xeric sites. This was inferred based on the large magnitude of MRI for May and June precipitation in Figures 5.12 (a) and 5.13 (a). Thus it appears that both oak species showed a similar response to variations in precipitation in that their radial growth was most affected by the amount of rainfall during the early growing season (May and June). 
Oaks complete their addition of earlywood by mid-May (Kennedy and Sutherland 1999) in the central Appalachian region, when stored food reserves from the previous growing season largely determine growth (Hinckley et al. 1979). Beginning in June, growth depends more on currently produced than previously accumulated photosynthates (Hinckley et al. 1976). Consistent with this is the fact that precipitation in May and June had a large measure of importance (MRI). Rentch et al. (2001) reported similar results where they found that correlations with June precipitation yielded the highest positive values for red oak and chestnut oak growing at WVU Forest. Generally strong positive correlation between radial growth and precipitation in the growing season conform to results obtained in nearly all dendroclimatic studies of oaks (Estes 1970, Asby and Fritts 1972, Jacobi and Tainter 1998, Pan et al. 1997, Rubino and McCarthy 2000, and Rentch et al. 2001).

Temperature: A negative response to temperatures during June through August and a positive response to temperature in the prior fall were observed for both species at the mesic and xeric sites. At the mesic site, temperatures in the previous June and current July (Figures 5.12 (b) and 5.13 (b)) had the largest negative influence. At the xeric site, temperature variables with large negative influences were those of the previous June, July, and current July for red oak and previous August, current March and June for chestnut oak.

Radial growth response to temperature for red oak and chestnut oak observed at the current study site showed agreements and differences with other dendroclimatic studies performed on oaks. In the current study, both species, irrespective of aspect, showed large negative correlations with the current July temperature, which may be 
associated with the fact that the study site experiences the highest monthly mean temperature in July (Table 4.7, chapter 4). This is in agreement with data reported by Pan et al. (1997) where they found that both species at the Fernow Experimental Forest showed large negative correlations with July temperature. Others (e.g., Jacobi and Tainter 1988, Rubino and McCarthy 2000, and Rentch et al. 2001) reported higher negative correlations between radial growth of oaks and June temperature. In the current study, negative correlations between radial growth and June temperature were obtained but were not significant except for chestnut oak at the xeric site.

These results underscore the fact that the intervals contained in calendar months may not correspond to the biological seasonality of physiological activity in oak species (Hicks 2001 personal communication), but given this, the best explanation for differences between mine and other studies may relate to the local growing season for these species. For example, in their study of radial growth of white oak in Ohio, Rubino and McCarthy (2000) indicated that although the hottest mean monthly temperature occurred in July, they found non-significant correlations between radial growth and July temperature. They speculated that such lack of correlations is likely due to the near cessation of secondary growth in white oak by this time of the year. They recommended that future research using dendrographs would be useful to determine the exact timing of growth cessation. This recommendation has immense practical importance since the knowledge of the normal local growing season (when growth begins and when it ends) provides a rational basis to study the relationship between growth and climate.

In the current study, both species showed positive responses to temperature in May at the mesic site but it was significant only for red oak (Figures 5.11 (a) and 5.12 
(a)). Significant positive correlations between radial growth and temperatures in one or more months of the growing season, although difficult to explain, are not uncommon. For example, Rubino and McCarthy (2000) found significant positive correlation between radial growth of white oak and prior July temperature. Pan et al. (1997), similar to my results, indicated that red oak responded positively and significantly to temperature in the current May. Rentch et al. (2001) reported that radial growth of red oak and chestnut oak were positively correlated with temperature in August and July, respectively.

Climate in the previous vs. current year: In addition to current growth-year climatic variables, several previous-year climatic variables were significantly correlated with radial growth of red oak and chestnut oak (Table 5.6). At both the mesic and xeric sites, the species had similar (comparable) numbers of significant climatic variables in the previous and the current year (Table 5.6) which suggests that climatic variations in the previous year is as important to radial growth of red oak and chestnut oak as the variation in climate during the current year.

How do red oak and chestnut oak compare with respect to sensitivity? At both the

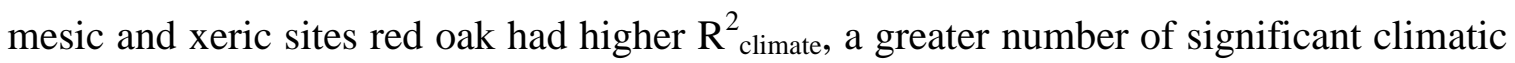
variables, and larger MRI for most variables compared to chestnut oak (Tables 5.5 and 5.6, and Figures 5.12 and 5.13). These findings suggest that red oak is more sensitive than chestnut oak to variations in climate. Red oak is a species that combines both conservative and exploitative growth strategies (Hicks 1998), outgrowing nearly all oaks in both height and lateral extension. Chestnut oak has a more conservative growth strategy than northern red oak (Hicks 1998). In comparison, chestnut oak has a relatively smaller live crown (Hicks 1998) and a lower crown expansion rate. 


\section{D.2 Effects of Aspect on the Growth-Climate Relationship of the Oaks}

Differences in $\mathbf{R}^{2}$ climate, MRI and frequency of significant variables: For both species, the proportion of variation in annual radial growth accounted for by climatic variables showed negligible difference between the mesic and xeric aspects (Table 5.5). For northern red oak, $\mathrm{R}_{\text {climate }}^{2}$ varied from $31 \%$ at the mesic site to $32.6 \%$ at the xeric site while for chestnut oak it varied from $23.8 \%$ at the mesic site to $25 \%$ at the xeric site. Compared to yellow-poplar, the oaks showed smaller difference in sensitivity between the two contrasting aspects.

The variation in the frequency of significant climatic variables between the mesic and xeric sites was also small (Table 5.6). From the 34 monthly variables analyzed, northern red oak had 15 significant variables at both the mesic and xeric sites while chestnut oak had 14 at the mesic site and 12 at the xeric site. Similarly, the number of climatic variables with large relative influence ( $|\mathrm{MRI}|>4)$ was approximately the same between the two aspects (Figures 5.12 and 5.13).

The dominant climatic factor: At both the mesic and xeric sites, precipitation had a greater influence than temperature on radial growth of red oak and chestnut oak. At the mesic site, the radial growth of both species showed a higher frequency of significant correlations with precipitation than with temperature (Table 5.6). More importantly, MRI of the significant variables (Figure 5.12 and 5.13) was larger for precipitation than for temperature indicating that precipitation is the dominant climatic factor affecting radial growth of the oaks. At the xeric site, although there were higher frequencies of significant correlations with temperature than with precipitation (Table 5.6), MRI was, on average, higher for precipitation than for temperature. The higher influence of precipitation, 
compared to temperature, on radial growth of oaks is consistent with the findings of Rentch et al. (2001). In their study of radial growth response of red oak and chestnut oak at the WVU Forest, Rentch et al. (2001) found that correlation values for precipitation generally had a greater absolute value than those for temperature.

Precipitation and temperature at the mesic vs. xeric aspects: The effect of both climatic factors on radial growth of oaks was slightly higher for trees growing at the xeric site. For precipitation, both species had higher numbers of significant variables at the mesic site (Table 5.6), but when MRI was averaged for the significant variables it was higher for oaks at the xeric site. For temperature, there were higher numbers of significant variables at the xeric site, especially for red oak. On average, the relative influence of temperature on radial growth was higher for the oaks growing at the xeric site (Figures 5.12 and 5.13).

Unlike for yellow-poplar, the small changes in $\mathrm{R}_{\text {climate, }}^{2} \mathrm{MRI}$ and frequency of significant variables between the two contrasting aspects indicate that, at the study site, oaks growing at the mesic aspects are as sensitive to climate as those growing at the xeric aspects, especially to precipitation. Therefore, in the current study site, there is no sufficient evidence to conclude that the variation in annual radial growth of the oak species between the mesic and xeric aspects conform to the model described in the alternative hypothesis. Yellow-poplar is a site selective species in that it does really well on some sites and outcompetes its competitors (Hicks 2001 personal communication). Red oak and chestnut oak are both tolerant of lower quality sites and outcompete yellowpoplar there. Red oak has the added ability to compete favorably on good sites. Thus the sensitivity to climate and site are attributes of yellow-poplar. The apparent site specificity 
of chestnut oak is not a function of sensitivity, rather of competitive ability (Hicks 2001 personal communication).

\section{D.3 Summary of Response Function of the Oaks}

The response to climate for red oak and chestnut oak may be summarized as follows:

- Precipitation in the early growing season (May and June) had the greates influence on radial growth of red oak and chestnut oak.

- Precipitation in the prior fall (September and November) was significantly and positively correlated with radial growth of the oaks, which suggest low rainfall in autumn limits their growth the following year.

- Radial growth showed the highest negative correlation with temperature in July and significant positive correlations were observed for temperature in the fall season (September and October).

- Regardless of aspect, precipitation is more dominant than temperature in affecting the radial growth of both species.

- Climatic variations in the previous year are as important to radial growth of both species as climatic conditions during the current year.

\section{E. Response Function of Red Maple}

Precipitation: Red maple at both the mesic and xeric sites (Figure 5.14) showed significant positive correlations between radial growth and precipitation in prior fall. Precipitation in current June had significant positive effect on red maple at the mesic site (Figure 5.14 (a)) while at the xeric site, precipitation in prior summer (July and August) and current April and July were positive and significant. 
Temperature: Similar to the other species, radial growth of red maple was inversely related to summer temperatures. For red maple at the mesic site, temperatures in the prior July and August and current June had a negative significant effect while for those at the xeric site temperature coefficients in the prior June and August and current May were negative and significant.

$\mathbf{R}_{\text {climate }}^{2}$ For red maple growing at the mesic site, climate explained only $10.4 \%$ of the variation in annual radial growth of the species (Table 5.5). This was the smallest $\mathrm{R}_{\text {climate }}^{2}$ obtained from any species and site combinations considered in the study. At the xeric site, however, the percentage of variation in annual radial growth of red maple explained by climate increased to $21 \%$.

\section{E.1 Discussion of results}

Precipitation: At both sites, red maple showed the highest positive response to precipitation during the fall season (September and November, Figure 5.15 (a)). There were the only two precipitation variables with $|\mathrm{MRI}|>3$ at the xeric site. During the growing season, red maple showed the highest response to precipitation in July (xeric site) and June (mesic site).

Temperature: Response to temperature from May through September was generally negative but unlike the other three species, the most important temperature variables for red maple were those in previous summer.

There were more significant climatic variables during the pervious year compared to the current year, especially for red maples at the mesic site. This may suggest that, for radial growth of red maple, climatic variation in the previous year may be more important than climatic variation in the current year. This result is not in agreement with the fact 
that red maple is a species with an indeterminate growth type (Marks 1975) and for such species, their growth is much dependent on conditions of the current year. There are no previous dendroclimatic studies in north central West Virginia to compare the results obtained in the current study.

Reviewing several studies on red maple dynamics, Abrams (1998) indicate that one of the most dramatic changes that has occurred in forests of eastern North America during the twentieth century is the increase in the dominance of red maple. Red maple is a species with a low resource requirement that can act as both an early and late successional species and thrives in a wide variety of environmental conditions. Although red maple is a subject of several investigations in stand dynamics, little is known about the radial growth response of red maple to climate.

The dendroclimatic analysis in the current study indicates that red maple is least sensitive to climate compared to the other three species. Abrams (1998) reported data that indicate red maple leaves tend to have low to average values for leaf structural parameters that determine gas exchange rates (leaf area, thickness, mass per unit area, stomatal density, and guard cell length). Foliar nitrogen level in red maple is also usually below those of other tree species (Abrams 1998). In most plants, low leaf nitrogen is related to low photosynthetic performance. Because of its modest leaf structural characteristics and low foliar nitrogen, red maple most likely has a relatively low rate of photosynthesis, even though its respiration rate, and light saturation and compensation points are lower than those of yellow-poplar, red oak and chestnut oak. 


\section{E.2. Effect of Aspect on the Growth-climate Relationship of Red Maple}

Differences in $\mathbf{R}_{\text {climate, }}^{2}$ MRI and frequency of significant variables: The variation in radial growth explained by climate was twice the magnitude for red maples growing at the xeric site $\left(\mathrm{R}_{\text {climate }}^{2}=21 \%\right)$ compared to $\mathrm{R}_{\text {climate }}^{2} 10 \%$ for red maples at the mesic site. There were higher numbers of significant climatic variables at the xeric site. From the 34 monthly climatic variables analyzed, there were 11 significant variables at the xeric site while at the mesic site only seven climatic variables were significant (Table 5.6). In fact, for red maples at the mesic site, there were no climatic variables with |MRI|>3 (Figure 5.15). The influence of monthly climatic variables (Figure 5.15) was considerably smaller compared to yellow-poplar (Figure 5.9) and the oaks (Figures 5.12 and 5.13).

The dominant climatic factor: Comparison of MRI for precipitation vs. temperature (Figure 5.15 (a) and (b)) shows that, on average, precipitation has a larger influence than temperature on radial growth of red maple at both the mesic and xeric sites. This suggests that precipitation, especially during the fall season, may be the dominant climatic factor affecting the growth of red maple at both aspects,

Precipitation and temperature at the mesic vs. xeric aspects: For both climatic factors, there were more significant variables at the xeric than at the mesic site (Table 5.6). Figure 5.15 shows that the relative influence of both precipitation and temperature is considerably higher on red maples growing at the xeric site.

Generally, the higher number of significant climatic variables, the higher $\mathrm{R}_{\text {climate, }}^{2}$ and the greater number of variables with larger influence (MRI) at the xeric site indicate that red maples at this site are more sensitive and show a higher response to climate 
compared to those growing at the mesic site. The data provide sufficient evidence supporting the alternative hypothesis, that red maples at the west and southwest aspects are more climatically sensitive than those at the north and east aspects. For 12-20 year old red maples, Abrams et al. (1998) reported a similar result where red maple at xeric sites showed considerably higher correlations with temperature and precipitation compared to those growing at mesic sites.

The response function of red maple (Table 5.6) contains fewer numbers of significant climatic variables compared to yellow-poplar, red and chestnut oak. At both aspects, the small values of $\mathrm{R}^{2}$ climate and the fact that there were no monthly variables with $|\mathrm{MRI}|>4$ indicate that red maple is the least climatically-sensitive species.

\section{E.3 Summary of Response Function of Red Maple}

The response to climate of red maple may be summarized as follows:

- The radial growth of red maple is affected the most by precipitation in the fall season, June and July.

- Red maple showed significant negative relationships with temperatures in previous summer and current May and June.

- At both the mesic and xeric aspects, precipitation is the dominant climatic factor affecting the radial growth of red maple.

- The variation in climate in the previous year may be more important to radial growth of red maple than climatic variations in the current year. This probably relates to the conservative strategy of red maple (Hicks 2001 personal communication). 


\section{F. DISCUSSION}

Using dendroclimatic analyses significant relationships were illucidated between annual variations in monthly climate and radial growth of four hardwood species. Furthermore, topographic aspect was found to be associated with the influence of climate on radial growth of the species. Three statistical measures, the percentage of variation in radial growth accounted for by climate $\left(\mathrm{R}_{\text {climate }}^{2}\right)$, the frequency of significant growthclimate relationships, and the frequency of variables with large measure of relative importance (MRI), proved to be useful criteria for assessing the influence of climate on radial increment of the four species across contrasting aspects. Based on these criteria it was found that among the four species studied, yellow-poplar and red maple showed greater sensitivity to climate on the west and southwest aspects (xeric site) while red oak and chestnut oak showed a similar response (sensitivity) to climate on both the mesic and xeric aspects. Therefore, the results for yellow-poplar and red maple appear to fit the model for eastern North America forests outlined by Phipps (1982), in which trees on xeric sites have greater climatic sensitivity than trees on more mesic sites. For the two

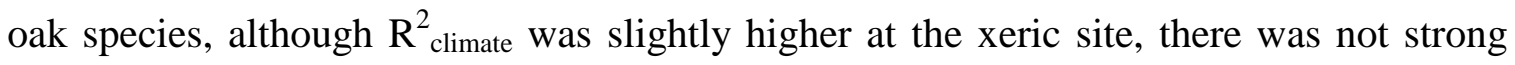
evidence in the current study site to support the model described in the alternative hypothesis.

Based on the response function analysis for all species, trees growing at the west and southwest aspects displayed higher response to precipitation. Similarly, higher frequency of significant correlations, and higher response (MRI) to temperature were observed for trees of all species growing at the west and southwest aspects. For all species, at both the mesic and xeric sites, precipitation was the dominant climatic factor 
affecting radial growth. At both aspects, yellow-poplar was the most sensitive tree species to variations in climate of the four examined. Order of the species with respect to climate sensitivity, from highest to least sensitive, was yellow-poplar, northern red oak, chestnut oak and red maple.

Radial growth of the species studied was generally positively correlated with precipitation, with larger magnitudes being for the months of May through September while for the same time period the response to temperature was negative. Interestingly, significant positive correlations between radial growth and temperature in the previous and current September were observed for yellow-poplar and the two oak species, especially at the mesic site. This probably means that in cases where water is not limiting (mesic sites), higher temperature in the fall allows for an extension of the growing season (Hicks 2001 personal communication). This is especially appropriate for the indeterminate yellow-poplar. For the oaks, it is not quite obvious but could have to do with greater root growth.

At the study site, although soil moisture differences between north and south facing slopes were found to be practically negligible especially during the growing season (Lee and Sypolt 1974), the dendroclimatic analysis in this study indicate that rainfall (moisture) is more limiting to (or has higher influence on) radial growth of trees growing at the xeric site, especially for yellow-poplar and red maple.

Seasonal Sensitivity of radial growth: Nearly all species were sensitive and showed a strong positive response to precipitation during the growing season. In fact, the climatic condition during the growing season accounted for the larger proportion of the significant growth-climate relationships. Between 50 and $70 \%$ of the significant climatic 
variables occurred during the growing season (May through September). This is reasonable since the greatest amount of wood is laid down at this time.

Radial growth sensitivity to precipitation at the study site can be the result of lowered soil moisture when summer precipitation is low. At the study area, the percentages of soil particles (sand, silt, and clay) in the primary rooting zone $(0-45 \mathrm{~cm}$ depth) were 41, 25, and $35 \%$ respectively (Lee and Sypolt 1974). The coarse soil in the primary root zone combined with the slope of the ground (25\%) may result in welldrained conditions (Tryon and Myers 1952), which allows water to drain rapidly from the soil. Thus low summer rainfall may not maintain soil moisture in the rooting zone at a level allowing for satisfactory annual radial growth of the species and the result is the production of a narrow growth ring when summer precipitation, and resulting soil moisture is low. In addition, the priority for growth allocation in trees is leaves > roots> diameter. Thus when a resource is limiting (water often is) the first place where this is felt is in diameter growth (Hicks 2001, personal communication).

During the growing season, year-to-year variability in monthly precipitation was 3 to 6 times higher compared to variability in temperature (Figure 5.16). The higher radial growth sensitivity (response) to precipitation during the growing season could also be attributed to the large annual variation in monthly rainfall.

Significance of fall precipitation: Most species showed a strong positive correlation between radial growth and precipitation during the fall season. This was not surprising because precipitation is generally lowest during fall. During the last 60 years precipitation during fall averaged $9.2 \mathrm{~cm}$ and varied from $4.4 \mathrm{~cm}$ (minimum) to $16.5 \mathrm{~cm}$ (maximum). The average precipitation in the fall was $30 \%$ below that of summer and 
$20 \%$ below spring. Low autumn precipitation in north central West Virginia was reported by Tryon and Myers (1952) and Pan et al. (1997). Rubino and McCarthy (2000) have also reported significant positive correlation between radial growth of white oak in Ohio and fall precipitation. Hence, it was reasonable that most species were sensitive and responded positively to increased precipitation during the fall season.

Radial growth and temperature relationships: Radial growth of most species showed a significant inverse relationship to summer temperatures suggesting that the trees produce narrow annual rings when summer temperatures are higher. The air temperature for optimum photosynthesis of forest species in the middle latitudes is about $25^{\circ} \mathrm{C}$ (Spurr 1964, Delvin 1975). A closer examination of the monthly mean temperature data at Coppers Rock weather station (Table 4.7, Chapter 4) indicate that the maximum mean monthly temperature during the last 60 years was $24^{\circ} \mathrm{C}$ (July) and does not exceed the optimum level for photosynthesis. Mean temperature during the growing season was $17.4{ }^{\circ} \mathrm{C}$ and ranged from $14^{\circ} \mathrm{C}$ to $20^{\circ} \mathrm{C}$. Measurements of air temperature within the WVU forest (Lee and Sypolt 1974) also indicate that during the growing season (May through September) mean temperatures ranged from $18^{\circ} \mathrm{C}$ to $24^{\circ} \mathrm{C}$ and were within the optimal level. Therefore, it appears that the significant inverse relationship between radial increment and temperature is not related to monthly air temperature alone.

The optimum temperature for net assimilation is frequently exceeded in naturally occurring plant communities (Spurr 1964, Lee and Sypolt 1974). At the WVU forest, Lee and Sypolt (1974) indicated that air temperature during midday (10-2pm) periods ranged from $22^{\circ} \mathrm{C}$ to $35^{\circ} \mathrm{C}$. While the rate of photosynthesis is fairly constant over a broad range of temperatures, respiration increases exponentially with increase in temperature. Rather 
than exceeding the optimum for photosynthesis, what is happening is that respiration rate is accelerating during this warm intervals and thus the plant "burns up" more photosynthate (Hicks 2001, personal communication). There may also be an indirect effect of temperature in creating moisture stress. These partly explain the negative correlations between temperature and radial increment. The positive correlations between radial growth and temperature in the fall may relate to extending the growing season (as long as water is not limiting) and/or accelerating root growth, the former seems more appropriate to yellow-poplar and the latter to oaks.

Site and temperature relationships: Within a forest in complex terrain all trees are not equally exposed to solar radiation. Those on east facing sites are exposed early in the morning while those on the west facing sites are exposed in the afternoon when the radiant flux density is the highest. At the study site, radiant energy input at south-facing slopes was estimated to be $24 \%$ higher than the energy input at north-facing slopes (Lee and Sypolt 1974). This is the main microclimatic difference that is due to slope aspect.

The relationship of photosynthesis with light intensity follows a logarithmic curve (Delvin 1975, Rosenberg et al. 1983). Provided that no other factor is limiting, at low light intensities (e.g. early in the morning), light is usually the most limiting factor, and the photosynthetic rate is proportional to light intensity. At high light intensities (e.g. in the afternoon), however, a further increase in intensity may retard the rate of photosynthesis as a result of stomatal closure, accelerated respiration, or the other effects of high light intensities (heating, etc.). High light intensity increases leaf temperature and transpiration and this may result in turgor loss and subsequently in stomatal closure. The increase in leaf temperature under high light intensities results in an exponential increase 
in respiration that depletes carbohydrates produced and if the warming is prolonged the temperature rise may result in thermal inactivation of enzymes which results in reduced photosynthesis (Kramer and Kozlowski 1979).

The forgoing gives evidence that a diurnal shift in factors most limiting to photosynthesis occurs in the forest. During a typical day first one factor and later another may be limiting. Photosynthesis in the morning as indicated above is correlated with light intensity, but later in the day it may be controlled by leaf water stress as it affects stomatal aperture and absorption of carbon dioxide. Therefore, trees at south-facing slopes experience higher leaf water stress (the limiting factor for photosynthesis in the afternoon) compared to those growing at north-facing slopes because they are exposed to solar radiation during the time of the day when flux density is highest and consequently have air temperatures considerably higher than those at north facing slopes. For example, midday air temperature, at the study site, averaged $25^{\circ} \mathrm{C}$ at the northeast aspect and $30^{\circ} \mathrm{C}$ at the southwest aspect, $5^{\circ} \mathrm{C}$ higher at the xeric site. The driving force for transpiration, vapor pressure difference between the leaf canopy and the air, is a function of leaf temperature (Kramer and Kozlowski 1960). The vapor pressure difference increases with increasing temperature (see Figures 3.8(a) and Figure 3.9 (Chapter 3)). Consequently, plant water stress as measured by vapor pressure deficit was estimated to be about $37 \%$ higher on the xeric aspects compared to the mesic aspects.

To summarize the point, the higher frequency of significant correlations between radial growth and temperature and its higher influence (MRI) for trees of nearly all species growing at the west and southwest aspects compared to those at north and east aspects is mainly a result of increased solar radiation received at these aspects and its 
direct and indirect effects on important plant processes (photosynthesis, respiration, water uptake).

It is, however, worth mentioning that one should take precautions in interpreting of the effects of temperature and precipitation on radial growth. Since the influence of these two climatic factors could be interacting, it is difficult to provide an independent estimate of the effect of temperature and precipitation. For example, higher summer temperatures may result in higher evapotransipiration and this in turn may induce a greater response to increased precipitation that recharges the soil moisture.

Response of oaks to climate/site: The dendroclimatic analysis in this study did not produce strong evidence to support the alternative hypothesis that the two oak species are more sensitive and responsive to climate (especially precipitation) at the xeric site. For the oaks, the percentage of variation in annual radial growth accounted for by climate $\left(\mathrm{R}_{\text {climate }}^{2}\right.$, which is one of the measures of sensitivity, showed negligible difference between the mesic and xeric sites. For red oak and chestnut oak $\mathrm{R}_{\text {climate was }}^{2} 31 \%$ and $23.8 \%$ at the mesic site while at the xeric site the estimates were $32.6 \%$ and $25 \%$ respectively. In addition, the frequency of significant precipitation variables and their relative influence as measured by MRI also tend to indicate that the two oak species are nearly as sensitive to precipitation at the mesic site as they are at the xeric site.

There are two interesting results with respect to oaks. First, oaks do respond to climate (especially precipitation), just not as much as yellow-poplar. Secondly, oaks do not show a site-specific response to climate. This is what one would expect from more conservative species (Hicks 2001 personal communication). Their responses are conditioned by the past more so than exploitive species like yellow-poplar. 


\section{G. SUMMARY}

This dendrochronological study revealed that all four species studied exhibited sensitivity to climatic factors, especially to growing-season precipitation. Sensitivity to climate followed the sequence yellow-poplar $>$ northern red oak $>$ chestnut oak $>$ red maple. In the case of yellow-poplar, the current year climatic factors contributed more to the explained variation $\left(\mathrm{R}_{\text {climate }}^{2}\right)$ than for other species.

Regarding the interaction of aspect and climatic sensitivity, again yellow-poplar displayed the greatest amount. The oaks showed little evidence of an aspect-related interaction with climate. For red maple, aspect did interact with climatic sensitivity, although this species showed an overall insensitivity to climate. In cases where site interactions were found, the xeric site proved more sensitive to climate than the mesic site. The results of this study are logical (Hicks 2001 personal communication) in terms of the ecological strategies of the species; yellow-poplar is widely known to be site specific and exploitive, whereas oaks and maples are more conservative. 
Table 5.5. The percentage of variation in annual radial growth of the species explained by climate $\left(\mathrm{R}_{\text {climate }}^{2}\right)$ across the four aspects.

\begin{tabular}{|c|c|c|c|}
\hline Species and aspect & $\begin{array}{l}\text { Ordinary } \\
\text { regression }\end{array}$ & $\begin{array}{c}\text { Principal } \\
\text { components } \\
\text { regressions }^{2} \\
\end{array}$ & $\begin{array}{l}\text { Number of principal components } \\
\text { selected using CIVPR followed } \\
\text { by significance test at } 15 \% \text { level }\end{array}$ \\
\hline \multicolumn{4}{|l|}{ Yellow-poplar } \\
\hline North & 59.9 & 43.3 & 12 \\
\hline East & 61.0 & 41.0 & 9 \\
\hline West & 70.5 & 53.2 & 13 \\
\hline Southwest & 69.2 & 49.9 & 15 \\
\hline Mesic & 63.5 & 46.9 & 11 \\
\hline Xeric & 73.5 & 59.8 & 13 \\
\hline \multicolumn{4}{|l|}{ Red oak } \\
\hline North & 55.1 & 30.1 & 8 \\
\hline East & 53.6 & 26.8 & 7 \\
\hline West & 56.7 & 31.3 & 9 \\
\hline Southwest & 57.0 & 32.8 & 9 \\
\hline Mesic & 56.3 & 31.0 & 7 \\
\hline Xeric & 56.5 & 32.6 & 10 \\
\hline \multicolumn{4}{|l|}{ Chestnut oak } \\
\hline North & No estimate & No estimate & --- \\
\hline East & No estimate & No estimate & --- \\
\hline West & 51.2 & 24.9 & 6 \\
\hline Southwest & 52.0 & 26.3 & 8 \\
\hline Mesic & 50.5 & 23.8 & 6 \\
\hline Xeric & 55.3 & 25.0 & 7 \\
\hline \multicolumn{4}{|l|}{ Red maple } \\
\hline North & 42.4 & 10.8 & 2 \\
\hline East & 40.9 & 12.5 & 4 \\
\hline West & 47.0 & 20.6 & 5 \\
\hline Southwest & 48.8 & 22.2 & 5 \\
\hline Mesic & 40.0 & 10.4 & 4 \\
\hline Xeric & 50.2 & 21.2 & 5 \\
\hline
\end{tabular}

${ }^{1}$ Estimates of $\mathrm{R}_{\text {climate }}^{2}$ are based on ordinary regression analysis. Since the procedure is not designed to handle problems associated with intercorrelated climatic variables, it provides overestimated (inflated) values of $\mathrm{R}_{\text {climate }}^{2}$

${ }^{2}$ Estimates of $\mathrm{R}_{\text {climate }}^{2}$ are obtained through principal components regression using elimination rule that is recommended in both statistical (Myers 1986) and dendrochronological (Fritts 1976, Guiot et al. 1982, Lidhoolm et al. 2000) literature. Principal components were eliminated using the cumulative eigenvalue product rule (CIVPR) followed by screening of the remaining components using a significance level of $15 \%$. These estimates were used for interpretation. 
Table 5.6. Frequency of significant climatic variables by species, aspect and growth period.

\begin{tabular}{|l|lccc|ccc|}
\hline & \multicolumn{4}{|c|}{ Mesic site } & \multicolumn{3}{c|}{ Xeric site } \\
\hline \multirow{2}{*}{ Yellow- } & & Precipitation & Temperature & Total & Precipitation & Temperature & Total \\
poplar & Previous & 2 & 3 & 5 & 5 & 4 & 9 \\
& Current & 7 & 5 & 12 & 6 & 6 & 12 \\
& Total & 9 & 8 & 17 & 11 & 10 & 21 \\
\hline Red & Previous & 5 & 2 & 7 & 3 & 5 & 8 \\
oak & Current & 4 & 4 & 8 & 3 & 4 & 7 \\
& Total & 9 & 6 & 15 & 6 & 9 & 15 \\
\hline Chestnut & Previous & 4 & 3 & 7 & 3 & 2 & 5 \\
oak & Current & 4 & 3 & 7 & 2 & 5 & 7 \\
& Total & 8 & 6 & 14 & 5 & 7 & 12 \\
\hline Red & Previous & 3 & 2 & 5 & 4 & 2 & 6 \\
maple & Current & 1 & 1 & 2 & 2 & 3 & 5 \\
& Total & 4 & 3 & 7 & 6 & 5 & 11 \\
\hline
\end{tabular}




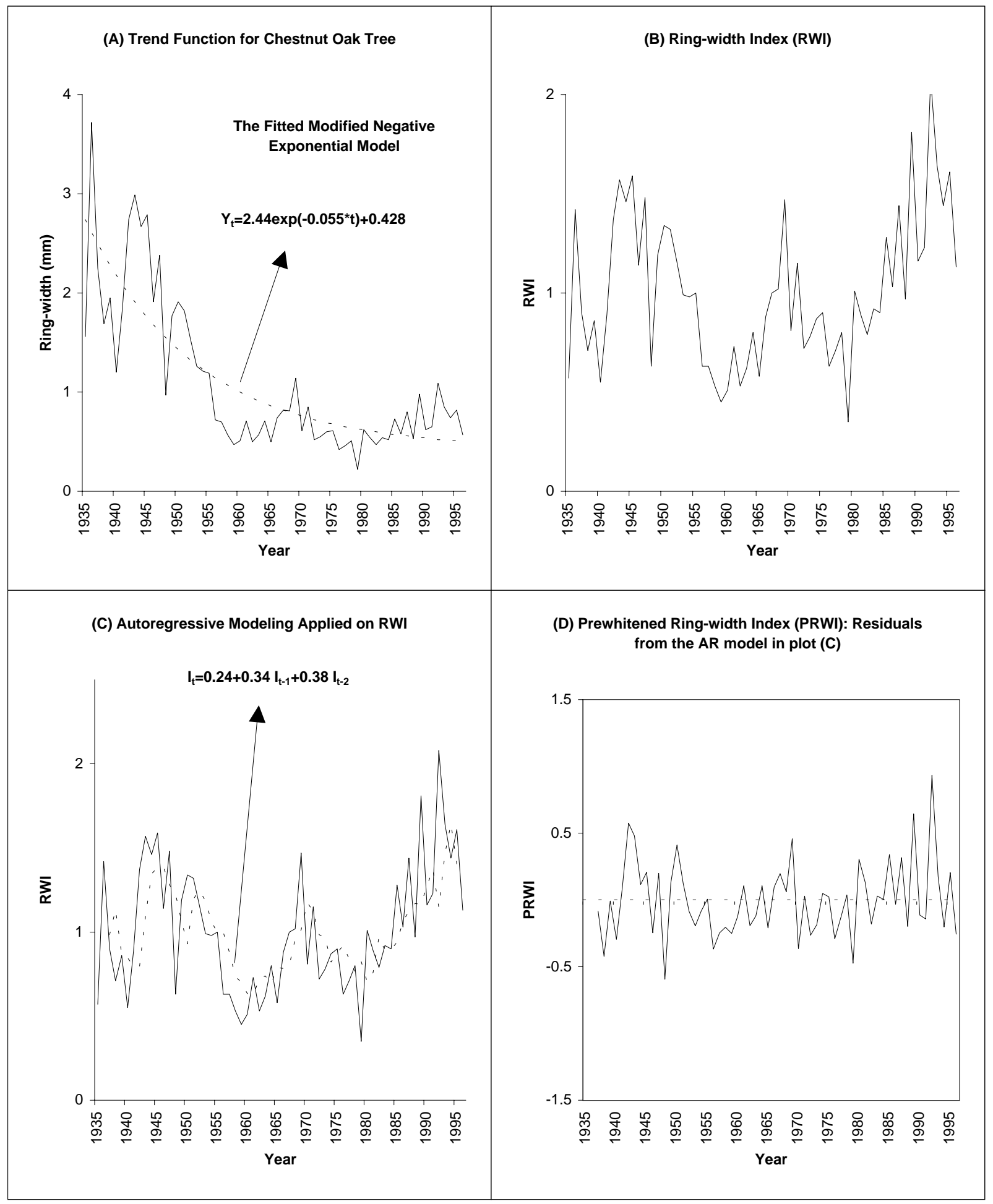

Figure 5.7. Stages of analysis applied to the raw ring-width series of a chestnut oak tree (tree \#1) sampled at the west facing site. 


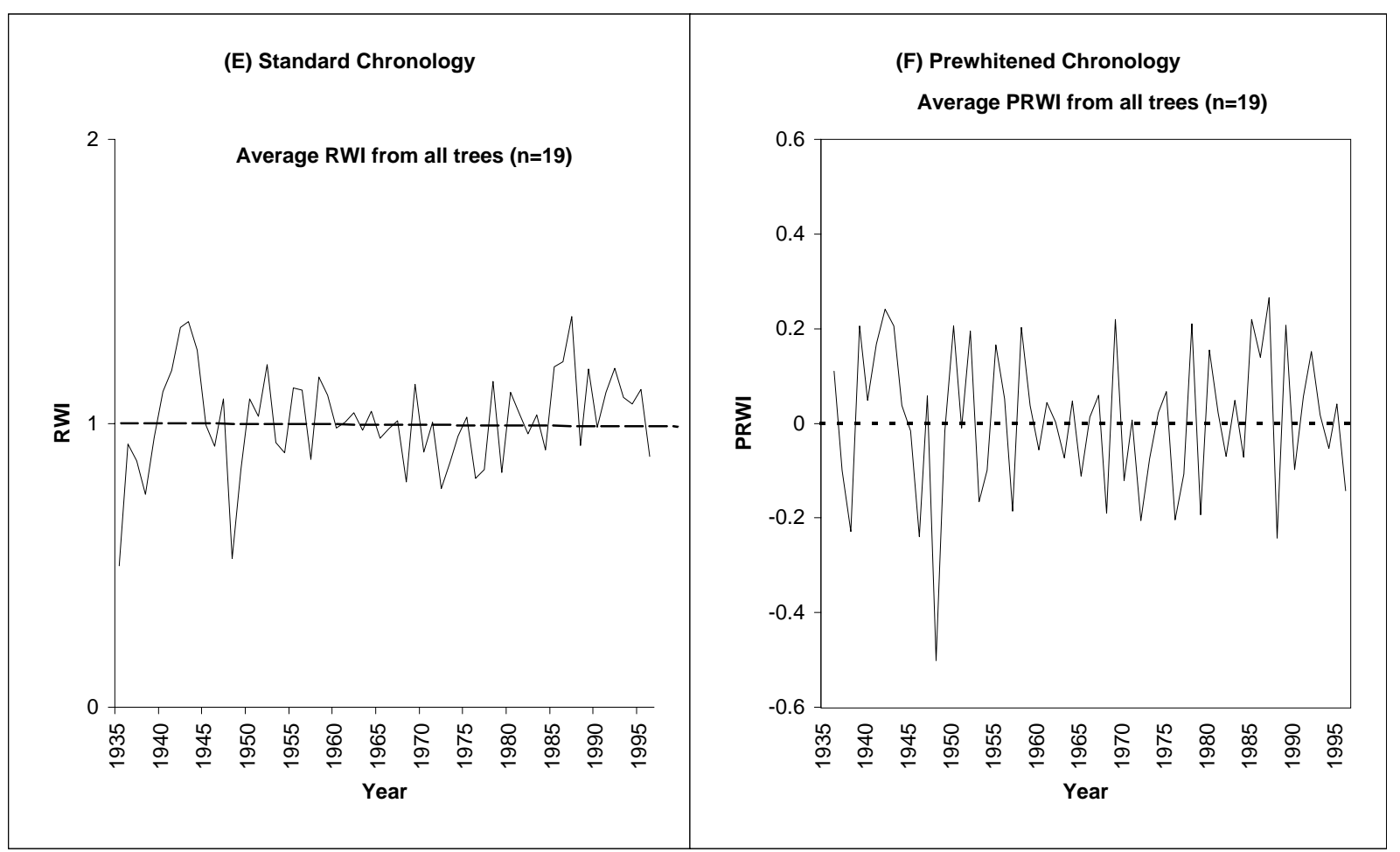

Figure 5.7 (contd.) 
(a) Mesic site (north and east aspects)

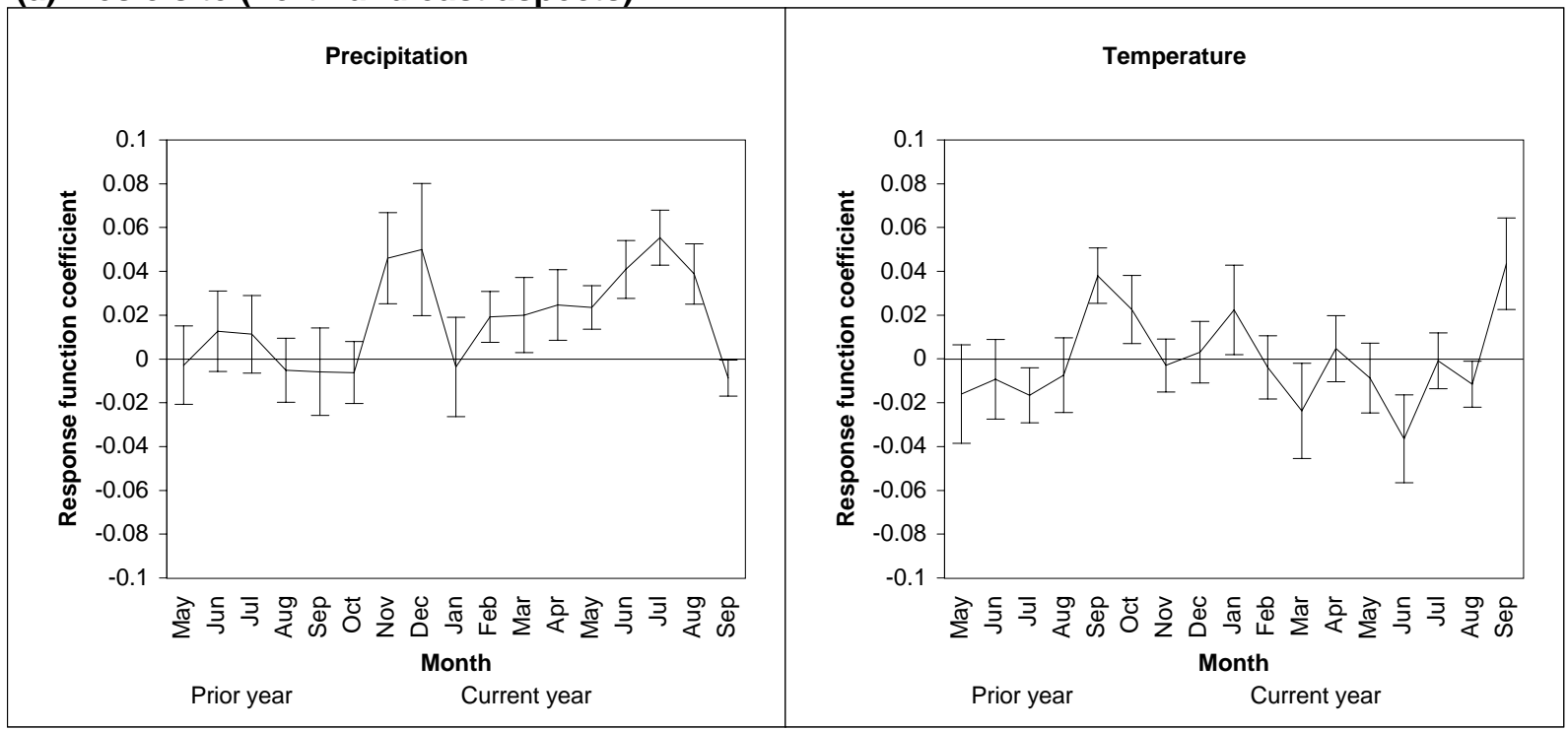

(b) Xeric site (west and southwest aspects)

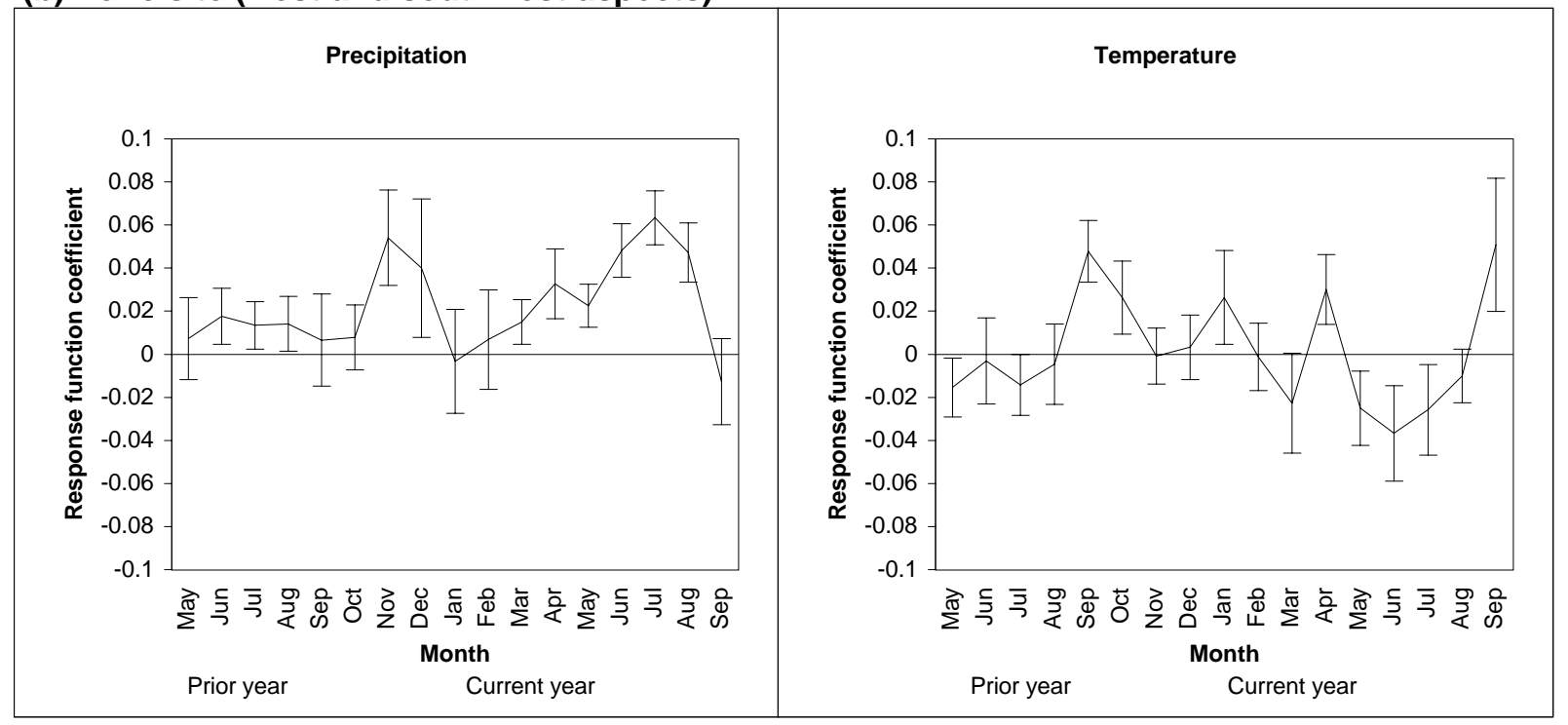

Figure 5.8. Response function of yellow-poplar. 


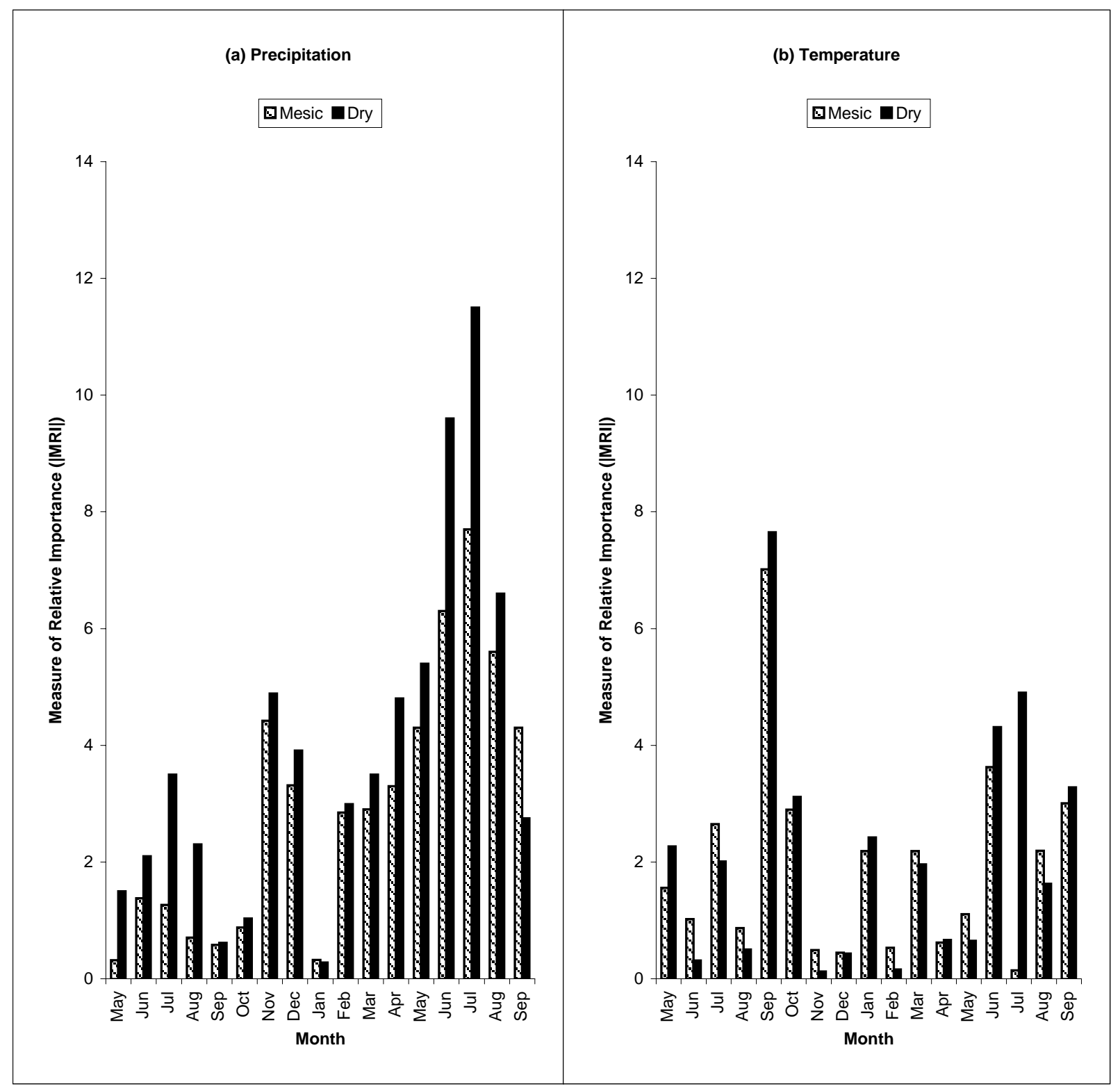

Figure 5.9. Measures of relative influence (MRI) comparing the importance of precipitation and temperature on radial growth of yellow-poplar between the mesic and xeric aspects. 
(a) Mesic site (north and east aspects)

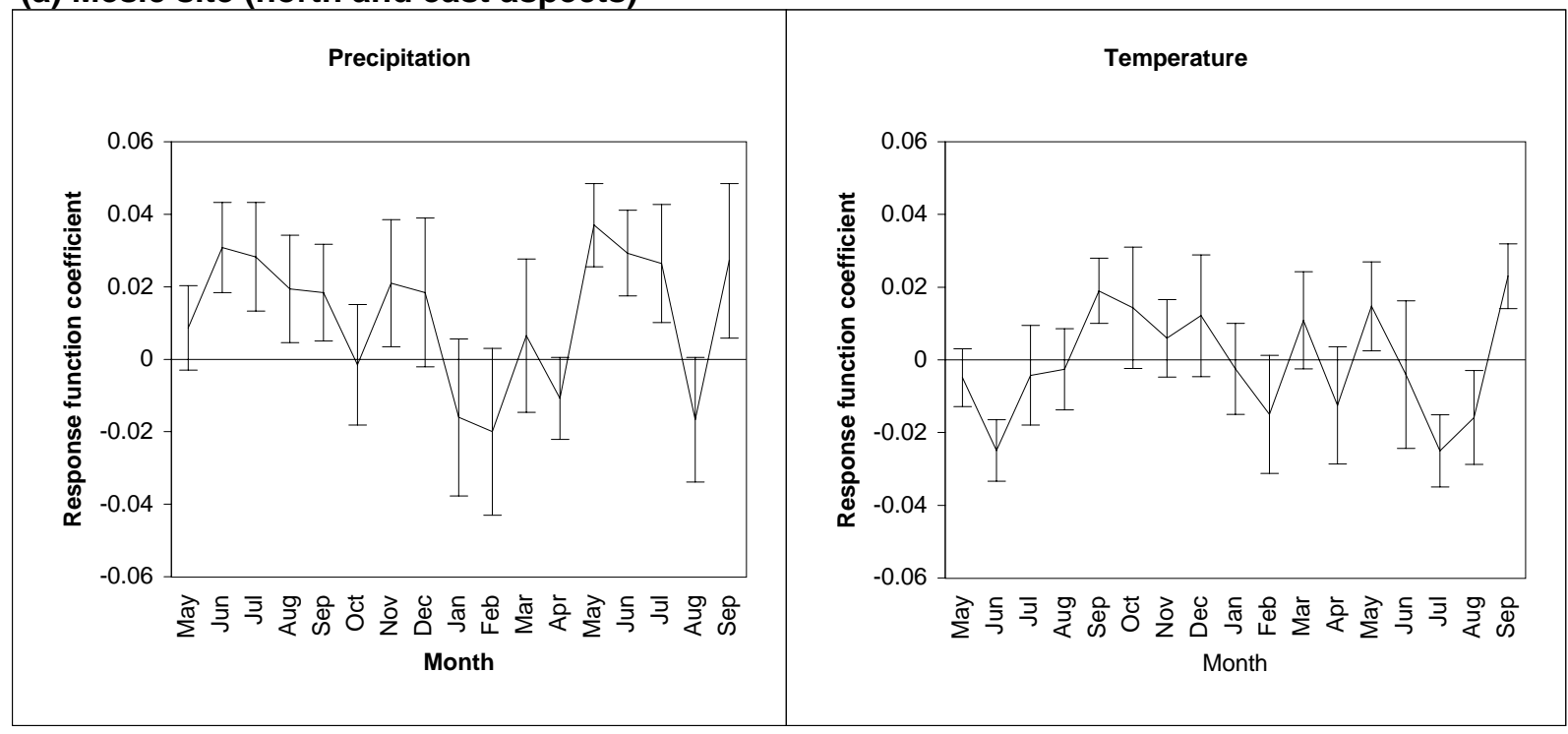

(b) Xeric site (West and southwest aspects)

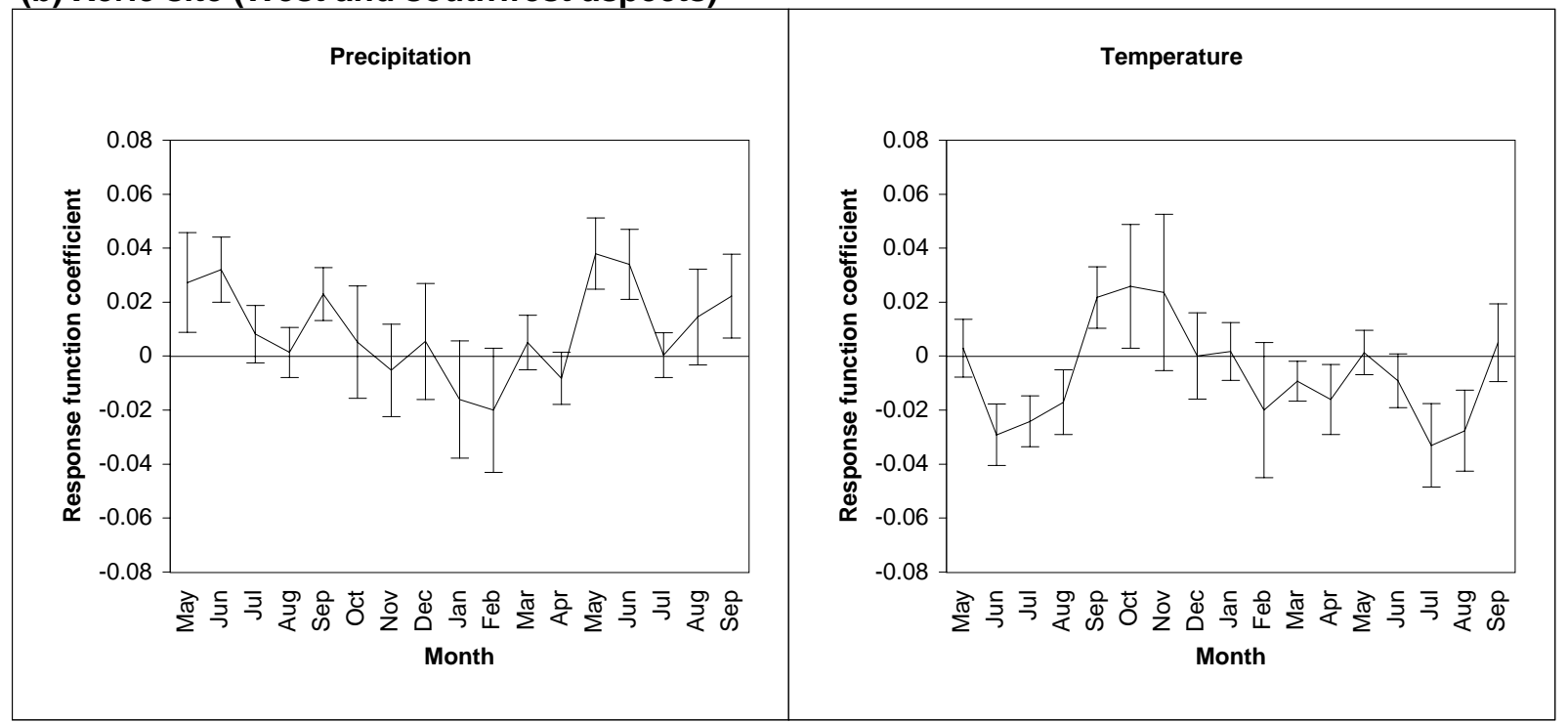

Figure 5.10. Response function of northern red oak. 
(a) Mesic site (north and east aspects)

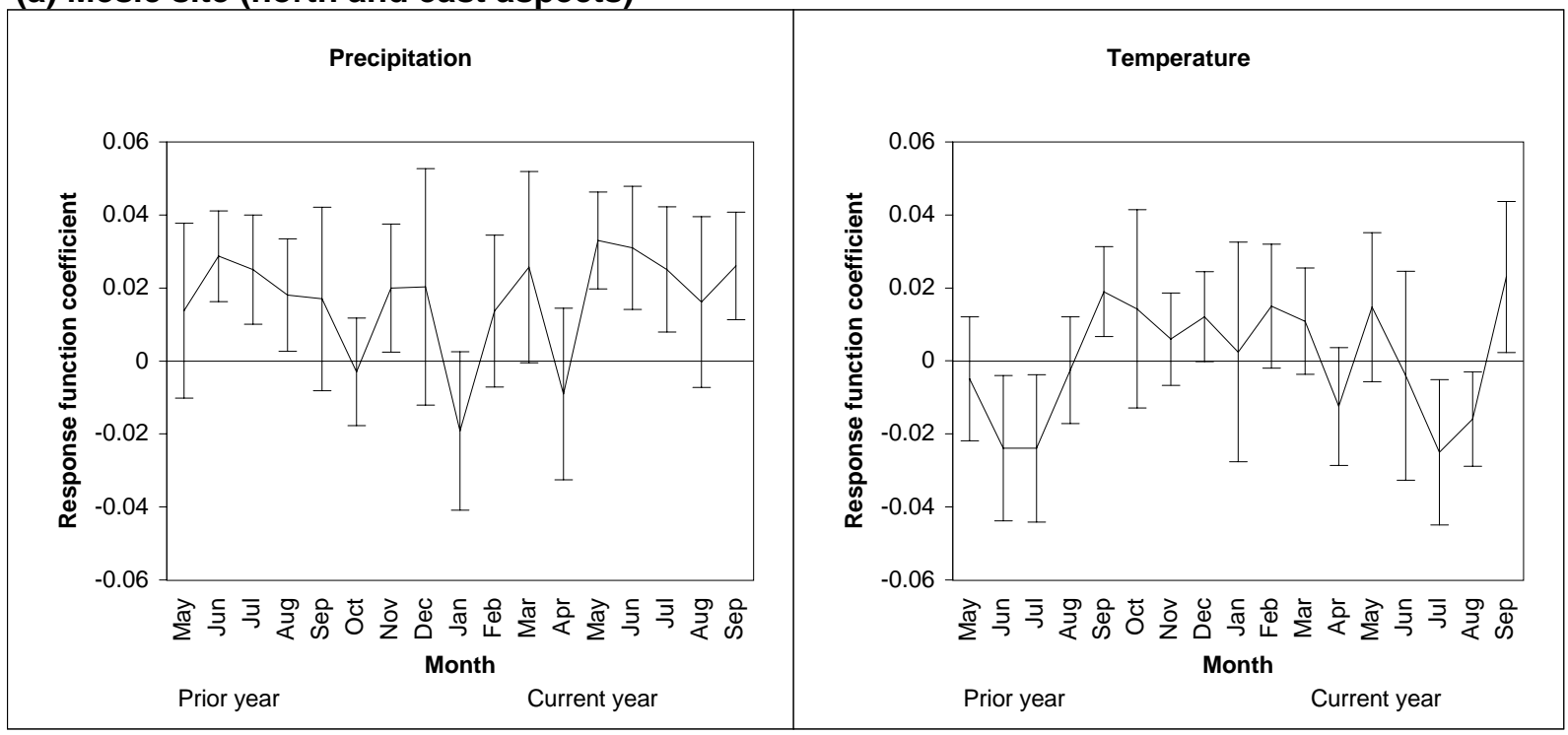

(b) Xeric site (west and southwest aspects)

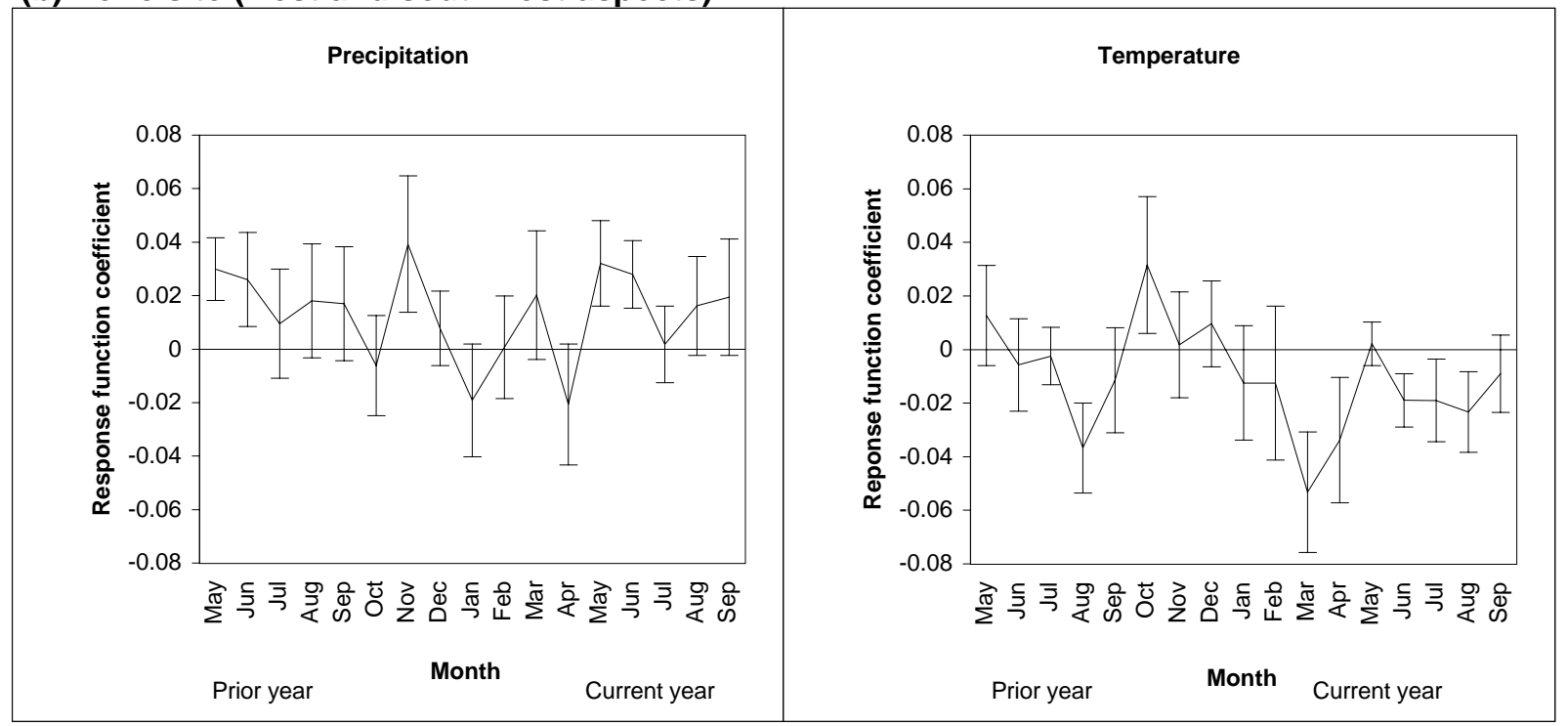

Figure 5.11. Response function of chestnut oak. 


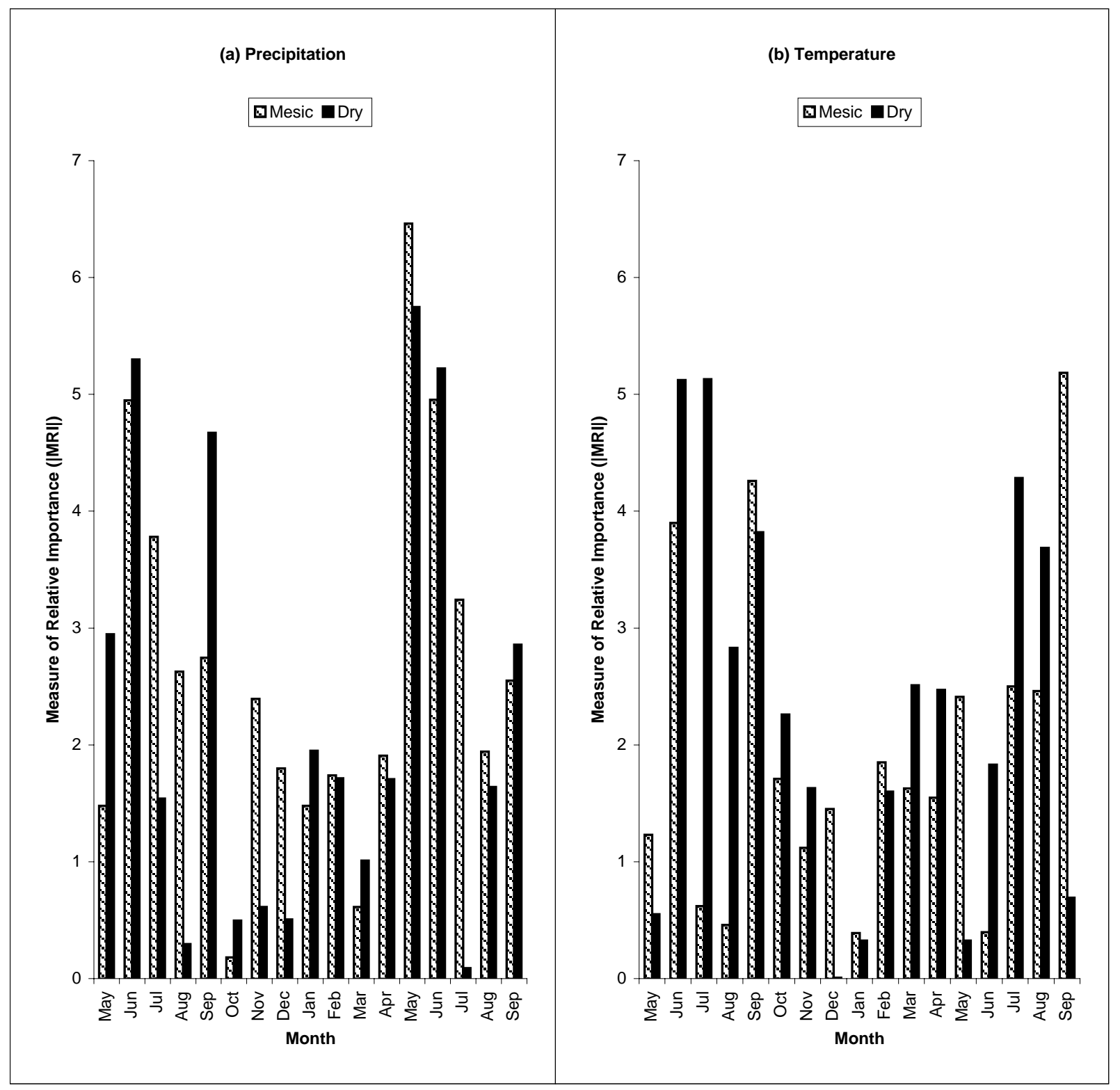

Figure 5.12. Measures of relative influence (MRI) comparing the importance of precipitation and temperature on radial growth of northern red oak between the mesic and xeric aspects. 


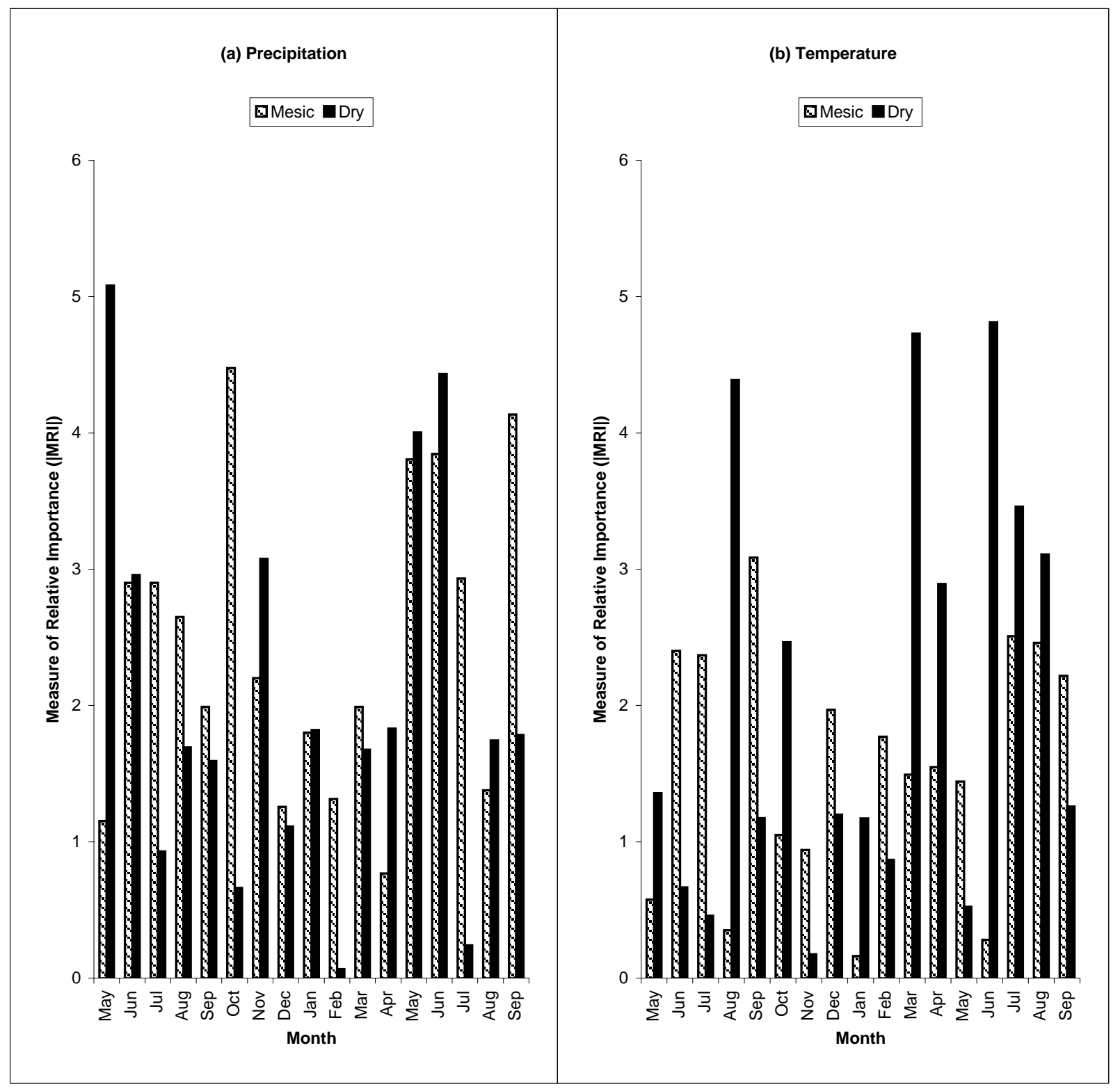

Figure 5.13. Measures of relative influence (MRI) comparing the importance of precipitation and temperature on radial growth of chestnut oak between the mesic and xeric aspects. 
(a) Mesic site (north and east aspects)

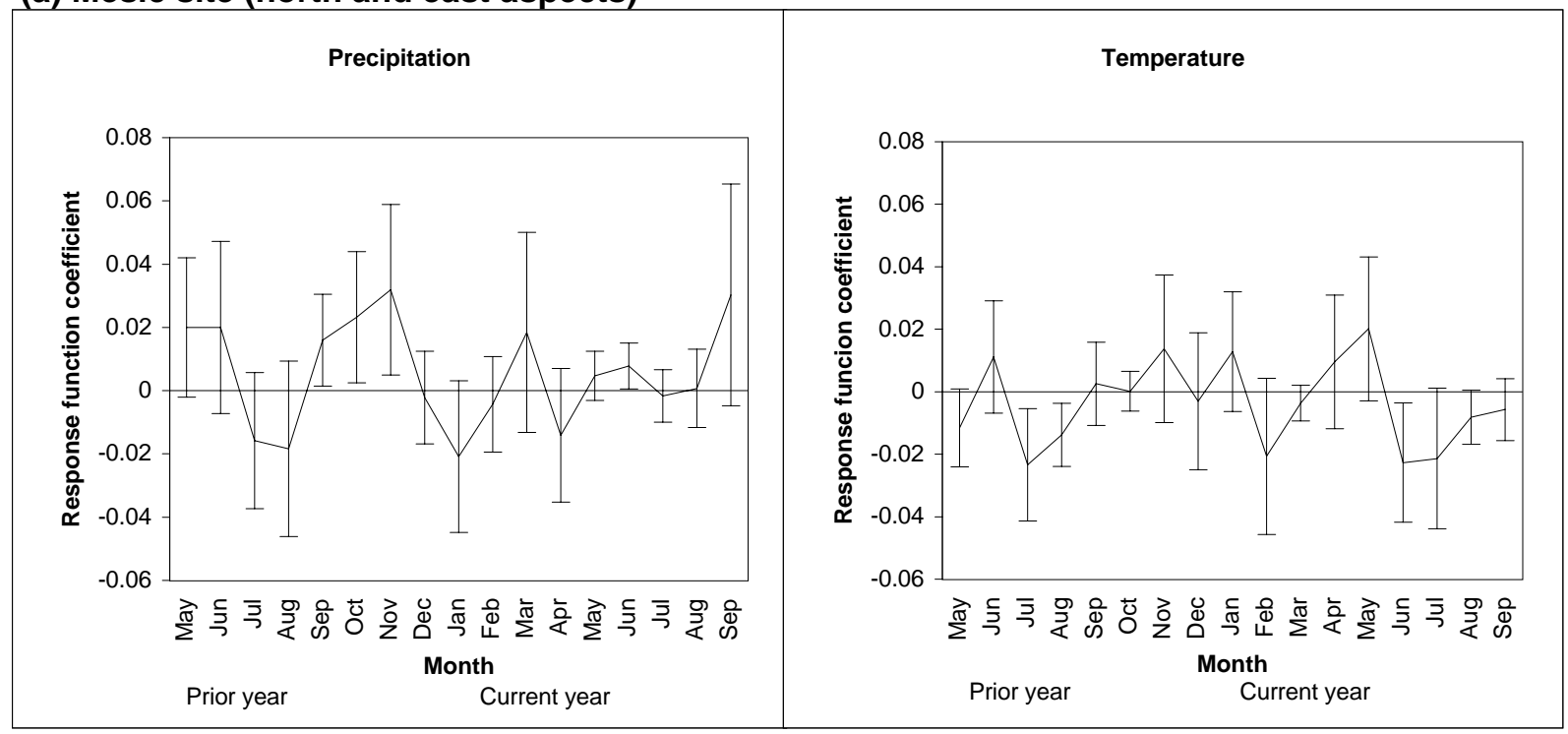

(b) Xeric site (west and southwest aspects)

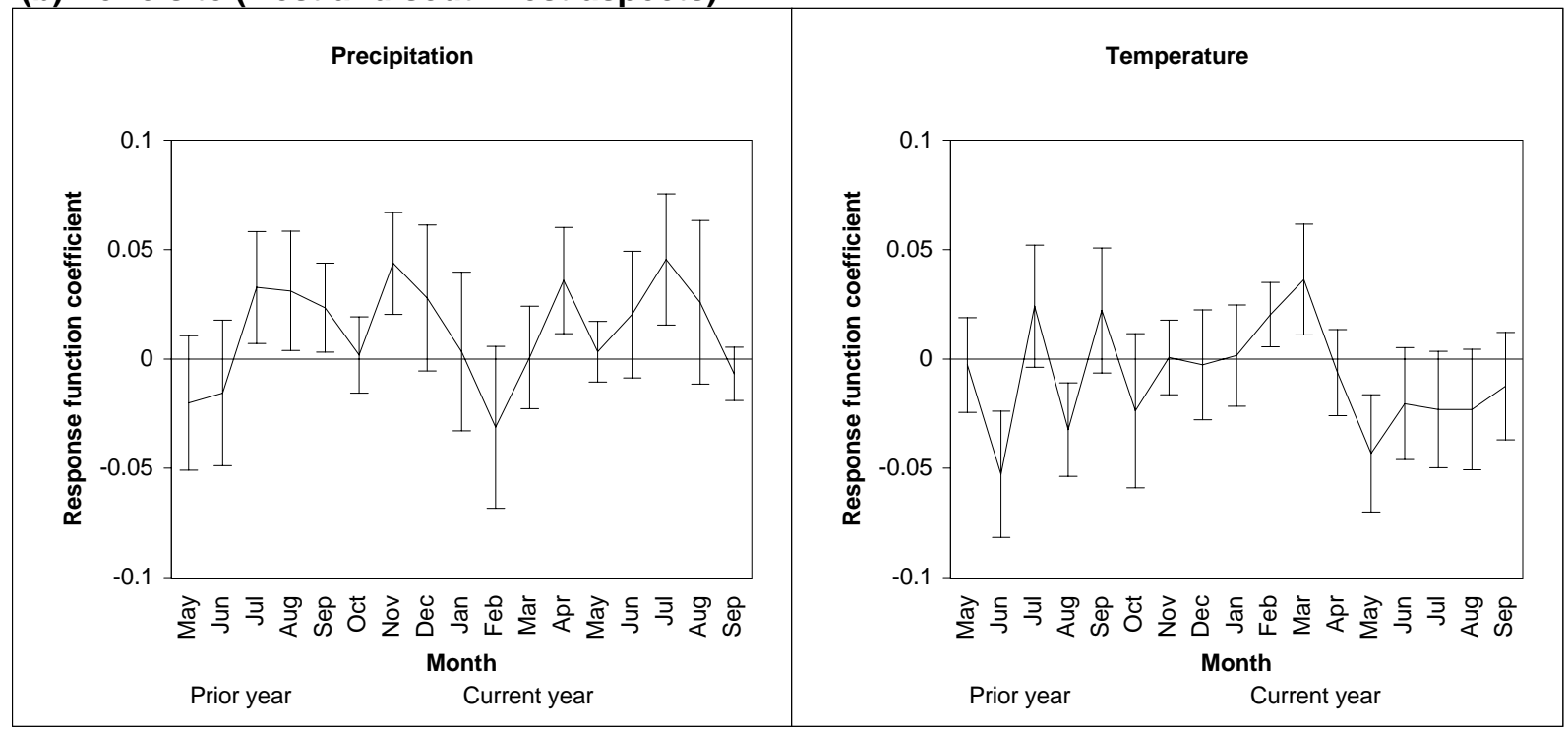

Figure 5.14. Response function of red maple. 


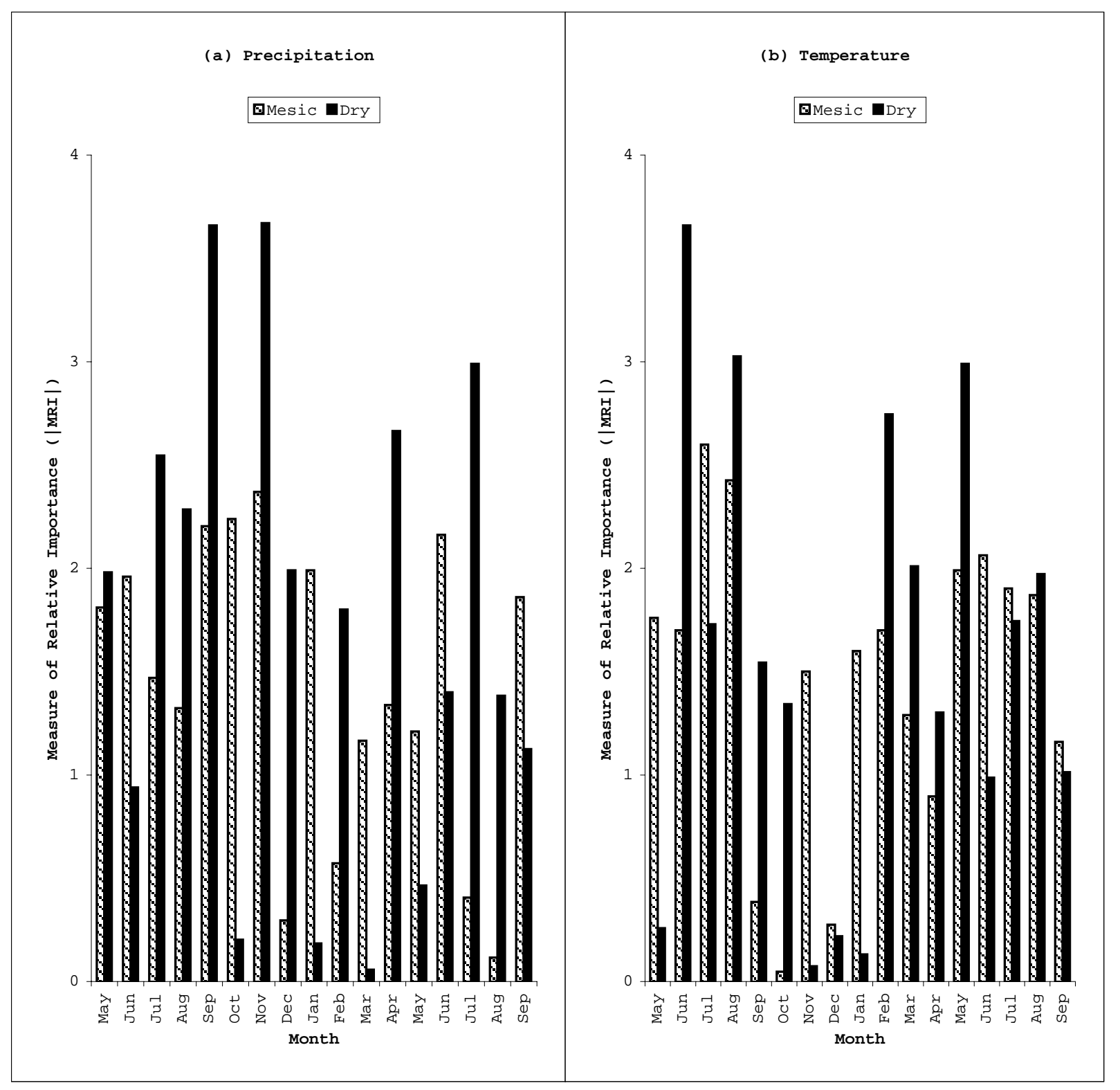

Figure 5.15. Measures of relative influence (MRI) comparing the importance of precipitation and temperature on radial growth of red maple between the mesic and xeric aspects. 


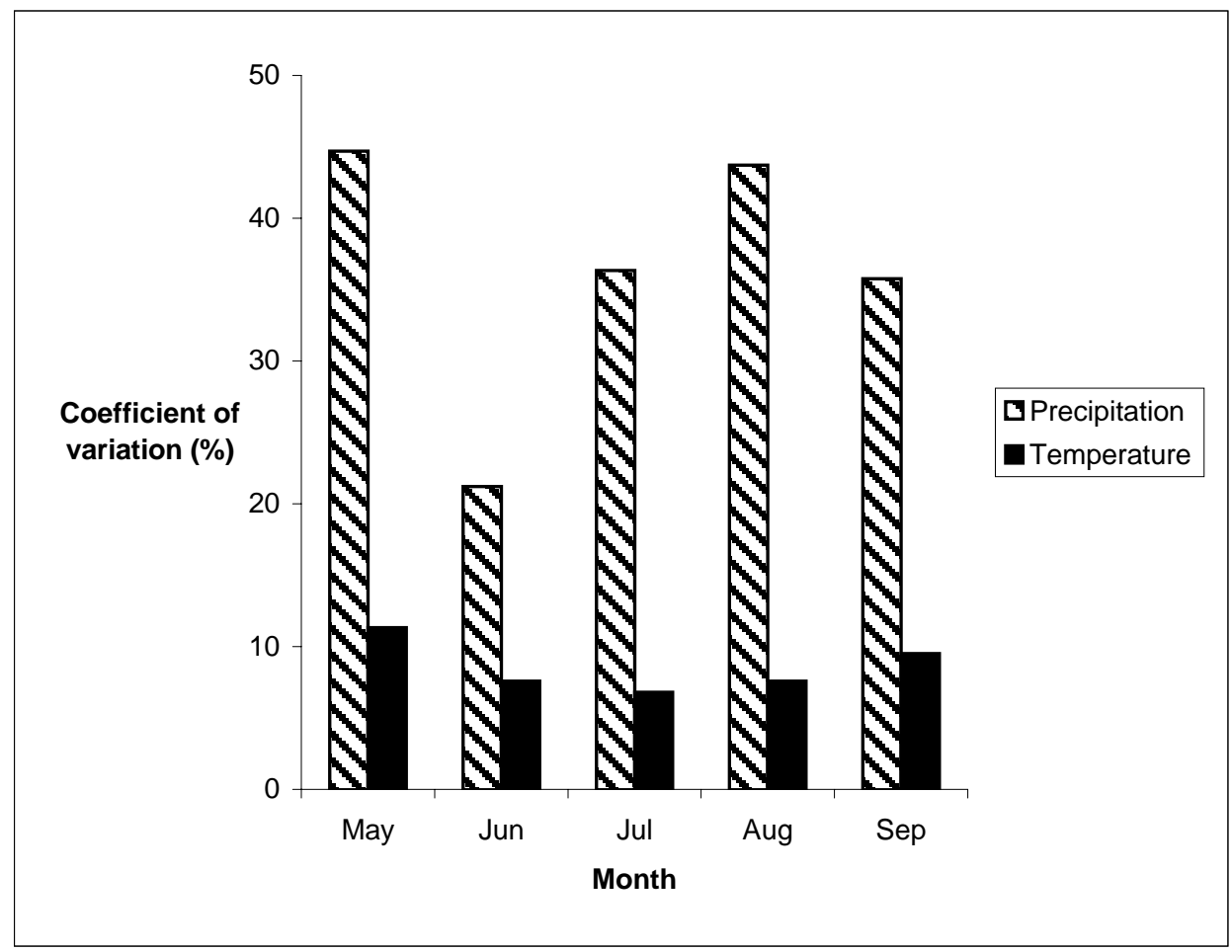

Figure 5.16. Coefficient of variation of precipitation and temperature (1930 to 1996). 


\section{CHAPTER 6: STUDY IV}

\section{EFFECT OF DETRENDING MODELS ON GROWTH-CLIMATE RELATIONSHIP}

\subsection{Introduction and Background to the Problem}

Model to describe ring-width variation in time: The use of tree-ring chronologies in studies of climatic and environmental change assumes that the chronologies being analyzed are accurate reflections of the response of trees to current and past growing conditions (Cook and Peters 1997). Based on the linear aggregate conceptual model (Cook 1987), tree-ring growth variation is considered a composite in accordance to the different factors influencing tree growth. This model, used to describe tree growth variations in time, may be expressed as:

$$
R_{i t}=A_{i t}+C_{t}+D 1_{i t}+D 2_{t}+P_{t}+E_{i t}
$$

where

$i \quad$ is the tree number

$t \quad$ is time

$R \quad$ is the observed ring-width

$A \quad$ is the growth trend related to tree age, size and stage of development

$C \quad$ is growth variations due to climate, affecting all sampled trees

$D 1$ is growth variations due to endogenous disturbances (e.g., competition among trees, gap-forming events) affecting a subset of sampled trees

D2 is growth variations due to natural disturbances, affecting all trees (e.g., wild fires, insect outbreaks)

$P \quad$ is growth variations due to anthropogenic disturbances, affecting all trees (e.g., thinning, selective cutting, pollution), and

$E \quad$ is the unexplained growth variations unique to individual trees.

Of these factors affecting tree growth, the most important non-climatic source of variation for tree-ring data is trends in growth due to age (i.e., the $A_{i t}$ component). While exogenous and endogenous disturbances are much more common in the mixed 
mesophytic forests of eastern North America, these factors are ignored in most dendroclimatic studies by sampling trees from sites with minimum exogenous and endogenous disturbances.

Standardizing (detrending) ring-width: In dendro-climatic analysis tree-ring researchers typically employ a methodology called tree-ring standardization before modeling the effect of environmental variables on tree growth and development (Fritts 1976, Cook and Peters 1981, Cook 1985, Monserud 1986, Briffa et al. 1987, and Heiner and Heiner 1995). The main purpose of standardization is to remove changes in the annual growth increment of individual trees that are mainly due to the aging process and then to average these individual detrended series to determine growth that reflects response to environmental change. Tree-ring standardization allows tree-ring widths from a number of neighboring trees to be properly averaged into a mean-value function which more reliably reflects the high frequency variations in growth presumably not related to the biological growth trends that were removed. When ring-width series are standardized, the mean and variance of the inner part (early growth) of each tree is made comparable to the outer part (more recent growth). Thus the rapid vigorous growth of the youth and the slower, steadier growth of the middle and old age are scaled to about the same mean and variance.

As indicated above, the standard practice in dendro-climatic analysis is to fit a detrending model to each tree-ring series and compute a more reliable measure of growth called ring-width index (RWI) as ratios of actual to expected growth. Although in most growth-climate studies RWI is commonly calculated as a ratio of actual to expected growth, other alternatives have also been used (Table 6.1). The equation given in [a] of Table 6.1 is the form that is widely used. Whereas the forms given in equation $[\mathrm{g}]$ and $[\mathrm{h}]$ are recent developments made by Cook and Peters (1997), but their applicability is restricted to long ring-width series (data from old trees). In this study the model form given in [a] of Table 6.1 is exclusively used.

Developing tree-ring chronology: Once the RWI is computed for each tree, then depending upon the presence or absence of statistical outlying data points in each treering index, a chronology is developed using either a biweight robust mean value (Cook 1985, 1987) or through simple arithmetic averaging. In some cases, before the 
chronology is developed, each tree-ring index is modeled as an autoregressive process (Cook 1985) to remove an additional source of variation in ring-width series, autocorrelation. Autocorrelation (serial correlation) arises from the persistence of climatic effects into subsequent years through variation in food reserves and preconditioning of growth (Fritts 1976). The chronology thus developed (standard or prewhitened standard chronology) is used as a response variable in growth-climate studies. Obviously, the values in the chronology are strongly dependent on the type of curve or model used for detrending each tree-ring series.

Commonly used detrending models: The choice of the detrending model is dictated as much by the observed ring-width pattern of each series as by the study objective. Models used for standardizing a tree-ring series include the modified negative exponential model (MNEM), the negative exponential model, polynomial models of low order, cubic smoothing splines, and in some exceptional cases, a simple linear equation generally with negative slope. Additional detrending methods, though not frequently used in dendro-climatic analysis, include Warren's (1980) growth model, digital filters (Briffa et al. 1987) and others (see Visser and Molenaar 1990). However, the use of polynomials and simple linear regression models in dendro-climatic analysis has been seriously questioned from the biological perspective (radial growth of trees) and polynomials of higher order have also been reported to remove signals related to short term climatic changes from a tree-ring series (Fritts 1976). Hence, the function most favored for detrending tree-ring series for growth-climate studies is the modified negative exponential model (MNEM), having the form (Fritts 1976)

$$
G_{t}=a e^{-b t}+k
$$

where $a$ is the growth intercept at time $t=0, b$ is the decay constant, $k$ is the asymptote, $t$ is time in years, and $G_{t}$ is the value of the fitted curve at time $t$ (it is the expected growth at year $t$ ). Note that the decay constant is defined such that a positive value for $b$ will produce a monotonic decreasing function due to the explicit minus sign. This explicit negative form gives rise to the name of the model in the dendrochronological literature. It should be pointed out here that in Fritts (1976, page 264) and in the ITRDB Manual (Grissino-Mayer et al. 1997, page 85) the statement is made that if the fitted curve has a positive slope $(b)$, that the curve is rejected in favor of a simple linear 
equation when in fact they mean that if the term "- $b$ " is positive, the curve is rejected (i.e., that $b$ is negative).

The performance (fit) of the modified negative exponential model in detrending a tree-ring series depends primarily on three factors: (1) the observed pattern of ring width over time (does the ring-width pattern conform with the assumption of the model? or is it so irregular that the modified negative exponential model may not be suitable?), (2) data size (length of the series), and (3) the iteration method, accuracy of the starting values, and the convergence criterion (Fekedulegn et al. (in preparation))

Restriction on parameters of the MNEM: Biologically, all the estimated parameters of the modified negative exponential model should be positive when fitted to a tree-ring series. This study emphasizes the idea that the values of the two parameters ( $a$ and $b$ ) should always be positive. However, the sign of the third parameter $(k)$ depends upon the pattern and length of the tree-ring series. But, researchers and even one of the most widely used tree-ring standardization programs (ARSTAN) rejects this model whenever the estimated value of $k$ is less than zero (Fritts 1976, Holms et al. 1986). It is also important to note that the modified negative exponential model is a nonlinear model and its parameters are estimated using an iterative process. Program ARSTAN also rejects this model when it fails to satisfy the convergence criterion.

For the simple reason that the asymptote $(k)$ is negative, researchers should not drop the modified negative exponential model for detrending short tree-ring series. From a biological point of view, one gets an honest estimate of the asymptote $(k)$ only if the tree-ring series comprises a sufficient portion of the life cycle of the tree. Moreover, it is worth mentioning that detrending models in growth-climate studies are solely used for the purpose of neutralizing the effect of increasing tree age or size; they are not used for “predictive' modeling of a biological phenomenon and therefore, for short series the sign of the asymptote $(k)$ should not be a concern unless it results in negative or unacceptable predicted values near the end of the tree-ring series.

\subsection{Objectives}

One of the objectives of this study, therefore, was to show that for short tree-ring series $(<100$ years) the estimated value of the asymptote $(\mathrm{k})$ of the modified negative exponential model can be negative, and still the model performs better compared to 
polynomials and linear equations. Second, the study shows that program ARSTAN, a program extensively used by researchers for standardizing and developing chronologies in dendroecology and dendroclimatology, uses the modified negative exponential model for detrending only when the estimated parameters are all positive. When this criterion $(a>0, b>0$, and $k>0$ ) fails it employs unacceptable alternative detrending model (simple linear curve with negative slope) that often results in a negative predicted or expected value. This is illustrated using specific example. Third, the study shows the effect of detrending models on autocorrelation structure of tree ring indexes, and on growth-climate relationships.

In the following section the study provides justification for favoring the modified negative exponential model in detrending tree-ring series for dendro-climatic studies. Then, the study briefly describes the reasoning or arguments as to why the asymptote should be a small positive number for long tree-ring series (over mature trees).

\subsection{Justification of the MNEM for Detrending}

Consider a series of radial increment measurements $R_{t}$ that is $n$ years in length, collected from a tree growing in a disturbance-free, open-canopy forest. Based on allometry of tree growth and its effect on radial increment (and ignoring the early juvenile growth increase often found in such trees), it is usually the case that this raw ring-width series will exhibit a decreasing trend with increasing age. This decrease tends to flatten out to some positive, asymptotic limit $\mathrm{k}$ as the tree matures so that age does not dominate the growth trend (Fritts 1976, and Cook and Peters 1997). A useful model for this age-related trend in ring-width series is the modified negative exponential model described in Eq.(6.2) and the curve may take various forms depending on the values of the coefficients (Figure 6.1).

As the above biological reasoning implies, the estimated value of $k$ should not be negative. But this should necessarily be true only if the tree-ring data are taken from a tree of sufficient age (middle aged or senescent tree). As trees mature and among-tree competition increases in a closed canopy forest, trees are forced to maintain canopy position to compete for sunlight. Height growth dominates and shortening of the crown follows but generally, this transition to middle age does not take place until the forest is 60-80 years old (Hicks 1998). Another empirical argument against a negative value of $k$ 
is that when $k$ is negative for a given tree-ring series then at the most recent end of a tree-ring curve, the observed value could be divided by a negative expected value and one would end up with negative ring width index. However, the experience of fitting the modified negative exponential model to short tree-ring series ( $<100$ years) of several central Appalachian hardwood species indicates that a negative value of $k$ has not resulted in negative expected values and consequently a negative tree-ring index.

The original negative exponential model (NEM) used for detrending has the form

$$
G_{t}=a e^{-b t}
$$

where the parameters are defined as in equation (6.2). Since this function (Eq.(6.3)) approaches zero as $t$ increases toward infinity it can not model the growth of those trees whose growth becomes relatively constant after a time. Consequently the modified negative exponential model (Eq.(6.2)) was used. This model (Eq.(6.2)) contains an additional additive parameter, $k$, constraining the growth curve from approaching zero. Since the parameter $k$ was introduced to prevent the negative exponential curve from approaching zero it cannot be negative. In other words, $k$ is the asymptotic limit where old trees settle down and maintain a reasonably constant radial growth rate over time. Since growth implies adding something, $k$ should not be negative for old trees.

The discussion and arguments above are presented to stress the point that one gets a meaningful estimate for $k$ when the tree-ring data is from old, mature or over-mature trees and the whole idea and definition of the asymptote $(k)$ revolves around the concept of old trees.

\subsection{Methods}

Tree-ring data from ten yellow-poplar trees were each fitted to five detrending models: the modified negative exponential model, the negative exponential model, a linear equation, a third-degree polynomial, and a cubic smoothing spline with 50\% cutoff of 32 years ( $L=32$ ). Note that a cubic spline is a segmented function consisting of thirddegree (cubic) polynomial functions joined together so that the whole curve, as well as the first and second derivatives, are continuous at the join points or knots. The segment length $(L)$ determines the flexibility or rigidity of the spline. The spline curve fits the ring-width series more closely as the segment length $L$ decreases. For detailed discussion on cubic splines see Cook and Peters (1981). 
All curve fitting was done in SAS (SAS Institute Inc. 1989) except for the cubic spline where program ARSTAN was used. After fitting each curve, ring-width index (RWI) was computed as ratio of actual to expected (curve value) growth. Ring-width index (RWI) obtained using the modified negative exponential model was then compared to RWI obtained using the other four detrending curves.

To explore the effect of detrending methods on growth-climate relationship five chronologies were developed using the five curve-fitting methods. A response function analysis (see Chapter 7) was then used to determine how $\mathrm{R}_{\text {climate }}^{2}$ and the relationship between radial growth and monthly climatic variables vary due to detrending models.

\subsection{Results and Discussion}

\section{A. Fitted Detrending Models}

Tree-ring data from the 10 trees were each fitted to the five detrending models. Specific issues are illustrated using ring-width data from four selected trees (Table 6.2). Figure 6.2 shows the plots of annual ring widths from the four trees. Superimposed on these plots are the fitted detrending curves that model the trend in radial growth associated with increasing tree-size.

All the estimated parameters of the modified negative exponential model (Table 6.3) were positive for trees 7 and 9 while the estimated values of the asymptote (k) were negative for trees 8 and 10. Will a negative asymptote result in negative predicted values? While the modified negative exponential model has a negative asymptote for trees 8 and 10, this model did not yield a negative expected growth (Figure 6.2), and showed better fit of the data when compared to the linear equation, the polynomial, and the cubic spline. For all trees, the modified negative exponential and the negative exponential models showed better fit $\left(\mathrm{R}^{2}>0.9\right)$ compared to the other three models (Table 6.3). This result goes against the argument that a negative asymptote may result in a negative expected growth near the end of the ring-width series. In fact, for tree 10, the linear and the polynomial models resulted in negative predicted values for 1993-1996 and 1996, respectively (Figure 6.2). In addition, for all four trees, the linear model consistently yielded smaller expected (predicted) values at the extreme ends of the ring-width series (Figure 6.2). 
From Table 6.3, one can see that not all the estimated parameters of the detrending models are statistically significant. It is important to understand that in dendroclimatic studies, detrending models are solely used to neutralize the effect of increasing tree-size, not for "predictive modeling" of a biological phenomenon. Hence, given an appropriate model, the fact that the parameters may not be statistically significant should not be a concern. Moreover, detrending models are not to be used for inferential purpose since from experience they generally overestimate the true age component of growth in tree-ring data.

\section{B. Effect of Detrending Models on Ring-width Index (RWI)}

In dendrochronology, ring-width index (RWI) has a sound interpretation. A RWI of one represents average growth while values above and below one represent above and below average growth respectively. However, this and other characteristics of RWI change with the detrending model fitted to obtain the index.

For each tree and detrending model, ring-width index $\left(I_{t}\right)$ was computed as the ratio of measured to expected growth. Figure 6.3 shows the plots of RWI for the four selected trees. The plots show that the linear equation and the negative exponential model (Eq.(6.3)) resulted in larger estimates of the ring-width index at the beginning and end of each series. Interestingly, the correlation coefficient between RWI from the modified negative exponential model (Eq.(6.2)) and those from the linear equation, Eq.(6.3), and the cubic spline were all above 0.6 and significant except for tree 10.

Another characteristics of RWI that reflects the suitability of detrending models is the variance ratio; ratio of variance of RWI during the early and late stage of growth. The purpose of detrending is to equalize the growth variations within cross-dated tree-ring series over time (Fritts 1976). Hence, a variance ratio close to one indicates an ideal situation. Table 6.4 compares the ratio of variance of RWI from 1935-1966 (early) to 1967-1996 (late). For the raw-ring width, the ratio of late-to-early period variance ranged from 0.13 for tree 7 to 0.38 for tree 9 (Table 6.4). After removal of the trend, the variance ratio improved (got closer to 1) indicating some degree of stability has been achieved. This is especially true for the modified negative exponential model.

The linear equation and the negative exponential model provided the largest estimates of variance ratio. Recall that the negative exponential model had a better fit of 
the tree-ring data compared to polynomial, and the cubic spline. However, it performed poorly in terms of variance stabilization. This suggests that higher $\mathrm{R}^{2}$ for a model fitted to ring-width data does not imply that the model is suitable for detrending. Although the modified negative exponential model had a negative asymptote for trees 8 and 10, this model performed well in terms of variance stabilization compared to the other four models. Hence a negative estimated value for $k$ does not necessarily imply a problem for short tree-ring series and the model can perform well (even better) than most commonly used functions, even with $k$ negative.

\section{Effect of Detrending Models on Autocorrelation}

Serial correlation (auto-correlation) in ring-width index (RWI) has an important biological interpretation. Autocorrelation in tree growth is essentially caused by climate. Climate during year t-1 affects growth for year t. A good climate year allows the tree to store energy that it can use the next year for say a vigorous leaf flush or to provide food from reserves during lean times. In addition, there is a recent growing interest among dendrochronologists for studying how autocorrelation of a particular species varies across sites, especially between mesic and dry sites. A recent discussion on ITRDB Forum posed a question: Is the magnitude of autocorrelation related with site characteristics? Or do trees of a species growing on more favorable site have higher or lower autocorrelation compared to trees growing on a more stressful site? Although there is no definite answer for this question, it is believed that autocorrelation in tree radial growth has an important linkage with the site characteristics that the tree is growing in and hence is recommended to be an area of important and timely investigation. Do detrending models affect autocorrelation in RWI?

To study the year to year dependence (autocorrelation) of radial growth, an autoregressive model of the form (Box and Jenkins, 1976)

$$
I_{t}=\phi_{0}+\phi_{i} \sum_{i=1}^{2} I_{t-i}+a_{t}
$$

where $I_{t}$ is the RWI at time $\mathrm{t}, \phi_{i}$ are the model parameters, and $a_{t}$ is the residual commonly called prewhitened RWI, was fitted to each ring-width index (RWI). Table 6.5 shows the estimated autoregressive parameters of the models that were fitted to ringwidth indexes of the selected trees after detrending each series using the five models. To 
assess how significant the autoregressive component was, the percentage of total variance of the detrended series that was explained by the autoregressive process (ExpVar or $\mathrm{R}^{2}$ ) was calculated (Table 6.5).

The result shows that the magnitude of autocorrelation depend on the detrending model (Table 6.5). The highest values of $\mathrm{R}^{2}$ were observed for Eq.(6.3) and the linear equation. These two models tend to overestimate the magnitude of autocorrelation and hence leave less climate related signals in the residual series. The more generally used modified negative exponential and spline functions appear to leave less autoregressive tendency in the index than do the linear or the simple negative exponential models. The autoregressive coefficient $\left(\phi_{1}\right)$ was also generally higher when the linear equation and Eq.(6.3) were used as detrending curves.

Most trees showed an autocorrelation structure of order 1, meaning that growth of this year is influenced by last year's growth. However, the use of a linear equation as a detrending function has resulted in a significant second order AR coefficient for tree 7. It is important to understand that not all trees of the same species can be modeled with the same order suggesting different degrees of responsiveness to the environment amongst trees. This could be related to genetic variation or to site heterogeneity, e.g., patches with different soil depths, micro-topography. But the result in Table 6.5 also indicates that differences in the magnitude and order of auto-correlation among tree-ring indexes of the same species could also result due to differences in the detrending function being employed.

\section{Effect of Detrending Models on Growth-climate Relationship}

The result showed that the percentage of total variability in growth explained by climate $\left(\mathrm{R}^{2}\right.$ climate) varied substantially. $\mathrm{R}^{2}$ climate was $46 \%$ when Eq.(2) was used for detrending, $40 \%$ for spline, $48 \%$ for the polynomial, $43 \%$ for Eq.(3), and $22 \%$ for the linear model. The linear model resulted in the smallest estimate of $\mathrm{R}^{2}$ climate. These data certainly suggests that the influence of climate on tree growth depends on the method used to remove the long-term trend. In addition, the significant climatic variables identified were different owing to the detrending curve used (Table 6.6).

Table 6.6 shows the sign and significant elements of the response function as a function of the model used to detrend the tree-ring data. All models indicate that radial 
growth is positively correlated with precipitation in current July and August. All except the linear model indicate significant positive correlation between radial growth and current June precipitation. Only the linear model yield negative correlations between radial growth precipitation in prior July and temperature in current August. Positive correlations between growth and precipitation in prior November and December are indicated only by the MNEM. According to the polynomial and spline model radial growth is negatively correlated to precipitation in current April. The data indicate important differences in growth-climate linkage caused by differences in detrending models. The linear model, although picks comparable number of significant monthly variables, provided $\mathrm{R}^{2}$ climate about $50 \%$ less compared to other models.

\section{E. Program ARSTAN}

Program ARSTAN produces chronologies from tree-ring measurement series by detrending and indexing (standardizing) the series, then applying a robust estimation of the mean value function to remove effects of endogenous stand disturbances (GrissinoMayer et al. 1997, Holmes et al. 1986). To detrend a tree-ring series, program ARSTAN uses three curve-fitting techniques. These are the modified negative exponential model, linear equation, and the cubic smoothing spline. The program rejects the modified negative exponential model if the estimated value of the asymptote $(k)$ is negative. The program fits a linear equation when the estimated value of $k$ is found to be negative.

After averaging the corresponding radii-sequences for each tree, the tree-specific ring-width series were analyzed using program ARSTAN. The program usually produces about 5 to 8 files containing various outputs. The "*.coe" file contains, for each series, the detrending curve used and its estimated parameters. Examination of this file showed that two trees (YPNF09 and YPNF07) were fitted with the modified negative exponential model and the remaining two (YPNF08 and YPNF10) were fitted with simple linear equation with negative slope. When tree-specific ring width series from all of the ten trees were analyzed in ARSTAN four were fitted with Eq.(6.2) and the remainder six were fitted with a linear equation.

The estimated values of the parameters of the modified negative exponential model (trees 7 and 9), and the linear equation (trees 8 and 10) from program ARSTAN were exactly the same as those obtained using SAS procedures. As opposed to SAS 
outputs, ARSTAN does not provide summary statistics such as standard error of the estimated values of the parameters, confidence intervals, and probability values (pvalues). However, the major concern is that since program ARSTAN fitted a linear equation to tree 10 regardless of the fact that the growth curve values for the last four years of the series (1993-1996) are negative and this obviously results in negative treering index for years 1993 to 1996. This could be a serious shortcoming of the program and hence users should use the estimated values of the coefficients to check for negative fitted values near the ends of each series.

\section{F. Suggested Modification of The Convergence Criterion}

The Statistical Analysis System (SAS, 1985) provides several well-known iterative methods (such as the Gauss-Newton, steepest descent, and the Marquardt) to fit and estimate parameters of a non-linear model. The iterative technique most favored is the Marquardt (1963) iterative algorithm, as it represents a compromise between the Gauss-Newton and steepest descent methods and appears to combine the best features of both while avoiding their most serious limitations (Draper and Smith, 1981). For a given non-linear model to be analyzed, this iterative technique requires specification of the names and starting values of the parameters to be estimated, the model using a single dependent variable, and the partial derivatives of the model with respect to each parameter (SAS, 1985).

However, regardless of the iterative technique being employed, SAS determines that iteration has converged to an optimal solution (global minimum sum of squared residuals) if

$$
\frac{S S R_{i}-S S R_{i-1}}{S S R_{i}+10^{-6}}<C
$$

Where $S S R$ is the sum of squared residuals, $i$ is the iteration number, and $C=10^{-8}$ (by default). The experience of fitting the modified negative exponential model to tree-ring data from the Central Appalachian region indicates that such a small value of $C$ is also a common cause for failure of the model to fit a particular tree-ring series.

While the default value worked on 7 of the 10 series, by changing the value of $C$ to $10^{-6}$ tree-ring data from the other three trees were fitted to the model. The iterations for these tree-ring series failed to converge when the default convergence criterion 
( $C=10^{-8}$ ) was used. The default value of $C$ is not a corner stone or yardstick and there is no research reported in the literature that indicates that this value should not be changed.

The analysis in this study suggests that to fit the modified negative exponential model to tree-ring data, one should first use the default convergence criterion. If the method fails to converge it could be a combination of three possible factors: (a) the observed ring-width pattern may be too irregular to fit the model, (b) the convergence criterion may be too small, or (c) the starting values of the parameters may not be as "accurate" as needed to assure convergence. If the cause is (a), of course, one has to resort to an alternative detrending model. But, the latter two causes could be solved by moderately increasing the default convergence criterion, $C$, to $10^{-6}$ and by specifying "accurate" starting values based on intelligent guesses, preliminary estimates obtained from earlier runs of the iterative process, or values suggested by information gained in fitting a similar model in related studies.

Researchers in dendroclimatic studies should indicate range of the estimated values of the parameters of the modified negative exponential model. This could be a valuable piece of information for researchers working on similar studies. For example, in this study, based on 10 trees fitted to the modified negative exponential model the value of $a$ ranges from 3.2 to $6.8, b$ from 0.006 to 0.06 , and $k$ from -0.3 to 2.8 . From this range of data, it would be reasonable to use $(5.0,0.01,1.0)$ as the vector of starting values for the iterative process.

It is also important to note that besides non-convergence of the iteration, wrong starting values could cause the iteration to converge to a non-optimal solution (local minimum sum of squared residuals) and there are few but unreliable diagnostic tools to detect such non-optimal convergence (Draper and Smith 1981, Fekedulegn et al. 1999).

\section{G. Summary and Recommendation}

This study showed that the percentage of variation in annual radial growth explained by climate $\left(\mathrm{R}^{2}\right.$ climate $)$ varied considerably due to differences in detrending models. The linear model, although is most widely used for detrending, removes climatic signals from a ring-width series. As a result, the variation in annual growth explained by 
climate was about 50\% smaller when a linear model was used for detrending ring-width series.

A variety of growth functions have been used for the curve-fitting process (detrending) in dendro-climatic studies. The simplest detrending method is to fit a linear equation to the data. It conforms to no theoretical model of tree growth, and is probably best used on series that are short or that have such an unusual growth pattern that the modified negative exponential model or the negative exponential model can not accommodate (Holmes et al. 1986). However, the results of this study indicate that for short-tree ring series the use of linear equations have resulted in tree-ring indices with undesirable properties and a negative expected growth near the late portion of some series. In addition, a ring-width index (RWI) obtained using a linear equation usually has a higher serial correlation, which is not explainable from a biological standpoint.

The results shown in this study indicate that abandoning the modified negative exponential model with a negative asymptote $(k)$ is certainly inappropriate unless it results in a negative expected growth. This model (with $k<0$ ) has performed better in stabilizing the mean and variance of the detrended series compared to a linear equation, cubic polynomial, the negative exponential model or a cubic spline of segment length 32 . However, program ARSTAN uses a linear equation when the asymptote $(k)$ is less than zero. The program fits a linear equation, regardless of the fact that at the late end of the series the expected growth was negative. This is a serious issue that needs to be looked at more carefully. Therefore, this study recommends that (a) users should check the expected growth (values from the fitted curve) when running program ARSTAN using the default options, (b) the negative exponential model and low order polynomials should also be included in Program ARSTAN as alternative detrending models and (c) the program should not reject the modified negative exponential model whenever $k$ is less than zero.

Although autocorrelation has sound biological interpretation, the degree (order) and extent of autocorrelation strongly depends on the detrending model used. That is, depending on the choice of the detrending model, autocorrelation of a particular species varies substantially. This obviously damages its biological interpretation and necessitates extreme cautions on its interpretation. In addition, this study has shown that significance 
of the elements of the response function and the variation in growth explained by climate is dependent on the detrending model used for removing the effect of tree size. The results suggest that for dendroclimatic studies to be comparable uniformity on the choice of the detrending method is essential and especially linear equations should not be considered as candidate detrending models for short tree-ring series ( $<100$ years). In light of the current interest in estimating, more objectively, the role of climate on radial growth of tree species in the northeast, the effects of detrending models deserve special considerations. 
Table 6.1. Model forms for computing ring-width index (RWI).

\begin{tabular}{cccc}
\hline & RWI as a ratio & \multicolumn{2}{c}{ RWI as a difference } \\
\hline$I_{t}=\frac{R_{t}}{G_{t}}$ & {$[\mathrm{a}]$} & $I_{t}=R_{t}-G_{t}$ & [b] \\
$I_{t}=\frac{R_{t(\log )}}{G_{t(\log )}}$ & {$[\mathrm{c}]$} & $I_{t}=R_{t(\log )}-G_{t(\log )}$ & [d] \\
$I_{t}=\frac{R_{t(+1)}}{G_{t(+1)}}$ & {$[\mathrm{e}]$} & $I_{t}=R_{t(+1)}-G_{t(+1)}$ & {$[\mathrm{f}]$} \\
$I_{t}=\frac{R_{t(\text { power })}}{G_{t(\text { power })}}$ & {$[\mathrm{g}]$} & $I_{t}=R_{t(\text { power })}-G_{t(\text { power })}$ & {$[\mathrm{h}]$}
\end{tabular}

where

$I_{t}$ is ring-width index (RWI) at time $t$

$R_{t}$ is the raw ring-width at time $t$

$G_{t}$ is the predicted value of ring-width at time $t$ from the model fitted to $R_{t}$

$R_{t(\log )}$ is $\log$ transformed ring-width

$G_{t(\log )}$ is the predicted value of ring-width from the model fitted to $R_{t(\log )}$

$R_{t(+1)}=R_{t}+1$

$G_{t(+1)}$ is the predicted value of ring-width from the model fitted to $R_{t(+1)}$

$R_{t(\text { power })}$ is power transformed ring-width

$G_{t(\text { power })}$ is the predicted value of ring-width from the model fitted to $R_{t(\text { power })}$ 
Table 6.2. Ring-width (mm) data from four yellow-poplar trees for the period 1935 to 1996. Data from trees 7 and 9 fit the modified negative exponential model with all parameters positive while data from trees 8 and 10 fit the model with a negative asymptote.

\begin{tabular}{lllllllllllllllllll}
\hline Disc No. & & & \multicolumn{10}{c}{ Average of two radii measurements } \\
\hline YPNF07 & 8.28 & 5.36 & 9.08 & 7.87 & 7.91 & 5.69 & 7.24 & 6.50 & 5.61 & 4.81 & 4.03 & 3.35 & 4.91 & 4.30 & 3.98 & 5.54 & 4.39 \\
& 4.86 & 2.46 & 3.40 & 4.57 & 5.45 & 4.69 & 5.87 & 4.10 & 4.37 & 4.41 & 2.78 & 2.66 & 3.61 & 2.62 & 1.78 & 2.11 & 1.30 \\
& 2.99 & 2.87 & 3.45 & 3.59 & 2.77 & 2.93 & 1.89 & 1.55 & 1.23 & 2.10 & 2.22 & 2.87 & 2.01 & 2.05 & 1.61 & 1.88 & 2.41 \\
& 2.66 & 2.31 & 1.97 & 2.11 & 1.27 & 1.31 & 2.48 & 1.23 & 2.01 & 1.62 & 1.76 & & & & & \\
YPNF09 & 7.10 & 5.62 & 6.29 & 6.15 & 6.28 & 4.97 & 6.22 & 4.91 & 4.85 & 4.97 & 4.66 & 3.64 & 5.41 & 4.60 & 3.79 & 5.83 & 4.88 \\
& 5.01 & 2.68 & 3.37 & 4.44 & 5.07 & 4.89 & 5.34 & 4.11 & 3.48 & 3.58 & 2.37 & 2.33 & 4.08 & 3.15 & 2.14 & 2.76 & 1.91 \\
& 2.92 & 3.66 & 4.01 & 3.25 & 2.70 & 3.00 & 2.57 & 2.58 & 2.66 & 3.62 & 3.87 & 5.00 & 3.14 & 3.29 & 2.27 & 2.63 & 2.95 \\
& 3.94 & 3.18 & 1.72 & 2.06 & 2.35 & 2.29 & 3.36 & 3.09 & 3.95 & 3.77 & 2.99 & & & & & \\
YPNF08 & 3.46 & 3.21 & 4.11 & 3.70 & 4.98 & 4.59 & 5.50 & 5.44 & 5.28 & 4.14 & 4.28 & 3.10 & 4.15 & 4.03 & 3.85 & 4.61 & 4.42 \\
& 4.89 & 2.31 & 1.85 & 2.42 & 1.48 & 1.16 & 2.05 & 2.14 & 2.20 & 1.75 & 1.22 & 1.11 & 2.65 & 2.04 & 1.40 & 1.56 & 1.24 \\
& 3.10 & 2.47 & 4.21 & 3.04 & 2.68 & 3.24 & 1.98 & 1.20 & 1.20 & 1.78 & 1.92 & 2.00 & 1.65 & 1.53 & 1.84 & 1.95 & 1.59 \\
& 1.78 & 1.53 & 0.68 & 0.79 & 1.18 & 0.63 & 1.14 & 0.95 & 0.89 & 1.35 & 0.96 & & & & & \\
& & & & & & & & & & & & & & & & \\
YPNF10 & 5.56 & 4.49 & 5.45 & 5.05 & 4.70 & 3.93 & 3.92 & 3.71 & 3.59 & 3.23 & 2.89 & 2.47 & 3.97 & 3.66 & 2.63 & 2.84 & 2.70 \\
& 2.59 & 1.57 & 1.31 & 2.03 & 2.82 & 2.45 & 3.72 & 2.57 & 2.52 & 2.88 & 1.73 & 1.78 & 2.80 & 2.09 & 1.25 & 1.54 & 0.83 \\
& 1.96 & 1.57 & 2.15 & 2.13 & 1.68 & 1.87 & 1.22 & 0.92 & 0.56 & 0.97 & 0.92 & 0.78 & 0.61 & 0.60 & 0.51 & 0.56 & 0.68 \\
& 0.52 & 0.39 & 0.29 & 0.38 & 0.39 & 0.37 & 0.32 & 0.38 & 0.29 & 0.33 & 0.37 & & & & & \\
\hline
\end{tabular}


Table 6.3. Parameter estimates and summary statistic of fit for five detrending models fitted to four selected trees.

\begin{tabular}{|c|c|c|c|c|c|c|c|c|c|c|c|c|c|c|c|c|}
\hline \multirow[b]{2}{*}{ Tree \# } & \multicolumn{4}{|c|}{$\begin{array}{l}\text { The modified negative exponential } \\
\text { model }\end{array}$} & \multicolumn{3}{|c|}{$\begin{array}{l}\text { The negative exponential } \\
\text { model }\end{array}$} & \multicolumn{5}{|c|}{ Third degree polynomial model $(\mathrm{p}=3)$} & \multicolumn{3}{|c|}{ The linear model } & \multirow{2}{*}{$\begin{array}{l}\text { Spline } \\
\mathrm{R}^{2}\end{array}$} \\
\hline & $\mathrm{a}$ & $\mathrm{b}$ & $\mathrm{k}$ & $\mathrm{R}^{2}$ & $\mathrm{a}$ & $\mathrm{b}$ & $\mathrm{R}^{2}$ & $\mathrm{~b}_{0}$ & $\mathrm{~b}_{1}$ & $\mathrm{~b}_{2}$ & $\mathrm{~b}_{3}$ & $\mathrm{R}^{2}$ & $\mathrm{~b}_{0}$ & $\mathrm{~b}_{1}$ & $\mathrm{R}^{2}$ & \\
\hline 9 & $4.09^{*}$ & $0.06^{*}$ & $2.79^{*}$ & 0.96 & $5.87^{*}$ & $0.01^{*}$ & 0.96 & $6.59^{*}$ & $-0.17^{*}$ & 0.002 & $-6 . \mathrm{E}-6$ & 0.64 & $5.44^{*}$ & $-0.05^{*}$ & 0.51 & 0.47 \\
\hline 7 & $6.79^{*}$ & $0.04^{*}$ & $1.33^{*}$ & 0.95 & $7.55^{*}$ & $0.03^{*}$ & 0.95 & $8.03^{*}$ & $-0.28^{*}$ & 0.005 & $-3 . \mathrm{E}-5$ & 0.79 & $6.39^{*}$ & $-0.09^{*}$ & 0.70 & 0.75 \\
\hline 8 & $5.11^{*}$ & 0.02 & -0.26 & 0.91 & $4.90^{*}$ & $0.02^{*}$ & 0.91 & $4.92^{*}$ & $-0.12^{*}$ & 0.001 & $-9 . \mathrm{E}-6$ & 0.62 & $4.37^{*}$ & $-0.06^{*}$ & 0.59 & 0.60 \\
\hline 10 & $5.97^{*}$ & $0.03^{*}$ & -0.88 & 0.96 & $5.35^{*}$ & $0.04^{*}$ & 0.96 & $5.27^{*}$ & $-0.20^{*}$ & $0.004^{*}$ & $-3 . E-5$ & 0.88 & $4.33^{*}$ & $-0.07^{*}$ & 0.85 & 0.88 \\
\hline
\end{tabular}

Table 6.4. Variance ratio ${ }^{1}$ of ring-width index.

\begin{tabular}{|c|c|c|c|c|c|c|c|c|}
\hline Tree \# & & & & & & & & \\
\hline Model Fitted & Mean $^{2}$ & Ratio & Mean & Ratio & Mean & Ratio & Mean & Ratio \\
\hline Exponential (2) & 1.00 & 1.54 & 1.00 & 1.07 & 1.00 & 1.56 & 1.00 & 1.47 \\
\hline Exponential (3) & 1.00 & 2.37 & 1.00 & 1.49 & 1.00 & 1.81 & 1.00 & 1.48 \\
\hline Linear & 1.00 & 2.21 & 1.00 & 2.97 & 0.13 & 1256 & 1.00 & 1.31 \\
\hline Polynomial $(\mathrm{p}=3)$ & 1.00 & 1.56 & 1.00 & 1.17 & 0.85 & 137 & 1.00 & 1.39 \\
\hline Cubic Spline & 1.00 & 1.64 & 1.00 & 1.50 & 1.00 & 1.59 & 1.00 & 1.65 \\
\hline Ring Width & 3.83 & 0.37 & 3.56 & 0.13 & 2.02 & 0.20 & 2.50 & 0.30 \\
\hline
\end{tabular}

${ }^{1}$ Variance ratio= (variance of RWI from 1935-1966/ variance of RWI from 1967-1996).

${ }^{2}$ Average RWI for the entire series.

Table 6.5. Parameter estimates and $\mathrm{R}^{2}$ (ExpVar) of the autoregressive models fitted to the RWI of selected trees.

\begin{tabular}{|c|c|c|c|c|c|c|c|c|c|c|c|}
\hline \multirow[b]{2}{*}{ Tree \# } & \multicolumn{2}{|c|}{ The MNEM } & \multicolumn{2}{|c|}{ Poly $(p=3)$} & \multicolumn{3}{|c|}{ Linear } & \multicolumn{2}{|c|}{ The NEM $^{1}$} & \multicolumn{2}{|c|}{ Spline } \\
\hline & $\phi_{1}$ & $\mathrm{R}^{2}(\%)$ & $\phi_{1}$ & $\mathrm{R}^{2}(\%)$ & $\phi_{1}$ & $\phi_{2}$ & $\mathrm{R}^{2}(\%)$ & $\phi_{1}$ & $\mathrm{R}^{2}(\%)$ & $\phi_{1}$ & $\mathrm{R}^{2}(\%)$ \\
\hline 9 & 0.38 & 14.4 & 0.37 & 13.5 & 0.54 & & 28.5 & 0.50 & 24.6 & 0.33 & 10.6 \\
\hline 7 & 0.31 & 10.0 & 0.31 & 10.5 & 0.40 & 0.41 & 40.0 & 0.34 & 11.4 & 0.27 & 7.2 \\
\hline 8 & 0.49 & 23.6 & 0.64 & 32.5 & 0.76 & & 34.0 & 0.63 & 39.0 & 0.39 & 14.0 \\
\hline $10^{*}$ & 0.54 & 29.0 & 0.53 & 28.9 & 0.55 & & 29.9 & 0.54 & 29.8 & 0.39 & 14.9 \\
\hline
\end{tabular}

${ }^{1} \mathrm{NEM}=$ the negative exponential model $(\mathrm{Eq}(3))$.

"The estimates for tree 10 using the polynomial model is after excluding the last two years and the estimates using the linear model is after excluding the last five-years. 
Table 6.6. Significant response function elements for five detrending models.

\begin{tabular}{|c|c|c|c|c|c|c|c|c|c|c|c|c|c|c|c|c|c|c|c|c|c|c|c|c|c|c|c|c|c|}
\hline \multirow[b]{2}{*}{ Model } & \multicolumn{15}{|c|}{ Precipitation } & \multicolumn{14}{|c|}{ Temperature } \\
\hline & $\mathrm{M}$ & $\mathrm{J} \mathrm{J}$ & A & $\mathrm{S}$ & $\mathrm{O}$ & $\mathrm{N}$ & D J & $\mathrm{F}$ & $\mathrm{M}$ & $\mathrm{A}$ & $\mathrm{M}$ & $\mathrm{J}$ & $\mathrm{J}$ & $\mathrm{A}$ & $S$ & $\mathrm{M}$ & $\mathrm{J}$ & $\mathrm{J}$ & $\mathrm{A}$ & $\mathrm{S}$ & $\mathrm{O}$ & $\mathrm{N}$ & D J F & $\mathrm{M}$ & A & $\mathrm{M}$ & $\mathrm{J}$ & $\mathrm{J} \mathrm{A}$ & $\mathrm{S}$ \\
\hline Expo2 & & & & & & $\mathrm{P}$ & $\mathrm{P} N$ & & & $\mathrm{P}$ & $\mathrm{P}$ & $\mathrm{P}$ & $\mathrm{P}$ & $\mathrm{P}$ & & & & $\mathrm{N}$ & & $\mathrm{P}$ & $\mathrm{P}$ & & & $\mathrm{N}$ & & $\mathrm{N}$ & $\mathrm{N}$ & & $\mathrm{P}$ \\
\hline Expo3 & & & & $\mathrm{N}$ & & & & & & & & $\mathrm{P}$ & $\mathrm{P}$ & $\mathrm{P}$ & & & $\mathrm{N}$ & $\mathrm{N}$ & $\mathrm{N}$ & & $\mathrm{P}$ & & $\mathrm{P}$ & $\mathrm{N}$ & $\mathrm{P}$ & $\mathrm{N}$ & $\mathrm{N}$ & & \\
\hline Poly & & & & $\mathrm{N}$ & & & & & & $\mathrm{N}$ & & $\mathrm{P}$ & $\mathrm{P}$ & $\mathrm{P}$ & & & & $\mathrm{N}$ & $\mathrm{N}$ & & $\mathrm{N}$ & & & $\mathrm{N}$ & $\mathrm{P}$ & $\mathrm{N}$ & $\mathrm{N}$ & & \\
\hline Spline & & & & $\mathrm{N}$ & & & & & & $\mathrm{N}$ & & $\mathrm{P}$ & $\mathrm{P}$ & $\mathrm{P}$ & & & & $\mathrm{N}$ & $\mathrm{N}$ & & $\mathrm{P}$ & & & & $\mathrm{P}$ & $\mathrm{N}$ & $\mathrm{N}$ & & \\
\hline Linear & & $\mathrm{N}$ & & $\mathrm{N}$ & & $\mathrm{P}$ & & & & & & & $\mathrm{P}$ & $\mathrm{P}$ & & $\mathrm{N}$ & & & & & $\mathrm{P}$ & $\mathrm{N}$ & $\mathrm{P}$ & & & $\mathrm{N}$ & $\mathrm{N}$ & $\mathrm{N}$ & \\
\hline
\end{tabular}

$\mathrm{P}$ indicates a positive element significant at $\alpha=0.05$ and $\mathrm{N}$ indicates a negative element significant at $\alpha=0.05$. 


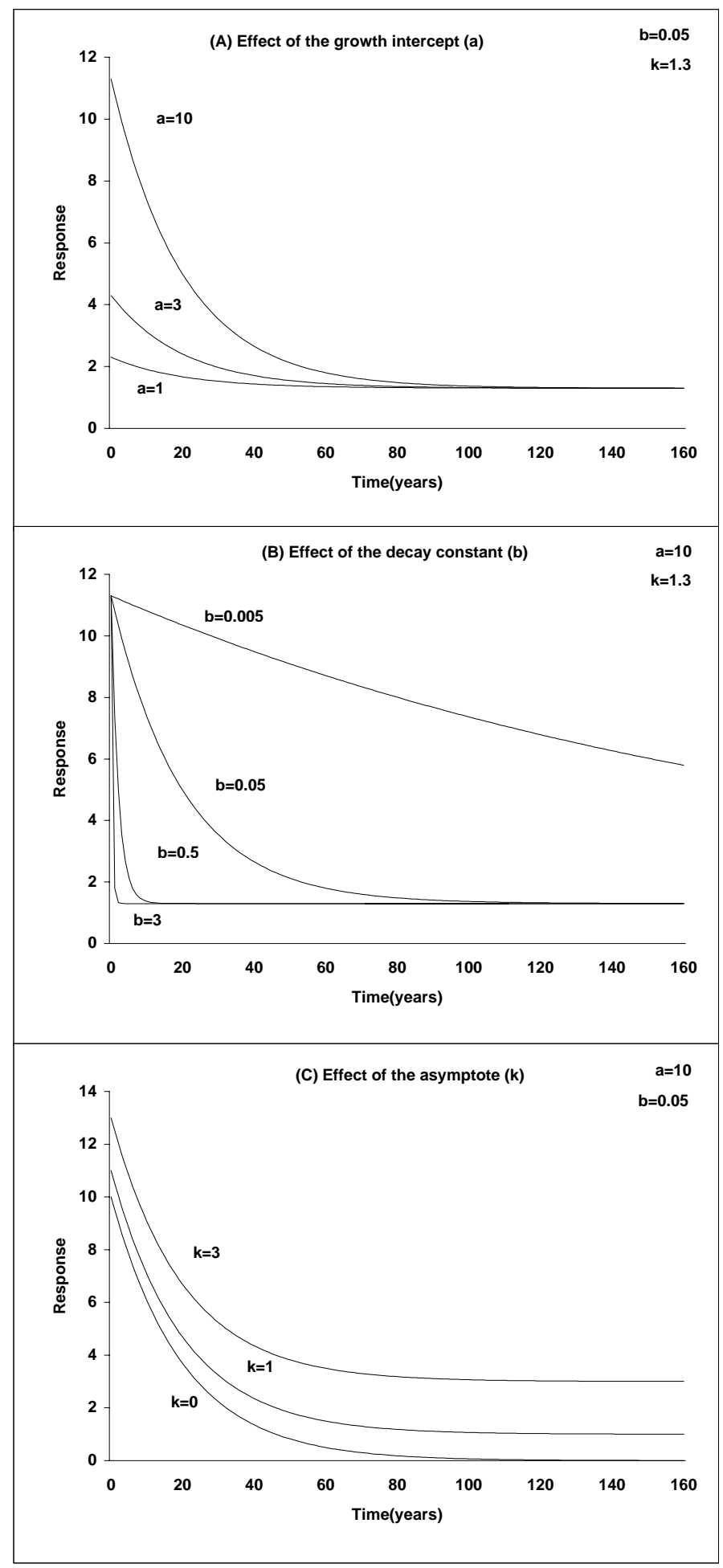

Figure 6.1. Forms of the modified negative exponential model depending on the parameters. 


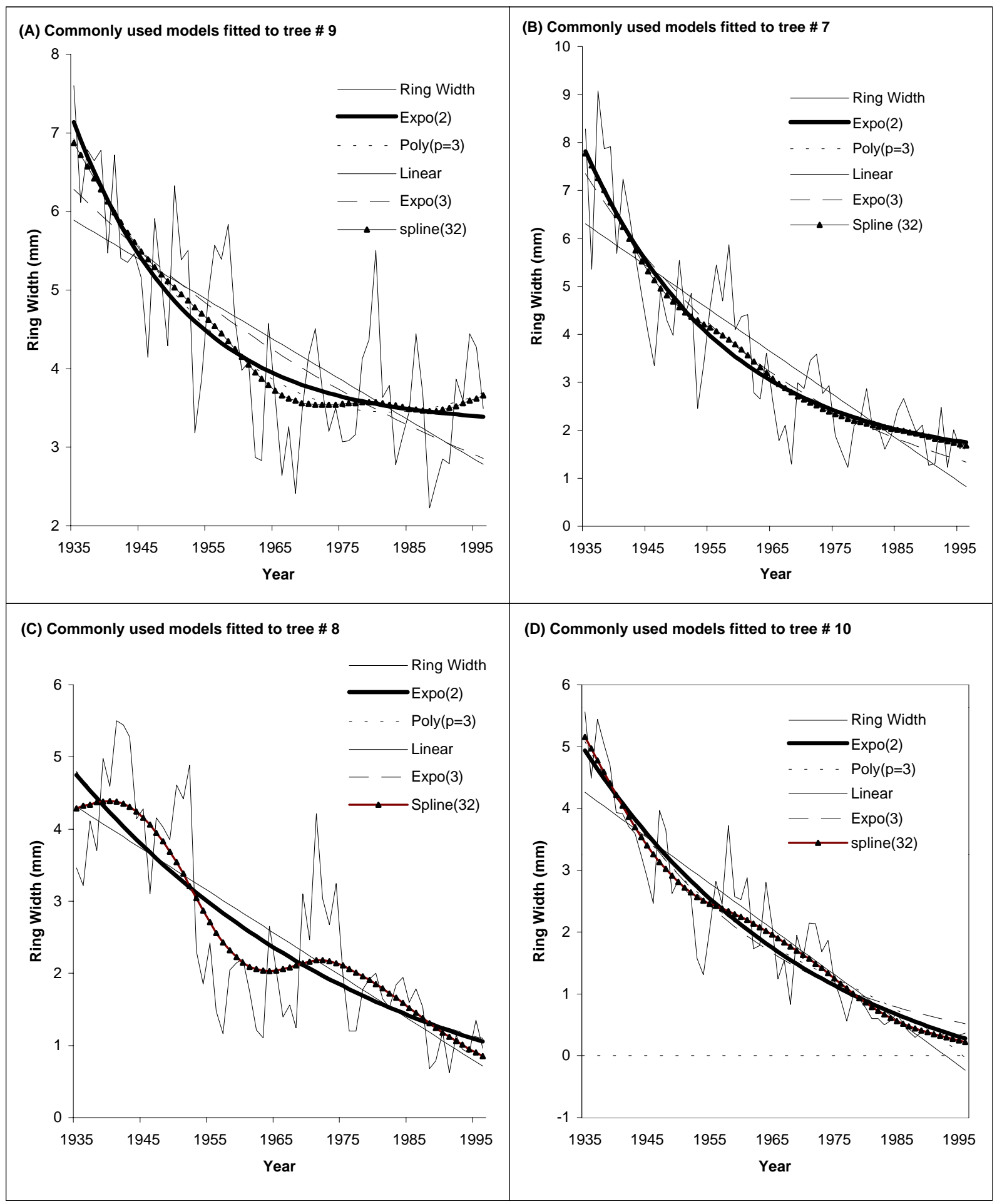

Figure 6.2. Commonly used detrending models fitted to ring-width series of selected trees. 


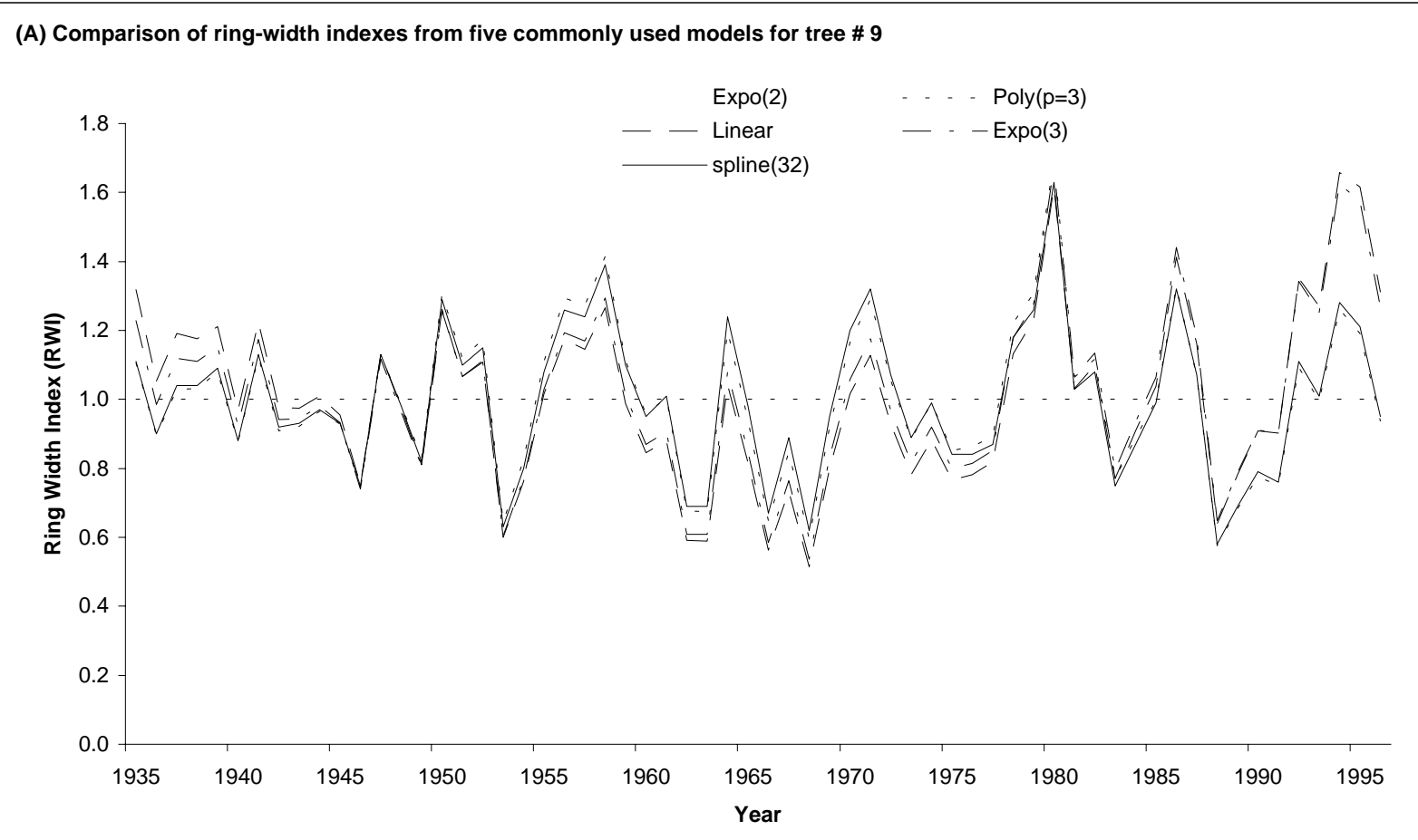

(B) Comparison of ring-width indexes from five commonly used models for tree \#7

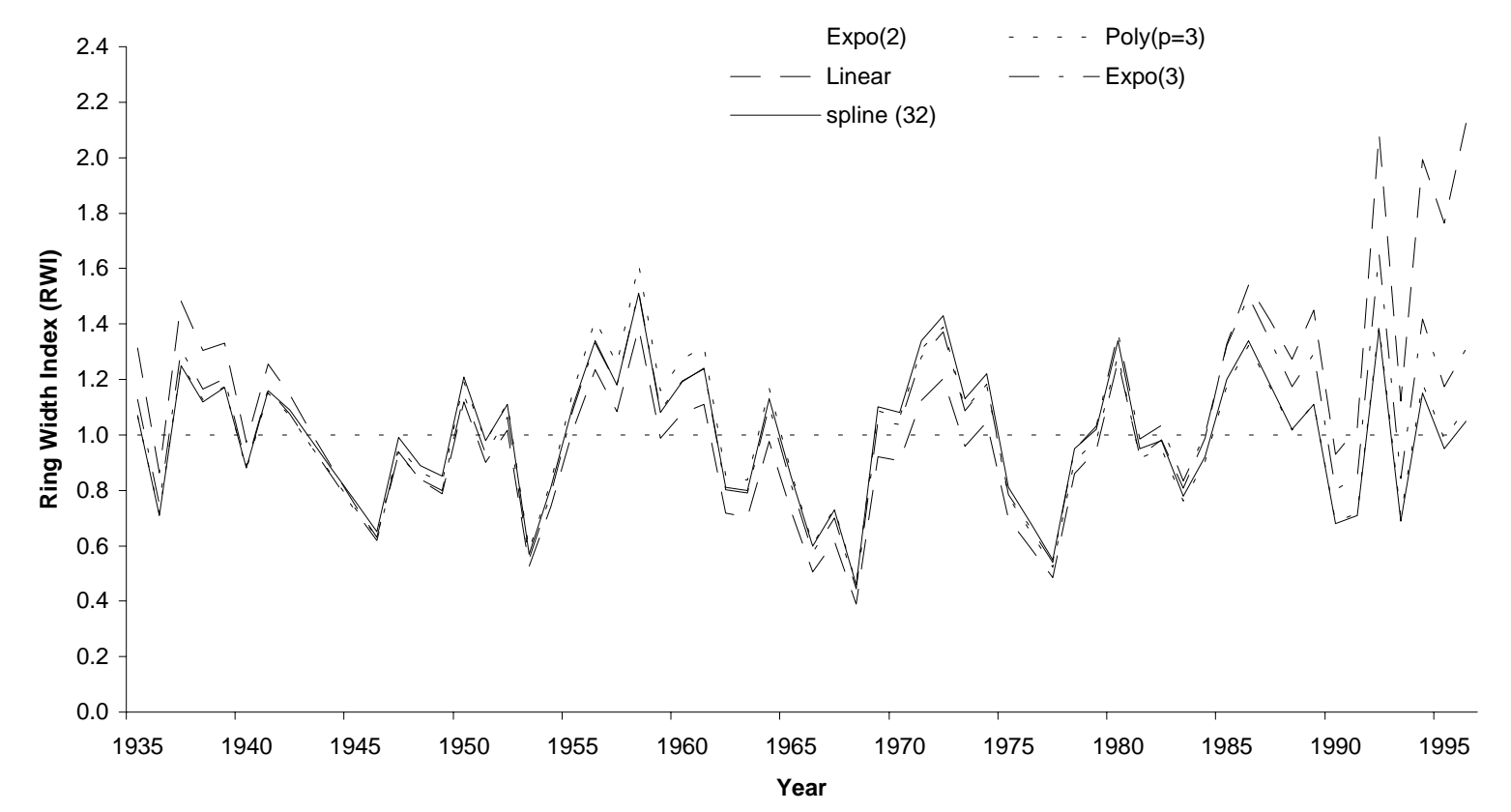

Figure 6.3 (a). Ring-width index for trees 9 and 7 based on five detrending models. 


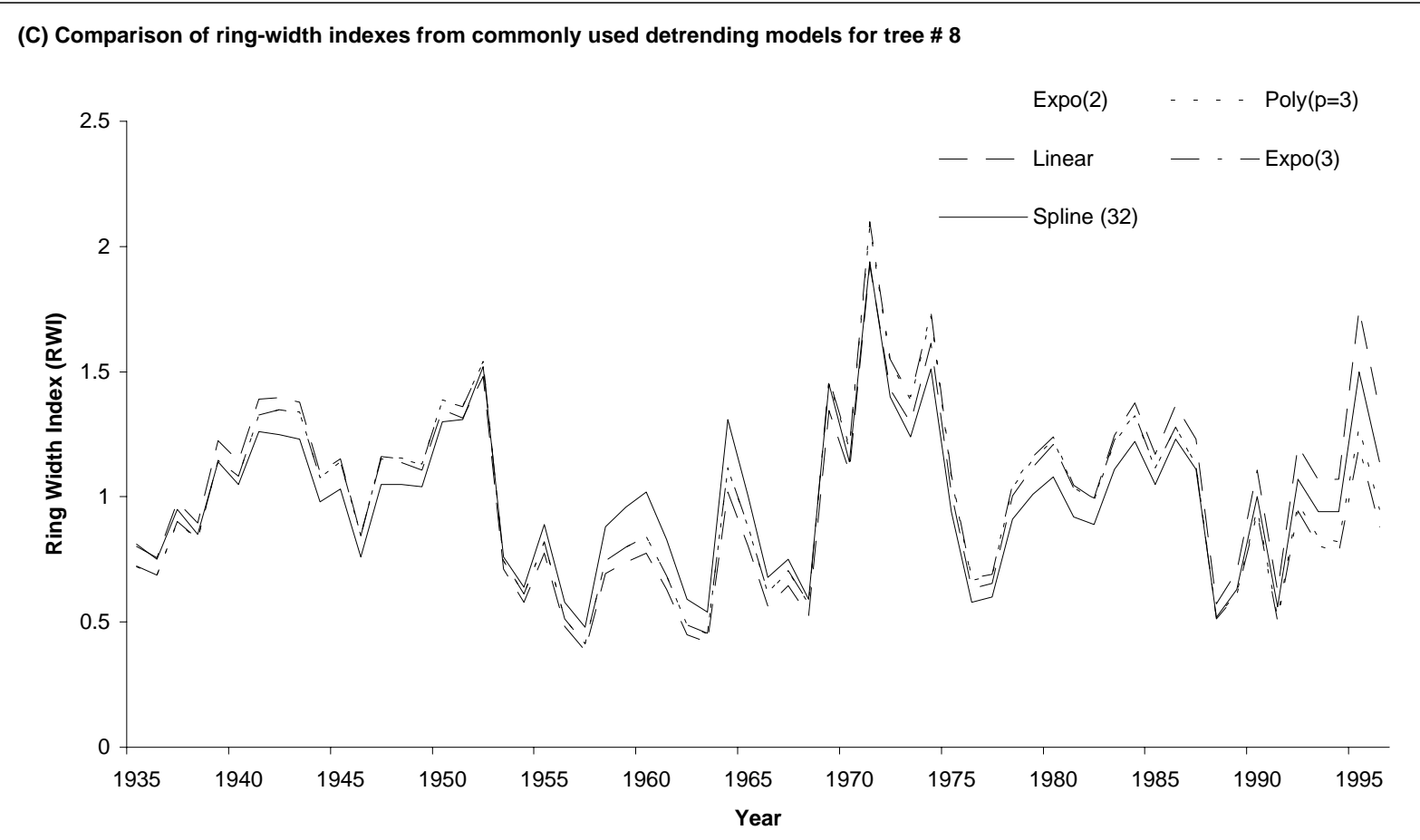

(D) Comparisson of ring-width indexes for tree \# 10
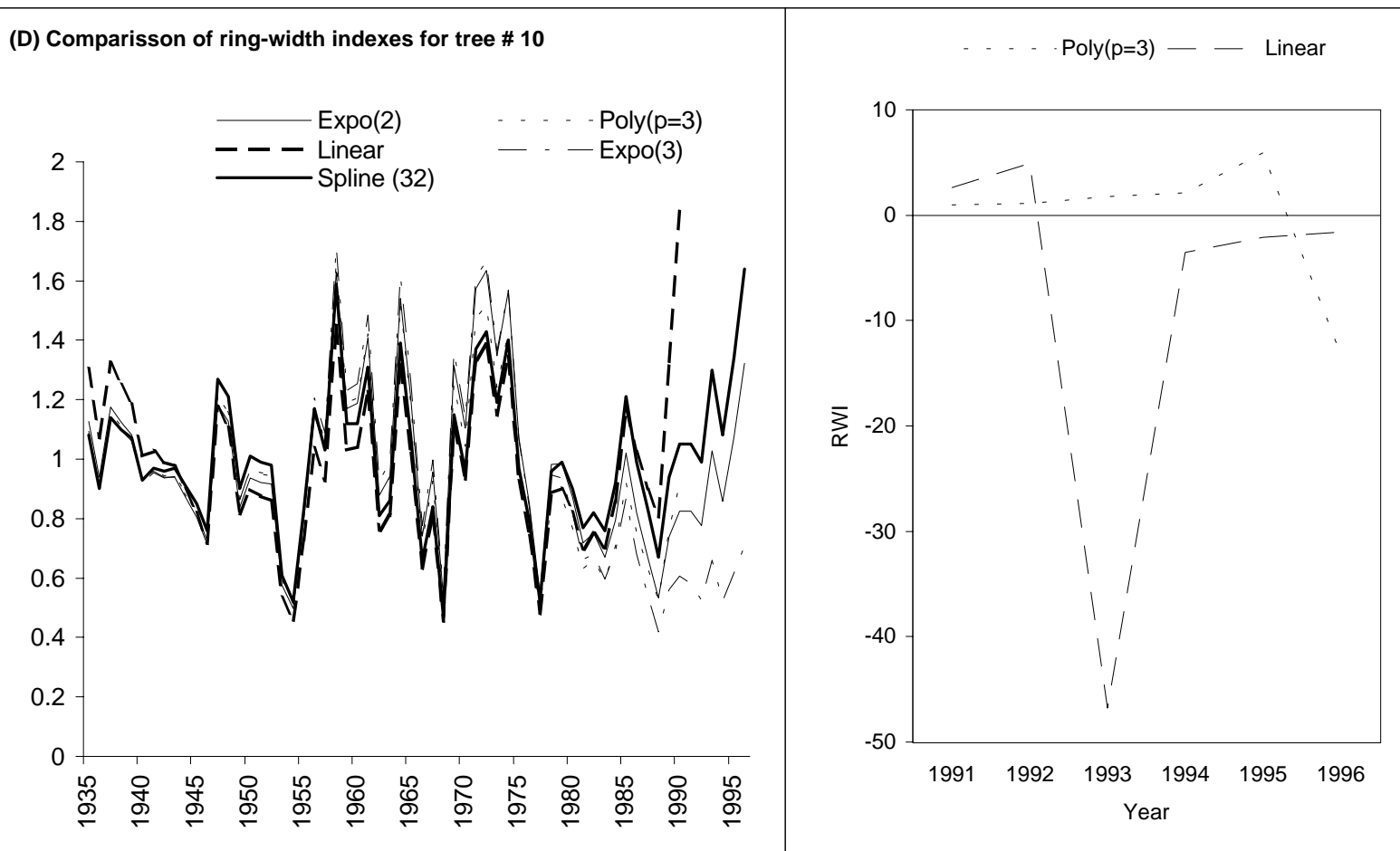

Figure 6.3 (b). Ring-width index for trees 8 and 10 based on five detrending models. 


\section{CHAPTER 7: STUDY V}

\section{DEVELOPMENT OF MULTIVARIATE RESPONSE FUNCTION FOR ANALYZING RADIAL INCREMENT IN RELATION TO CLIMATE}

\subsection{Introduction and Background to the Problem}

The model relating ring-width to monthly climate: The aim of the response function in dendroclimatology is to diagnose the influence of climate on the annual radial growth of trees using a model of the form

$$
y_{i}=\beta_{0}+\beta_{1} x_{1 i}+\beta_{2} x_{2 i}+\ldots+\beta_{k} x_{k i}+\varepsilon_{i}(i=1,2, \ldots, n)
$$

where the response variable $y$ is the standard, prewhitened, or postwhitened tree ring chronology, the predictors $x_{1}, x_{2}, \ldots, x_{k}$ are the climatic variables (monthly total precipitation and monthly mean temperature), $\beta_{0}, \beta_{1}, \beta_{2}, \ldots, \beta_{k}$ are the regression coefficients or parameters to be estimated, $i=1,2, \ldots, n$ is the number of years, and $\varepsilon_{i}$ is a model error, assumed uncorrelated from observation to observation, with mean zero and constant variance $\left(\sigma^{2}\right)$.

Effect of multicollinearity: Because climatic variables are often highly intercorrelated (Guiot et al. 1982) use of ordinary least squares (OLS) to estimate the parameters of the response function given in Eq.(1) results in instability and variability of the regression coefficients. That is, use of OLS when the climatic variables exhibit multicollinearity may result in regression coefficients much larger than physical or practical situation would deem reasonable (Draper and Smith 1981), coefficients that wildly fluctuate in sign and magnitude due to a small change in the response or climatic variables, and coefficients with inflated standard errors. Therefore, using ordinary regression procedure under high level of correlations among the climatic variables damages the three characteristics of the coefficients that are of major interest to dendroclmatologists.

In general, a dendroclimatologist interested in drawing inferences from the sign or magnitude of the regression coefficients should be aware that least squares coefficients of the climatic variables are poorly estimated in the presence of multicollinearity. Similarly, 
if the interest is developing a linear prediction equation one should be warned that even though the model fits the data quite well, multicollinearity severely prohibit quality predictions (Gunst and Mason 1980, Myers 1986). It is worth mentioning at this point that the major interest in dendroclimatology is diagnosis of the effects of climatic variables rather than developing a prediction model. However, regardless of the purpose for which the parameters of the growth response model are estimated multicollinearity poses serious difficulties on regression results and hence provides misleading information on the nature of the relationship between climatic variables and radial growth.

Statistical methods that account for multicollinearity: There are three biased estimation techniques to handle the problem of multicollinearity and produce stable and meaningful coefficients for the climatic variables. These include principal, ridge, and latent root regression. Hence, Fritts et al. (1971) was the first to introduce the method of principal components regression rather than OLS for estimating response functions in dendroclimatology. The estimators of the parameters, in the response function of Eq.(1), obtained after performing PCR are referred to as principal component estimators (Gunst and Mason 1980) and Fritts (1976) refers to the values of these estimators as elements of the response function. An excellent discussion on the concept and interpretation of response functions can be found in Fritts (1976).

The methodology of developing a radial growth response model using PCR as presented by Fritts et al. (1971), Fritts (1976), and Guiot et al. (1982) suffers from three drawbacks. First, it employs an incorrect distribution of the test statistic used for assessing the significance of the climatic variables. Second, the definition of the elements of the response function and the method of estimating their standard errors (measure of how precise the climatic coefficients are) are not in agreement. Third, the principal component selection rule suggested eliminates some of the most important components that explain the largest variation in the original climatic data.

In addition, the discussion of the methodology presented in these earlier studies does not contain a demonstration of the technique and lacks the statistical and algebraic details required for a clear understanding and estimation of the response function using principal components regression. In this study statistical and algebraic techniques are used to present a step-by-step procedure that clearly illustrates the estimation of a radial 
growth response model using principal components regression. In addition, for all subsequent discussions this study uses the standard matrix representation of the model given in Eq.(1), where the values of the tree-ring chronology are arranged in a column vector and the climatic variables are represented in a matrix where each row contains a reading or measurement for each climatic variable. The earlier studies use a nonstandard matrix representation and this may lead to confusion.

Interpreting response function: Information regarding the influence of climatic variables on tree radial growth is extracted from the sign, magnitude, and statistical significance of the elements of the response function. The sign indicates the direction of the relationship, the magnitude indicates the degree of influence, and the significance indicates whether the influence was due to chance or not. Fritts et al. (1971), Fritts (1976), and Guiot et al. (1982) test the statistical significance of each element of the response function by constructing a $95 \%$ confidence interval (CI) using a test-statistic whose source or theoretical derivation is not indicated. Hence, this study present the inferential procedure that uses the appropriate test-statistic given by Gunst and Mason (1980) but the original work was made by Mansfield et al. (1977). This new test-statistic tests the hypothesis $H_{0}: \beta_{j}=0$ vs. $H_{0}: \beta_{j} \neq 0$ using the principal component estimator of the coefficient of the $j^{\text {th }}$ climatic variable.

The construction of a CI using the method described by the early dendroclimatic studies or Mansfield et al. (1977) requires an estimate of the standard error for each element of the response function. Fritts (1976) provides an equation that estimates the square of the standard errors of the elements of the response function. However, the result from this equation provides the square of standard errors or variances of the principal component estimators of the regression coefficients associated with the standardized climatic variables and not with the original or natural climatic variables. Recall that Fritts (1976) defines elements of the response function as the values of the principal component estimators of the regression coefficients that are associated with original or initial climatic variables. Hence this study presents a complete and clear derivation of the method used to estimate standard errors of the principal component estimators and compare the result with that of Fritts (1976). 
In addition to the problem of multicollinearity among the climatic variables which necessitates the use of a biased estimation technique, an entirely different set of difficulties arise when developing a diagnostic model using ring-width as measure of growth. This is because ring-width violates the two critically important assumptions of the proposed response model (Eq.(1)). These are the assumptions of independence and homogeneity of variance. This chapter also addresses the methods used to transform ringwidth series so as it satisfies these two assumptions.

\subsection{Objectives}

Having reviewed the limitations with the current method of developing a radial growth response function the objectives of this chapter are: to recalibrate the current methodology and present a step-by-step procedure for estimating a response function using principal components regression, to present a derivation of the standard error of the principal component estimators of the coefficients of the climatic variables, to introduce the test statistic that is appropriate for testing the significance of the regression coefficients using the principal component estimators, and to demonstrate the application of principal components regression in dendroclimatology.

\subsection{Methods}

\subsubsection{The Multiple Regression Model}

Consider a dendroclimatic research in which the data consists of a tree ring chronology that spans $n$ years (i.e., the response variable $y$ ) and $k$ climatic variables $x_{1}, x_{2}, \ldots, x_{k}$. If the researcher assumes that in the region of the $x$ 's defined by the data, $y$ is related approximately linearly to the climatic variables, then a model of the form given in Eq.(1), where $y_{i}$ is the tree ring index at the $i^{\text {th }}$ year, $x_{j i}$ is the $i^{\text {th }}$ year reading on the $j^{\text {th }}$ climatic variable and $\varepsilon_{i}$ is the $i^{\text {th }}$ year model error, assumed uncorrelated from observation to observation, with mean zero and constant variance, $\sigma^{2}$, may be reasonable. In addition, for purpose of testing hypothesis and calculating confidence intervals it is assumed that $\varepsilon_{i}$ is normally distributed. Using matrix notation, the model in Eq.(1) can be written:

$$
\mathbf{y}=\mathbf{X} \boldsymbol{\beta}+\boldsymbol{\varepsilon}
$$

where 


$$
\mathbf{y}=\left[\begin{array}{c}
y_{1} \\
y_{2} \\
\cdot \\
\cdot \\
\cdot \\
y_{n}
\end{array}\right]_{n \times 1} \quad \mathbf{X}=\left[\begin{array}{ccccccc}
1 & x_{11} & x_{21} & \cdot & \cdot & \cdot & x_{k 1} \\
1 & x_{12} & x_{22} & \cdot & \cdot & \cdot & x_{k 2} \\
\cdot & \cdot & \cdot & & \cdot \\
\cdot & \cdot & \cdot & & \\
\cdot & \cdot & \cdot & & & \cdot \\
1 & x_{1 n} & x_{2 n} & . & . & . & x_{k n}
\end{array}\right]_{n \times(k+1)} \quad \boldsymbol{\beta}=\left[\begin{array}{c}
\beta_{0} \\
\beta_{1} \\
\beta_{2} \\
\cdot \\
\cdot \\
\cdot \\
\beta_{k}
\end{array}\right]_{(k+1) \times 1} \quad \text { and } \boldsymbol{\varepsilon}=\left[\begin{array}{c}
\varepsilon_{1} \\
\varepsilon_{2} \\
\cdot \\
\cdot \\
\cdot \\
\varepsilon_{n}
\end{array}\right]_{n \times 1}
$$

The least squares estimator $\mathbf{b}=\left(\begin{array}{lllllll}b_{0} & b_{1} & b_{2} & . & . & b_{k}\end{array}\right)^{\prime}$ of the regression coefficients of the climatic variables is (assuming $\mathbf{X}$ is of full column rank) $\hat{\boldsymbol{\beta}}=\mathbf{b}=\left(\mathbf{X}^{\prime} \mathbf{X}\right)^{-1} \mathbf{X}^{\prime} \mathbf{y}$ and the variance-covariance matrix of the estimated regression coefficients in vector $\mathbf{b}$ is $\operatorname{Var}(\mathbf{b})=\sigma^{2}\left(\mathbf{X}^{\prime} \mathbf{X}\right)^{-1}$ (Draper and Smith 1981, Myers 1986). Each column of $\mathbf{X}$ represents measurements for a particular climatic variable. If one assumes that there is a constant term (intercept) in the model, then the first column of $\mathbf{X}$ is a column of ones.

The multiple linear regression model in Equations (1) and (2) can be written in alternative forms by transforming the climatic variables. The commonly used transformations of the climatic variables in dendroclimatology are centering and scaling, and standardizing. These alternative formulations are used for better parameter estimation and interpretation (Gunst and Mason 1980). Transforming the climatic variables by centering and scaling, or standardizing has special merit in dendroclimatology in that it allows results from different studies to be comparable. These methods are given below.

\section{A. Centering and Scaling}

Suppose that the climatic variables (each column of $\mathbf{X}$ ) are centered and scaled, i.e., $x_{j i}$, the $i^{\text {th }}$ year measurement on the $j^{\text {th }}$ climatic variable $\left(x_{j}\right)$ in the natural units, is transformed into $x_{j i}^{*}$ as follows:

$$
x_{j i}^{*}=\frac{x_{j i}-\bar{x}_{j}}{s_{j}}
$$


where $s_{j}=\sqrt{\sum_{i=1}^{n}\left(x_{j i}-\bar{x}_{j}\right)^{2}}$. The process of centering and scaling allows for an alternative formulation of Eq.(1) as follows:

$$
y_{i}=\beta_{0}^{*}+\beta_{1}^{*}\left[\frac{x_{1 i}-\bar{x}_{1}}{s_{1}}\right]+\beta_{2}^{*}\left[\frac{x_{2 i}-\bar{x}_{2}}{s_{2}}\right]+\ldots+\beta_{k}^{*}\left[\frac{x_{k i}-\bar{x}_{k}}{s_{k}}\right]+\varepsilon_{i}
$$

Consider the model formulation in Eq.(4). Removal of the usual column of ones in the first column of the $\mathbf{X}$ matrix results in the model form

$$
\mathbf{y}=\beta_{0}^{*} \mathbf{1}+\mathbf{X}^{*} \boldsymbol{\beta}^{*}+\boldsymbol{\varepsilon}
$$

where, in this form, $\boldsymbol{\beta}^{*}=\left(\begin{array}{lllll}\beta_{1}^{*} & \beta_{2}^{*} & . & . & \beta_{k}^{*}\end{array}\right)^{\prime}$ is the vector of coefficients, apart from the intercept, and $\mathbf{X}^{*}$ is then $n \times k$ matrix of centered and scaled climatic variables. The notation $\mathbf{1}$ is used to denote an $n$-vector of ones. Centering and scaling makes $\mathbf{X}^{* \prime} \mathbf{X}^{*}$ to be the $k \times k$ correlation matrix of the climatic variables. Let the vector $\mathbf{b}^{*}=\left(\begin{array}{lllll}b_{1}^{*} & b_{2}^{*} & . & . & b_{k}^{*}\end{array}\right)^{\prime}$ be the least squares estimator of $\boldsymbol{\beta}^{*}$.

If a dendroclimatic data set is used to fit the centered and scaled model of Eq.(4), one can obtain the estimated coefficients in the original model of Eq.(1). The coefficients of the natural climatic variables in the model of Eq.(1) are obtained by dividing the $j^{\text {th }}$ estimated coefficient in the centered and scaled model by $s_{j}$. That is

$$
b_{j}=\frac{b_{j}^{*}}{s_{j}} j=1,2, \ldots, k
$$

The estimate of the intercept, $\beta_{0}$, is obtained by computing

$$
b_{0}=b_{0}^{*}-\frac{b_{1}^{*} \bar{x}_{1}}{s_{1}}-\frac{b_{2}^{*} \bar{x}_{2}}{s_{2}}-\ldots-\frac{b_{k}^{*} \bar{x}_{k}}{s_{k}}
$$

where $b_{j}^{*}$ are estimates from the centered and scaled model of Eq.(4) and $b_{0}^{*}=\bar{y}$.

\section{B. Standardizing}

Consider the model in Eq.(1). Suppose the climatic variables $x_{1}, x_{2}, \ldots, x_{k}$ are standardized as follows: $x_{j i}$ is transformed into $x_{j i}^{s}$ using 


$$
x_{j i}^{s}=\frac{x_{j i}-\bar{x}_{j}}{S_{x_{j}}}
$$

where $S_{x_{j}}$ is the standard deviation of the climatic variable $x_{j}$ and the super subscript $s$ indicates that the climatic variables are standardized. The process of standardizing the climatic variables allows for an alternative formulation of Eq.(1) as follows:

$$
y_{i}=\beta_{0}^{s}+\beta_{1}^{s}\left[\frac{x_{1 i}-\bar{x}_{1}}{S_{x_{1}}}\right]+\beta_{2}^{s}\left[\frac{x_{2 i}-\bar{x}_{2}}{S_{x_{2}}}\right]+\ldots+\beta_{k}^{s}\left[\frac{x_{k i}-\bar{x}_{k}}{S_{x_{k}}}\right]+\varepsilon_{i}
$$

The model in Eq.(9) can be written in matrix form as:

$$
\mathbf{y}=\beta_{0}^{s} \mathbf{1}+\mathbf{X}^{s} \boldsymbol{\beta}^{s}+\boldsymbol{\varepsilon}
$$

where, in this form, $\boldsymbol{\beta}^{s}=\left(\begin{array}{lllll}\beta_{1}^{s} & \beta_{2}^{s} & . & . & \beta_{k}^{s}\end{array}\right)^{\prime}$ is the vector of regression coefficients, apart from the intercept, and $\mathbf{X}^{s}$ is then $n \times k$ matrix of standardized climatic variables.

Let $\mathbf{b}^{s}=\left(\begin{array}{llllll}b_{1}^{s} & b_{2}^{s} & . & . & b_{k}^{s}\end{array}\right)^{\prime}$ be the least squares estimator of $\boldsymbol{\beta}^{s}$. If a data set is used to fit the standardized model in Eq.(9), then the estimate of the coefficients of the natural climatic variables in model of Eq.(1) can be obtained from the estimates of the coefficients for the standardized climatic variables using the following transformation:

$$
b_{j}=\frac{b_{j}^{s}}{S_{x_{j}}}, j=1,2, \ldots, k
$$

and

$$
b_{0}=b_{0}^{s}-\frac{b_{1}^{s} \bar{x}_{1}}{S_{x_{1}}}-\frac{b_{2}^{s} \bar{x}_{2}}{S_{x_{2}}}-\ldots-\frac{b_{k}^{s} \bar{x}_{k}}{S_{x_{k}}}
$$

A careful consideration of the transformations given above indicates that it is always possible to move from one model formulation to another regardless of which model was used for the analysis. Any statistic related to the predicted response is the same for models of Eq.(1), Eq.(4), and Eq.(9). Therefore, if the analysis is accomplished solely for prediction of tree growth based on the climatic variables, the model formulation may be either Eq.(1), Eq.(4), or Eq.(9). The $t$-test on the regression coefficients (apart from the constant term) is the same for the three model formulations, and the estimate of the intercept terms in models of Eq.(4) and Eq.(9) is $\bar{y}$. If the purpose 
of developing the model is to interpret regression coefficients of the climatic variables or to extract information regarding the roles of individual climatic variables, then it is clear that the coefficients do not have the same interpretation for the three model formulations.

\subsubsection{Principal Components Regression (PCR)}

\section{A. The Underlying Concept}

Principal components regression (PCR) is a biased estimation technique for combating multicollinearity. The method results in estimation and prediction that is superior to ordinary least squares when used successfully (Draper and Smith 1981, Myers 1986). With this method, the original $k$ climatic variables are transformed into a new set of orthogonal or uncorrelated variables called principal components of the correlation matrix. This transformation ranks the new orthogonal variables in order of their importance and the procedure then involves eliminating some of the principal components to effect a substantial reduction in variance. After elimination of the least important principal components, a multiple regression analysis of the response variable against the reduced set of principal components is performed using ordinary least squares estimation (OLS). Once the regression coefficients for the reduced set of orthogonal variables have been calculated, they may be mathematically transformed into a new set of coefficients that correspond to the original or initial correlated set of variables. These new coefficients are principal component estimators (Gunst and Mason 1980). In dendroclimatic literature the values of these estimators are referred to as elements of the response function (Fritts, 1976). The computation of principal components regression is described below.

\section{B. Computational Technique}

Let $\mathbf{X}^{*}$ be the centered and scaled $n \times k$ data matrix as given in Eq.(5). The $k \times k$ correlation matrix of the climatic variables is then $\mathbf{C}=\mathbf{X}^{* *} \mathbf{X}^{*}$. Let $\lambda_{1}, \lambda_{2}, \ldots, \lambda_{k}$ be the eigenvalues of the correlation matrix, and $\mathbf{V}=\left[\begin{array}{llllll}\mathbf{v}_{1} & \mathbf{v}_{2} & . & . & \mathbf{v}_{k}\end{array}\right]$ be the $k \times k$ matrix consisting the normalized eigenvectors associated with each eigenvalue. Note that the eigenvalues are the solutions of the determinantal equation $\left|\mathbf{X}^{* *} \mathbf{X}^{*}-\lambda \mathbf{I}\right|=0$ (Draper and Smith 1981) and associated with each eigenvalue, $\lambda_{j}$, is a vector $\mathbf{v}_{j}$ which satisfies the homogeneous set of equations $\left(\mathbf{X}^{* \prime} \mathbf{X}^{*}-\lambda_{j} \mathbf{I}\right) \mathbf{v}_{j}=\mathbf{0}$. 
The vector $\mathbf{v}_{j}=\left(\begin{array}{llllll}v_{1 j} & v_{2 j} & . & . & v_{k j}\end{array}\right)^{\prime}$ are the normalized solutions such that $\mathbf{v}_{j}^{\prime} \mathbf{v}_{j}=1$ and $\mathbf{v}_{j}^{\prime} \mathbf{v}_{i}=0$. That is, the eigenvectors have a unit length and are orthogonal to each other. Hence, the eigenvector matrix $\mathbf{V}$ is orthonormal, i.e., $\mathbf{V \mathbf { V } ^ { \prime }}=\mathbf{I}$.

Now consider the model formulation given in Eq.(5). That is, $\mathbf{y}=\beta_{0}^{*} \mathbf{1}+\mathbf{X}^{*} \boldsymbol{\beta}^{*}+\boldsymbol{\varepsilon}$. Since $\mathbf{V} \mathbf{V}^{\prime}=\mathbf{I}$ one can write the original regression model (Eq.(5)) in the form

$$
\mathbf{y}=\beta_{0}^{*} \mathbf{1}+\mathbf{X}^{*} \mathbf{V} \mathbf{V}^{\prime} \boldsymbol{\beta}^{*}+\boldsymbol{\varepsilon}
$$

or

$$
\mathbf{y}=\beta_{0}^{*} \mathbf{1}+\mathbf{Z} \boldsymbol{\alpha}+\boldsymbol{\varepsilon}
$$

where $\mathbf{Z}=\mathbf{X}^{*} \mathbf{V}$ and $\boldsymbol{\alpha}=\mathbf{V}^{\prime} \boldsymbol{\beta}^{*}$. $\mathbf{Z}$ is an $n \times k$ matrix of principal components and $\boldsymbol{\alpha}=\left(\begin{array}{lllll}\alpha_{1} & \alpha_{2} & . & . & \alpha_{k}\end{array}\right)^{\prime}$ is a $k \times 1$ vector of new coefficients. The model formulation in Eq.(14) can be expanded as $y=\beta_{0}^{*}+\alpha_{1} z_{1}+\alpha_{2} z_{2}+\ldots+\alpha_{k} z_{k}+\varepsilon$, where $z_{1}, z_{2}, \ldots, z_{k}$ are the $k$ new variables called principal components of the correlation matrix. Hence, the model formulation in Eq.(14) is nothing more than the regression of the response variable on the principal components, and the transformed data matrix $\mathbf{Z}$ consists of the $k$ principal components.

For the model in Eq.(14) the principal components are computed using:

$$
\mathbf{Z}=\mathbf{X}^{*} \mathbf{V}
$$

where $\mathbf{X}^{*}$ is the $n \times k$ matrix of centered and scaled climatic variables without the column of ones, and $\mathbf{V}$ is the $k \times k$ orthonormal matrix of eigenvectors. The principal components are orthogonal to each other, that is:

$$
\mathbf{Z}^{\prime} \mathbf{Z}=\left(\mathbf{X}^{*} \mathbf{V}\right)^{\prime}\left(\mathbf{X}^{*} \mathbf{V}\right)=\mathbf{V}^{\prime} \mathbf{X}^{*} \mathbf{X}^{*} \mathbf{V}=\mathbf{V}^{\prime} \mathbf{C} \mathbf{V}=\operatorname{diag}\left(\lambda_{1}, \lambda_{2}, \ldots, \lambda_{k}\right)
$$

Equation (16) shows that $\mathbf{z}_{j}^{\prime} \mathbf{z}_{j}=\mathbf{v}_{j}^{\prime} \mathbf{C} \mathbf{v}_{j}=\lambda_{j}$ and $\mathbf{z}_{j}^{\prime} \mathbf{z}_{i}=0$. From Eq.(15) one can see that the principal components are simply linear functions of the centered and scaled climatic variables and the coefficients of this linear combination are the eigenvectors. For example, the elements of the $j^{\text {th }}$ principal component, $z_{j}$, are computed as follows:

$$
z_{j}=v_{1 j} x_{1}^{*}+v_{2 j} x_{2}^{*}+\ldots+v_{k j} x_{k}^{*}
$$


where $v_{1 j}, v_{2 j}, \ldots, v_{k j}$ are elements of the eigenvector associated with $\lambda_{j}$, and $x_{j}^{*}$, s are the centered and scaled climatic variables obtained using Eq.(3). Note that $\sum_{i=1}^{n} z_{j i}=0$ and the sum of squares of the elements of $z_{j}\left(\sum_{i=1}^{n} z_{j i}^{2}\right)$ is $\lambda_{j}$. Since $\sum_{j=1}^{k} \lambda_{j}=k$ then the total sum of squares, $\sum_{j=1}^{k}\left(\sum_{i=1}^{n} z_{j i}^{2}\right)$, is $k$. Therefore, $z_{j}$ accounts for $\lambda_{j}$ of the total variance.

If the response variable (tree-ring index) is regressed against the $k$ principal components using the model in Eq.(14), then the least squares estimator for the regression coefficients in vector $\boldsymbol{\alpha}$ is the vector $\hat{\boldsymbol{\alpha}}=\left(\mathbf{Z}^{\prime} \mathbf{Z}\right)^{-1} \mathbf{Z}^{\prime} \mathbf{y}$ and the variancecovariance matrix of the estimated coefficients in vector $\hat{\boldsymbol{\alpha}}$ is given by

$$
\operatorname{Var}(\hat{\boldsymbol{\alpha}})=\sigma^{2}\left(\mathbf{Z}^{\prime} \mathbf{Z}\right)^{-1}=\sigma^{2} \operatorname{diag}\left(\lambda_{1}^{-1}, \lambda_{2}^{-1}, \ldots, \lambda_{k}^{-1}\right)
$$

If all of the $k$ principal components are retained in the regression model of Eq.(14), then all that has been accomplished by the transformation is essentially a rotation of the $k$ original climatic variables. Even though the new variables are orthogonal, the same magnitude of variance is retained. But, if multicollinearity is severe, there will be at least one small eigenvalue. An elimination of one (or at least one) principal component, associated with the smallest eigenvalue, may reduce the total variance in the model and thus produce an appreciably improved diagnostic or prediction model (Draper and Smith 1981, Myers 1986).

\section{Elimination of Principal Components}

If all $k$ principal components are used in the model of Eq.(14), the information contained in the complete matrix of principal components $(\mathbf{Z})$ describes all the original climatic data. In other words, the principal component matrix $\mathbf{Z}$ contains exactly the same information as the original centered and scaled climatic data set $\left(\mathbf{X}^{*}\right)$, except that the data are arranged into a set of new variables which are completely uncorrelated with one another and which can be ordered or ranked with respect to the magnitude of their eigenvalues (Draper and Smith 1981, Myers 1986). Note that $z_{j}$ corresponding to the largest $\lambda_{j}$ accounts for the largest portion of the variation in the original data. Further 
$z_{j}$ 's explain smaller and smaller proportions, until all the variation is explained; that is, $\sum_{j=1}^{k} \lambda_{j}=k$

Therefore, in regression model of Eq.(14) one does not use all the $z$ 's, but follows some sort of selection rule. The property that makes PCR unique and more complex is that there is no universally agreed upon procedure in selecting the $z_{j}$ 's to be included in model of Eq.(14) (Draper and Smith 1981). The methods used to determine which and how many principal components should be removed to gain a substantial reduction in variance include:

(a) The strategy of elimination of principal components should be to begin by discarding the component associated with the smallest eigenvalue. The rationale being that the principal component with smallest eigenvalue is the least informative. Using this procedure, principal components are eliminated until the remaining components explain some pre-selected percentage of the total variance (for example, 85 percent or more). That is, one selects the set of largest $r$ contributors (principal components), which first achieve $\sum_{j=1}^{r} \lambda_{j} / k>0.85$.

(b) Some researchers use the rule that only principal components associated with eigenvalues greater than one are of interest (Draper and Smith 1981).

(c) Others use the selection rule that keeps the first principal components whose combined eigenvalue product is greater than one (Guiot et al. 1982).

(d) A more objective statistical strategy is to treat the principal component reduction as if it were a standard variable screening problem. Since the principal components are orthogonal regressor variables, a reasonable criterion to control the order of reduction are the $t$-statistics given by (Myers 1986)

$$
t=\frac{\hat{\alpha}_{j}}{S_{\hat{\alpha}_{j}}}=\frac{\hat{\alpha}_{j} \sqrt{\lambda_{j}}}{S}
$$

where $S_{\hat{\alpha}_{j}}$ is the standard error (s.e) of $\hat{\alpha}_{j}$. Recall that from Eq.(18) $\operatorname{Var}\left(\hat{\alpha}_{j}\right)=S^{2} \lambda_{j}^{-1}$, where $S^{2}=\hat{\sigma}^{2}$ and hence, s.e $\left(\hat{\alpha}_{j}\right)=S\left(\sqrt{\lambda_{j}}\right)^{-1}$. In this procedure $t$-values should be rank 
ordered and components should be considered for elimination beginning with the smallest $t$-value, in magnitude.

Suppose that some such selection rule results in elimination of $r$ principal components, that is, the model in Eq.(14) will now use only $k-r$ components. Let us denote the reduced $\mathbf{Z}$ matrix of Eq.(14) by $\mathbf{Z}_{k-r}(n \times(k-r)$ matrix $)$. Let the reduced vector of coefficients $(\boldsymbol{\alpha})$ be $\boldsymbol{\alpha}_{k-r}=\left(\begin{array}{lllll}\alpha_{1} & \alpha_{2} & . & . & \alpha_{k-r}\end{array}\right)^{\prime}$. The reduced model, after elimination of $r$ principal components, can be written as

$$
\mathbf{y}=\beta_{0}^{*} \mathbf{1}+\mathbf{Z}_{k-r} \boldsymbol{\alpha}_{k-r}+\boldsymbol{\varepsilon}^{\circ}
$$

The $\circ$ symbol on $\boldsymbol{\varepsilon}$ is used simply to differentiate it from $\boldsymbol{\varepsilon}$ in Eq.(14), since they are not the same. But the predicted values and residuals of the model in Eq.(13) or (14) are the same as those in Eq.(1) or (2), (4) or (5), and (9) or (10). Note that:

$$
\mathbf{Z}_{k-r}=\mathbf{X}^{*} \mathbf{V}_{k-r}
$$

where $\mathbf{V}_{k-r}=\left[\begin{array}{llllll}\mathbf{v}_{1} & \mathbf{v}_{2} & . & . & \mathbf{v}_{k-r}\end{array}\right]$ is a $k \times(k-r)$ matrix of eigenvectors associated with the retained eigenvalues or principal components.

The least squares procedure is then used to obtain a prediction equation for the response $y$ as a function of the selected $z$ 's, that is fitting the model in Eq.(20) using ordinary least squares. Once the fitted equation is obtained in terms of the selected $z$ 's, it can be transformed back into a function of the original $x$ 's as described in the following sub-section.

\section{Transformation Back to the Original Climatic Variables}

Suppose with $k$ variables and hence $k$ principal components, $r<k$ components are eliminated. From Eq.(14), with the retention of all components, $\boldsymbol{\alpha}=\mathbf{V}^{\prime} \boldsymbol{\beta}^{*}$, and the coefficients for the centered and scaled climatic variables are obtained as:

$$
\boldsymbol{\beta}^{*}=\mathbf{V} \boldsymbol{\alpha}
$$

If one eliminates $r$ components and fit the model given in Eq.(20), the principal component estimators of the regression coefficients, in terms of the centered and scaled climatic variabls, for all $k$ parameters of the model in Eq.(5) are given by (Gunst and Mason 1980, Myers, 1986) 


$$
\begin{aligned}
& \mathbf{b}_{p c}^{*}=\mathbf{V}_{k-r} \hat{\boldsymbol{\alpha}}_{k-r}
\end{aligned}
$$

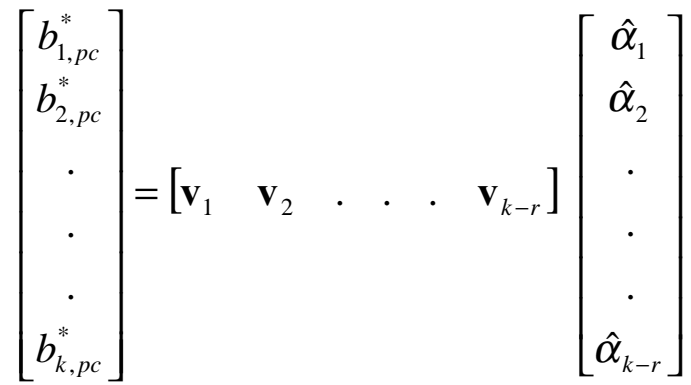

where $\mathbf{V}_{k-r}$ is defined as in Eq.(21), $\hat{\boldsymbol{\alpha}}_{k-r}$ is the vector of estimated coefficients (apart from the intercept) in the model of Eq.(20), and $\mathbf{b}_{p c}^{*}$ is a vector of estimated coefficients (apart from the intercept) of the parameters in vector $\boldsymbol{\beta}^{*}$ of Eq.(5). Note that the elements of $\mathbf{b}_{p c}^{*}$ are principal component estimators of the coefficients of the centered and scaled climatic variables, and subscript $p c$ is simply used to denote that the estimators are principal component estimators rather than ordinary least squares estimators. Since the $x$ 's are centered and scaled the estimate of the constant term $\left(\beta_{0}^{*}\right)$ in the model of Eq.(5) and (20) is $\bar{y}$, that is, $\hat{\beta}_{0}^{*}=\bar{y}$.

Transformation to the coefficients of the natural climatic variables is done as follows: the principal component estimator, $\mathbf{b}_{p c}=\left(\begin{array}{lllll}b_{0, p c} & b_{1, p c} & . & . & b_{k, p c}\end{array}\right)^{\prime}$, of $\boldsymbol{\beta}$ is

$$
b_{j, p c}=\frac{b_{j, p c}^{*}}{s_{j}}, j=1,2, \ldots, k
$$

and

$$
b_{0, p c}=b_{0, p c}^{*}-\frac{b_{1, p c}^{*} \bar{x}_{1}}{s_{1}}-\frac{b_{2, p c}^{*} \bar{x}_{2}}{s_{2}}-\ldots-\frac{b_{k, p c}^{*} \bar{x}_{k}}{s_{k}}
$$

\subsection{Tree-ring and Climatic Data}

To recalibrate the methodology of PCR and demonstrate its application tree-ring data from 38 dominant and codominant yellow-poplar (Liriodendro tulipefera $\mathrm{L}$.) trees sampled at the mesic site were used. The climatic variables considered to develop the response function were mean monthly temperature and total monthly precipitation for a 17-month period extending from May of the preceding year to September of the current year. Hence there are a total of 34 monthly climatic variables. As indicated in chapter 4 
there were 48 pairs of significant correlations among the climatic variables (21 of them were just between temperature variables, 4 between precipitation variables, and 23 were between temperature and precipitation variables). The damaging effects of these significant correlations are the sole reason for resorting to a biased and more complex estimation technique to develop the response function. Having the tree-ring and climatic data, the main steps towards computing the response function are development of an appropriate measure of tree growth (from tree-ring data) followed by application of PCR.

\subsection{RESULTS AND DISCUSSION}

\subsubsection{Development of an Appropriate Response Variable}

\section{A. Violation of the Two Assumptions on the Response Model}

Using the raw ring-width measurements as the response variable (measure of tree growth) in the multiple regression model of Eq.(1) violates the two important assumptions on the model: ring-width measurements are independent (uncorrelated), and have a constant (homogeneous) variance independent of time or age of the tree. However, ring-width is a time series data that is recorded every year and a good growth at year t-1 has a positive effect on growth on year $t$; this characteristic violates the assumption of independence. In addition, the variability of ring-width is a function of age and decreases with increasing time, a characteristic that violates the assumption of homogeneity of variance.

Figure 7.1 shows an example of ring-width pattern from selected yellow-poplar trees. The plots indicate that the absolute ring-width decreases with increasing age or size of the tree, a characteristics of most trees from undisturbed forest environment. To illustrate the linear dependence or autocorrelation within the ring-width measurements, ring width of the current year was plotted against the ring-width of the prior year (Figure 7.2). The scatter plot in Figure 7.2 show that there is a strong positive linear association between prior and current years growth (violation of independence). Table 7.1 shows the first $\left(r_{1}\right)$-and second $\left(r_{2}\right)$-order autocorrelation coefficients of the raw ring-width

measurements for selected trees. For the entire 38 yellow-poplar trees sampled at the mesic site $r_{1}$ ranged from 0.56 to 0.89 and $r_{2}$ ranged from 0.43 to 0.84 . These autocorrelation coefficients were significant at 5\% level. The sample data in Figure 7.2 
and Table 7.1 demonstrate the fact that raw-ring widths are highly interdependent in that prior growth has strong positive influence on current growth.

To illustrate the violation of the assumption of homogeneity of variance, the ringwidth series of selected trees was partitioned into five-year segments. The standard deviation of the five-year segments was plotted against age (Figure 7.3). The plots in Figure 7.3 indicate that variability of ring-width is a function of age and decreases with increasing tree age. To assess the significance of the decrease a linear line was fitted and $\mathrm{R}^{2}$ values were calculated. For all 38 trees analyzed the values of $\mathrm{R}^{2}$ varied from 0.01 to 0.89 with $74 \%$ of the samples having $\mathrm{R}^{2} \geq 0.5$.

The raw ring-width series is shown to have sources of variation not related to climate (i.e., tree-size related long term decreasing trend), and violates the assumptions of independence and homogeneity of variance. Hence, the raw ring-width is not an appropriate response variable to be used in the multiple regression model of Eq.(1). The following sub-sections deal with the transformations needed to create an appropriate response variable.

\section{B. Transformation Applied to the Raw-ring Width Measurements \\ B.1 Removing the Long Term Trend (Detrending)}

There are several models for removing the long-term trend from the raw ringwidth series (Fritts 1976, Cook 1985, Monserud 1986). However, the choice of one detrending model over another depends on study objective and the actual pattern of the tree-ring series. The choice of detrending model affects the characteristic of the ringwidth index (RWI) and results of growth-climate relations. This issue was addressed in chapter 6 .

The most useful model for removing this age-related trend in ring-width series is the modified negative exponential model (Fritts 1976) that has the form

$$
G_{t}=a \exp (-b t)+k
$$

where $a, b$, and $k$ are coefficients to be estimated by least squares, $t$ is age in years and $G_{t}$ is the value of the fitted curve at time $t$. Detrending is accomplished by fitting the model in Eq.(26) to the raw ring-width series of each tree and calculating the detrended 
series (usually called ring-width index) as ratios of actual to fitted values. That is, the tree-ring index at time $t, I_{t}$ is

$$
I_{t}=\frac{R_{t}}{G_{t}}
$$

The modified negative exponential model (MNEM) was fitted to each raw-ring width series of the 38 trees. However, there were few trees where the MNEM did not fit well in which case a smoothing-spline of length 32 was used. The raw ring-width were fitted to MNEM using PROC NLIN in SAS as well as the modified convergence criterion suggested in chapter 6. Examples of fitted models are shown in Figure 7.4. The estimated parameters of the fitted models and the $\mathrm{R}^{2}$ values are given in Table 7.2. Figure 7.5 shows plots of the RWI series. The plots in Figure 7.5 indicate that unlike the raw ringwidth measurements the RWI series does not exhibit a decreasing trend with increasing age, i.e., the age related trend is removed. In other words, the variability of the RWI series is not a function of time. In order to illustrate this characteristic each RWI series was partitioned into five-year segments. The standard deviation of these five-year segments was calculated and plotted against age (see Figure 7.6).

The small and insignificant values of $\mathrm{R}^{2}$ in Figure 7.6 suggests that the variability of the detrended series (RWI) does not seem to depend on age. Hence, the RWI series fairly satisfy the assumption of homogeneous variance. However, the values of the RWI series are still interdependent, i.e., low values follow low and high values follow high (violation of the assumption of independence). This characteristic can be seen from Table 7.3. Table 7.3 shows the mean, standard deviation, first-and second-order autocorrelation coefficients of the RWI series for selected trees. The tree-ring indexes still exhibit a high degree of serial correlation. The first order autocorrelation coefficients are significant at $5 \%$ level of significance. Hence the auto-dependence in the RWI series has to be removed and this is the topic of the next sub-section.

\section{B.2 Autoregressive Modeling}

After removing the age related growth component from each series, some structure in the ring-width index is apparent. That is, low values follow low values, and likewise, high follow high (Figure 7.5). This indicates the presence of autocorrelation in the ring-width index series. The damaging effects of positive autocorrelation is that it 
increases the power of the test for assessing the significance of the climatic variables in the response model of Eq.(1) (SAS, 1999). Positive autocorrelation underestimates the error variance in the model of Eq.(1) and this results in narrower confidence intervals and higher test-statistic. Hence, it leads to a tendency of concluding the effect of a particular climatic variable is significant when it is not. The importance of removing autocorrelation (prewhitening) before climatic models are explored has been discussed by various authors (Cook 1985, Monserud 1986, Visser and Molenaar 1990). However, most dendroclimatic studies use the average RWI series (usually called standard chronology) as the response variable in the model of Eq.(1) and to handle the problem of autocorrelation they include two or three lagged variables of the response into the climatic dataset. This was suggested by Fritts (1976) and is still being commonly practiced (e.g., Lindholm 2000). But, it has been long recognized in time series literature (Granger and Morris 1976) and in some recent dendroclimatic studies (Visser and Moelanaar 1990) that averaging time series data before removing autocorrelation leads to an averaged series with even higher order of autocorrelation and affects its proper interpretation.

Therefore, in this study autoregressive models (Box and Jenkins 1976, Visser and Moelanaar 1990) were used to remove the autocorrelation from each RWI series before creating an average for the species. The autoregressive model of order $p(\operatorname{AR}(p))$ that was used has the form

$$
I_{t}=\left(\sum_{i=1}^{p} \phi_{i} I_{t-i}\right)+a_{t}
$$

where $a_{t}$ is a purely random process with mean zero and variance $\sigma_{a}^{2}$, i.e., "white noise" or prewhitened series, $I_{t}$ and $I_{t-i}$ represent observations (standardized ring-width index) at time $t$ and $t-i$ respectively, and $\phi_{i}$ 's are the autoregressive parameters. In order to decide the order of the autoregressive model, the autocorrelation function (ACF) and partial autocorrelation function (PACF) were computed in SAS and plotted for each series under analysis. An example of these plots is shown in Figure 7.7. The order of the specific model $(p)$ was then decided by using these plots in conjunction to Akaike's information criterion (AIC) and the Mallow's $C_{p}$ statistic. The decision on the order of 
the $\operatorname{AR}(p)$ model was not based purely on empirical results. The biology of tree growth was also considered as a criterion. After devising the adequate order for each sequence, the autoregressive coefficients were estimated by fitting the model using procedure AUTOREG in SAS.

AR process of low order has proved adequate in modeling the autocorrelation structure of the detrended series for all trees. Table 7.4 shows the estimated autoregressive parameters of the AR(1) models that were fitted to the RWI series of selected trees. The fitted AR(1) models and the resulting residuals (prewhitened RWI series) are displayed in Figure 7.8.

With few exceptions, the ring-width indexes of all sampled yellow-poplar trees showed an autocorrelation structure of order one, meaning that growth of current year is influenced by prior year's growth. The first order autocorrelation coefficients of the residuals from the autoregressive modeling were small and not significant. The significance of the autocorrelation coefficients of the prewhitened RWI series was tested using the Durbin-Watson (D-W) statistic. The value of this statistic was about 2 for most sampled trees and this indicates that the values of the prewhitened ring-width index are fairly independent. Table 7.4 shows the result of autoregressive modeling for selected trees.

The average of the prewhitened ring-width index form all trees (see plot (a) of Figure 7.9) which from here on is referred to as the prewhitened tree-ring chronology is the appropriate response variable to be used in the multiple regression model of Eq.(1). The prewhitened chronology satisfies the assumptions of independence (plot (b) of Figure 7.9) and homogeneity of variance. All growth-climate analysis in this study is based on the prewhitened ring-width index as a measure of tree growth. 


\subsubsection{Recalibrated Method of Estimating Response Function in Dendroclimatology}

In section 7.5.1 raw ring-width measurements were transformed in order to remove non-climatic sources of variation. The measure of growth that was developed, the prewhitened tree-ring chronology, contains signals related to variations in climatic variables. The main goal at this point is to relate the prewhitened chronology $(y)$ with a set of 34 climatic variables $(k=34)$ using the model given in Eq.(1). However, multicollinearity among the climatic variables necessitates the use of PCR rather than OLS to develop the response function. In addition, there is no software that is specifically designed to perform PCR. Although most statistical software's perform the most difficult steps of PCR they do not yield the final result and hence a user should comprehend how to complete the remaining steps in a spreadsheet such MS Excel. Therefore, the procedures below show how to compute the principal component estimators of the climatic variables in the model of Eq.(1).

\section{A. Response Function Based on Centered and Scaled Climatic Variables}

1) Compute the $k \times k$ correlation matrix, $\mathbf{C}=\mathbf{X}^{* \mathbf{X}^{*}}$, of the climatic variables.

2) Compute the $k$ eigenvalues of the above correlation matrix, $\lambda_{1}, \lambda_{2}, \ldots, \lambda_{k}$.

3) Compute the $k$ eigenvectors, $\mathbf{v}_{1}, \mathbf{v}_{2}, \ldots, \mathbf{v}_{k}$, associated with each eigenvalue. Let

$$
\mathbf{V}=\left[\begin{array}{cccccc}
v_{11} & v_{12} & \cdot & \cdot & \cdot & v_{1 k} \\
v_{21} & v_{22} & \cdot & \cdot & \cdot & v_{2 k} \\
\cdot & \cdot & & & & \\
\cdot & \cdot & & & \\
\cdot & \cdot & & & \\
v_{k 1} & v_{k 2} & \cdot & \cdot & \cdot & v_{k k}
\end{array}\right]
$$

represent the $k \times k$ orthonormal matrix of eigenvectors. The matrix is orthonormal because its columns satisfy the conditions $\mathbf{v}_{j}^{\prime} \mathbf{v}_{j}=1$ and $\mathbf{v}_{j}^{\prime} \mathbf{v}_{i}=0, j \neq i$.

4) Compute the $k$ principal components (new variables), $z_{1}, z_{2}, \ldots, z_{k}$, of the correlation matrix. Let $\mathbf{Z}$, an $n \times k$ matrix, represent the $n$ readings on the $k$ new variables or principal components. Then 


$$
\begin{aligned}
& \mathbf{Z}=\mathbf{X}^{*} \mathbf{V}
\end{aligned}
$$

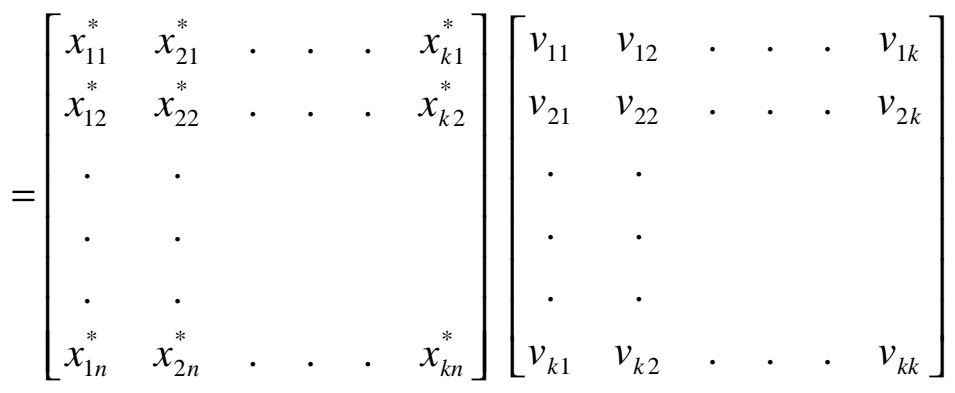

$$
\begin{aligned}
& =\left[\begin{array}{cccccc}
z_{11} & z_{21} & \cdot & \cdot & \cdot & z_{k 1} \\
z_{12} & z_{22} & \cdot & \cdot & \cdot & z_{k 2} \\
\cdot & \cdot & & & \\
\cdot & \cdot & & & \\
\cdot & \cdot & & & & \\
z_{1 n} & z_{2 n} & \cdot & \cdot & \cdot & z_{k n}
\end{array}\right]
\end{aligned}
$$

where $\mathbf{X}^{*}$ is $n \times k$ matrix of centered and scaled climatic variables without the column of ones as given in the model of Eq.(5), and $\mathbf{V}$ is defined in Eq.(29). The elements of matrix $\mathbf{Z}$ are usually called scores or amplitudes of principal components. As described in Eq.(17) the elements of matrix $\mathbf{Z}$ are linear functions of the centered and scaled climatic variables. For example, the first element of the first principal component, i.e., $z_{11}$, is computed as $z_{11}=v_{11} x_{11}^{*}+v_{21} x_{21}^{*}+\ldots+v_{k 1} x_{k 1}^{*}$ and the first element of the last principal component $\left(z_{k 1}\right)$ is computed as $z_{k 1}=v_{1 k} x_{11}^{*}+v_{2 k} x_{21}^{*}+\ldots+v_{k k} x_{k 1}^{*}$. Some of the properties of these new variables or principal components are as follows: (a) mean of $z_{j}$ is zero, $\bar{z}_{j}=0$, (b) the sum of squares of $z_{j}$ is $\lambda_{j}, \mathbf{z}_{j}^{\prime} \mathbf{z}_{j}=\sum_{i=1}^{n}\left(z_{j i}-\bar{z}_{j}\right)^{2}=\sum_{i=1}^{n} z_{j i}^{2}=\lambda_{j}$, (c) the variance of $z_{j}$ is hence $\lambda_{j} / n-1$, and (d) since $\mathbf{z}_{j}^{\prime} \mathbf{z}_{i}=0$ the principal components are independent (orthogonal) of each other, and $\mathbf{Z}^{\prime} \mathbf{Z}=\operatorname{diag}\left(\lambda_{1}, \lambda_{2}, \ldots, \lambda_{k}\right)$.

5) Using principal components selection rule discussed in sub-section 3.2 (rules (a), (b) or (c)) eliminate some of the principal components. Suppose $r<k$ components are eliminated.

6) Regress the prewhitened tree-ring chronology $y$ against the remaining $k-r$ principal components using ordinary least squares (OLS) procedure. That is, estimate the parameters of the model in Eq.(20). The selection methods discussed 
commonly practiced in dendroclimatology (rules (a), (b) or (c)) still leave some principal components that have non-significant weight on the dependent variable and hence they can be rejected using the strategy described in (d). However, to this date most dendroclimatic studies (e.g., Fritts (1976), Guiot et al. (1982), Lindholm (2000)) use a stepwise procedure to enter the useful principal components that are significant at $15 \%$ level.

That is, in dendro-climatic analysis, after step (5), further screening of the principal components is accomplished by performing stepwise regression analysis. The stepwise method adds principal components in the model of Eq.(20) if they are significant at $15 \%$ level. The following comments or changes are necessary at this point: (a) what is being accomplished by the stepwise analysis can be done using the teststatistic in Eq.(19). Therefore, the stepwise analysis is unnecessary, and (b) if one decides to use the stepwise analysis to select the principal components then it is important to understand that the order of entry of the principal components is irrelevant since they are orthogonal to one another. Once a principal component is added in to the model of Eq.(20) then its effect is not altered by the components already in the model or by the addition of other components. This is due to the fact that each principal component has an independent contribution in explaining the variation in the response variable.

Generally, in dendroclimatic studies the selection of principal components is accomplished in two stages: (a) eliminate $r<k$ principal components using the product rule (rule (c)), then (b) further screen the remaining $k-r$ components through a stepwise regression using a significance level of $15 \%$. Suppose the stepwise method or use of the test statistic in Eq.(19) results in retention of $l$ of the $k-r$ components, i.e., a total of $k-l$ components are eliminated. The response function will then be computed based on these $l$ principal components.

7) Regress the prewhitened tree-ring chronology $y$ against these $l$ principal components. That is, fit the model

$$
\mathbf{y}=\beta_{0}^{*} \mathbf{1}+\mathbf{Z}_{l} \boldsymbol{\alpha}_{l}+\boldsymbol{\varepsilon}^{\circ \circ}
$$

where $\mathbf{Z}_{l}=\mathbf{X}^{*} \mathbf{V}_{l}$ is an $n \times l$ matrix, $\mathbf{V}_{l}$ is a $k \times l$ matrix of eigenvectors corresponding to these $l$ components, and $\boldsymbol{\alpha}_{l}$ is $l \times 1$ vector of coefficients associated with the $l$ 
components. For example, with $k=34$ climatic variables and hence 34 principal components, suppose that at step (5) the last 8 principal components with small eigenvalues are eliminated, that is, $r=8$, and $k-r=26$. Further assume that the stepwise regression at step (6) or the test statistic of Eq.(19) eliminates 17 of the 26 principal components, that is, $l=9$. It is important to understand that the 9 components that remained in the model of Eq.(31) are not necessarily the first 9 principal components. The 9 components could, for example, be $z_{2}, z_{5}, z_{6}, z_{12}, z_{13}, z_{16}, z_{17}, z_{18}$, and $z_{20}$. Hence, the matrix $\mathbf{V}_{l}$ contains the eigenvectors corresponding to these components.

8) Compute the mean square error (MSE), and standard error of the estimated coefficients in vector $\hat{\boldsymbol{\alpha}}_{l}$ of the model in Eq.(31). Recall that from Eq.(18) s.e $\left(\hat{\alpha}_{j}\right)=S\left(\sqrt{\lambda_{j}}\right)^{-1}\left(S^{2}=\hat{\sigma}^{2}\right)$. Let the estimated standard errors of the estimated coefficients in $\hat{\boldsymbol{\alpha}}_{l}$ be represented by an $l \times 1$ vector

$$
\mathbf{K}=\left(\begin{array}{lllll}
s . e_{\hat{\alpha}_{1}} & \text { s.e } & & \text {. } & \text {. s.e } e_{\hat{\alpha}_{1}}
\end{array}\right)^{\prime}
$$

These standard errors will be used later for testing the statistical significance of the elements of the response function, i.e., to construct confidence intervals.

9) Obtain the principal component estimators of the coefficients in terms of the centered and scaled climatic variables using Eq.(23) given in sub-section 3.2. That is, $b_{0, p c}^{*}=\bar{y}$ and the remaining estimators are obtained as follows:

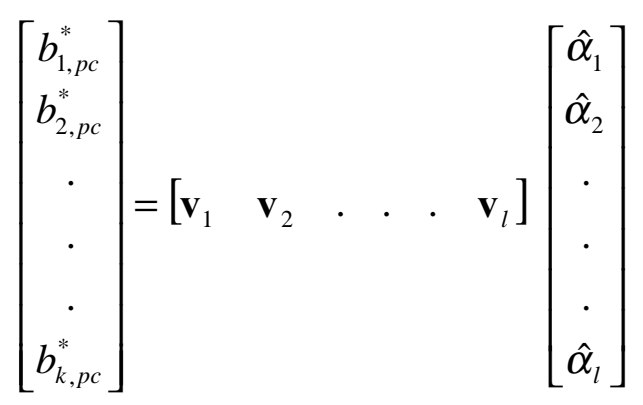

10) Now transform the coefficients back to the natural climatic variables using Eq.(24) and (25) from section 3.2

The coefficients obtained at step (10) are the principal component estimators of the regression coefficients of the climatic variables in the model of Eq.(1). The coefficients obtained at step (9) are the principal component estimators of the regression 
coefficients of the climatic variables in the model of Eq.(5). The principal component estimators at step (9) and (10) have the same sign and test-statistic but different magnitudes and standard errors.

If one decides to report the values of the principal component estimators at step (10) then two difficulties arise: (a) if response functions are calculated by different researchers who use different scales of measurement on the same variables (for example, inches and centimeters for precipitation, degree-Fahrenheit and degree-Centigrade for temperature), the resulting coefficients are not directly comparable, and (b) when comparing the relative importance of several climatic variables in the response function, the climatic variable with the largest magnitude might not be the most influential variable. Its magnitude could be due mainly to the scale in which it was measured. Therefore, to avoid the aforementioned problems researchers should report the principal component estimates of the centered and scaled climatic variables obtained at step (9).

\section{B. Response Function Based on Standardized Climatic Variables}

Statistical packages such as SAS (1990) compute amplitudes or scores of the principal components as a function of the standardized climatic variables as follows:

$$
\mathbf{Z}^{s}=\mathbf{X}^{s} \mathbf{V}
$$

where $\mathbf{X}^{s}$ is $n \times k$ matrix of standardized climatic variables without the column of ones as given in Eq.(10), $\mathbf{V}$ is defined in Eq.(26), and $\mathbf{Z}^{s}$ is $n \times k$ matrix of principal components, $z_{1}^{s}, z_{2}^{s}, \ldots, z_{k}^{s}$. The supersubscript $s$ is used to denote that the components are computed using the standardized regressors.

Properties of the principal components computed using Eq.(34) are (a) mean $z_{j}^{s}$ is zero, $\bar{z}_{j}^{s}=0$, (b) the variance of $z_{j}^{s}$ is $\lambda_{j}$, and (c) the components are orthogonal or independent. That is, $\mathbf{Z}^{\prime s} \mathbf{Z}^{s}$ is a diagonal matrix where the diagonal elements are the sums of squares of the principal components.

If a user is interested to compute a response function using principal components computed using Eq.(34) he/she should follow the steps outlined in section 4.1 by making the following adjustments (note that steps (1) to (3) are standard computations needed in either approach): (a) at step (4) the principal components should be computed using Eq.(34) rather than Eq.(30). That is, replace $\mathbf{Z}$ by $\mathbf{Z}^{s}$ and $\mathbf{X}^{*}$ by $\mathbf{X}^{s}$, (b) at step (7) 
replace $\mathbf{Z}_{l}$ by $\mathbf{Z}_{l}^{s}, \boldsymbol{\alpha}_{l}$ by $\boldsymbol{\alpha}_{l}^{s}$, and $\mathbf{V}_{l}$ by $\mathbf{V}_{l}^{s}$, (c) at step (8) replace $\mathbf{k}$ by $\mathbf{k}^{s}$, (d) at step (9) in Eq.(33) replace $b_{j, p c}^{*}$ by $b_{j, p c}^{s}$. The results obtained at step (9) will be coefficients for the standardized climatic variables (rather than centered and scaled variables). Note that $b_{0, p c}^{s}=\bar{y}$, and (e) the appropriate transformation of the coefficients back to the natural (original) variables at step (10) is accomplished by using Eq.(11) and (12). That is,

$$
b_{j, p c}=\frac{b_{j, p c}^{s}}{S_{x_{j}}}, j=1,2, . ., k
$$

and

$$
b_{0, p c}=b_{0, p c}^{s}-\frac{b_{1, p c}^{s} \bar{x}_{1}}{S_{x_{1}}}-\frac{b_{2, p c}^{s} \bar{x}_{2}}{S_{x_{2}}}-\ldots-\frac{b_{k, p c}^{s} \bar{x}_{k}}{S_{x_{k}}}
$$

where $S_{x_{j}}$ is the standard deviation of the $j^{\text {th }}$ original climatic variable $x_{j}$ and $b_{0, p c}^{s}$, $b_{1, p c}^{s}, b_{2, p c}^{s}, \ldots, b_{k, p c}^{s}$ are coefficients of the standardized climatic variables obtained at step (9).

\subsubsection{Standard Errors of the Principal Component Estimators}

Let $\hat{\boldsymbol{\alpha}}_{l}=\left(\begin{array}{lllll}\hat{\alpha}_{1} & \hat{\alpha}_{2} & . & . & \hat{\alpha}_{l}\end{array}\right)^{\prime}$ be the vector of the estimated coefficients in

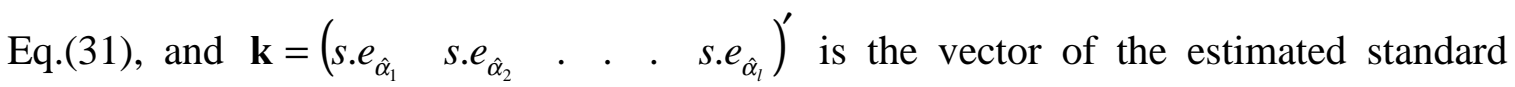
errors of the coefficients in vector $\hat{\boldsymbol{\alpha}}_{l}$. Note that both $\hat{\boldsymbol{\alpha}}_{l}$ and $\mathbf{k}$ are $l \times 1$ column vectors. Let $\mathbf{V}_{l}$ be the $k \times l$ matrix of eigenvectors.

Now, the prewhitened tree-ring chronology can be statistically predicted from the climatic data using the fitted model of Eq.(31):

$$
\hat{\mathbf{y}}=\hat{\beta}_{0}^{*} \mathbf{1}+\mathbf{Z}_{l} \hat{\boldsymbol{\alpha}}_{l}=\hat{\beta}_{0}^{*} \mathbf{1}+\left(\mathbf{X}^{*} \mathbf{V}_{l}\right) \hat{\boldsymbol{\alpha}}=\hat{\beta}_{0}^{*} \mathbf{1}+\mathbf{X}^{*}\left(\mathbf{V}_{l} \hat{\boldsymbol{\alpha}}_{l}\right)=\hat{\beta}_{0}^{*} \mathbf{1}+\mathbf{X}^{*} \mathbf{b}_{p c}^{*}
$$

Recall that the principal component estimators of the coefficients of the centered and scaled climatic variables, $\mathbf{b}_{p c}^{*}$, was given by $\mathbf{b}_{p c}^{*}=\mathbf{V}_{l} \hat{\mathbf{a}}_{l}$. From the expression $\mathbf{b}_{p c}^{*}=\mathbf{V}_{l} \hat{\boldsymbol{\alpha}}_{l}$ one can easily recognize that the coefficients in vector $\mathbf{b}_{p c}^{*}$ are linear combinations of the coefficients of vector $\hat{\boldsymbol{\alpha}}_{l}$. That is 


$$
\left[\begin{array}{c}
b_{1, p c}^{*} \\
b_{2, p c}^{*} \\
\cdot \\
\cdot \\
\cdot \\
b_{k, p c}^{*}
\end{array}\right]=\left[\begin{array}{cccccc}
v_{11} & v_{12} & \cdot & \cdot & \cdot & v_{1 l} \\
v_{21} & v_{22} & \cdot & \cdot & \cdot & v_{2 l} \\
\cdot & \cdot & & & & \\
\cdot & \cdot & & & & \\
\cdot & \cdot & & & & \\
v_{k 1} & v_{k 2} & \cdot & \cdot & \cdot & v_{k l}
\end{array}\right]\left[\begin{array}{c}
\hat{\alpha}_{1} \\
\hat{\alpha}_{2} \\
\cdot \\
\cdot \\
\cdot \\
\hat{\alpha}_{l}
\end{array}\right]
$$

For example, the first coefficient $b_{1, p c}^{*}$ is computed as $b_{1, p c}^{*}=v_{11} \hat{\alpha}_{1}+v_{12} \hat{\alpha}_{2}+\ldots+v_{1 l} \hat{\alpha}_{l}$. Hence, $b_{1, p c}^{*}$ is a linear function of $\hat{\alpha}_{1}, \hat{\alpha}_{2}, \ldots$, and $\hat{\alpha}_{l}$ where the coefficients of the linear combination are the eigenvectors. In addition, it is extremely important to note that the estimators $\hat{\alpha}_{1}, \hat{\alpha}_{2}, \ldots$, and $\hat{\alpha}_{l}$ are independent since they are coefficients of $l$ orthogonal variables (principal components). Mutual independence of $\hat{\alpha}_{1}, \hat{\alpha}_{2}, \ldots$, and $\hat{\alpha}_{l}$ facilitates easy computation of the variance (or standard error) of any linear combination involving these estimators.

Therefore, the variance and standard error of the coefficients in vector $\mathbf{b}_{p c}^{*}$ can be easily computed given the variance and standard error of the estimated coefficients in vector $\hat{\boldsymbol{\alpha}}_{l}$. For example, the variance of $b_{1, p c}^{*}$ is computed as:

$$
\begin{aligned}
& \operatorname{var}\left(b_{1, p c}^{*}\right)=\operatorname{var}\left(v_{11} \hat{\alpha}_{1}+v_{12} \hat{\alpha}_{2}+\ldots+v_{1 l} \hat{\alpha}_{l}\right)=\operatorname{var}\left(v_{11} \hat{\alpha}_{1}\right)+\operatorname{var}\left(v_{12} \hat{\alpha}_{2}\right)+\ldots+\operatorname{var}\left(v_{1 l} \hat{\alpha}_{l}\right) \\
& \operatorname{var}\left(b_{1, p c}^{*}\right)=v_{11}^{2} \operatorname{var}\left(\hat{\alpha}_{1}\right)+v_{12}^{2} \operatorname{var}\left(\hat{\alpha}_{2}\right)+\ldots+v_{1 l}^{2} \operatorname{var}\left(\hat{\alpha}_{l}\right)
\end{aligned}
$$

To generalize the above formulation using a matrix notation let us label the equations used to calculate the variance of each element of the vector $\mathbf{b}_{p c}^{*}$ from [1] to [k] as follows:

$$
\begin{aligned}
& \operatorname{var}\left(b_{1, p c}^{*}\right)=v_{11}^{2} \operatorname{var}\left(\hat{\alpha}_{1}\right)+v_{12}^{2} \operatorname{var}\left(\hat{\alpha}_{2}\right)+\ldots+v_{1 l}^{2} \operatorname{var}\left(\hat{\alpha}_{l}\right) \\
& \operatorname{var}\left(b_{2, p c}^{*}\right)=v_{21}^{2} \operatorname{var}\left(\hat{\alpha}_{1}\right)+v_{22}^{2} \operatorname{var}\left(\hat{\alpha}_{2}\right)+\ldots+v_{2 l}^{2} \operatorname{var}\left(\hat{\alpha}_{l}\right) \\
& \text {. } \\
& \operatorname{var}\left(b_{k, p c}^{*}\right)=v_{k 1}^{2} \operatorname{var}\left(\hat{\alpha}_{1}\right)+v_{k 2}^{2} \operatorname{var}\left(\hat{\alpha}_{2}\right)+\ldots+v_{k l}^{2} \operatorname{var}\left(\hat{\alpha}_{l}\right)
\end{aligned}
$$

In matrix notation the expressions from [1] to [k] can be rewritten as follows: 


$$
\operatorname{Var}\left(\mathbf{b}_{p c}^{*}\right)=\left[\begin{array}{cccccc}
v_{11}^{2} & v_{12}^{2} & \cdot & \cdot & \cdot & v_{1 l}^{2} \\
v_{21}^{2} & v_{22}^{2} & \cdot & \cdot & \cdot & v_{2 l}^{2} \\
\cdot & \cdot & & & & \\
\cdot & \cdot & & & \\
\cdot & \cdot & & & \\
v_{k 1}^{2} & v_{k 2}^{2} & \cdot & . & \cdot & v_{k l}^{2}
\end{array}\right]\left[\begin{array}{c}
\operatorname{var}\left(\hat{\alpha}_{1}\right) \\
\operatorname{var}\left(\hat{\alpha}_{2}\right) \\
\cdot \\
\cdot \\
\cdot \\
\operatorname{var}\left(\hat{\alpha}_{l}\right)
\end{array}\right]=\operatorname{Var}\left(\mathbf{b}_{p c}^{*}\right)=\mathbf{V}_{l}^{2} \mathbf{k}^{2}
$$

The vector $\operatorname{Var}\left(\mathbf{b}_{p c}^{*}\right)$, therefore, gives the variance of the principal component estimators of the coefficients for the centered and scaled climatic variables. The standard deviation of the sampling distribution of the elements of $\mathbf{b}_{p c}^{*}$ (also called standard error) is simply the square root of the variance of the coefficients. That is

$$
\operatorname{s.e}\left(\mathbf{b}_{p c}^{*}\right)=\left[\operatorname{Var}\left(\mathbf{b}_{p c}^{*}\right)\right]^{\frac{1}{2}}
$$

The principal component estimators of the regression coefficients in the model of Eq.(1) are obtained using the relationship $b_{j, p c}=b_{j, p c}^{*} / s_{j}$ where $s_{j}$ is a scale constant defined in Eq.(3). Hence standard error of the principal component estimators of the coefficients of the natural climatic variables are obtained as follows (for the $j^{\text {th }}$ principal component estimator):

$$
\operatorname{s.e}\left(b_{j, p c}\right)=\sqrt{\operatorname{var}\left(b_{j, p c}\right)}=\sqrt{\operatorname{var}\left(\frac{b_{j, p c}^{*}}{s_{j}}\right)}=\sqrt{\frac{1}{s_{j}^{2}} \operatorname{var}\left(b_{j, p c}^{*}\right)}=\frac{\operatorname{se}\left(b_{j, p c}^{*}\right)}{s_{j}}
$$

where s.e $\left(b_{j, p c}^{*}\right)$ is the standard error of the principal component estimator of the coefficient associated with the $j^{\text {th }}$ centered and scaled climatic variable, or it is the $j^{\text {th }}$ element of the vector given in Eq.(41).

When the elements of the response function are derived using the form described in section 5.2(b), i.e., when the principal components are computed as a function of the standardized climatic variables, the same methodology illustrated in section 5.3 should be used to compute the standard errors. In this case, the variance of the principal component estimators of coefficients for the standardized climatic variables is given by

$$
\operatorname{Var}\left(\mathbf{b}_{p c}^{s}\right)=\left(\mathbf{V}_{l}^{s}\right)^{2}\left(\mathbf{k}^{s}\right)^{2}
$$

and the corresponding standard errors are given by 


$$
\operatorname{s.e}\left(\mathbf{b}_{p c}^{s}\right)=\left[\operatorname{Var}\left(\mathbf{b}_{p c}^{s}\right)\right]^{\frac{1}{2}}
$$

Recall that the principal component estimator of the coefficients of the original climatic variables are obtained using Eq.(35). Hence the standard error of the principal component estimator associated with the $j^{\text {th }}$ original variable is

$$
s . e\left(b_{j, p c}\right)=\frac{s . e\left(b_{j, p c}^{s}\right)}{S_{x_{j}}}
$$

\subsubsection{Inference Techniques}

To test a hypothesis about the significance of the influence of each climatic variable $\left(H_{0}: \beta_{j}^{*}=0\right.$ vs. $\left.H_{a}: \beta_{j}^{*} \neq 0\right)$ using the principal component estimators, Mansfield et al. (1977) and Gunst and Mason (1980) have shown that the appropriate statistic to use is

$$
t=\frac{b_{j, p c}^{*}}{\left[\operatorname{MSE}\left(\sum_{m=1}^{l} \lambda_{m}^{-1} v_{j m}^{2}\right)\right]^{\frac{1}{2}}}
$$

where $b_{j, p c}^{*}$ is the principal component estimator of $\beta_{j}^{*}, M S E$ is the mean square error of the model in Eq.(31), $v_{j m}$ is the $j^{\text {th }}$ element of the eigenvector $\mathbf{v}_{m}(m=1,2, \ldots, l), \lambda_{m}$ is the corresponding eigenvalue, and the summation in Eq.(46) is taken over only those components retained at the end of the stepwise analysis. The statistic in Eq. (46) follows the Student's $t$ distribution with $(n-k-1)$ degrees of freedom under $H_{0}$ provided that the true coefficients of the components eliminated at step (5) and (6) of section 5.2 are zero. Therefore, to test $H_{0}: \beta_{j}^{*}=0$ vs. $H_{a}: \beta_{j}^{*} \neq 0$ with significance level of $\alpha$, reject $H_{0}$ if the absolute value of the test statistic in Eq.(46) is greater than or equal to the critical value $\left(t_{(\alpha / 2, n-k-1)}\right)$.

The denominator in Eq. (46) is the standard error of $b_{j, p c}^{*}$, the $j^{\text {th }}$ element of the vector given in Eq.(41). That is, from Eq.(40) one can see that (note: $\left.\operatorname{Var}\left(\hat{\alpha}_{j}\right)=\hat{\sigma}^{2} / \lambda_{j}=\operatorname{MSE} / \lambda_{j}\right)$ 


$$
\begin{aligned}
& \operatorname{Var}\left(b_{j, p c}^{*}\right)=v_{j 1}^{2} \operatorname{var}\left(\hat{\alpha}_{1}\right)+v_{j 2}^{2} \operatorname{var}\left(\hat{\alpha}_{2}\right)+\ldots+v_{j l}^{2} \operatorname{var}\left(\hat{\alpha}_{l}\right) \\
& =v_{j 1}^{2} \frac{M S E}{\lambda_{1}}+v_{j 2}^{2} \frac{M S E}{\lambda_{2}}+\ldots+v_{j l}^{2} \frac{M S E}{\lambda_{l}} \\
& =\operatorname{MSE}\left(\sum_{m=1}^{l} \frac{v_{j m}^{2}}{\lambda_{m}}\right)
\end{aligned}
$$

Hence, the test statistics in Eq.(46) simplifies to $t=b_{j, p c}^{*} / s . e\left(b_{j, p c}^{*}\right)$. Note that this test statistic can also be used to test the hypothesis $H_{0}: \beta_{j}=0$ vs. $H_{a}: \beta_{j} \neq 0$. However, if the hypothesis to be tested is $H_{0}: \beta_{j}^{s}=0$ vs. $H_{a}: \beta_{j}^{s} \neq 0$, then the test statistic becomes

$$
t=\frac{b_{j, p c}^{s}}{\left[\frac{M S E}{n-1}\left(\sum_{m=1}^{l} \lambda_{m}^{-1} v_{j m}^{2}\right)\right]^{\frac{1}{2}}}
$$

The denominator of the test-statistic in Eq.(48) is the standard error of $b_{j, p c}^{s}$, the $j^{\text {th }}$ element of the vector given in Eq.(44). Note that if principal component scores are computed using Eq.(34) then $\mathbf{Z}^{\prime s} \mathbf{Z}^{s}=\operatorname{diag}\left(\lambda_{1}(n-1), \lambda_{2}(n-1), \ldots, \lambda_{k}(n-1)\right)$ and the matrix $\operatorname{Var}\left(\hat{\boldsymbol{\alpha}}^{s}\right)=\operatorname{MSE}\left(\mathbf{Z}^{\prime s} \mathbf{Z}^{s}\right)^{-1}=\operatorname{MSE} \times \operatorname{diag}\left(\frac{1}{\lambda_{1}(n-1)}, \frac{1}{\lambda_{2}(n-1)}, \ldots, \frac{1}{\lambda_{k}(n-1)}\right)$ is the variance-covariance matrix of the estimated coefficients associated with the principal components. Hence, $\operatorname{Var}\left(\hat{\alpha}_{j}^{s}\right)=M S E / \lambda_{j}(n-1)$. From Eq.(43) the variance of $b_{j, p c}^{s}$ is then

$$
\begin{aligned}
& \operatorname{Var}\left(b_{j, p c}^{s}\right)=v_{j 1}^{2} \operatorname{var}\left(\hat{\alpha}_{1}^{s}\right)+v_{j 2}^{2} \operatorname{var}\left(\hat{\alpha}_{2}^{s}\right)+\ldots+v_{j l}^{2} \operatorname{var}\left(\hat{\alpha}_{l}^{s}\right) \\
& =v_{j 1}^{2} \frac{M S E}{\lambda_{1}(n-1)}+v_{j 2}^{2} \frac{M S E}{\lambda_{2}(n-1)}+\ldots+v_{j l}^{2} \frac{M S E}{\lambda_{l}(n-1)} \\
& =\frac{M S E}{n-1}\left(\sum_{m=1}^{l} \frac{v_{j m}^{2}}{\lambda_{m}}\right)
\end{aligned}
$$

Fritts et al. (1971) and Fritts (1976) shows that the hypothesis $H_{0}: \beta_{j}^{*}=0$ vs. $H_{a}: \beta_{j}^{*} \neq 0$ can be tested by constructing a $95 \%$ confidence interval of the form $b_{j, p c}^{*} \pm \sqrt{F_{0.05, v_{1}, v_{2}}} \times s . e\left(b_{j, p c}^{*}\right)$, where $v_{1}$ is the number of non-zero elements of $\hat{\boldsymbol{\alpha}}_{l}$ and $v_{2}=n-2-v_{1}$. However, Fritts et al. (1971) and Fritts (1976) does not indicate the 
source for the above $F$ statistic nor do they give a theoretical derivation. In dendroclimatic studies where the sample size and the number of climatic variables are large the two inferential procedures lead to contrasting results and hence users should adopt the test statistic developed by Mansfield et al. (1977) for testing significance of the regression coefficients in the model of Eq.(1), Eq.(5) or Eq.(10).

\subsubsection{Comparison with the Fritts' Approach}

Fritts et al. (1971) and Fritts (1976) illustrate the concept, method of computation, and interpretation of the response function in dendro-climatic analysis. The approach in these and other dendroclimatic literature uses a standard chronology (average of tree-ring indexes from a set of trees) as a response variable. The regressors are the climatic variables, and additional three-predictor variables that represent ring-width indexes for the three most prior years. The purpose of the three additional predictor variables was to account for the presence of interdependence in ring width indexes measured by the first-, second-, and third-order autocorrelation.

As opposed to Fritts et al. (1971) and Fritts (1976) method, the approach presented here assumes that the user should prewhitene tree-ring indexes from each tree before computing the chronology. Therefore, the use of additional predictor variables that represent ring-width indexes of prior years is not necessary since the response variable (the prewhitened chronology) is "free" of serial correlation. Averaging tree-ring indexes from a set of trees, where each series exhibit a certain degree of autocorrelation, will in general yield a standard chronology with a higher order of autocorrelation (Granger and Morris 1976; and Cook 1985) masking the true autodependence of tree growth. This is undesirable for inferential purposes. Hence, prewhitening each ring-width index independently, and using the resulting prewhitened chronology as a response variable in computation of the response function has statistical advantages (Berger et al. 1979).

Fritts et al. (1971) and Fritts (1976) compute amplitudes of the principal components of the correlation matrix as a function of the standardized climatic variables. That is, using the form described in Eq.(34). The discussion on the computation of the response function, though not clearly presented in terms of statistical and linear algebra details, is essentially the same as the procedure presented in section 5.2 of this study. However, it is worth indicating that Fritts et al. (1971) and Fritts (1976) use the three 
additional predictor variables for the first time in the stepwise analysis of step (6). Note that the three additional regressors are not used in computation of the principal components.

Fritts (1976, pages 353 and 364) defines the elements of the response function as the estimated regression coefficients associated with the original (or natural) climatic variables. In this study, these are coefficients obtained at step (10) of section 5.2 given that the principal components are computed using Eq.(34). But the magnitude of the coefficients at step (10) are scale dependent and hence are not appropriate to report in research results. Fritts et al. (1971) and Fritts (1976) compute standard errors of the elements of the response function, s.e $\left(b_{j, p c}\right)$, from the standard errors of the coefficients in the vector $\hat{\boldsymbol{\alpha}}_{l}^{s}$. Using the notation in this study, the required transformation given in Fritts (1976, page 365) is

$$
\mathbf{S}=\mathbf{V}_{l}^{s} \mathbf{U} \mathbf{U} \mathbf{V}_{l}^{s}
$$

where $\mathbf{V}_{l}^{s}$ is $k \times l$ matrix of eigenvectors, $\mathbf{U}$ is $l \times l$ diagonal matrix whose diagonal elements are standard errors of the coefficients in $\hat{\boldsymbol{\alpha}}_{l}^{s}$, i.e., the diagonal elements of $\mathbf{U}$ are elements of the vector $\mathbf{k}^{s}$ and $\mathbf{S}$ is $k \times k$ symmetric matrix whose diagonal elements are the square of the standard errors of the elements of the response function. However, the diagonal elements of $\mathbf{S}$ are not the square of the standard errors of the elements of the response function, rather they are the variances (square of the standard errors) of the coefficients for the standardized climatic variables. That is, the $j^{\text {th }}$ diagonal element of $\mathbf{S}$ is not the same as $\operatorname{var}\left(b_{j, p c}\right)$ but it is the same as $\operatorname{var}\left(b_{j, p c}^{s}\right)$.

The diagonal elements of the matrix $\mathbf{S}$ from Fritts (1976) are equivalent to elements of the vector $\operatorname{Var}\left(\mathbf{b}_{p c}^{s}\right)$ given in Eq.(43). A user that employs Fritts (1976) equation, i.e., Eq.(50), ends up getting variances of the coefficients for the standardized climatic variables and hence, if the need arises, a straightforward follow up computation is needed to obtain variance (or standard errors) of the elements of the response function. That is, the standard error of the $j^{\text {th }}$ element of the response function should be computed as 


$$
\text { s.e }\left(b_{j, p c}\right)=\frac{\sqrt{j^{t h} \text { diagonal element of matrix } \mathbf{S}}}{S_{x_{j}}}=\left(s_{j j}\right)^{\frac{1}{2}} S_{x_{j}}^{-1}
$$

\subsubsection{Applications}

In this section a demonstration of the computation of response function using the methodology described in section 7.5.2(b) is presented. The eigenvalues, eigenvectors, and the orthogonal principal components of the correlation matrix were computed in SAS. The eigenvalue product rule retained the first 25 principal components and eliminated the last 9. The prewhitened tree-ring chronology was regressed against the 25 orthogonal variables and further screening of the retained components was carried out using the test-statistic given in Eq.(19) and at the probability level of 15\%. This has resulted in retention of only 8 components.

For the model relating the response with the 8 selected components, the estimated regression coefficients (apart from the intercept), $\hat{\boldsymbol{\alpha}}_{l}^{s}$, and the matrix of eigenvectors associated with the $l=8$ retained principal components, $\mathbf{V}_{l}^{s}$ are given below:

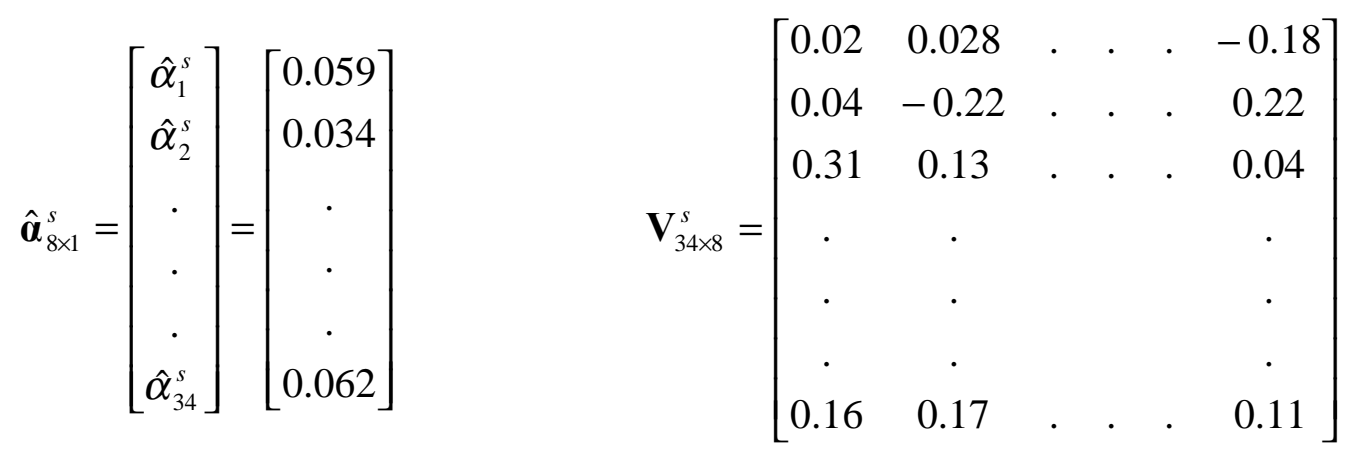

The estimated standard errors of the coefficients in vector $\hat{\boldsymbol{\alpha}}_{8 \times 1}^{s}$ are given by

$$
\mathbf{k}^{s}=\left[\begin{array}{llllll}
0.01 & 0.011 & . & . & 0.016
\end{array}\right]^{\prime}
$$

The principal component estimators of the coefficients of the standardized

climatic variables were obtained using Eq.(33). That is, $\mathbf{b}_{j, p c}^{s}=\mathbf{V}_{34 \times 8}^{s} \hat{\boldsymbol{\alpha}}_{8 \times 1}^{s}$ (Note: the intercept $\left.b_{0, p c}^{s}=\bar{y}=0.00\right)$ : 


$$
\left[\begin{array}{c}
b_{1, p c}^{s} \\
b_{2, p c}^{s} \\
\cdot \\
\cdot \\
\cdot \\
b_{34, p c}^{s}
\end{array}\right]=\left[\begin{array}{cccccc}
0.02 & 0.028 & \cdot & \cdot & \cdot & -0.18 \\
0.04 & -0.22 & \cdot & \cdot & \cdot & 0.22 \\
0.31 & 0.13 & \cdot & \cdot & \cdot & 0.04 \\
\cdot & \cdot & & & \cdot \\
\cdot & \cdot & & & \cdot \\
\cdot & \cdot & & & & \cdot \\
0.16 & 0.17 & \cdot & \cdot & \cdot & 0.11
\end{array}\right]\left[\begin{array}{c}
0.059 \\
0.034 \\
\cdot \\
\cdot \\
\cdot \\
0.062
\end{array}\right]=\left[\begin{array}{c}
-0.0028 \\
0.0126 \\
\cdot \\
\cdot \\
\cdot \\
0.0434
\end{array}\right]
$$

Transformation of the coefficients back to the original (or natural) climatic variables was done using Eq.(35) and (36). The estimated intercept using Eq.(36) is 1.07. The coefficients of the original climatic variables were obtained by dividing the coefficients of the standardized variables by the standard deviation of the original variables:

$$
\left[\begin{array}{c}
b_{1, p c}^{s} \\
b_{2, p c}^{s} \\
\cdot \\
\cdot \\
\cdot \\
b_{34, p c}^{s}
\end{array}\right]=\left[\begin{array}{c}
-0.0028 / 5.57 \\
0.0126 / 5.37 \\
\cdot \\
\cdot \\
\cdot \\
0.0434 / 1.40
\end{array}\right]=\left[\begin{array}{c}
-0.00051 \\
0.002357 \\
\cdot \\
\cdot \\
\cdot \\
0.0308
\end{array}\right]
$$

The variance of the principal component estimators of the coefficients for the standardized climatic variables, using Eq.(43), is

$$
\begin{aligned}
& \operatorname{Var}\left(\mathbf{b}_{p c}^{s}\right)=\left(\mathbf{V}_{34 \times 8}^{s}\right)^{2}\left(\mathbf{k}_{8 \times 1}^{s}\right)^{2}
\end{aligned}
$$

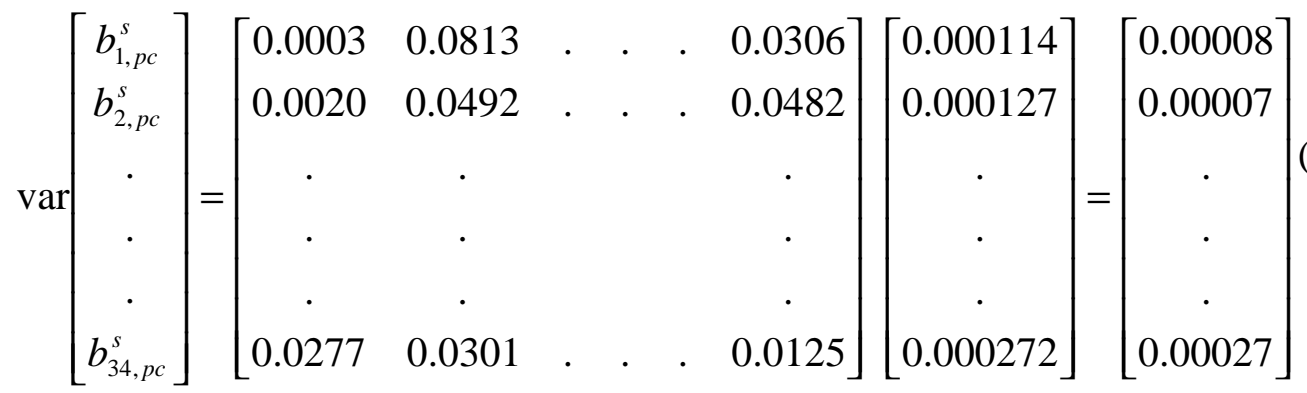

Notice that the elements of the vector in Eq.(52) can also be obtained by evaluating Eq.(49). The standard error of the principal component estimators of the coefficients of the standardized climatic variables is then 


$$
s . e\left[\begin{array}{c}
b_{1, p c}^{s} \\
b_{2, p c}^{s} \\
\cdot \\
\cdot \\
\cdot \\
b_{34, p c}^{s}
\end{array}\right]=\left[\operatorname{Var}\left(\mathbf{b}_{p c}^{s}\right)\right]^{\frac{1}{2}}=\left[\begin{array}{c}
0.009 \\
0.008 \\
\cdot \\
\cdot \\
\cdot \\
0.017
\end{array}\right]
$$

The standard error of the principal component estimators of the coefficients for the original climatic variables is

$$
\text { s.e }\left[\begin{array}{c}
b_{1, p c} \\
b_{2, p c} \\
\cdot \\
\cdot \\
\cdot \\
b_{34, p c}
\end{array}\right]=\left[\begin{array}{c}
0.009 / 5.57 \\
0.008 / 5.37 \\
\cdot \\
\cdot \\
\cdot \\
0.017 / 1.40
\end{array}\right]=\left[\begin{array}{c}
0.0016 \\
0.0015 \\
\cdot \\
\cdot \\
\cdot \\
0.012
\end{array}\right]
$$

Standard error computation using Fritts (1976) method is performed in order to compare it with the result obtained in Eq.(54). The diagonal matrix $\mathbf{U}$ is

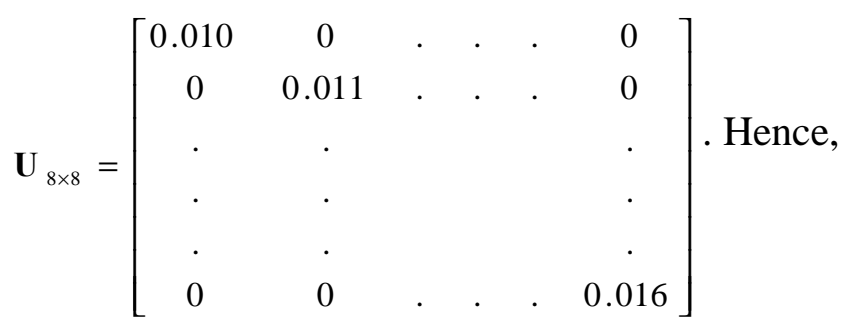

$\mathbf{S}_{34 \times 34}=\mathbf{V}_{34 \times 8}^{s}\left(\mathbf{U}_{8 \times 8} \mathbf{U}_{8 \times 8}\right) \mathbf{V}_{8 \times 34}^{\prime s}$

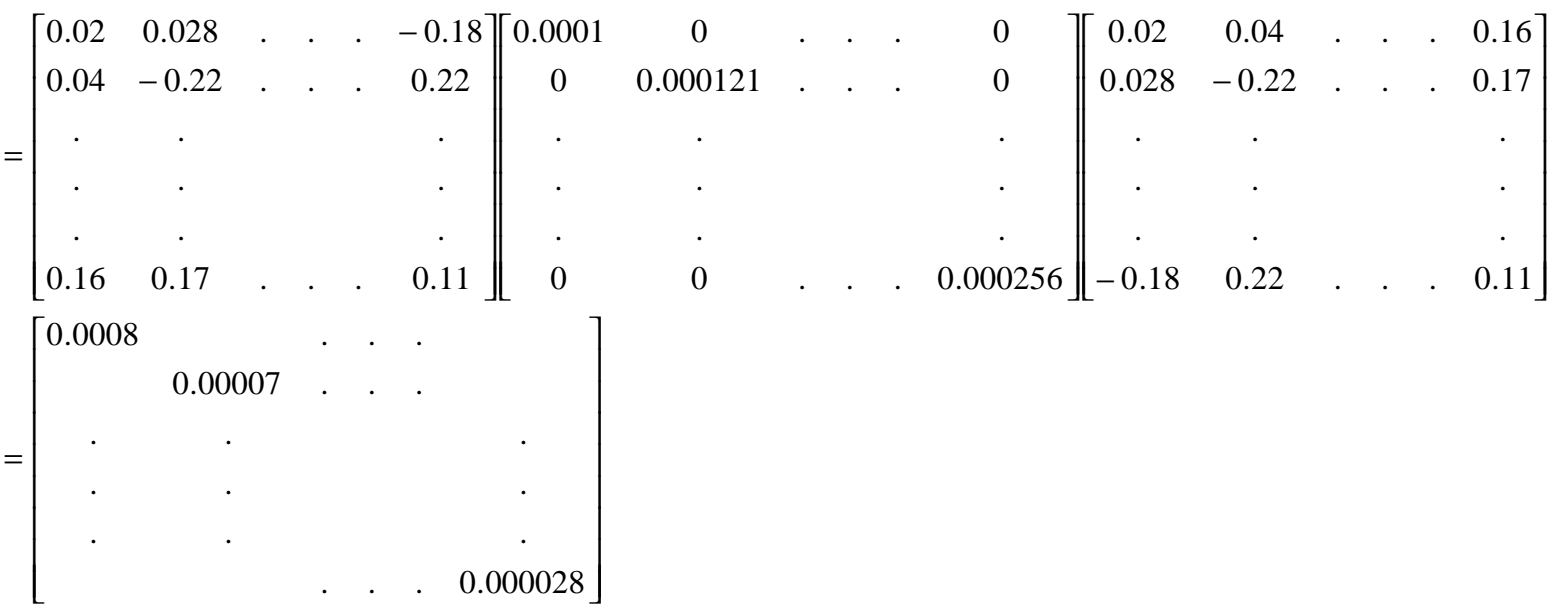


According to Fritts (1976) the diagonal elements of $\mathbf{S}$ are the square of the standard errors (i.e., variances) of the elements of the response function. But notice that the diagonal elements of $\mathbf{S}$ are in fact the variances (or the square of standard errors) of the coefficients of the standardized climatic variables. The diagonal elements of $\mathbf{S}$ are the same as the elements of the vector $\operatorname{Var}\left(\mathbf{b}_{p c}^{s}\right)$ given in Eq.(52).

\section{A. The Response Function and Comparison of the Inferential Procedures}

Using the inferential procedure described in section 5.4 the significance of the estimated coefficients is tested at 5\% level of significance. Table 7.5 shows the significant climatic variables identified based on three procedures. That is, the hypothesis $H_{0}: \beta_{j}=0$ vs. $H_{a}: \beta_{j} \neq 0$ was tested using (a) the t-statistic given by Mansfield et al. (1977), (b) the F-statistic given by Fritts (1976), and (c) using the classical regression test procedure where the model is estimated using OLS. The values of the principal component estimators for the standardized climatic variables and their $95 \%$ confidence intervals were plotted by month for both temperature and precipitation (see Figure 7.10). Figure 7.10 and Table 7.5 indicate that the two inferential procedures ( $t$ and F-statistic) yield nearly similar results but there are some differences. First, the F-statistic tends to give more number of significant climatic variables than the t-statistic. Second, there are four variables where the two procedures yield different results in terms of significance. These are precipitation of current September, and temperature of current August, September and prior May. The critical value of the F-statistic depends on the number of the principal components retained for developing the response function whereas the $\mathrm{t}$ statistic is only a function of the length of the chronology and the number of parameters in the model. Therefore, as the number of principal components varies the two procedures yield different results. When the response function is estimated using OLS (classical method) there are only four significant variables (Table 7.5). These are precipitation of current April, July, August and temperature of current September. Besides picking few numbers of significant variables the classical method also suggests some unrealistic results such as larger radial growth when the temperature of current July is higher than average. This is one of the main reasons for using a more advanced procedure than OLS to study radial growth of trees in relation to climate. 


\section{B. Comparison of PCR and OLS}

The two methods of estimation (PCR and OLS) showed noticeable differences in terms of the sign, magnitude, and significance of the climatic variables. These differences are results of multicollinearity among the climatic variables. Table 7.5 shows that the two methods yield opposite signs for six of the climatic variables. To compare the magnitude of the two estimates, the absolute value of the principal component estimates (PCE) was subtracted from the absolute value of the least squares estimates (LSE). The difference in magnitude was plotted in Figure 7.11(a). It shows that the LS estimates are larger in magnitude for about 21 of the climatic variables. The standard errors of the least squares and principal component estimators are plotted in Figure 7.11(b). The principal component estimators have lower standard errors for all climatic variables indicating that the procedure results in a more precise and reliable coefficients of the climatic variables. The plot in Figure 7.11(b) also shows larger differences in standard errors of temperature variables than precipitation variables. This was because there were more significant correlations among the temperature variables (21 pairs) than among precipitation variables (4 pairs).

\section{Sensitivity of the Response Function to Principal Components Selection Rules}

Five methods of selecting principal components are compared (Table 7.6). The methods select principal components to be included in to the model of Eq.(20) based on five different criteria. The first method selects the first components which explain $85 \%$ of the total variance in the original data, the second selects only those components with eigenvalues greater than unity, the third selects the first components whose combined eigenvalue product is greater than unity, the fourth selects only those components significant at $5 \%$ level, and the fifth method first applies the eigenvalue product rule to select the principal components and further screens these selected components by using a significance level of $15 \%$. Note that to accomplish the selection using the fourth method the response was first regressed against the 34 principal components. The fifth selection method requires regressing the response against those components selected using the product rule.

For each selection method, the response was regressed against the selected components. Table 7.6 shows the selected components and $\mathrm{R}^{2}$ of the fitted models. The 
table shows that the fourth and fifth methods select fewer principal components and still have similar measures of fit $\left(\mathrm{R}^{2}, \mathrm{SSE}\right.$, and MSE) as the first three methods that include a larger number of components. The result in Table 7.6 indicates that retaining fewer components does seem to result in smaller total variance. Most importantly, it shows that keeping the components with large eigenvalues do not necessarily reduce the model variance. In fact, the last two selection rules, which retain fewer components with smaller eigenvalues, seem to be more effective in reducing the error variance (noise) in the model.

The principal component estimators of the standardized climatic variables were computed and compared for each selection method. The result showed that there are differences in sign and magnitude of the estimated coefficients attributable to the selection method. Comparison of standard errors of the estimated coefficients showed that the fourth method (selecting components significant at 5\% level) yield estimates with smallest standard errors and the third method (using the eigenvalue product rule) gives estimates with largest standard errors. With respect to significance of the variables the first three selection methods yield less significant variables than the last two. The last two methods tend to provide similar results. Generally, the result in this section clearly illustrate that the sign, magnitude, and statistical significance of the estimated coefficients of the response function depends on the method used to select or eliminate the principal components. This issue deserves special consideration in growth-climate studies.

The principal component estimators of the standardized climatic variables were computed and compared for each selection method. The result showed that there are differences in sign and magnitude of the estimated coefficients attributable to the selection method. Comparison of standard errors of the estimated coefficients showed that the fourth method (selecting components significant at $5 \%$ level) yield estimates with smallest standard errors and the third method (using the eigenvalue product rule) gives estimates with largest standard errors. With respect to significance of the variables the first three selection methods yield less significant variables than the last two. The last two methods tend to provide similar results. Generally, the result in this section clearly illustrate that the sign, magnitude, and statistical significance of the estimated coefficients 
of the response function depends on the method used to select or eliminate the principal components. This issue deserves special consideration in growth-climate studies.

\subsection{Summary and Conclusions}

The theoretical procedure as well as the application of PCR in dendroclimatology is illustrated. Selection of principal components is the most important step that makes the procedure unique. Depending on the selection rule, the percentage of variation in annual growth explained by climate varied from 43 to $67 \%$. However, dendroclimatic studies are not consistent with respect to principal components selection rules. For example, Fritts (1976) and Lindholm et al. (2000) use the cumulative eigenvalue product rule followed by screening of components significant at $15 \%$ level while Pan et al. (1997) choose the first $r$ components that explained certain pre-selected percentage of the variation in the original climatic data. The method of selecting principal components is shown to affect all the important attributes of the resulting model used for interpreting the effects of climatic variables on radial growth.

While diverse methodologies for studying annual growth of trees in relation to climate exists, the method of principal components regression has been recognized as the best tool for developing response functions. However differences in the procedure (estimation of standard errors and test of significance) lead to differences in interpretations regarding tree growth and climatic variables. The accuracy and reliability of the procedure has not been fully explored in dendrochronologial literature. Therefore, based on the analysis made in this chapter the following conclusions are drawn: (a) the difficulty of the method as it is shown in section 7.5.6(c) is to decide how many principal components to introduce and what criterion to use for the selection process. The comparison of the various selection procedures showed that the three characteristics (sign, magnitude, and significance) of the coefficients of the climatic variables change depending on the selection rule. This entails that consistency in selection rules adapted is necessary for results of dendroclmatic studies to be comparable. In addition, there is no universally accepted rule for selecting principal components and most current selection rules eliminate principal components that account for the largest variance in the original climatic data and this property is taught to be undesirable (Harner, WVU, Department of Statistics, Personal Communication). Therefore, this issue deserves further investigation, 
(b) this study has shown a complete derivation of the method used for estimating the standard errors of the principal component estimators for both the natural and transformed climatic variables. In early dendroclimatic studies (Fritts et al. 1971, Fritts 1976, Guiot et al. 1982) the method used to estimate standard errors of the elements of the response function provides variances of the coefficients associated with standardized climatic variables. Hence, if one uses the equation given in these earlier studies, then a subsequent computation given by Eq. (51) is necessary to obtain standard errors of the elements of the response function, (c) inference procedures given in earlier dendroclimatic studies use a test-statistic that has an incorrect distribution. In addition, the critical value of this test-statistic depends on the number of principal components chosen. This test-statistic also tends to result in more number of significant climatic variables than the appropriate test-statistic given in statistical literature. Therefore, in dendroclimatic studies use of the appropriate test-statistic, which also does not depend on principal components selection rule, is recommended, (d) finally, provided that one has a regression data set where the predictors exhibit problem of multicollinearity, the result given in this chapter can be used in any discipline to develop a more stable model, estimate standard errors of the principal component estimators and test the statistical significance of the individual regressors. The fact that there are no well known statistical packages that perform the entire steps of PCR and absence of demonstration of the methodology in dendroclimatology make this chapter an important study. 
Table 7.1. The firs $\left(\mathrm{r}_{1}\right)$-and second $\left(\mathrm{r}_{2}\right)$ - order autocorrelation coefficients of raw ringwidth measurements for selected yellow-poplar trees.

\begin{tabular}{ccccc}
\hline Disc No. & $\mathrm{r}_{1}$ & $\mathrm{r}_{2}$ & Mean $(\mathrm{mm})$ & Stdev. $(\mathrm{mm})$ \\
\hline YPNF01 & 0.83 & 0.76 & 2.48 & 1.39 \\
YPNF02 & 0.85 & 0.75 & 1.92 & 1.35 \\
YPNF03 & 0.67 & 0.53 & 3.75 & 1.21 \\
YPNF04 & 0.78 & 0.69 & 3.45 & 1.84 \\
YPNF05 & 0.77 & 0.66 & 3.59 & 1.44 \\
YPNF06 & 0.85 & 0.82 & 3.04 & 1.33 \\
\hline
\end{tabular}

Table 7.2. The estimated parameters of the modified negative exponential model fitted to the raw ring-width series and the percentage of variability in ring-width explained by the fitted models.

\begin{tabular}{ccccc}
\hline Disc No. & $a$ & $b$ & $k$ & $\mathrm{R}^{2}(\%)$ \\
\hline YPNF01 & 5.14 & 0.0217 & -0.286 & 91 \\
YPNF02 & 5.97 & 0.0264 & -0.878 & 96 \\
YPNF03 & 4.08 & 0.0596 & 2.788 & 96 \\
YPNF04 & 6.79 & 0.0449 & 1.329 & 95 \\
YPNF05 & 4.53 & 0.0231 & 1.198 & 93 \\
YPNF06 & 4.32 & 0.0532 & 2.648 & 94 \\
\hline
\end{tabular}

Table 7.3. The firs $\left(\mathrm{r}_{1}\right)$-and second $\left(\mathrm{r}_{2}\right)$ - order serial correlation coefficients for RWI of selected trees.

\begin{tabular}{ccccc}
\hline Disc No. & $\mathrm{r}_{1}$ & $\mathrm{r}_{2}$ & Mean $(\mathrm{mm})$ & Stdev. $(\mathrm{mm})$ \\
\hline YPNF01 & 0.54 & 0.36 & 1 & 0.34 \\
YPNF02 & 0.48 & 0.29 & 1 & 0.27 \\
YPNF03 & 0.38 & 0.06 & 1 & 0.22 \\
YPNF04 & 0.34 & 0.22 & 1 & 0.25 \\
YPNF05 & 0.52 & 0.26 & 1 & 0.26 \\
YPNF06 & 0.37 & 0.08 & 1 & 0.20 \\
\hline
\end{tabular}


Table 7.4. The estimated parameters of the first order autoregressive models fitted to the RWI series of selected trees and the percentage of variability of the RWI series explained by the autoregressive models. The fourth column ( $\left.r_{1}\right)$ shows the first order autocorrelation coefficient of the residuals (prewhitened ring-width index series) from the AR models. The last column shows the Durbin-Watson test statistic used to detect autocorrelation in the prewhitened ring-width index.

\begin{tabular}{ccccc}
\hline Disc No. & $\phi_{1}$ & $\mathrm{R}^{2}(\%)$ & $\mathrm{r}_{1}$ & $\mathrm{D}-\mathrm{W}$ \\
\hline YPNF01 & 0.54 & 30 & -0.066 & 2.12 \\
YPNF02 & 0.49 & 23 & -0.040 & 2.05 \\
YPNF03 & 0.38 & 14 & 0.039 & 1.91 \\
YPNF04 & 0.31 & 10 & -0.032 & 2.04 \\
YPNF05 & 0.52 & 29 & 0.025 & 1.95 \\
YPNF06 & 0.49 & 31 & 0.018 & 2.01 \\
\hline
\end{tabular}

Table 7.5. The sign and statistical significance of the climatic variables identified using (a) the t-statistic given by Gunst and Mason (1980), and Mansfield et al. (1977), (b) the F-statistic given by Fritts (1976). The last row (classical method) shows the significant variables obtained after the model is estimated using OLS. ' $\mathrm{S}$ ' indicates climatic variables significant at $5 \%$ level.

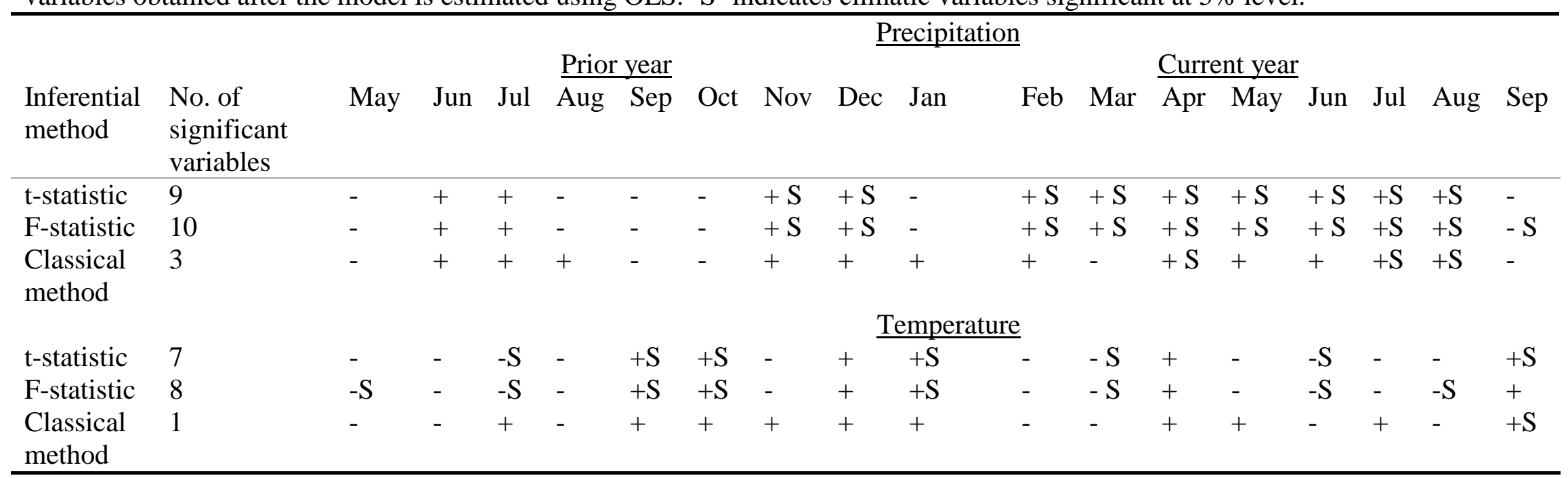


Table 7.6. Principal components selected using five different criteria and measures of fit of the multiple regression models relating the response with the selected components.

\begin{tabular}{|c|c|c|c|c|}
\hline $\begin{array}{l}\text { Selection } \\
\text { method }\end{array}$ & Selection criteria & $\begin{array}{c}\text { Number of } \\
\text { principal } \\
\text { components } \\
\text { selected }\end{array}$ & $\begin{array}{c}\text { The } \\
\text { principal } \\
\text { components } \\
\text { selected }\end{array}$ & $\mathrm{R}^{2}$ \\
\hline (a) & The first $r$ components that & 18 & $\begin{array}{l}\text { The first } 18 \\
\text { components }\end{array}$ & 0.55 \\
\hline (b) & All components with $\lambda_{j}>1$ & 13 & $\begin{array}{l}\text { The first } 13 \\
\text { components }\end{array}$ & 0.52 \\
\hline (c) & $\begin{array}{l}\text { The first } r \text { components that } \\
\text { satisfy } \prod^{r} \lambda_{j}>1\end{array}$ & 25 & $\begin{array}{l}\text { The first } 25 \\
\text { components }\end{array}$ & 0.67 \\
\hline (d) & $\begin{array}{l}\text { Those components significant at } \\
5 \% \text { level }\end{array}$ & 6 & $\begin{array}{l}4,5,8,9 \\
23, \text { and } 24\end{array}$ & 0.43 \\
\hline (e) & $\begin{array}{l}\text { Apply method (c) first then select } \\
\text { those components significant at } \\
15 \% \text { level. }\end{array}$ & 8 & $\begin{array}{l}4,5,8,9 \\
14,21,23 \\
\quad \text { and } 24\end{array}$ & 0.49 \\
\hline
\end{tabular}




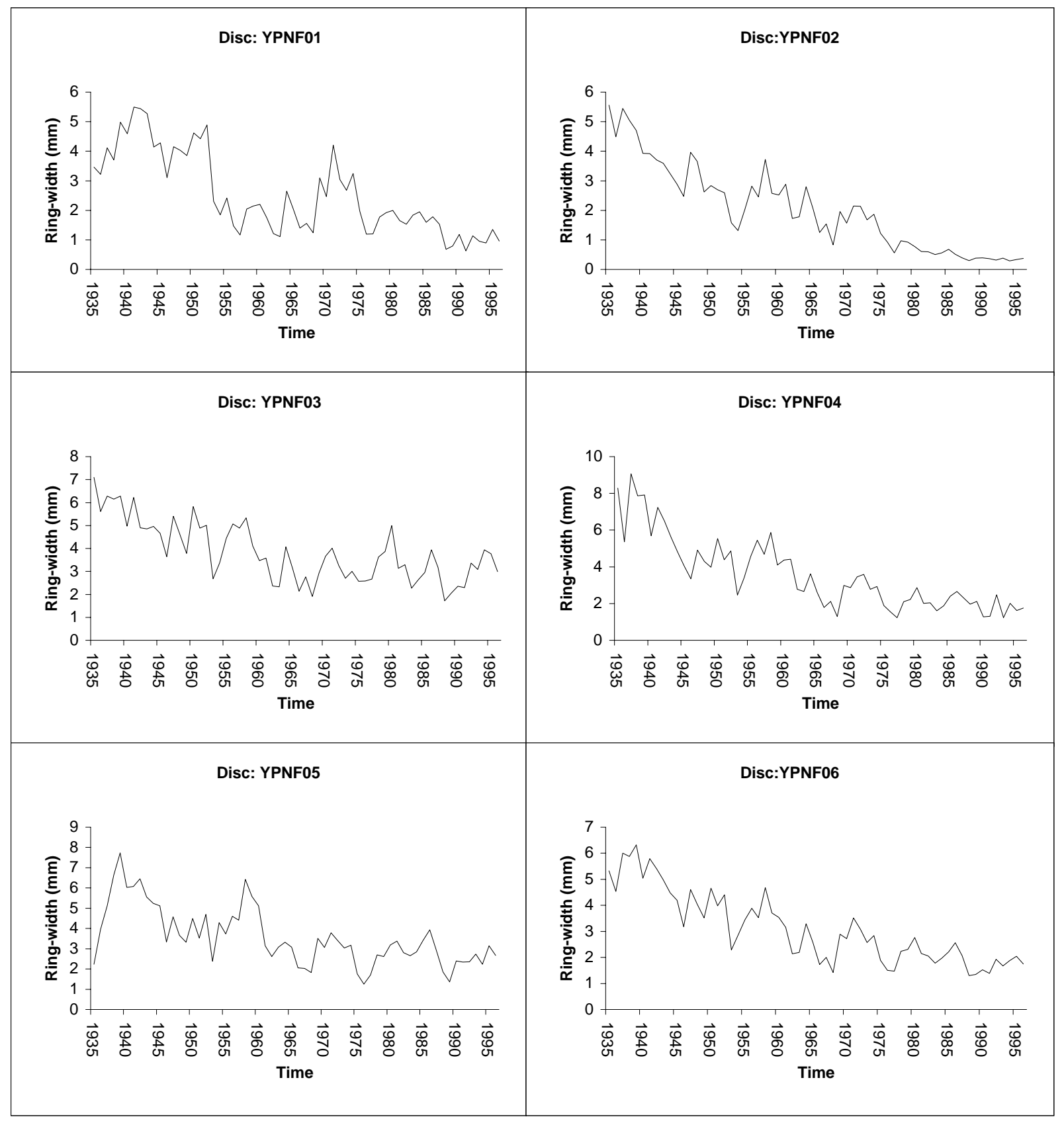

Figure 7.1. A time series plot of ring-width showing a decreasing pattern with increasing age. This is a typical pattern of ring-width of a tree grown in an open, disturbance free environment 


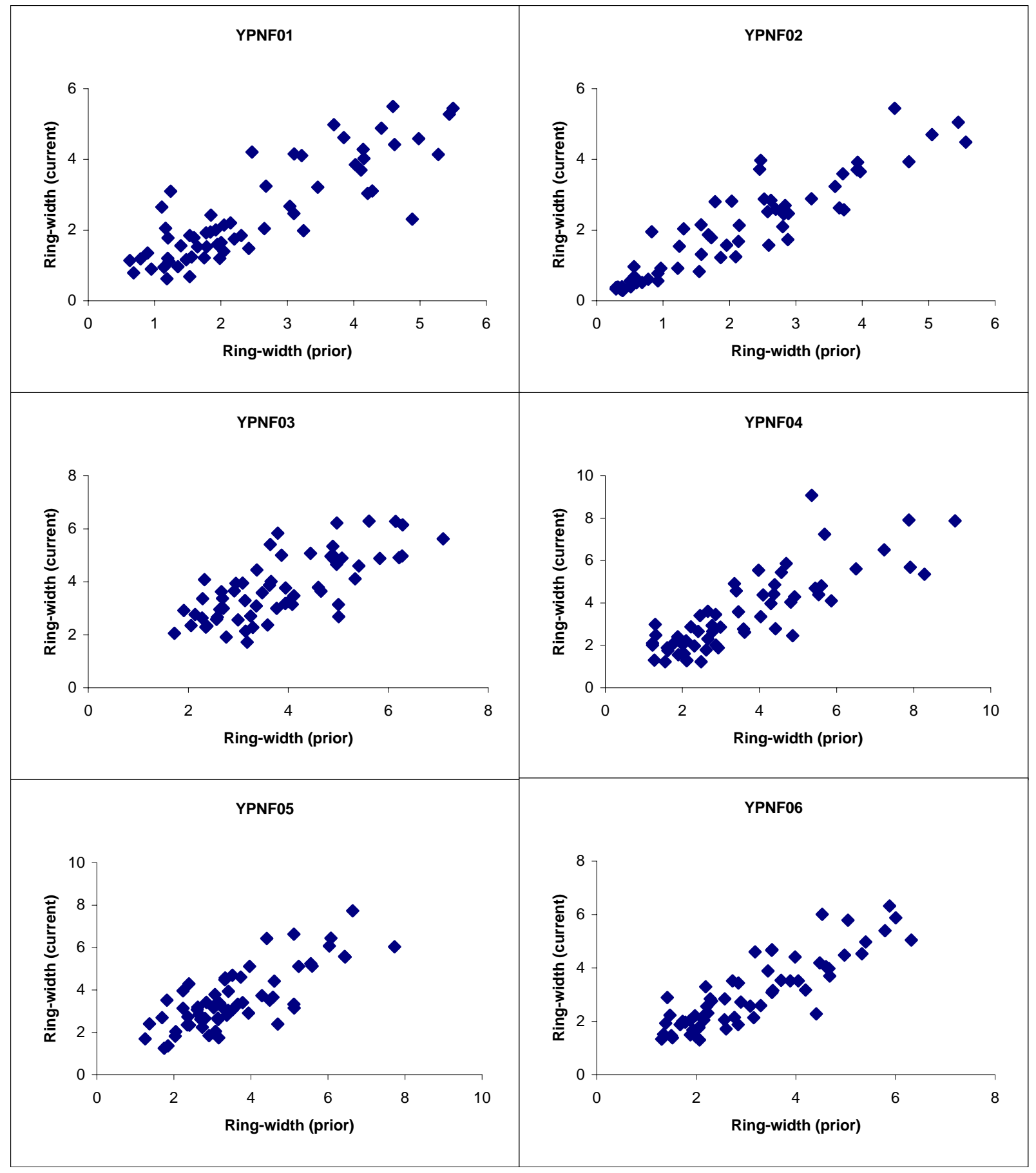

Figure 7.2. A scatter plot of current year ring-width against prior year ring-width indicating strong autocorrelation. 


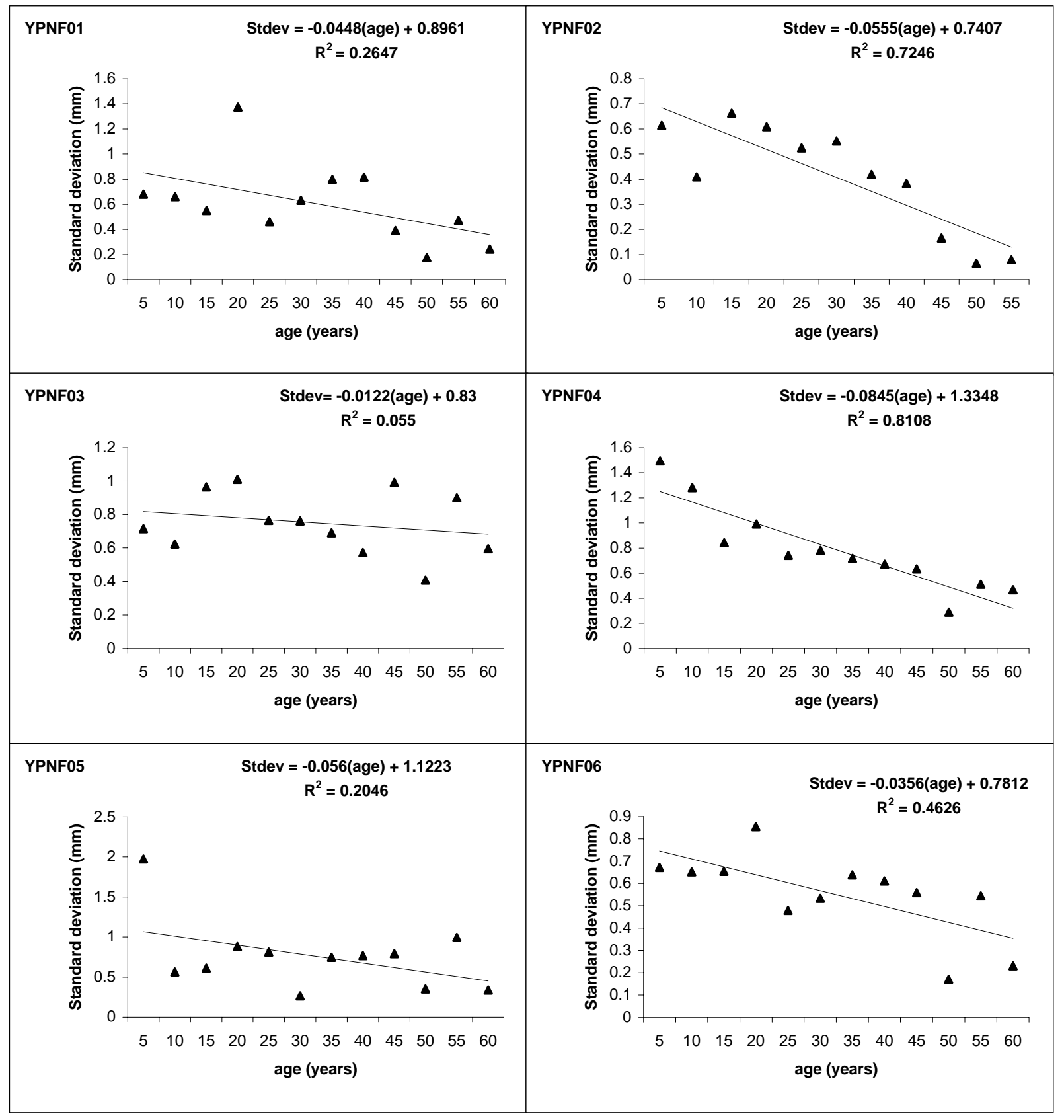

Figure 7.3. The pattern of standard deviation of five-year segments of the ring-width series for selected trees. The variability of ring-width decreases with increasing time or age. 


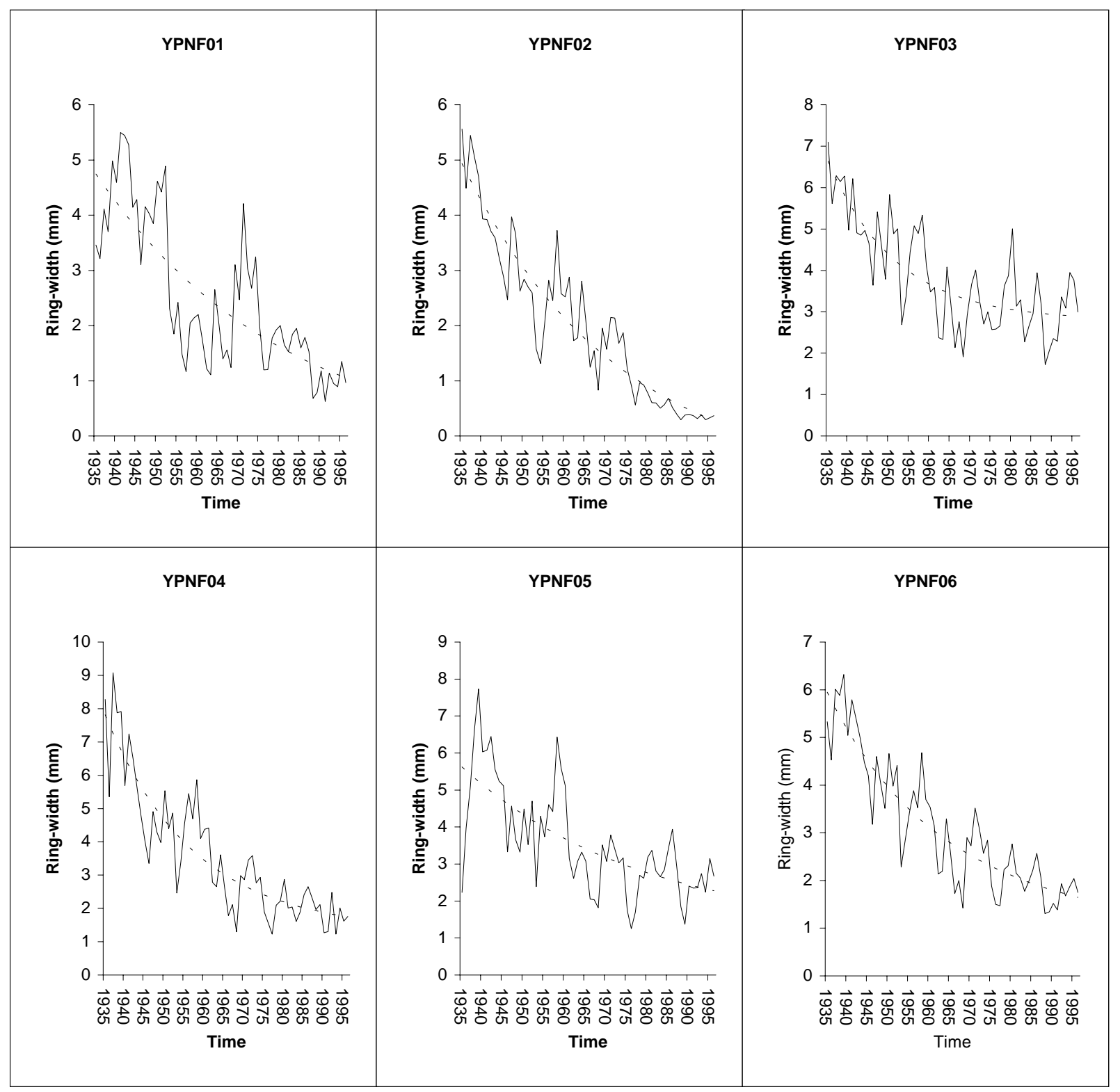

Figure 7.4. A plot of the modified negative exponential model fitted to the ring-width series of selected trees. 


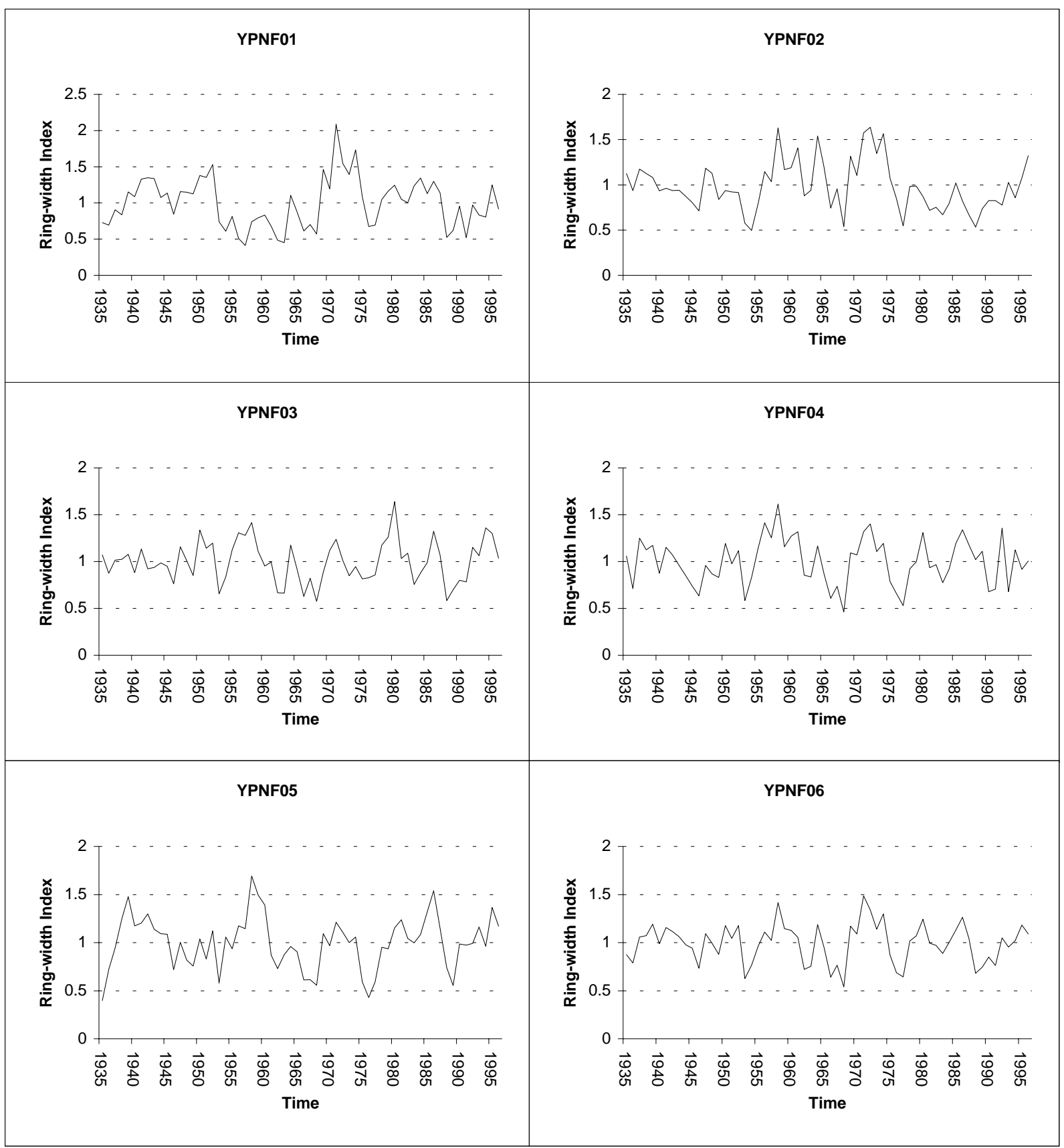

Figure 7.5. The pattern of the detrended series (RWI) for selected trees. The plots indicate that detrending has removed the age-related trend. However, the plots also indicate that the values of the detrended series are interdependent, that is high values follow high values and low value follow low values. 


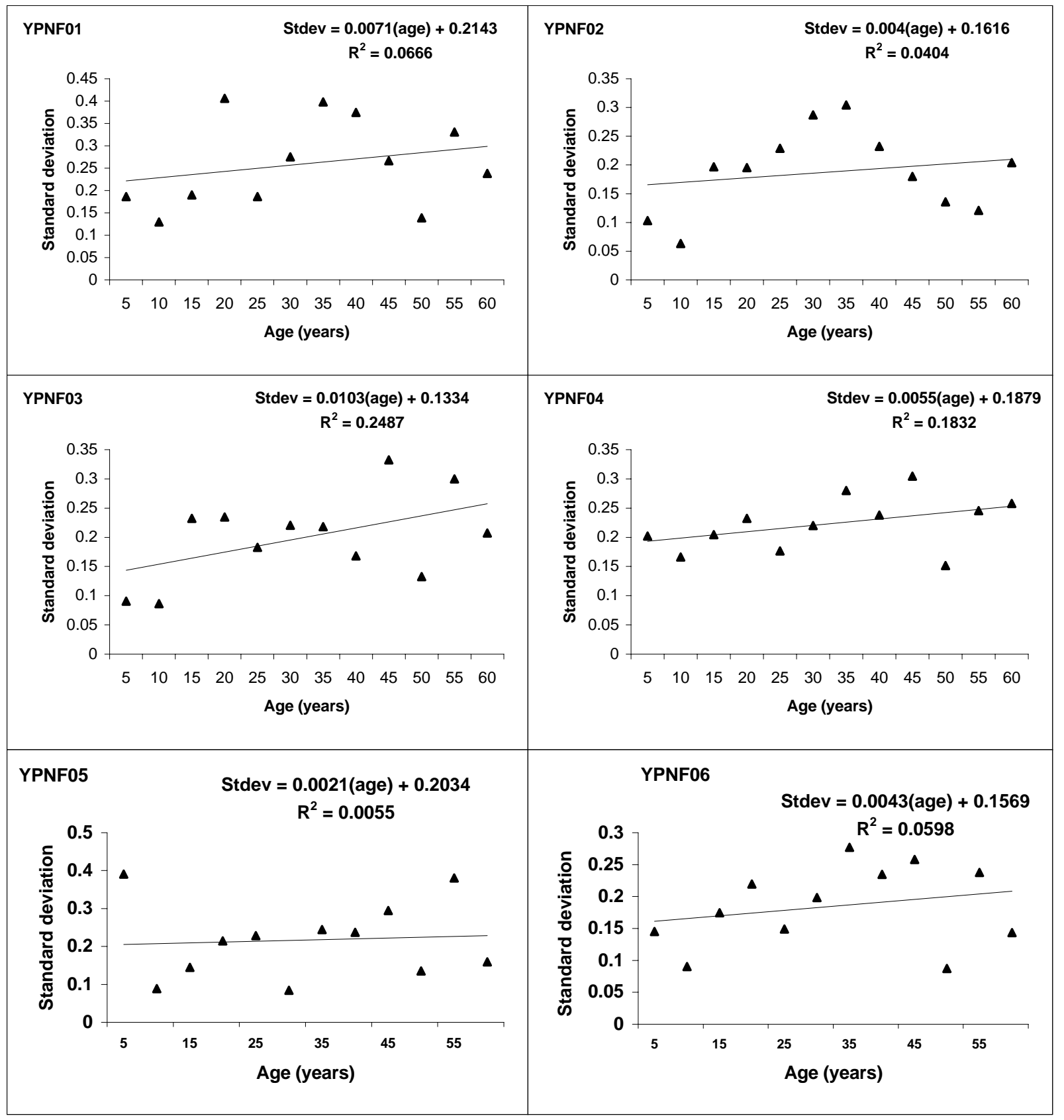

Figure 7.6. The pattern of standard deviation of the five-year segments of the detrended series. The plots indicate that variability of the RWI series is not a function of age and the tree-ring indexes satisfy the assumption of homogeneity of variance. 


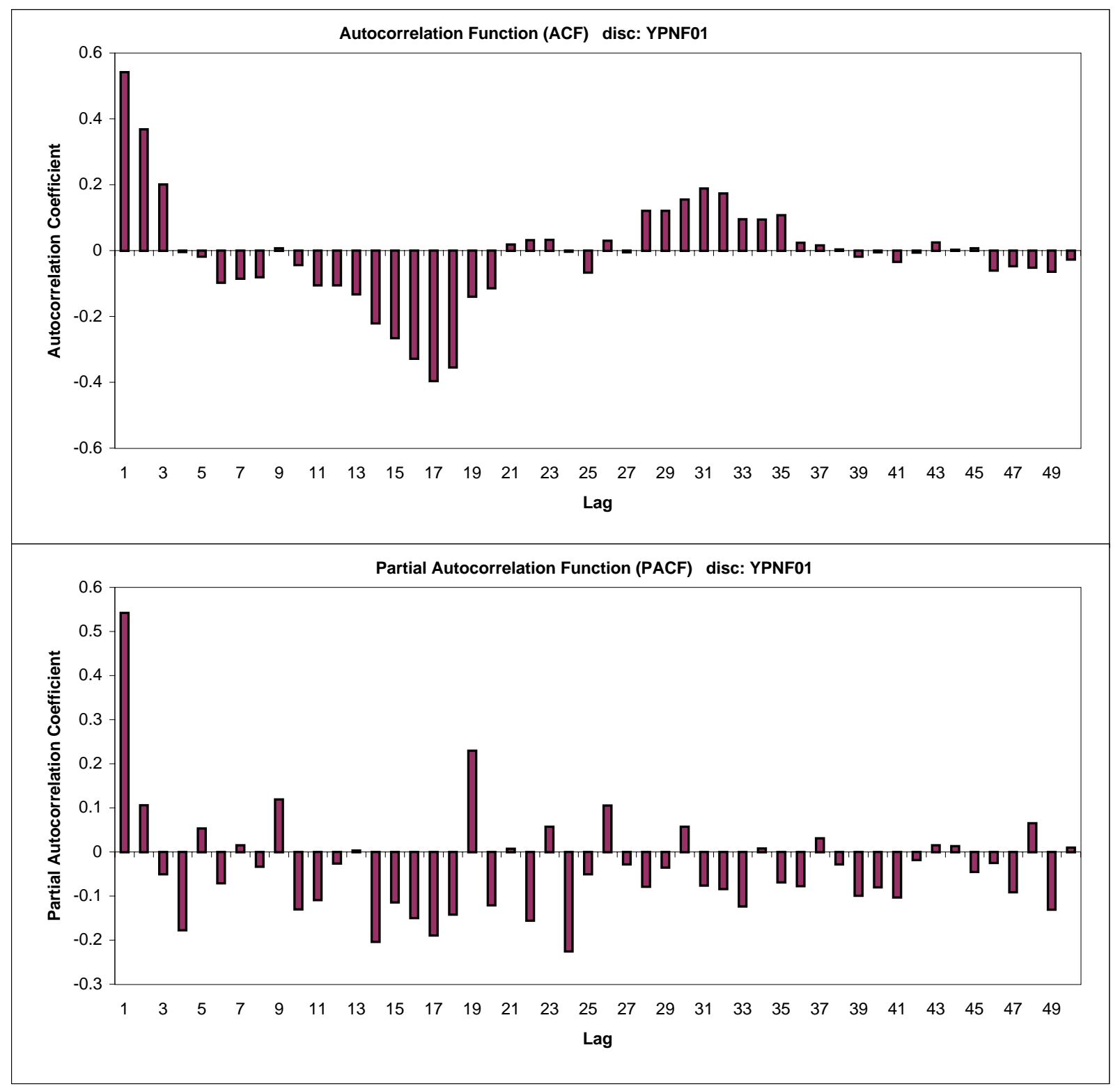

Figure 7.7. The autocorrelation (AC) and partial autocorrelation (PAC) functions for the RWI series of YPNF01. The higher peak at lag 1 indicates that an autoregressive model of order 1 is sufficient to remove the autocorrelation form the RWI series of this particular tree. 


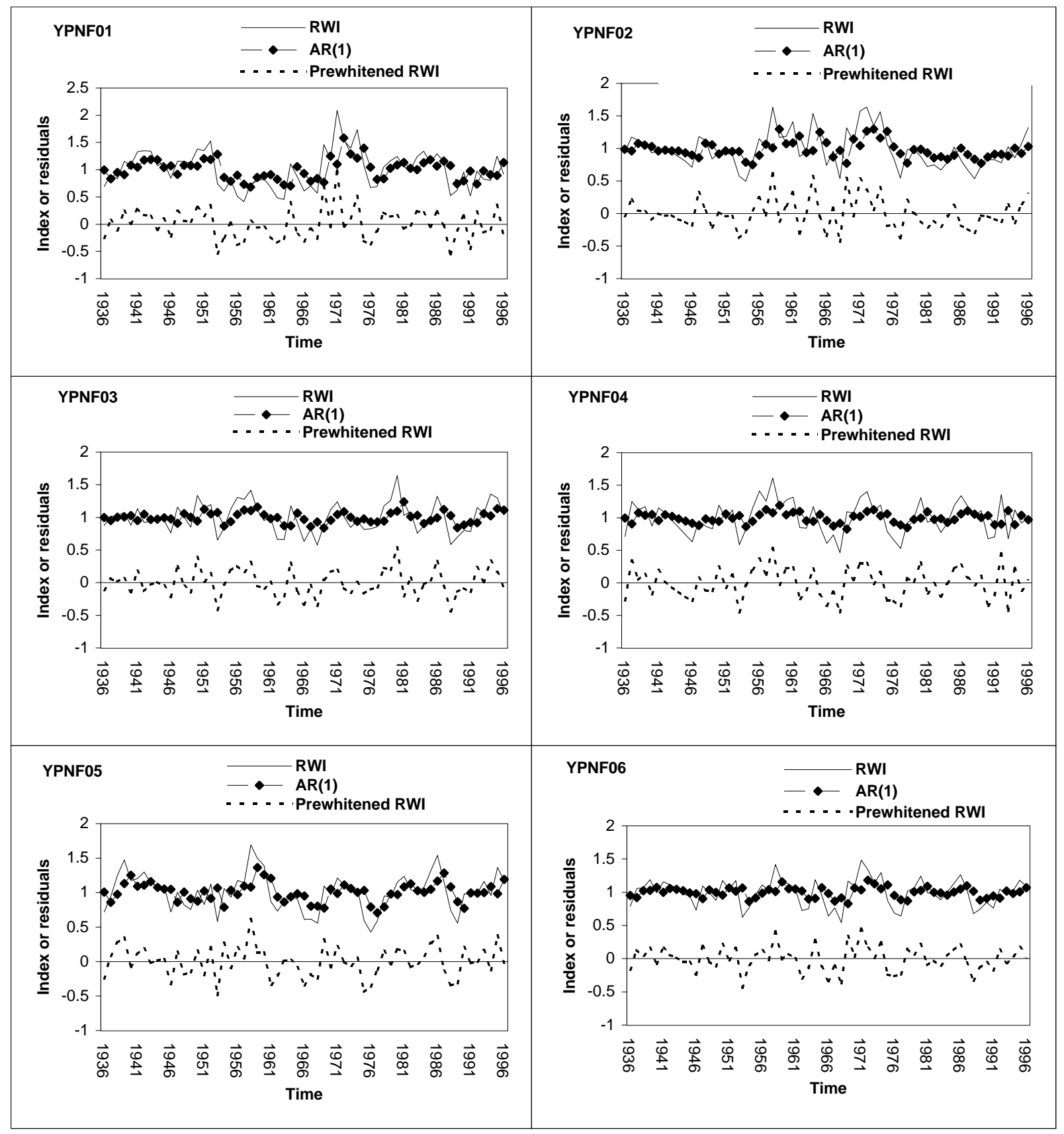

Figure 7.8. The plot of the first order autoregressive models (AR(1)) fitted to the detrended series (RWI) of selected trees and the resulting residuals (or prewhitened tree-ring indexes). 


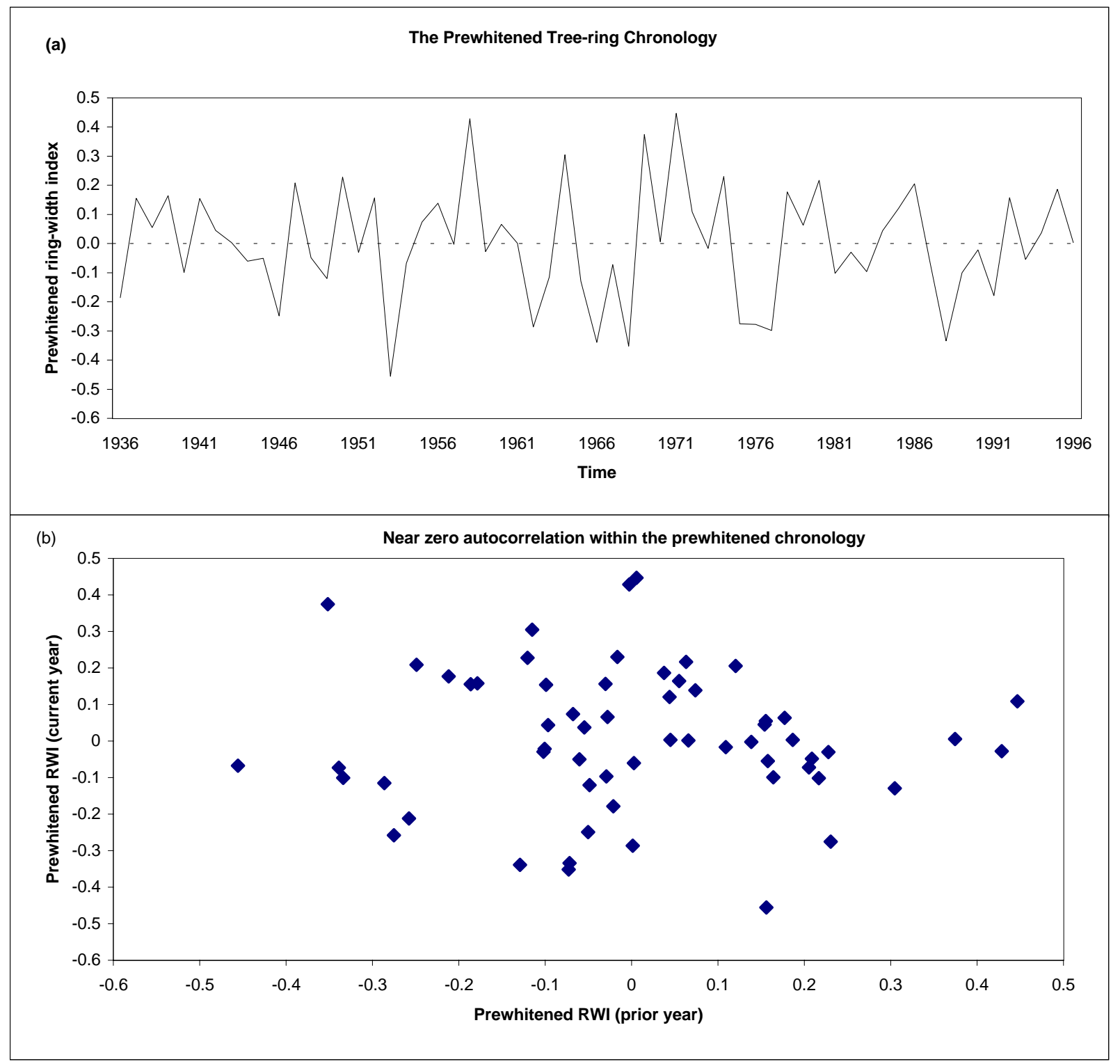

Figure 7.9. The prewhitened tree-ring chronology for yellow-poplar (plot (a)). Plot (b) shows that autoregressive modeling of the tree-ring indexes (RWI) has removed the serial correlation making the values of the prewhitened series independent. 


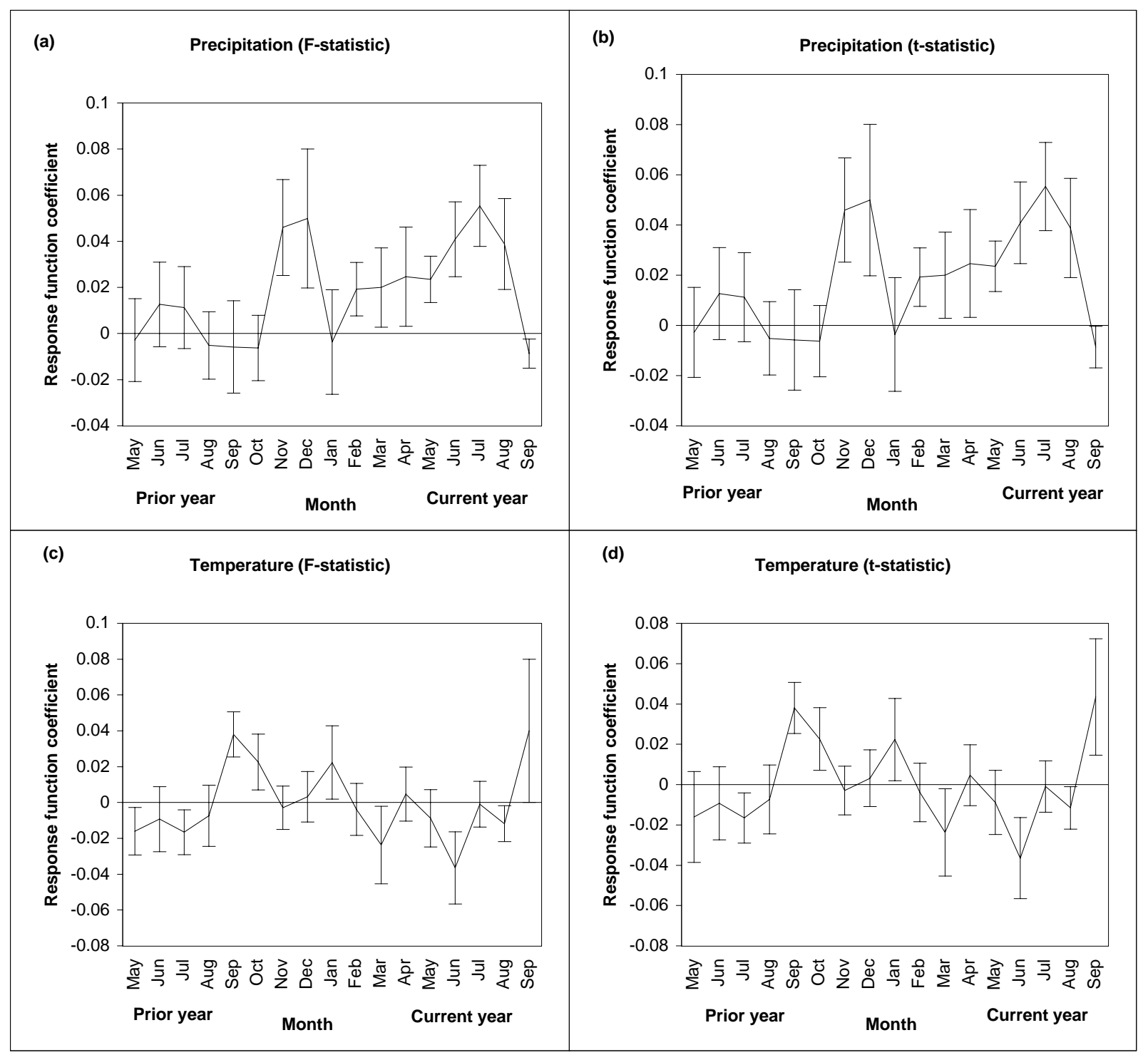

Figure 7.10. Response function for yellow-poplar. The statistical significance of the parameter: was tested according to the F-statistic (plots a and c) given by Fritts (1976) and the t-statistic (plots b and d) given by Mansfield et al. (1977) and Gunst and Mason (1980). Vertical bars represent the $95 \%$ confidence interval for each of the response function elements. Significant elements are those for which the confidence interval does not cross the zero line. 


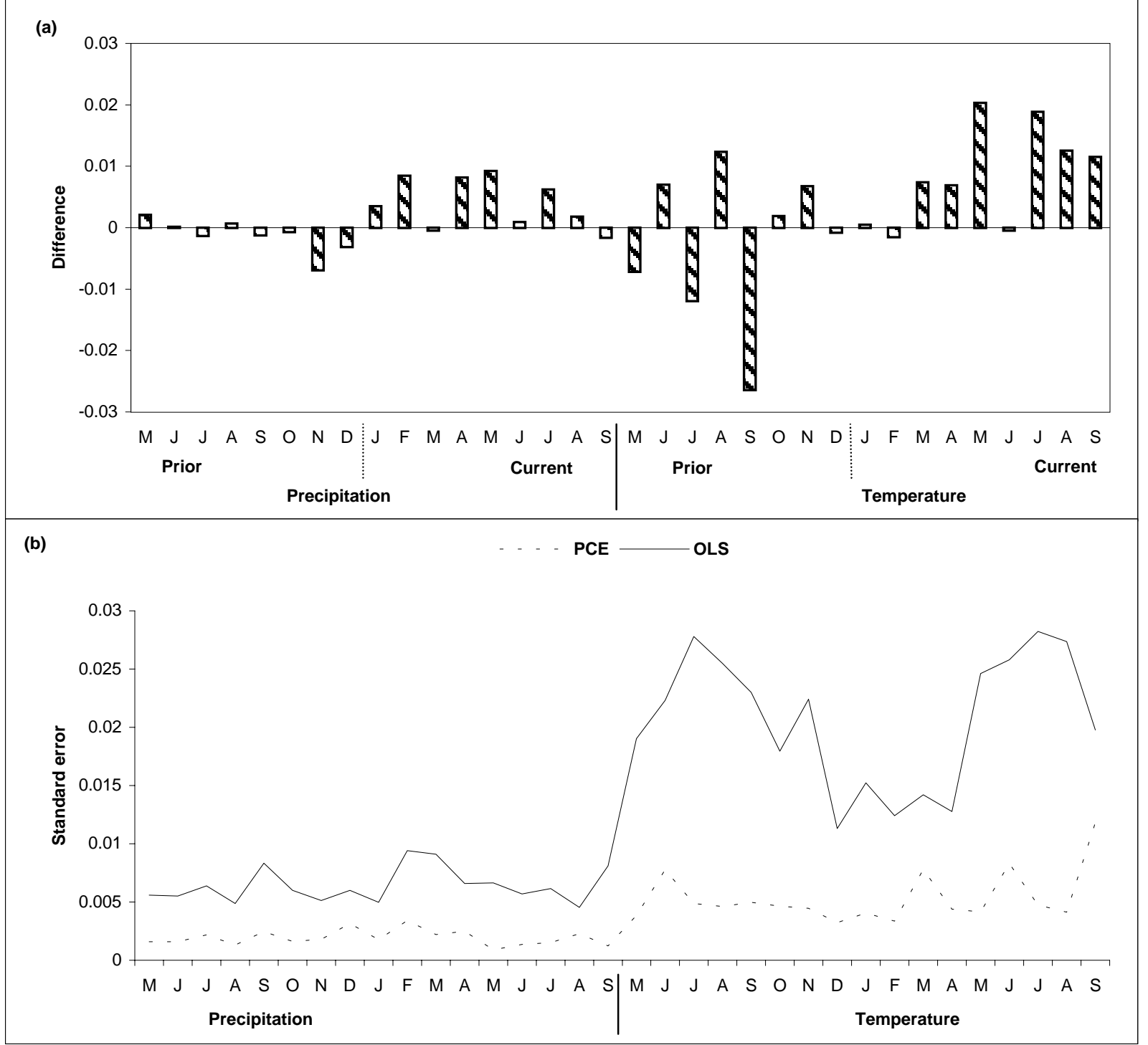

Figure 7.11. Comparison of ordinary least squares (OLS) and principal component estimators (PCE) of the coefficients of the climatic variables. Plot (a) shows the difference in magnitude between the two estimates, and (b) compares their standard error. 


\section{LITERATURE CITED}

Abrams, M. D. 1998. The red maple paradox: what explains the widespread expansion of red maple in eastern forests. BioScience 48: 355-364.

Abrams, M. D., Ruffner, M. C., and Morgan, T. A. 1998. Tree-ring responses to drought across species and contrasting sites in the ridge and valley of central Pennsylvania. Forest science 44: 550-558.

Auchmoody, L. R., and Smith, H. C. 1979. Oak soil-site relationships in northwestern West Virginia. USDA For. Serv. NEFES Res. Pap. NE-434, 27 pp.

Auten, J. T. 1945. Prediction of site index for yellow-poplar from soil and topography. J. For. 43: 662-668.

Barrett, J. W. 1995. Regional silviculture of the United States. John Wiley \& Sons, Inc., New York, NY.

Bonkoungou, G. J. E., Raynal, D. J., and Geis, J. W. 1983. Tree pollution dynamics in relation to climate and forest history in the Oswegatchie Plains, northern New York. Vegetation 54: 37-59.

Box, G. E .P., and Jenkins, G. M. 1976. Time series analysis: forecasting and control. Rev. Ed., Holden Day Publ., San Francisco, CA.

Boyles, R. L. and Tajchman, S. J. 1984. Stoniness and rockiness of a forested Appalachian Catchment. For. Ecol. Manage. 7: 311-322.

Brady, N. C. 1974. The nature and properties of soils. MacMillan Publishing Co., New York, NY.

Brenneman, B. B., Frederick, D. J., Gradner, W. E., Schoenhafen, L. H., and Marsh, P. L. 1978. Biomass of species and stands of West Virginia hardwoods. Proceedings of the Central Hardwood Forest Conference II, Purdue University, West Lafayette, Indiana, November 16, 1978, pp. 159-178.

Briffa, K. R., Wigley, T. M. L. and Jones, P. D. 1987. Towards an objective approach to standardization. In: Kairiukstis, L., Bednarz, Z., and Feliksik, E., (每ditors), Methods of dendrochronology-I, Proceedings of the Task Force Meeting on Methodology of Dendrochronology: East/West Approaches, June 2-6, 1986, Krakow, Poland. Polish Academy of Sciences, Warsaw, pp. 69-86.

Brown, G. B. 1988. Growth dynamics of some Appalachian hardwoods. Ph. D. Dissertation, West Virginia University. 
Brubaker, S. C., Jones, A. J., Lewis, D. T. and Frank, K. 1993. Soil properties associated with landscape position. Soil Sci. Soc. Am. J. 57: 235-239.

Brubaker, S. C., Jones, A. J., and Frank, K., Lewis, D. T. 1994. Regression models for estimating soil properties by landscape position. Soil Sci. Soc. Am. J. 58: 17631767.

Burman, B., and Pochop, L. O. 1994. Evaporation, Evapotranspiration, and climatic data. Elsevier, Amsterdam.

Campbell, R. A. 1961. Silvical characteristics of chestnut oak. USDA For. Serv. SEFES Res. Pap. SE-138, 12 pp.

Carmean, W. H. 1967. Soil refinements for predicting black oak site quality in southern Ohio. Soil Sci. Soc. Amer. Proc. 31: 805-810.

Carmean, W. H. 1975. Forest site quality evaluation in the United States. Adv. Agronomy 27: 209-269.

Carmean, W. H. and Kahn, J. T. 1983. Site comparisons for upland oaks and yellowpoplar in the central states. J. For. 81: 736-739.

Carvell, K. L. 1973. Stand composition: effect of the past on the present. West Virginia University Agricultural and Forest Experiment Station, Morgantown, WV. West Virginia Forestry Notes, No.1: 3-5.

Carvell, K. L. 1983. A summary of 1973-1982 weather data from the West Virginia University Forest. West Virginia University Agricultural and Forest Experiment Station, Morgantown, WV. West Virginia Forestry Notes, No.10: 13-16.

Ciha, A. J. 1984. Slope position and grain yield of soft white winter wheat. Agron. J. 76: 193-196.

Colinvaux, P. A. 1986. Ecology. John Wiley \& Sons, Inc., New York, NY.

Conover, W. J. 1999. Practical nonparametric statistics. John Wiley and Sons, Inc., New York, NY.

Conover, W. J., and Iman, R. L. 1981. Rank transforms as a bridge between parametric and nonparametric statistics. American Statistician 35: 124-129.

Cook, E. R., 1985. A time series analysis approach to tree-ring standardization. Ph. D Dissertation. University of Arizona, Tucson, Arizona.

Cook E. R. 1987. The decomposition of tree-ring series for environmental studies. Tree-Ring Bulletin 47: 37-59. 
Cook, E. R., and Jacoby, G. C., Jr. 1977. Tree-ring-drought relationships in the Hudson Valley, New York. Science 198: 399-401.

Cook, E. R., Johnson, A. H., and Blasing, T. J. 1987. Forest deline: modeling the effect of climate in tree-rings. Tree Physiol. 3: 27-40.

Cook, E. R. and Peters, K. 1981. The smoothing spline: a new approach to standardizing forest interior tree-ring width series for dendroclimatic studies. TreeRing Bulletin 41: 45-53.

Cook, E. R. and Peters, K. 1997. Calculating unbiased tree-ring Indices for the study of climatic and environmental studies. The Holocene 7: 361-370.

Dean, D. R. 1968. Radial growth response and eccentric growth of northern red oak and yellow-poplar border trees surrounding clear-cut openings. M. S. Thesis, West Virginia University.

Delvin, R. M. 1975. Plant physiology. D. Van Nostrand Co., New York, NY.

Delvin, R. M., and Baker, A. V. 1971. Photosynthesis. D. Van Nostrand Reinhold, New York, NY.

Doolittle, W. T. 1957. Site index of scarlet and black oak in relation to southern Appalachian soil and topography. Forest Science 3: 114-124.

Doolittle, W. T. 1958. Site index comparison for several forest species in the southern Appalachians. Soil Sci. Soc. Am. Proc. 22: 455-458.

Douglass, A. E. 1920. Evidence of climatic effects in the annual rings of trees. Ecology 1: 24-32.

Draper, N. R. and Smith, H. 1981. Applied regression analysis. John Wiley \& Sons Inc., New York, NY.

Federer, C. A. 1968. Spatial variation of net radiation, albedo and surface temperature of forests. Journal of Applied Meteorology 7: 789-795.

Fekedulegn, D., Colbert, J. J., and Hicks, R. R. Jr. (in preparation). Principal components regression: method for computing response function in dendroclimatic analysis. Division of Forestry, West Virginia University.

Fekedulegn, D., Colbert, J. J., Hicks, R. R. Jr., and Suchuckers, M. E. (in preparation). The modified negative exponential model in dendro-ecological analysis: issues on the parameters for short tree-ring series. Division of Forestry, West Virginia University. 
Fekedulegn, D., Mac Siurtain, M. P., \& Colbert, J. J. 1999. Parameter estimation of nonlinear growth models in forestry. Silva Fennica 33:327-336.

Ferguson, C. W. 1970. Concepts and techniques of dendrochronology. In: Scientific methods in medieval archaeology, Rainer Berger (editor). University of California Press, Berkeley, Los Angeles.

Forth, H. D. 1978. Fundamentals of soil science. John Wiley \& Sons, Inc., New York, NY.

Fowells, H. A. (editor) 1965. Silvics of forest trees of the United States. USDA Agricultural Handbook No. 271, 762 pp.

Frank, P. S., Jr., Hicks, R. R., Jr., and Harner, E. J., Jr. 1984. Biomass prediction by soil-site factors: a case study in north central West Virginia. Can. J. For. Res. 14: 137140.

Fritts, H. C. 1962. The relation of growth ring width in American beech and white oak to variation in climate. Tree-Ring Bulletin 25: 2-10.

Fritts, H. C. 1976. Tree rings and climate. Academic Press, New York, NY.

Fritts, H. C., Blasing, T. J., Hayden, B. P., and Kutzbach, J. E. 1971. Multivariate techniques for specifying tree-growth and climate relationships and for reconstructing anomalies in paleoclimate. J. Appl. Meteorol. 10: 845-864.

Fritts, H. C., and Swetnam, T. W. 1989. Dendroecology: a tool for evaluating variations in past and present forest environments. Adv. Ecol. Res. 19: 111-188.

Granger, C. W. J., and Morris, M. J. 1976. Time series modeling and interpretation. J. Royal Stat. Soc. Am. 139: 246-257.

Graumlich, L. J. 1992. Response of tree growth to climatic variation in the mixed conifer and deciduous forests of the upper Great Lakes region. Can. J. For. Res. 23: 133-143.

Grissino-Mayer, H., Holmes, R. L., and Fritts, H. C. 1997. International Tree-Ring Data Bank Program Library Version 2.1. International Tree Ring Data Bank, University of Arizona, Tucson, Arizona. USA.

Guiot, J., Berger, A. L., and Munaut, A. V. 1982. Response functions. In: climate from tree rings, 7-11 July, 1980, Norwich, UK. Hughes, M. K., Kelly, P. K., Pilcher, J. R., and LaMarche, V. C. (每itors). Cambridge University Press, Cambridge, England.

Gunst, R. F., and Mason, R. L. 1980. Regression analysis and its application: a dataoriented approach. Marcel Dekker, Inc., New York, NY. 
Hanna, A. Y., Harlan, P. W., and Lewis, D. T. 1982. Soil available water as influenced by landscape position and aspect. Agron. J. 74: 99-104.

Heiner, K. W., and Heiner, K. S. 1995. Tree rings in the Northern Shawangunks. Tree-Ring Bulletin 8: 30-37.

Hicks, R. R., Jr. 1998. Ecology and Management of Central Hardwood Forests. John Wiley \& Sons, Inc., New York, NY.

Hicks, R. R., Jr., and Frank, P. S., Jr. 1984. Relationship of aspect to soil nutrients, species importance and biomass in a forested watershed in West Virginia. For. Ecol. Manage. 8: 281-291.

Holmes, R. L. 1983. Computer-assisted quality control in tree-ring dating and measurement. Tree-Ring Bulletin 43: 69-78.

Holmes, R. L., Adams, R. K., and Fritts, H. C. 1986. Tree-ring chronologies of Western North America: California, Eastern Oregon and Northern Great Basin with procedures used in the chronology development work including users manual for computer programs COFECHA and ARSTAN. Laboratory of Tree-Ring Research. University of Arizona. Tucson, Arizona.

Hornbeck, J. W. 1987. Growth patterns of red oak and red and sugar maple relative to atmospheric deposition. Sixth Central Hardwood Forest Conference, Knoxville, TN.

Jacobi, J. C., and Tainter, F. H. 1988. Dendroclimatic examination of white oak along an environmental gradient in the Piedmont of South Carolina. Castanea 53: 252-262.

Jones, A. J., Mielke, L. N., Bartles, C. A., and Miller, C. A. 1989. Relationship of landscape position and properties to crop production. J. Soil Water Conservation 44: 328-332.

Kim, E., 1988. Radial growth patterns of tree species in relation to environmental factors. Ph.D. Dissertation, Yale University.

Knight, R. 1980. Overstory biomass on the Little Laurel Watershed of the W.V.U. Forest. M. S. Thesis, West Virginia University.

Kolb, T. E., Steiner, K. C., McCormick, L. H., and Bowersox, T. W. 1990. Growth response of northern red-aok and yellow-poplar seedlings to light, soil moisture and nutrients in relation to ecological strategy. For. Ecol. Manage. 38: 65-78.

Kolb, T. E., and McCormick, L. H. 1993. Etiology of sugar maple decline in four Pennsylvania stands. Can. J. For. Res. 23: 2395-2402. 
Kondratyev, K. Y. 1977. Radiation income of inclined slopes. World Meteorological Organization.

Kramer, P. J., and Kozlowski, T. T. 1960. Physiology of trees. McGraw-Hill, New York, NY.

Kramer, P. J., and Kozlowski, T. T. 1979. Physiology of woody plants. Academic Press, New York, NY.

Kubiske, M. E., and Abrams, M. D. 1994. Ecophysiological analysis of woody species in contrasting temperature communities during wet and dry years. Oecologia 98: 303-312.

Lanasa, M. J. 1971. Radial growth response of understory sugar maple adjacent to group selection openings. M. S. Thesis, West Virginia University.

Lang, G. E., and Orndorff, K. A. 1983. Surface litter, soil organic matter and the chemistry of minoval soil and foliar tissue: Landscape patterns in forests located on mountainous terrain in West Virginia. In: R. N. Muller (editor), Proc. $4^{\text {th }}$ Cent. Hardwood Conf., 8-10 November 1982, Lexington, KY. University of Kentucky, Lexington, KY.

Lee, R. 1978. Forest microclimatology. Columbia University Press, New York, NY.

Lee, R., and Sypolt, C. R. 1974. Toward a biological evaluation of forest site potential. Forest science 20: 145-154.

Lindholm, M., Lethonen, H., Kolstrom, T., Merilainen, J., eronen, M., and Timonen, M. 2000. Climatic signals extracted from ring-width chronologies of Scots pines from the northern, middle and southern parts of the boreal forest belt in Finland. Silva Fennica 34: 317-330.

Lioyd, W. J. and P. E. Lemmon. 1970. Rectifying Azimuth in studies of soil-site index relationships. In: Spurr S. H. and Barnes, B. V. 1980. Forest Ecology. John Wiley \&Sons, Inc., New York.

Liu, Y., and Muller, R. N. 1993. Effect of drought and frost on radial growth in red oaks is associated with short-term changes in climate. Eur. J. For. Path. 20: 95-105.

Loach, K. 1970. Shade tolerance in tree seedlings. II. Growth analysis of plants raised under artificial shade. New Phytol. 69: 273-292.

Lorimer, C. G. 1984. Development of the red maple understory in northeastern oak forests. Forest Science 30: 3-22. 
Luken, J. O., Porter, D., and Agard, D. B. 1994. Relationships between recent growth and climate for rural and urban Fraxinus Americana L. Trans. Ky. Acad. Sci. 55: 102-107.

Luxmoore, R. J., Huff, D. D., McConathy, R. K., and Dinger, B. E. 1978. Some measured and simulated plant water relationships of yellow-poplar. Forest Science 24: 327-341.

Malo, D. D., Worcester, B. K., Cassel, D. K., and Matzdorf, K. D. 1974. Soillandscape relationships in a closed drainage system. Soil Sci. Soc. Am. Proc. 38: 813818.

Mansfield, E. R., Webster, J. T., and Gunst, R. F. 1977. An analytic variable selection technique for principal components regression. Applied statistics 6: 34-40.

Marquardt, D. W. 1963. An algorithm for least squares estimation of nonlinear parameters. Journal of the Society of Industrial Applied Mathematics 2: 431-441.

McCarthy, B.C., and Bailey, D. R. 1996. Composition, structure, and disturbance history of Crabtree Woods: an old-growth forest of western Maryland. Bull. Torrey Bot. Club 123: 350-365.

McClenahen, J. R., and Dochinger, L. S. 1985. Tree ring response of white oak to climate and air pollution near the Ohio River Valley. J. Envir. Qual. 14: 274-280.

McNab, W. H. 1989. Terrain shape index: quantifying effect of minor landforms on tree height. Forest Science 35: 91-104.

McNab, W. H. 1993. A topographic index to quantify the effect of mesoscale landform on site productivity. Can. J. For. Res. 23: 1100-1107.

Melillo, J. M., Aber, J. D., and Muratore, J. F. 1982. Nitrogen and lignin control of hard-wood leaf litter decomposition dynamics. Ecology 44: 322-331.

Monserud, R. A. 1986. Time series analysis of tree-ring chronologies. Forest Science 32: 349-372.

Myers, R. H. 1986. Classical and modern regression analysis with applications. Duxbury Press, Boston.

National Climatic Data Center and National Oceanic and Atmospheric Administration. 2001. CLIMVIS information: Selection criteria for displaying period of record. http://www.ncdc.noaa.gov/onlineprod/drought/xmgrg3.html.

National Drought Mitigation Center. 1999. Drought information website. http://enso.unl.edu/ndmc/enigma/indices.htm. 
Nowacki, G. J., and Abrams, M. D. 1994. Forest Composition, structure, and disturbance history of the Alan Seeger Natural Area, Huntington County, Pennsylvania. Bull. Torrey Bot. Club 121: 277-291.

Oliver, C. D., and Larson, B. C. 1996. Forest stand dynamics. John Wiley \& Sons, Inc., New York, NY.

Olson, D. F. 1969. Silvical characteristics of yellow-poplar. USDA For. Serv. SEFES Res. Pap. SE-48, 16 pp.

Olson, D. F., Jr., and Della-Bianca, L. 1959. Site index comparisons for several tree species in the Virginia-Carolina Piedmont. USDA For. Serv. SEFES. Res. Pap. SE104, 9 pp.

Orwig, D. A., and Abrams, M. D. 1997. Variation in radial growth responses to drought among species, site, and canopy strata. Tree 11: 474-484.

Pan, C. 1995. Climatic aspects of forest growth in an Appalachian watershed. M. S. Thesis, West Virginia University.

Pan, C., Tajchman, S. J., and Kochenderfer, J. N. 1997. Dendroclimatological analysis of major forest species of the central Appalachians. For. Ecol. Manage. 98: 77-87.

Panshin, A. J. 1980. Textbook of wood technology. McGraw-Hill, New York, NY.

Peters, K., Jacoby, G. C., and Cook, E. R. 1981. Principal component analysis of treering sites. Tree-ring bulletin 41: 1-19.

Phillips, E. A. 1959. Methods of Vegetation Study. Holt, Rinehart and Winston, New York, NY.

Phillips, J. J. 1966. Site Index of yellow-poplar related to soil and topography in southern New Jersey. USDA For. Serv. NEFES Res. Pap. NE-52, 10 pp.

Phipps, R. L. 1967. Annual growth of suppressed chestnut oak and red maple, a basis for hydrological reference. U. S. Geol. Survey Prof. Paper 485-c, 27 pp.

Phipps, R. L. 1982. Comments on interpretation of climatic information from tree rings, eastern North America. Tree-Ring Bulletin 42: 11-22.

Phipps, R. L. 1983. Ring-width analysis. In: Air pollution and the productivity of the forest. Davis, D. D., (editor). Izaak Walton League, Washington, DC. p. 225-271. 
Pierson, F. B., and Mulla, D. J. 1990. Aggregate stability in the palouse region of Washington: effect of landscape position. Soil Sci. Soc. Am. J. 54: 1407-1412.

Renshaw, J. F., and Doolittle, W. T. 1958. Silvical characteristics of yellow-poplar. USDA For. Serv. SEFES Res. Pap. SE-89, 18 pp.

Rentch, S. J., Fekedulegn, D., and Miller, G. W. (accepted). Climate, canopy disturbance, and radial growth averaging in a second growth mixed-oak forest in West Virginia, U. S. A. Can. J. For. Res.

Rosenberg, N. J., Blad, B. L., and Verma, S. B. 1983. Microclimate-the biological environment. John Wiley \& Sons, Inc., New York, NY.

Rubino, D. L., and McCarthy, B. C. 2000. Dendroclimatological analysis of white oak (Quercus alba L., Fagaceae) from an old-growth forest of southeastern Ohio, U.S.A. Journal of the Torrey Bot. Soc. 127: 240-250.

Rumney, G. R. 1968. Climatology and the world's climates. The Macmillan Company, New York, NY.

Sander, I. L. 1957. Silvical characteristics of northern red oak. Central States For. Exp. Sta. Misc. Release 17, pp. 15.

SAS Institute Inc. 1985. SAS/STAT user's guide, version $6,4^{\text {th }}$ edition. Volume 1. SAS Institute Inc., Cary, N.C.

SAS Institute Inc. 1989. SAS/STAT user's guide, version $6,4^{\text {th }}$ ed. Volume 2. SAS Institute Inc., Cary, N.C.

SAS Institute Inc. 1990. SAS/STAT user's guide, version $6,4^{\text {th }}$ ed. Volume 2. SAS Institute Inc., Cary, N.C.

SAS Institute Inc. 1999. SAS/STAT user's guide, version $6,4^{\text {th }}$ ed. Volume 2. SAS Institute Inc., Cary, N.C.

Schwegler, D. E. 1983. Dendroclimatology in northern West Virginia. M. S. Thesis, West Virginia University.

Shugart, H. H. Jr., Emanuel, W. R., West, D. C., and DeAngelis, D. 1979. Environmental gradients in a simulation model of a beech-yellow-poplar stand. Math. Biosci. 50: 163-170.

Spurr, S. H. 1964. Forest Ecology. The Ronald Press Co., New York, NY.

Spurr, S. H. and Barnes, B. V. 1980. Forest Ecology. John Wiley \& Sons, Inc., New York, NY. 
Stokes, M. A., and Smiley, T. L. 1968. An introduction to tree-ring dating. University of Chicago Press, Chicago, IL.

Tainter, F. H., Retzlaff, W. A., Starkey, D. A., and Oak, S. W. 1990. Decline of radial growth in red oaks is associated with short-term changes in climate. Eur. J. For. Path. 20: 95-105.

Tajchman, S. J. and Wiant, H. V. Jr. 1983. Topography and biomass characteristics of a forested catchment in the northern Appalachians. For. Ecol. Manage. 5: 55-69.

Tajchman, S. J. and Lacey, C. J. 1985. Bioclimatic factors in forest site potential. For. Ecol. Manage. 14: 211-218.

Tajchman, S. J., and Minton, C. M. 1986. Soil temperature regime in a forested Appalachian watershed. Can. J. For. Res. 16: 624-629.

Tajchman, S. J., Fu, H., Kochenderfer, J.N., and Chunshen, P. 1995. Spatial charcterstics of topography, energy exchange, and forest cover in a central Appalachian watershed. $10^{\text {th }}$ Central Hardwood Conference Procedding, Morgantown, WV, March 5-8, 1995.

Tift, D. B., and Fajvan, M. A. 1999. Red maple dynamics in Appalachian stands in West Virginia. Can. J. For. Res. 29: 157-165.

Trimble, G. R., Jr. 1964. An equation for predicting oak site index without measuring soil depth. J. For. 62: 325-327.

Trimble, G. R., Jr. 1969. Diameter growth of individual hardwood trees. USDA For. Serv. NEFES Res. Pap. NE-145, 25 pp.

Trimble, G. R., Jr. 1975. Summaries of some silvical characteristics of several Appalachian hardwood trees. USDA For. Serv. Gen. Tech. Rep. NE-16, 5 pp.

Trimble, G. R., Jr., and Weitzman, S. 1956. Site index studies of upland oaks in the northern Appalachians. Forest Science 2: 162-173.

Tryon, E. H., and Myers, C. A. 1952. Periodic precipitation affects growth of yellowpoplar on West Virginia hillside. Castanea 17: 97-102.

Tryon, E. H., Cantrell, J. O., and Carvell, K. L. 1957. Effect of precipitation and temperature on increment of yellow-poplar. Forest Science 3: 32-44.

Tryon, E. H., and True, R. P. 1958. Recent reductions in annual radial increment in dying scarlet oaks related to rainfall deficiencies. Forest Science 4: 219-230. 
Tryon, E. H., and True, R. P. 1962. Radial increment reduction in American beech caused by a freeze. Phytopathology 52: 1221.

Patton, B.J., W.W Beverage, and G.G. Pholeman. 1959. Soil Survey of Preston County, West Virginia. USDA Soil Conservation Service, Washington, D.C.

Van Deusen, P. C. 1989. A model-based approach to tree-ring analysis. Biometrics 45: 763-779.

Visser, H. 1995. Note on the relation between ring widths and basal area increments. Forest Science 41: 297-304.

Visser, H., and Molenaar, J. 1990. Estimating trends in tree-ring data. Forest science 36: 87-100.

Walters, R. S., and Yawney, H. W. 1990. Acer rubrum, red maple. In: Silvics of North America, Vol. 2: Hardwoods, Burns, R. M., and Honkala, B. H. (editors). USDA For. Serv. Agric. Handbook 654: 60-67.

Ward, W. W., and Bowersox, T.W. 1970. Upland oak response to fertilization with nitrogen, phosphorus, and calcium. Forest Science 16: 113-120.

Warren, W. G. 1980. On removing the growth trend from dendrochronological data. Tree-Ring Bulletin 40: 35-44.

Weitzman, S., and Trimble, G. R. 1957. Some natural factors that govern the management of oaks. USAD For. Serv. NEFES Res. Pap. NE-88, 40 pp.

Yamaguchi, D. K. 1991. A simple method for cross-dating increment cores from living trees. Can. J. For. Res. 21: 414-416.

Yin, X., and Arp, P. A. 1994. Tree-ring based growth analysis for sugar maple stand: relations to local climate and transient soil properties. Can. J. For. Res. 24: 15671574.

Zobel, D. B. 1974. Local variation in intergrading Abies grandis-A. concolor populations in the central Oregon Cascades. II. Stomatal reaction to moisture stress. Bot. Gaz. (Chicago) 135: 200-210. 